\title{
The Performance of Timber-framed Load-bearing Gypsum Plasterboard Walls Subjected to Two-sided Fire Exposure
}

A thesis submitted in partial fulfilment of the requirements for the degree of Master of Engineering in Fire Engineering

\author{
By \\ Hohyung (Frank) Kang
}

Supervised by

Associate Professor Anthony Abu (University of Canterbury) Adjunct Associate Professor Peter Moss (University of Canterbury)

Mr Hans Gerlich (Winstone Wallboards Ltd) and

Dr Richard Hunt (Winstone Wallboards Ltd)

Department of Civil and Natural Resources Engineering
University of Canterbury
Christchurch, New Zealand

March 2021 



\section{Abstract}

Gypsum plasterboard lined timber-framed walls are commonly used in construction and provide excellent fire resistance. When these walls are required to perform a load-bearing function, fire resistance is generally assessed by standard fire-resistance testing, exposing a specimen to fire from one side only. When load-bearing walls are themselves not fire separations, they can potentially be exposed to fire from both sides simultaneously. No current tests exist to reliably measure the performance of such gypsum plasterboard lined walls and there is very limited information for a recognised fire engineering design method.

In this research, Abaqus/CAE finite element software is used to develop thermal and structural models for the load-bearing timber-framed gypsum plasterboard lined walls subjected to one and two-sided fire exposures and three full-scale fire-resistance tests, designed to expose the load-bearing wall specimen on both sides simultaneously, are conducted. The experimental and modelling results are then analysed to formulate design methodologies which predict the structural adequacy of the load-bearing timber-framed gypsum plasterboard lined walls exposed to fire from both sides. 


\section{Acknowledgements}

I would like to express my deepest gratitude to my supervisors:

- Associate Professor Anthony Abu (University of Canterbury) - Your inspiration, guidance and support for the in-depth discussions have benefited me immensely in completing this research project. I would also like to express my deepest appreciation for all your support throughout the journey of completing a master's degree program.

- Adjunct Associate Professor Peter Moss (University of Canterbury) - Working on this research project under your guidance was a truly invaluable and rewarding experience.

- Hans Gerlich (Winstone Wallboards Ltd) - Your guidance and willingness to support in every way throughout this research project have been immeasurable and greatly appreciated. I have been very fortunate to have you as a supervisor, and am extremely grateful for your insight and advice.

- Richard Hunt (Winstone Wallboards Ltd) - Your positive outlook and confidence in my research project inspired me to be more trusting and to greater accomplishments.

The experimental program of this research was conducted at the fire testing laboratory of the Building Research Association of New Zealand (BRANZ). Financial support for the fireresistance testing was funded by the BRANZ Building Research Levy. I would like to thank all the staff at BRANZ, especially George Hare and Paul Chapman for sharing their experience and knowledge. A very special thanks to the fire testing lab technicians, Rik Engel, Brett Millin and Aman Kumar for their extraordinary efforts and taking the time to help with conducting the experiments.

I greatly appreciate and acknowledge the sincere encouragement and support from my employer, Winstone Wallboards Ltd. I am extremely grateful to Hamish Ewan and John Jamison who have been constant and enthusiastic supporters even during the leave of absence. I want to thank my friends and all my family, especially my parents and parents-in-law for their support and generous care throughout the journey of completing this research project.

Last but foremost, I would like to thank my loving wife, Jen and my little daughter, Erae for their continued support and understanding during my pursuit of a master's degree. Without your encouragement and patience, this would never have been completed. 


\section{Table of Contents}

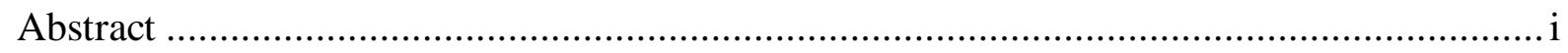

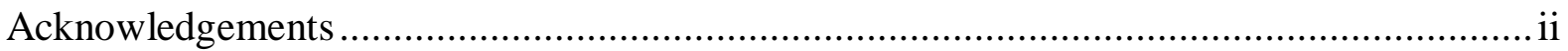

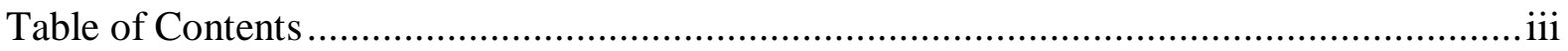

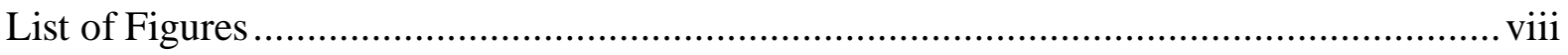

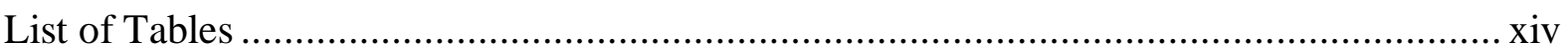

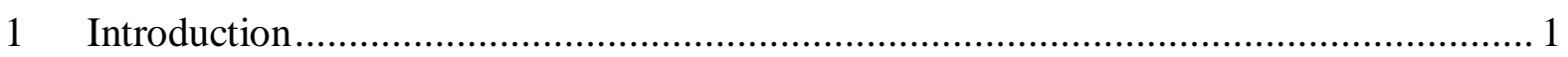

1.1 Gypsum plasterboard as a building material ................................................... 1

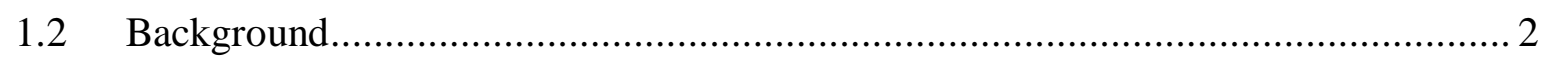

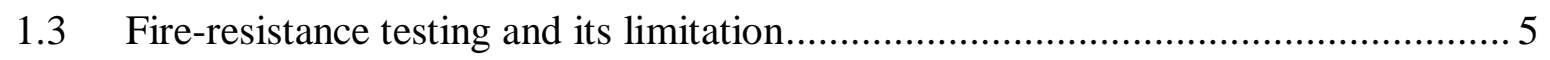

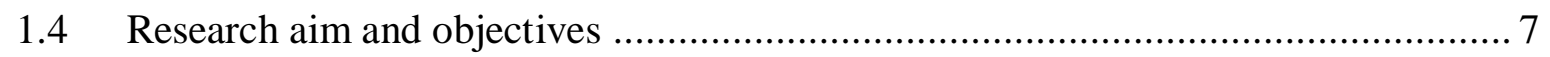

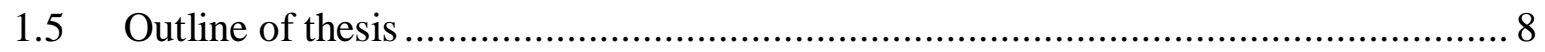

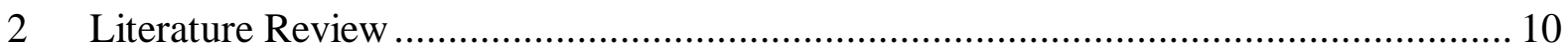

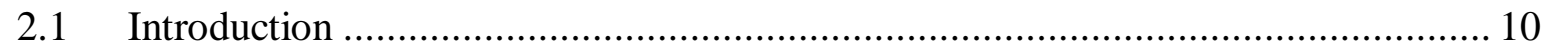

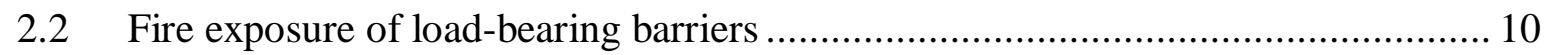

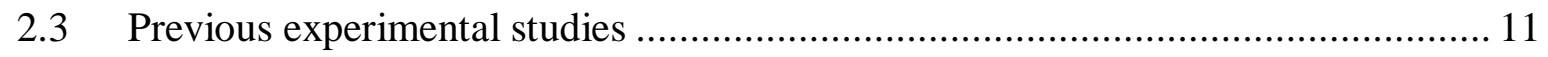

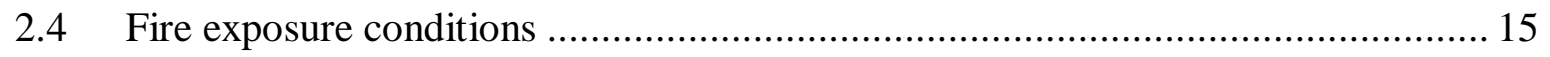

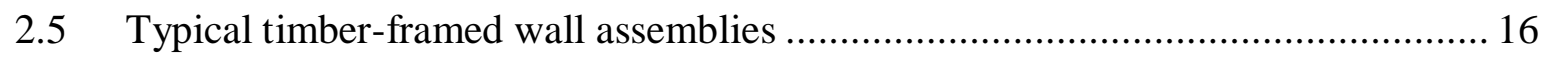

2.6 Thermal properties of timber-framed wall assemblies .................................. 17

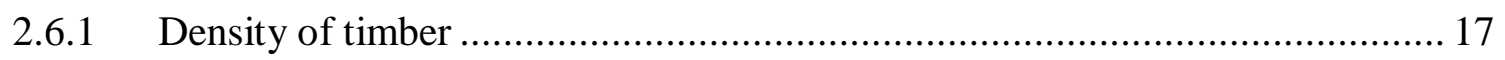

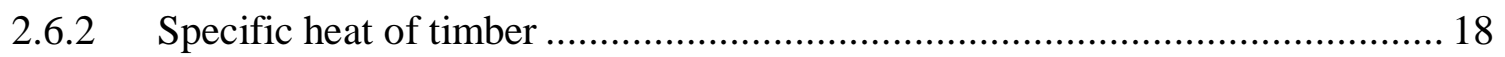

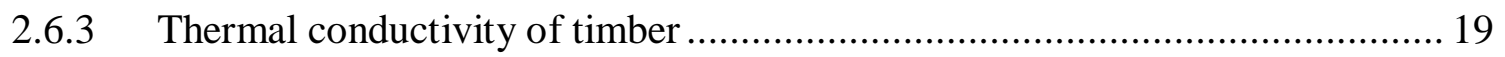

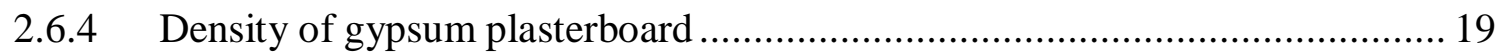

2.6.5 Specific heat of gypsum plasterboard ................................................ 21

2.6.6 Thermal conductivity of gypsum plasterboard ......................................... 22

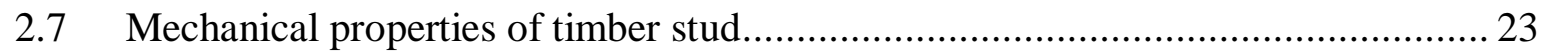

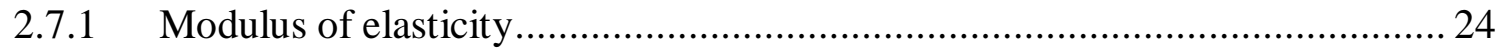


2.7.2 Elastic ratio

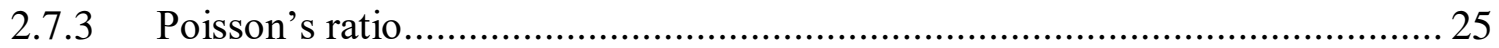

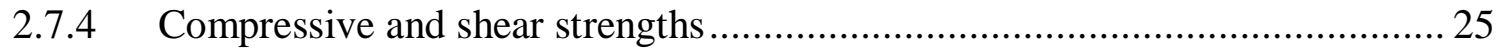

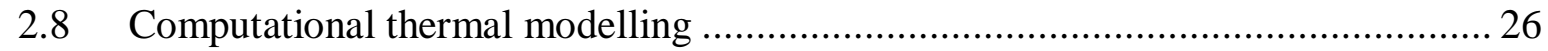

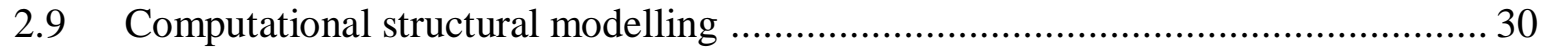

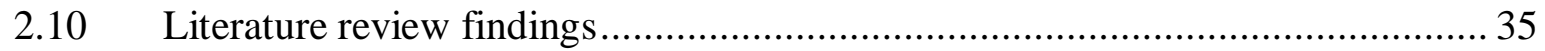

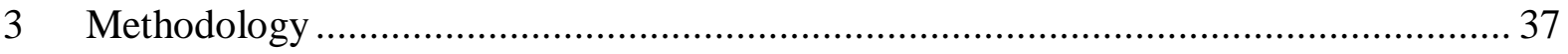

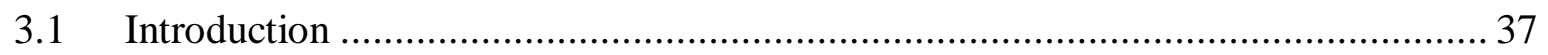

Finite element modelling ............................................................................ 37

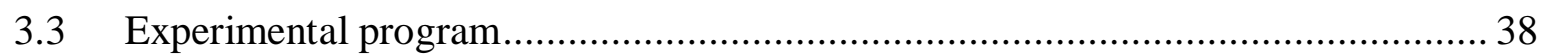

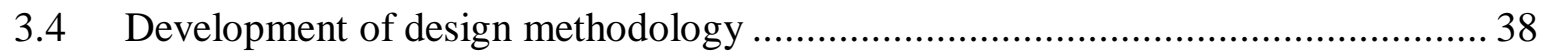

4 Computational Finite Element Modelling ......................................................... 40

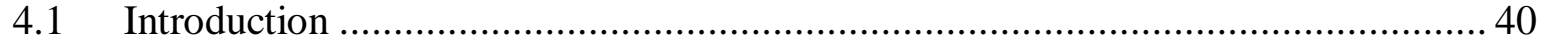

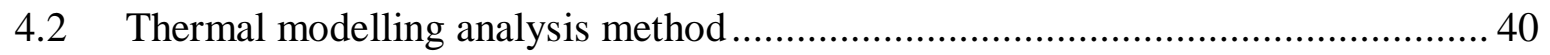

4.2.1 Thermal properties of gypsum plasterboard ............................................ 41

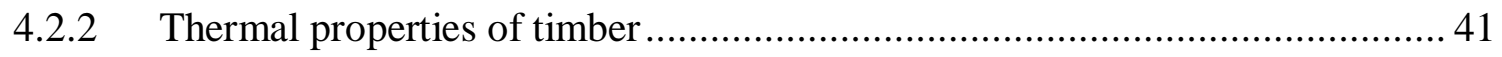

4.2.3 Thermal model for one-sided fire exposure ........................................... 41

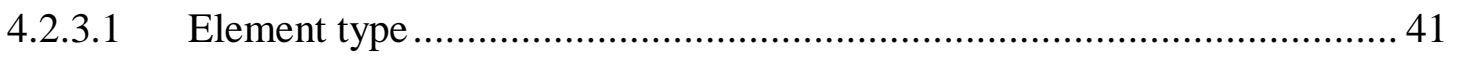

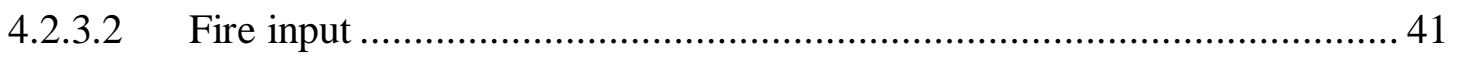

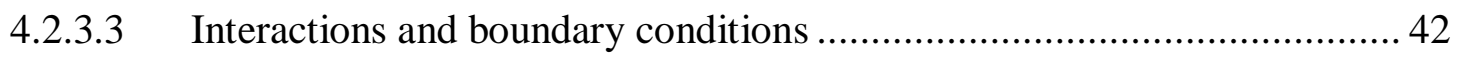

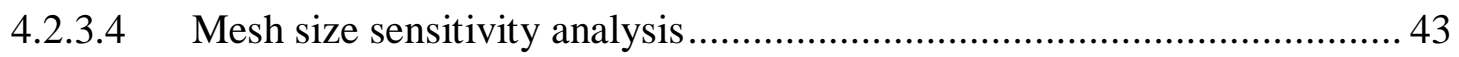

4.2.4 Thermal model for two-sided fire exposure ............................................... 44

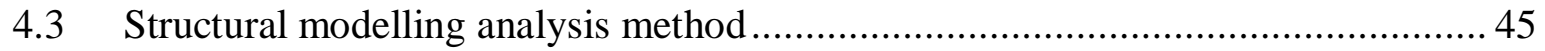

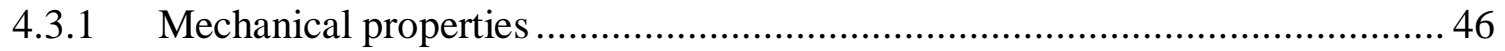

4.3.2 Structural model under ambient conditions.............................................. 49

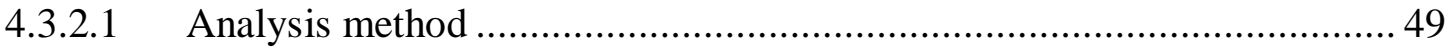

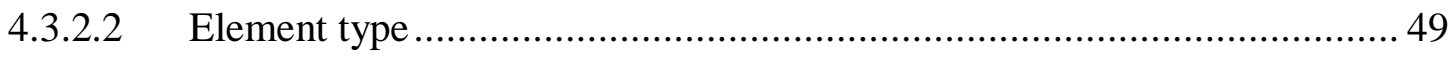




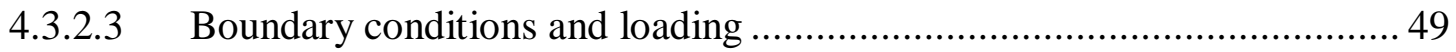

4.3.2.4 Mesh size sensitivity analysis and results ........................................ 50

4.3.3 Structural model under fire conditions......................................................... 52

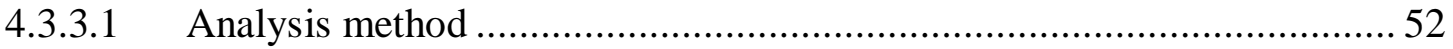

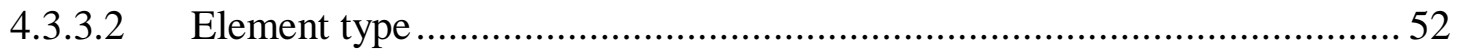

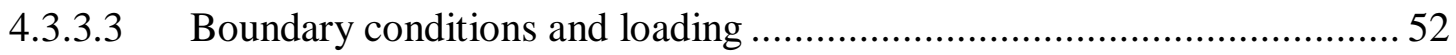

4.3.3.4 Mesh size sensitivity analysis and results ........................................ 53

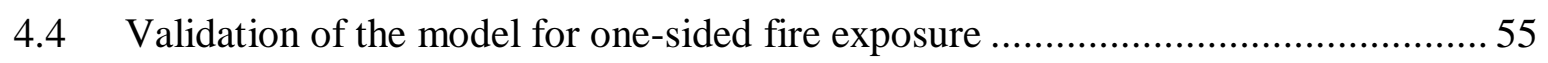

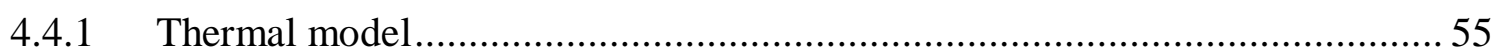

4.4.1.1 FR1611 full-scale fire-resistance test............................................... 57

4.4.1.2 FR1571 full-scale fire-resistance test..................................................59

4.4.1.3 FR1570 full-scale fire-resistance test..............................................5 59

4.4.1.4 FR1141 full-scale fire-resistance test................................................ 60

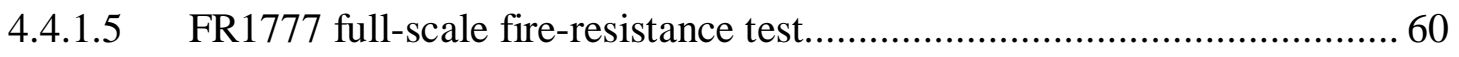

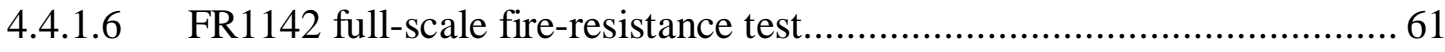

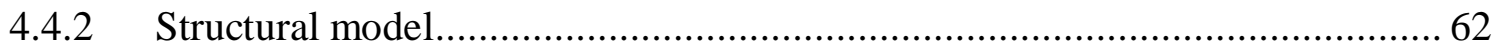

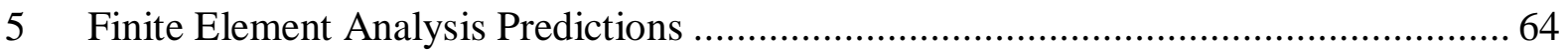

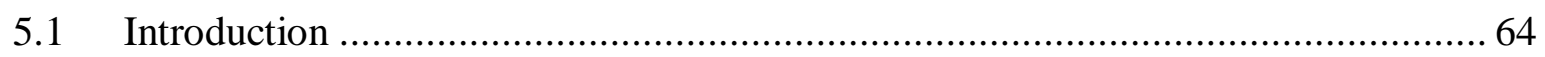

5.2 One-sided fire exposure thermal modelling result .......................................... 64

5.3 Two-sided fire exposure thermal modelling result .......................................... 66

5.4 One-sided fire exposure structural modelling result .......................................... 69

5.5 Two-sided fire exposure structural modelling result .......................................... 70

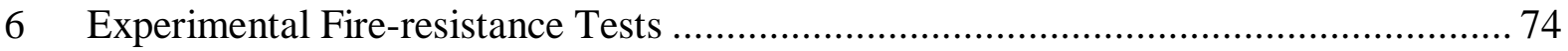

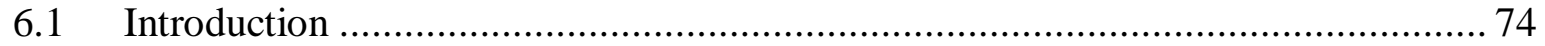

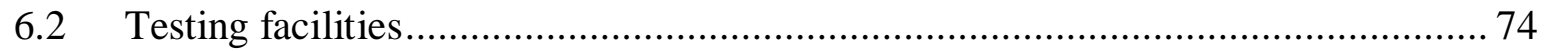

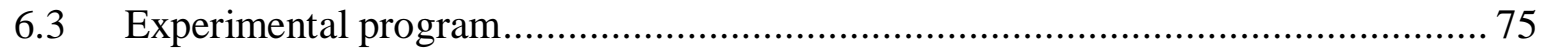

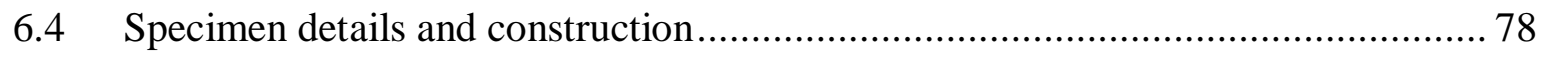




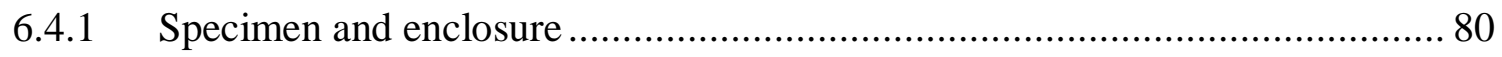

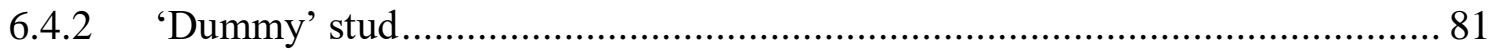

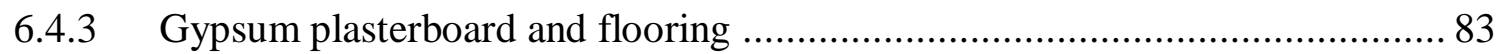

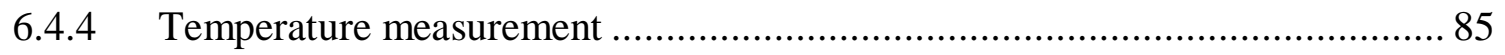

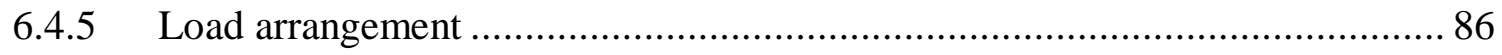

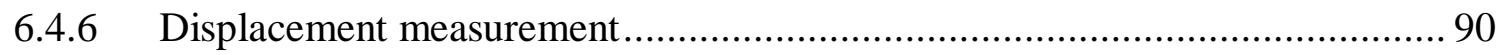

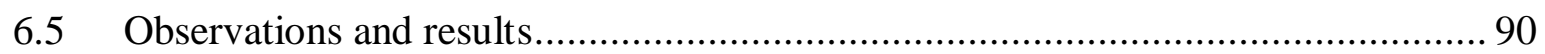

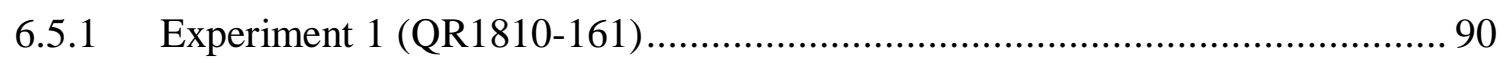

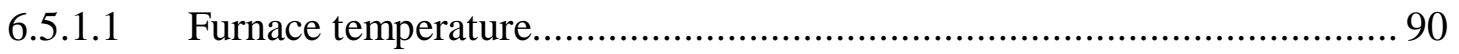

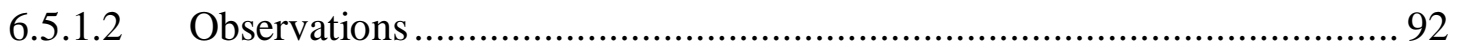

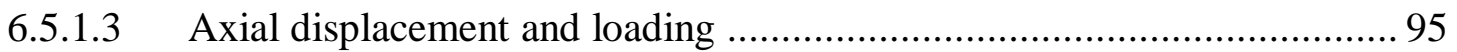

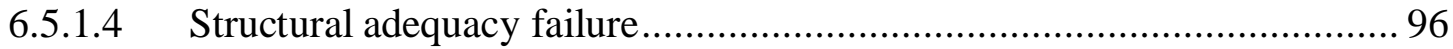

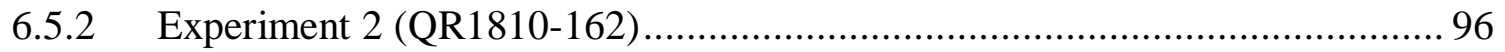

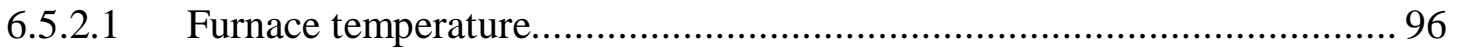

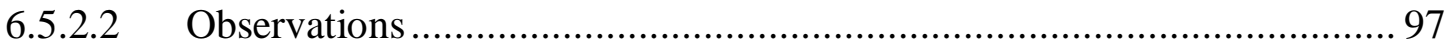

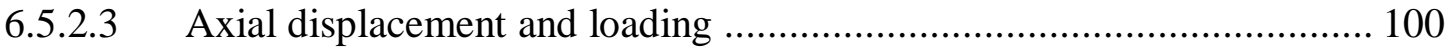

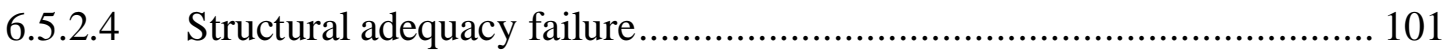

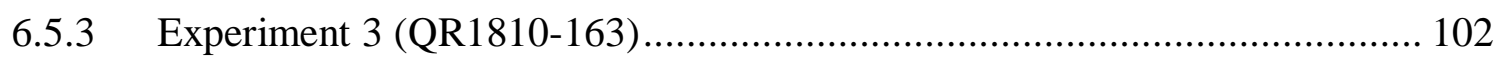

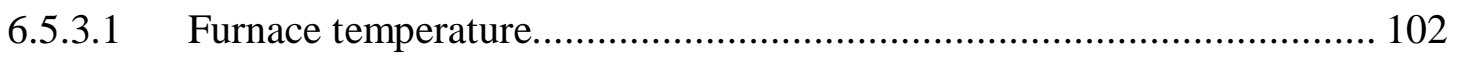

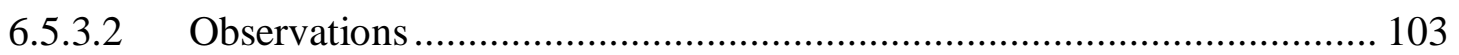

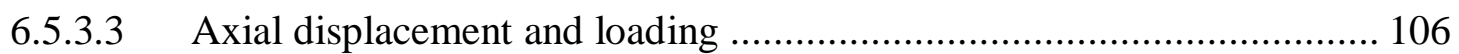

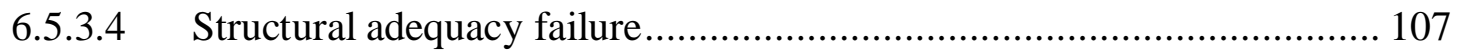

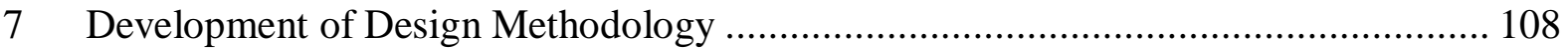

7.1 Computational finite element modelling for lower exposure ............................. 108

7.1.1 Measured stud temperature comparison with prediction model.................... 109

7.1.2 Measured axial displacement comparison with prediction model.................. 112

7.1.3 Measured structural adequacy failure with prediction model ...................... 112 
7.1.4 Measured residual section comparison with prediction model

7.2 Comparative performance assessment between one and two-sided fire exposures 116

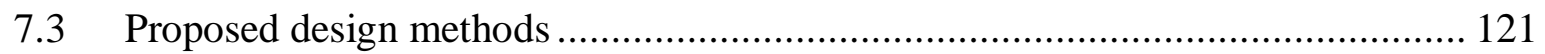

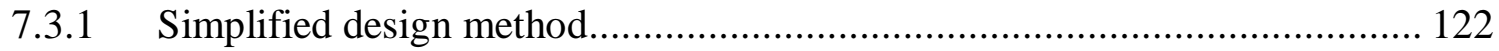

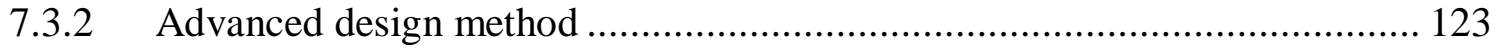

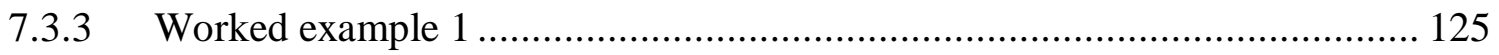

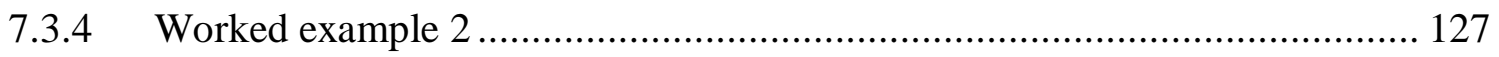

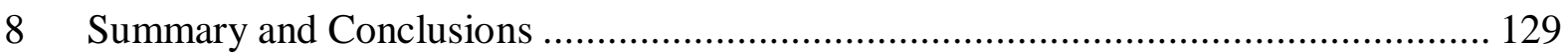

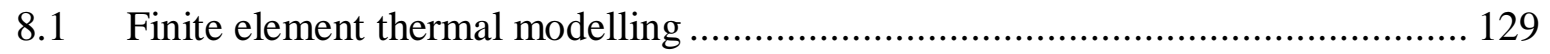

8.2 Finite element structural modelling ............................................................... 130

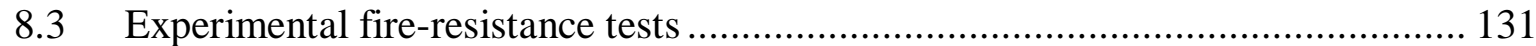

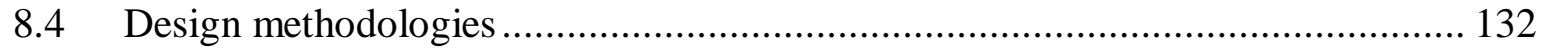

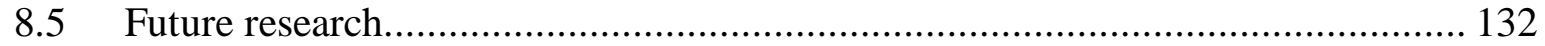

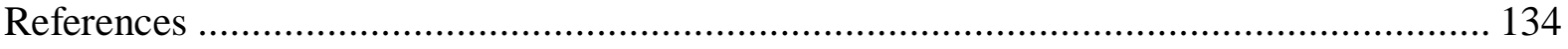

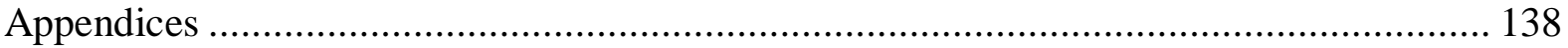




\section{List of Figures}

Figure 1.1 - Basic configuration of gypsum plasterboard 1

Figure 1.2 - Typical examples of gypsum plasterboard wall construction with (a) light timber and (b) steel 2

Figure 1.3 - Load-bearing gypsum plasterboard wall exposed to fire on one side 3

Figure 1.4 - Typical floor plan of apartment units in a multi storey building 3

Figure 1.5 - Typical section view of office mezzanine in an industrial warehouse

Figure 1.6 - (a) Doubling gypsum plasterboard linings on both sides of the timber or steelframed wall and (b) applying thicker linings to the timber-framed wall ..... 5

Figure 1.7 - Full-scale fire furnace and rail mounted trolley. 6

Figure 1.8 - Standard fire time-temperature curve from AS 1530.4:2014 [5] ...................... 6

Figure 2.1 - LB wall specimen arrangement by König [10]

Figure 2.2 - Residual cross-section of timber studs from standard fire-resistance tests by König [10] (Original dimension in dotted lines) 12

Figure 2.3 - Test arrangement for LB wall assemblies by Gerlich and Buchanan [7] 13

Figure 2.4 - Horizontal fire-resistance test furnace and vertical heating chamber set-up by (a) Lee et al. [21] and (b) Ryu et al. [14] 14

Figure 2.5 - Various fire exposure conditions investigated by Chen et al. [24] 15

Figure 2.6 - Typical light timber-framed house [1]. 16

Figure 2.7 - Density loss of softwood with increasing temperatures at a moisture content of $12 \%[6]$ 18

Figure 2.8 - Specific heat of softwood with increasing temperatures [6] 18

Figure 2.9 - Thermal conductivity of softwood with increasing temperatures [6] 19

Figure 2.10 - Density loss of gypsum plasterboard with increasing temperatures proposed by various researchers $[19,25,31,33-35]$ 20

Figure 2.11 - Specific heat of gypsum plasterboard with increasing temperatures proposed by various researchers $[19,25,31,33-35]$ 21 
Figure 2.12 - Thermal conductivity of gypsum plasterboard with increasing temperatures proposed by various researchers $[19,25,31,33-35]$

Figure 2.13 - Three principal axes of timber [28]

Figure 2.14 - Reduction factors for modulus of elasticity parallel to grain of softwood from Eurocode 5: Part 1-2 [6]

Figure 2.15 - Reduction factors for strength parallel to grain of softwood from Eurocode 5: Part 1-2 [6].....

Figure 2.16 - Three-dimensional thermal model of light-gauge steel-framed gypsum plasterboard lined wall developed by Rusthi [33]

Figure 2.17 - Time-temperature profiles of (a) light-gauge steel stud and (b) gypsum plasterboards by Rusthi [33]. 27

Figure 2.18 - Two-dimensional thermal models of light timber-framed gypsum plasterboard lined walls developed by (a) Thomas [19] and (b) Mehaffey et al. [41] 28

Figure 2.19 - Time-temperature profiles of (a) gypsum plasterboards and (b) timber stud by Mehaffey et al. [41] (model - solid line, experiment - dashed line)

Figure 2.20 - Two-dimensional thermal model mesh of light-gauge steel-framed gypsum plasterboard lined walls developed by Feng et al. [39]................................................ 30

Figure 2.21 - Time-temperature profiles of gypsum plasterboards by Feng et al. [39] ......... 30

Figure 2.22 - Sequentially coupled temperature-displacement model developed by Rusthi [33]

Figure 2.23 - Fully coupled temperature-displacement model developed by Rusthi [33] ..... 32

Figure 2.24 - Steel stud temperature variation assigned to nodes by Rusthi [33]................ 32

Figure 2.25 - Three-dimensional structural model developed by Thomas [19]. 33

Figure 2.26 - Three-dimensional finite element structural model with mechanical boundary conditions and loading by Gunalan [20] 34

Figure 2.27 - Temperature distribution to the flanges and web of the steel stud 35

Figure 4.1 - Timber-framed wall section modelled in finite element model 40

Figure 4.2 - Layout of the geometry for the timber-framed wall assembly model 41 
Figure 4.3 - One-sided fire exposure heat transfer modes through timber-framed wall 42

Figure 4.4 - Boundary conditions assigned in one-sided fire exposure heat transfer model.. 42

Figure 4.5 - Time-temperature profiles for 2, 3, 5 and $10 \mathrm{~mm}$ square mesh sizes 43

Figure 4.6 - Two-sided fire exposure heat transfer modes through timber-framed wall 44

Figure 4.7 - Boundary conditions assigned in two-sided fire exposure heat transfer model.. 45

Figure 4.8 - Typical timber-framed wall assembly 46

Figure 4.9 - Structural 3-D finite element model of timber stud 50

Figure 4.10 - General eigenvalue buckling analysis results of 90 x 45 x 2910 mm timber stud

Figure 4.11 - Proposed timber stud temperature distribution when subjected to (a) one-sided fire exposure and (b) two-sided fire exposure 53

Figure 4.12 - Length mesh size sensitivity analysis 54

Figure 4.13 - Global buckling failure of 90 x 45 x $2910 \mathrm{~mm}$ timber stud subjected to one-sided fire exposure .55

Figure 4.14 - Typical thermocouple location layout .57

Figure 4.15 - Test FR 1611 time-temperature comparison with thermal model for the wall lining .58

Figure 4.16 - Test FR1611 time-temperature comparison with thermal model for the timber stud .58

Figure 4.17 - Test FR1571 time-temperature comparison with thermal model. 59

Figure 4.18 - Test FR1570 time-temperature comparison with thermal model. 60

Figure 4.19 - Test FR1141 time-temperature comparison with thermal model. 60

Figure 4.20 - Test FR1777 time-temperature comparison with thermal model. 61

Figure 4.21 - Test FR1142 time-temperature comparison with thermal model. 62

Figure 5.1 - Predicted time-temperature profiles for 13 and $16 \mathrm{~mm}$ fire-rated gypsum plasterboard subjected to one-sided fire exposure

Figure 5.2 - Predicted time-temperature profiles for 13 and $16 \mathrm{~mm}$ fire-rated gypsum plasterboard subjected to two-sided fire exposure 
Figure 5.3 - Temperature contours across the $13 \mathrm{~mm}$ fire-rated gypsum plasterboard lined wall assembly subjected to one-sided fire exposure.

Figure 5.4 - Temperature contours across the $13 \mathrm{~mm}$ fire-rated gypsum plasterboard lined wall assembly subjected to two-sided fire exposure

Figure 5.5 - Temperature contours across the $16 \mathrm{~mm}$ fire-rated gypsum plasterboard lined wall assembly subjected to one-sided fire exposure.

Figure 5.6 - Temperature contours across the $16 \mathrm{~mm}$ fire-rated gypsum plasterboard lined wall assembly subjected to two-sided fire exposure 68

Figure 5.7 - Variation of predicted structural adequacy failure time with load ratio under onesided fire exposure 70

Figure 5.8 - Axial compression failure mode of 90 x 45 x $2910 \mathrm{~mm}$ timber stud subjected to two-sided fire exposure 71

Figure 5.9 - Variation of predicted structural adequacy failure time with load ratio under twosided fire exposure

Figure 6.1 - (a) Full-scale fire furnace and (b) specimen holder in the BRANZ fire testing laboratory. 75

Figure 6.2 - Two-sided fire exposure fire-resistance test configuration (plan view) 76

Figure 6.3 - Two-sided fire exposure fire-resistance test configuration (section view)..... 77

Figure 6.4 - (a) Full-scale fire-resistance test of a light timber frame wall taken from Buchanan and Abu [1] and (b) modified test for two-sided fire exposure 79

Figure 6.5 - Load-bearing specimen and enclosure structures 81

Figure 6.6 - Dummy studs for recording time-temperature profiles through the stud 82

Figure 6.7 - Location of thermocouple embedded into a sectioned dummy stud 83

Figure 6.8 - Fire-rated gypsum plasterboard and flooring installation. 84

Figure 6.9 - Location of MIMS thermocouple and plate thermometer 85

Figure 6.10 - Disc-type thermocouple and wire thermocouples set-up for load-bearing wall specimen 86

Figure 6.11 - Location of thermocouple in experiments 89 
Figure 6.12 - (a) Hydraulic jacks and (b) a hydraulic pump 89

Figure 6.13 - Linear variable differential transducers installed at each end ....................... 90

Figure 6.14 - Measured average furnace time-temperature profiles in QR1810-161 ...........91

Figure 6.15 - Photos of QR1810-161 during the test .................................................. 92

Figure 6.16 - Enclosure exposed cavity temperature comparison with past tests................. 93

Figure 6.17 - Dummy stud time-temperature profiles of QR1810-161_............................ 94

Figure 6.18 - Residual load-bearing wall specimen of QR1810-161 ............................... 94

Figure 6.19 - Measured axial displacement in QR1810-161 ....................................... 95

Figure 6.20 - Measured applied load per hydraulic jack in QR1810-161 _........................ 96

Figure 6.21 - Measured average furnace time-temperature profiles in QR1810-162 _.......... 97

Figure 6.22 - Photos of QR1810-162 during the test .............................................. 98

Figure 6.23 - Enclosure unexposed face temperature comparison with past tests................ 99

Figure 6.24 - Dummy stud time-temperature profiles of QR1810-162 ............................ 99

Figure 6.25 - Residual load-bearing wall specimen of QR1810-162 ….......................... 100

Figure 6.26 - Measured axial displacement in QR1810-162 ....................................... 101

Figure 6.27 - Measured applied load per hydraulic jack in QR1810-162 _....................... 101

Figure 6.28 - Measured average furnace time-temperature profiles in QR1810-163 ......... 102

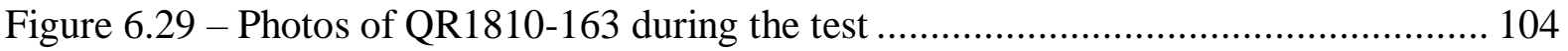

Figure 6.30 - Load-bearing wall specimen exposed cavity temperature .......................... 104

Figure 6.31 - Dummy stud time-temperature profiles of QR1810-163........................... 105

Figure 6.32 - Residual load-bearing wall specimen and failure of timber studs observed in

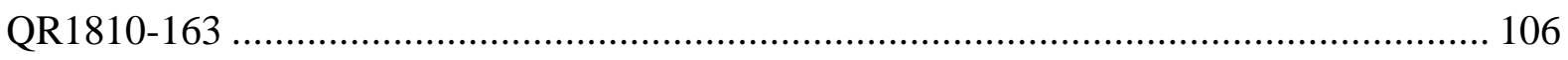

Figure 6.33 - Measured axial displacement in QR1810-163 ........................................ 107

Figure 6.34 - Measured applied load per hydraulic jack in QR1810-163 _....................... 107

Figure 7.1 - Two-sided fire exposure heat transfer modes with lower exposure on the enclosure

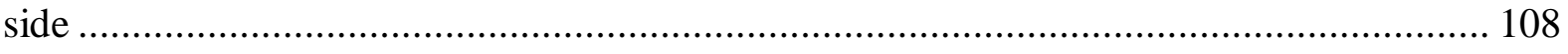


Figure 7.2 - Two-sided fire exposure temperature distribution with lower exposure on enclosure side

Figure 7.3 - Experimental and modelled timber stud temperatures for QR1810-161 109

Figure 7.4 - Experimental and modelled timber stud temperatures for QR1810-162......... 110

Figure 7.5 - Experimental and modelled timber stud temperatures for QR1810-163......... 111

Figure 7.6 - Experimental and modelled vertical axial displacements............................ 113

Figure 7.7 - Modelled residual timber stud section at failure ..................................... 116

Figure 7.8 - Predicted buckling failure comparison between (a) one and (b) two-sided fire exposure.

Figure 7.9 - Modelled lateral displacement at mid-height when subjected to (a) one and (b) two-sided fire exposure 118

Figure 7.10 - Variation of predicted failure time with load ratio for $90 \mathrm{~mm}$ x $45 \mathrm{~mm}$ timber stud

Figure 7.11 - Variation of predicted failure time with load ratio for $140 \mathrm{~mm}$ x $45 \mathrm{~mm}$ timber stud

Figure 7.12 - Predicted structural adequacy when subjected to two-sided fire exposure as a function of one-sided fire exposure 122

Figure 7.13 - Structural adequacy failure time retention factor for $90 \mathrm{~mm}$ x $45 \mathrm{~mm}$ stud with $13 \mathrm{~mm}$ and $16 \mathrm{~mm}$ fire-rated gypsum plasterboard 124

Figure 7.14 - Structural adequacy failure time retention factor for $140 \mathrm{~mm}$ x $45 \mathrm{~mm}$ stud with $13 \mathrm{~mm}$ and $16 \mathrm{~mm}$ fire-rated gypsum plasterboard 125 


\section{List of Tables}

Table 2.1 - Heat transfer coefficients selected by Thomas [19] 28

Table 2.2 - Comparison between the sequentially coupled and fully coupled analyses by Rusthi [33]

Table 2.3 - Test wall details and comparison between the predicted and measured structural failure times by Thomas [19] 34

Table 4.1 - Simulation run-time for 2, 3, 5 and $10 \mathrm{~mm}$ square mesh sizes 43

Table 4.2 - Temperature-dependent modulus of elasticity, Poisson's ratio and modulus of rigidity of SG8 Radiata pine used for engineering constants orthotropic elasticity 47

Table 4.3 - Temperature-dependent compressive and shear strength of SG8 Radiata pine ... 48

Table 4.4 - Temperature-dependent compressive and shear strength ratios of SG8 Radiata pine used in Hill's Potential Function 48

Table 4.5 - Simultion run-time for 5, 10, 50, 100 and $200 \mathrm{~mm}$ mesh size in length 51

Table 4.6 - Modelling run-time and predicted structural adequacy failure time for each mesh size in length 54

Table 4.7 - Summary of past fire-resistance tests for validation. 56

Table 4.8 - Summary of past fire-resistance tests for validation.

Table 5.1 - Predicted structural adequacy failure time of timber stud lined with $13 \mathrm{~mm}$ firerated gypsum plasterboard subjected to one-sided fire exposure

Table 5.2 - Predicted structural adequacy failure time of timber stud lined with $16 \mathrm{~mm}$ firerated gypsum plasterboard subjected to one-sided fire exposure

Table 5.3 - Predicted structural adequacy failure time of timber stud lined with $13 \mathrm{~mm}$ firerated gypsum plasterboard subjected to two-sided fire exposure 71

Table 5.4 - Predicted structural adequacy failure time of timber stud lined with $16 \mathrm{~mm}$ firerated gypsum plasterboard subjected to two-sided fire exposure

Table 6.1 - Full-scale fire-resistance test specimens for two-sided fire exposure 78

Table 6.2 - Nominal load per hydraulic jack for each experiment 86

Table 7.1 - Measured and predicted structural adequacy failure times 114 
Table 7.2 - Average timber stud temperatures measured from QR1810-161

Table 7.3 - Average timber stud temperatures measured from QR1810-162.

Table 7.4 - Average timber stud temperatures measured from QR1810-163.

Table 7.5 - Predicted failure times of $90 \mathrm{~mm}$ x $45 \mathrm{~mm}$ stud with $13 \mathrm{~mm}$ fire-rated gypsum plasterboard

Table 7.6 - Predicted failure times of $90 \mathrm{~mm}$ x $45 \mathrm{~mm}$ stud with $16 \mathrm{~mm}$ fire-rated gypsum plasterboard

Table 7.7 - Predicted failure times of $140 \mathrm{~mm}$ x $45 \mathrm{~mm}$ stud with $13 \mathrm{~mm}$ fire-rated gypsum plasterboard

Table 7.8 - Predicted failure times of $140 \mathrm{~mm}$ x $45 \mathrm{~mm}$ stud with $16 \mathrm{~mm}$ fire-rated gypsum plasterboard 


\section{Introduction}

\subsection{Gypsum plasterboard as a building material}

Gypsum plasterboard has been used as a construction material for many decades and is widely used for interior linings in residential and commercial buildings. Gypsum $\left(\mathrm{CaSO}_{4} \cdot 2 \mathrm{H}_{2} \mathrm{O}\right)$ is composed of calcium sulphate or anhydrite $\left(\mathrm{CaSO}_{4}\right)$ with two water molecules $\left(2 \mathrm{H}_{2} \mathrm{O}\right)$ for each molecule of calcium sulphate or anhydrite [1]. Gypsum plaster is manufactured by heating finely ground gypsum to approximately $140{ }^{\circ} \mathrm{C}$ to drive the moisture out so it loses about $75 \%$ of its water of crystallisation. This produces dehydrated calcined gypsum powder, calcium sulphate hemihydrate $\left(\mathrm{CaSO}_{4} \cdot 1 / 2 \mathrm{H}_{2} \mathrm{O}\right)$ which is also known as plaster of Paris. The dehydration process of gypsum is described in the chemical formula in Equation (1.1) below.

$$
\mathrm{CaSO}_{4} \cdot 2 \mathrm{H}_{2} \mathrm{O} \text { heat } \rightarrow \mathrm{CaSO}_{4} \cdot 1 / 2 \mathrm{H}_{2} \mathrm{O}+{ }^{3} /{ }_{2} \mathrm{H}_{2} \mathrm{O}
$$

Gypsum plasterboard is then manufactured by mixing the dehydrated calcined gypsum powder with water and letting the slurry harden between two sheets of cardboard-like plaster liner board as shown in Figure 1.1. This rehydration process which is described in the chemical formula in Equation (1.2) below reverts to the original calcium sulphate dihydrate.

$$
\mathrm{CaSO}_{4} \cdot 1 / 2 \mathrm{H}_{2} \mathrm{O}+{ }^{3} / 2 \mathrm{H}_{2} \mathrm{O} \rightarrow \mathrm{CaSO}_{4} \cdot 2 \mathrm{H}_{2} \mathrm{O}+\text { heat }
$$

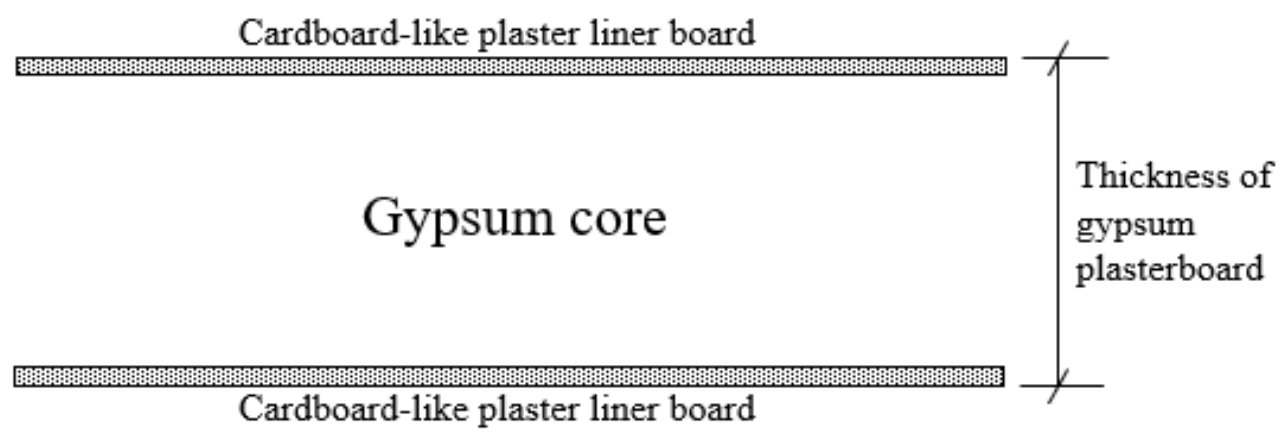

Figure 1.1 - Basic configuration of gypsum plasterboard 
When gypsum plasterboard is heated in a fire, a dehydration reaction (calcination) occurs when bound crystalline moisture is evaporated. This causes gypsum to lose strength and eventually decompose into a powdery state again [2]. The decomposition reaction is endothermic, and hence, excellent fire resistance can be achieved depending on the composition of the plaster, thickness, density and number of layers of gypsum plasterboard.

A gypsum plasterboard wall assembly consists of the interior lining fixed to each side of light steel or timber-framed wall construction consisting of vertical wall studs and either horizontal timber plates or steel channels. Typical examples of gypsum plasterboard wall construction are provided in Figure 1.2.

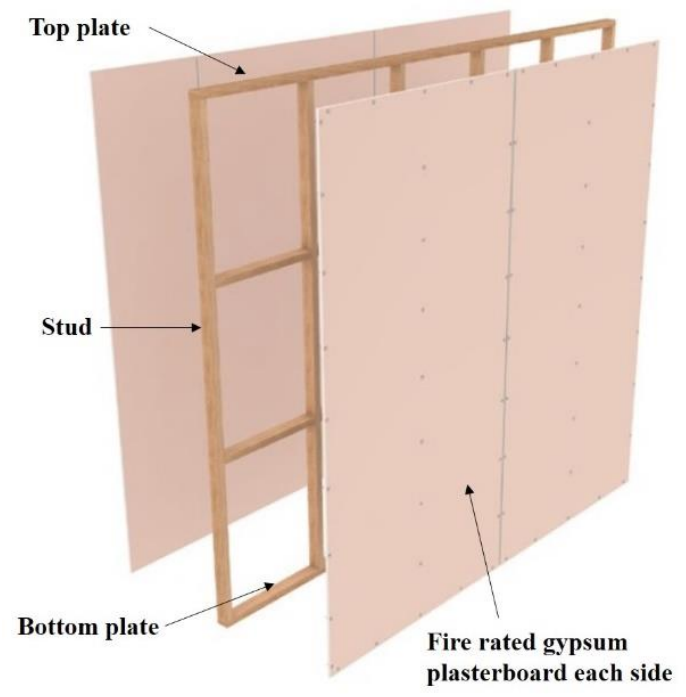

(a)

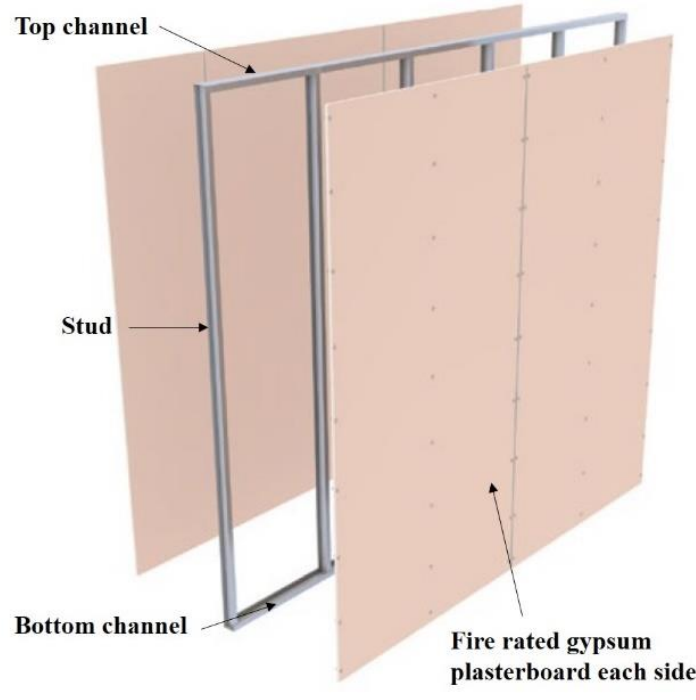

(b)

Figure 1.2 - Typical examples of gypsum plasterboard wall construction with (a) light timber and (b) steel

\subsection{Background}

Gypsum plasterboard wall construction is widely used in residential construction and is commonly used as partitions in commercial and industrial buildings as it provides fire resistance, acoustic performance, bracing and thermal separation. As such, fire-rated gypsum plasterboard wall assemblies are also often used by building designers to protect load-bearing timber or steel-framed walls located within buildings. 
The building designers commonly specify a fire rated wall assembly for load-bearing walls that has been tested in accordance with Australian Standard AS 1530.4:2014 with a standard fire exposure on one side only as shown in Figure 1.3. However, there are typical design scenarios of simultaneous two-sided fire exposure of internal load-bearing walls located within apartment units in a multi storey building, and walls supporting a mezzanine floor in an industrial warehouse as shown in Figures 1.4 and 1.5. These design scenarios are often overlooked, ignored and misinterpreted by building designers which can potentially affect the building's fire safety design as load-bearing walls may fail to resist applied gravity loads before the required time of Fire Resistance Rating (FRR) due to two-sided fire exposure.

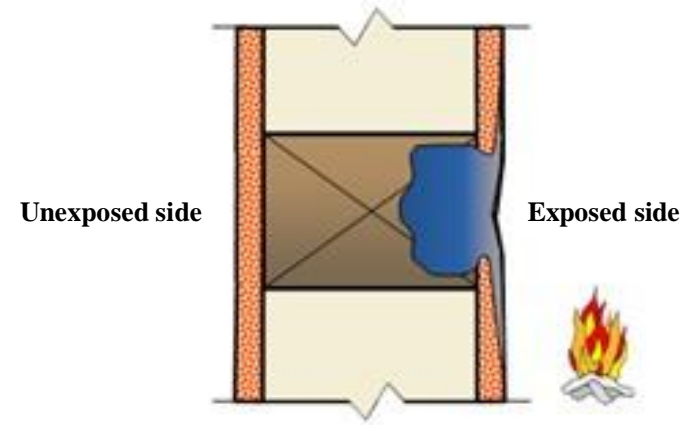

Figure 1.3 - Load-bearing gypsum plasterboard wall exposed to fire on one side

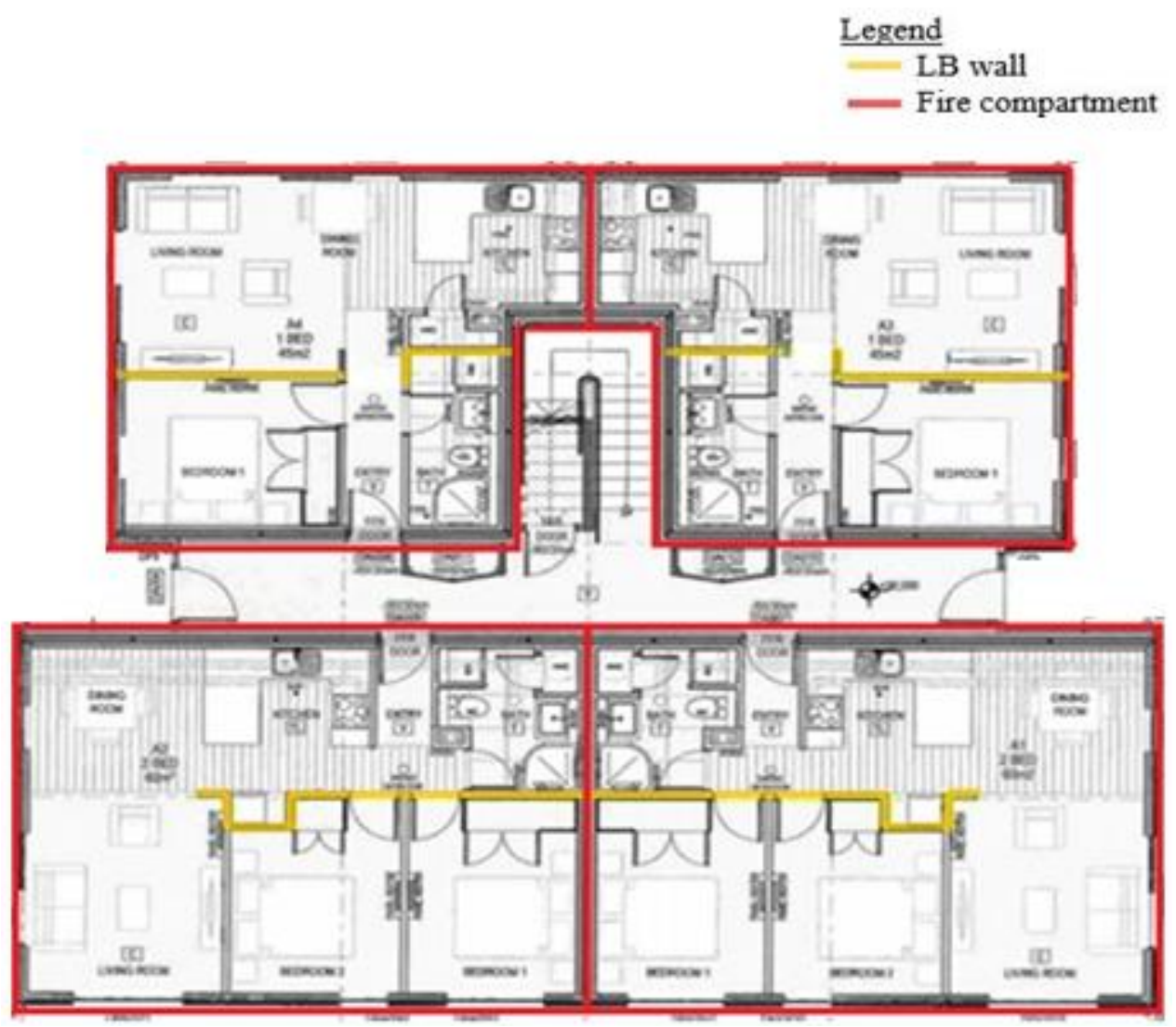

Figure 1.4 - Typical floor plan of apartment units in a multi storey building

Page $\mid 3$ 


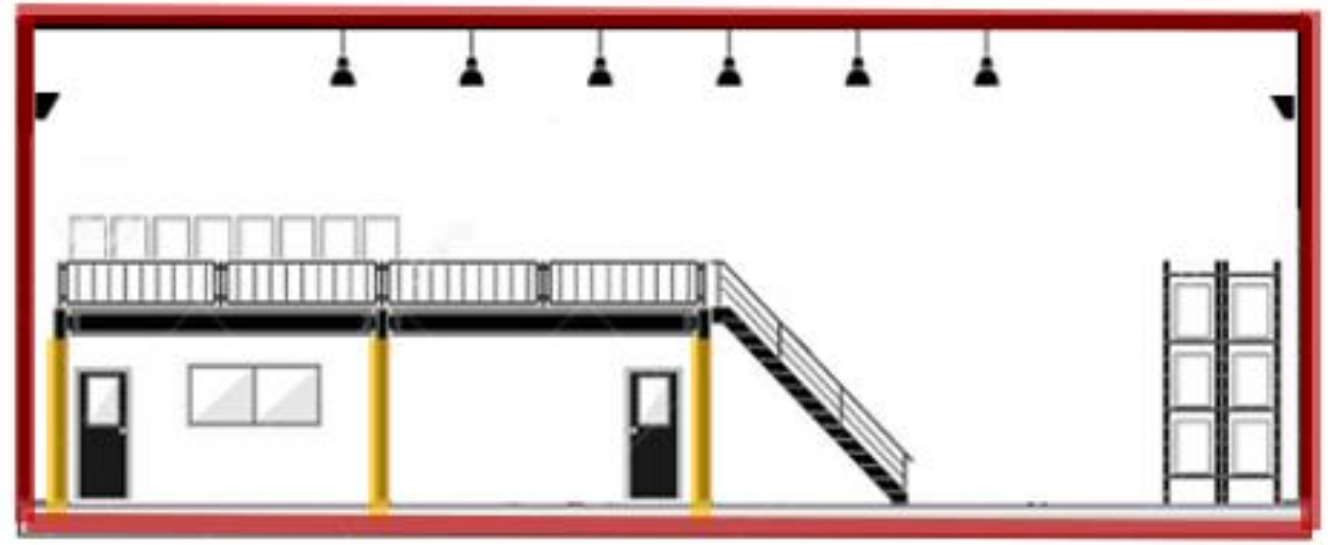

Figure 1.5 - Typical section view of office mezzanine in an industrial warehouse

It is noted that both the exposed and unexposed gypsum plasterboard linings contribute to achieve the FRR of a wall element exposed from one side. The exposed gypsum plasterboard protects the framing and acts as a radiation shield for the unexposed gypsum plasterboard whilst the unexposed gypsum plasterboard delays insulation failure. A load-bearing gypsum plasterboard wall subjected to two-sided fire exposure is anticipated to fail structural adequacy earlier compared with a wall subjected to one-sided fire exposure as the cavity and stud temperatures will rise much quicker.

Currently, there is no suitable test method to determine the performance of load-bearing gypsum plasterboard walls exposed to fire from both sides simultaneously. When the issue is identified in a building, the design approximations include (see Figure 1.6):

- Doubling gypsum plasterboard linings on both sides of the wall to either limit timber char or steel temperature rise. The cavity temperature rise at the back of the exposed lining is limited to no greater than $300{ }^{\circ} \mathrm{C}$ when subjected to one-sided fire exposure in accordance with AS 1530.4:2014.

- Applying thicker gypsum plasterboard linings to the timber-framed wall to limit timber char which occurs on both sides. The residual timber stud section should then be no less than the residual stud section from a reference wall specimen that has been tested from one side in accordance with AS 1530.4:2014. 


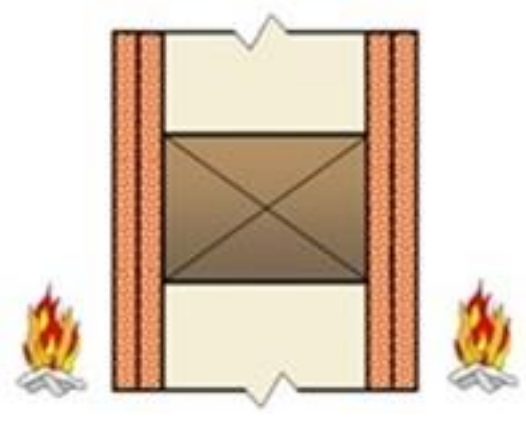

(a)

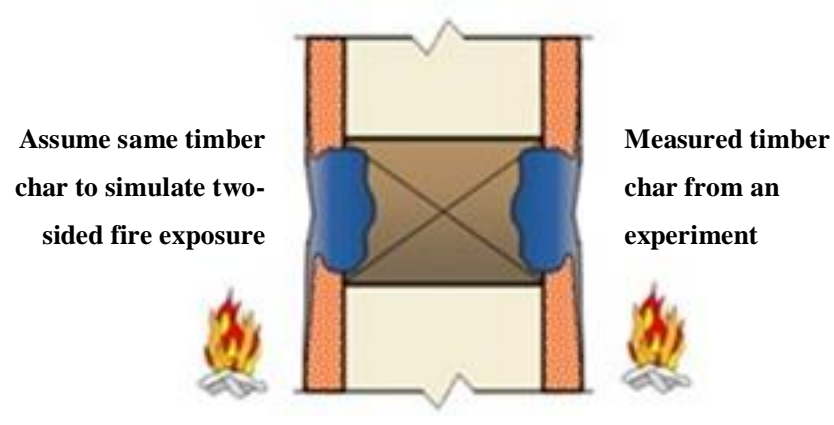

(b)

Figure 1.6 - (a) Doubling gypsum plasterboard linings on both sides of the timber or steel-framed wall and (b) applying thicker linings to the timber-framed wall

However, it is noted that these design approximations are not based on an agreed fire engineering design approach founded on sound engineering analysis or experimental data. In normal heavy timber construction, fire exposure from two adjacent sides results in accelerated charring $[3,4]$. Hence, the notion that applying the expected timber char layer on both sides as shown in Figure 1.6(b) does not necessarily translate to better performance when load-bearing timber-framed walls are subjected to two-sided fire exposure.

\subsection{Fire-resistance testing and its limitation}

Fire-resistance testing in New Zealand is commonly carried out in accordance with AS 1530.4:2014 to determine the behaviour of load-bearing and non-load-bearing vertical or horizontal construction elements exposed to fire conditions. Wall fire-resistance testing evaluates the fire-resistance of a specimen mounted vertically in a specimen holder. Figure 1.7 shows a rail mounted trolley which allows a wall specimen to roll up and fully cover the face of the vertical fire-resistance test furnace. 


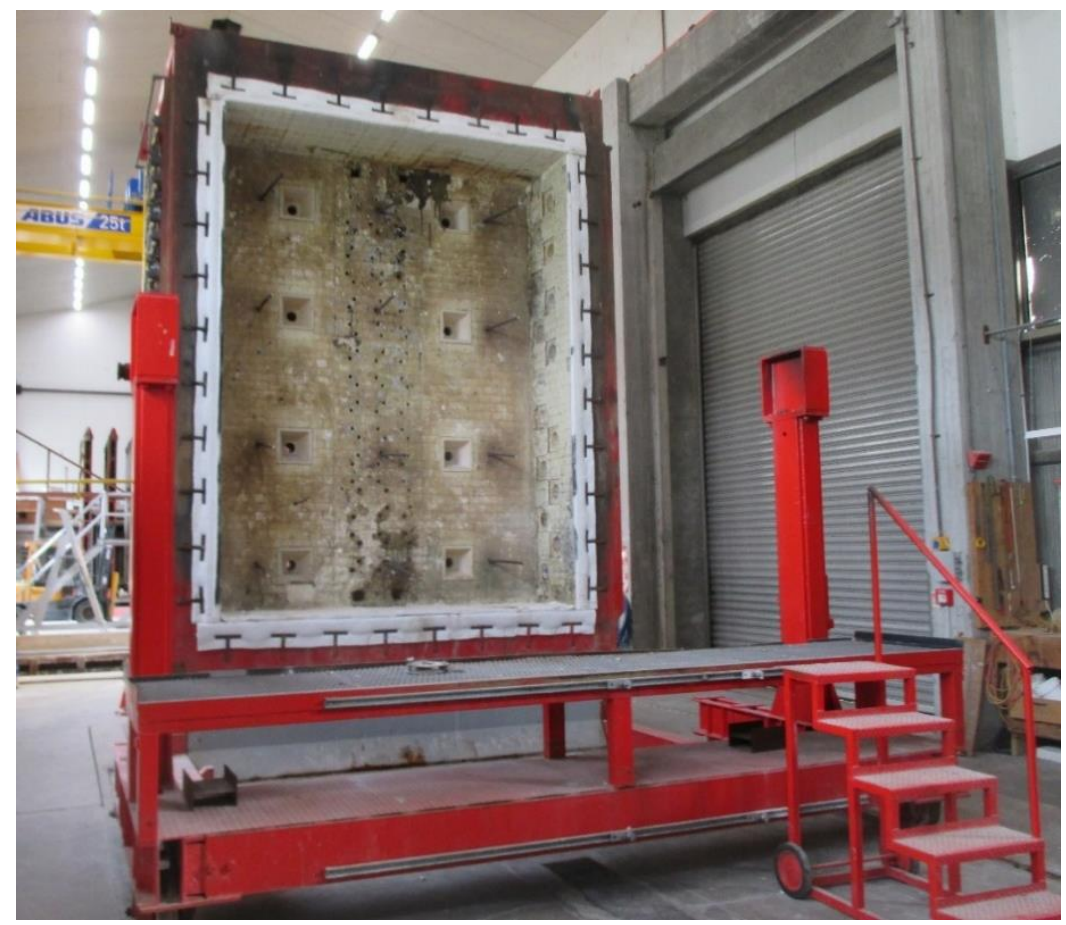

Figure 1.7 - Full-scale fire furnace and rail mounted trolley

The wall specimen is then exposed to a standard time-temperature curve on one side of the specimen. The standard time-temperature relationship as specified in ISO 834 is shown in Figure 1.8.

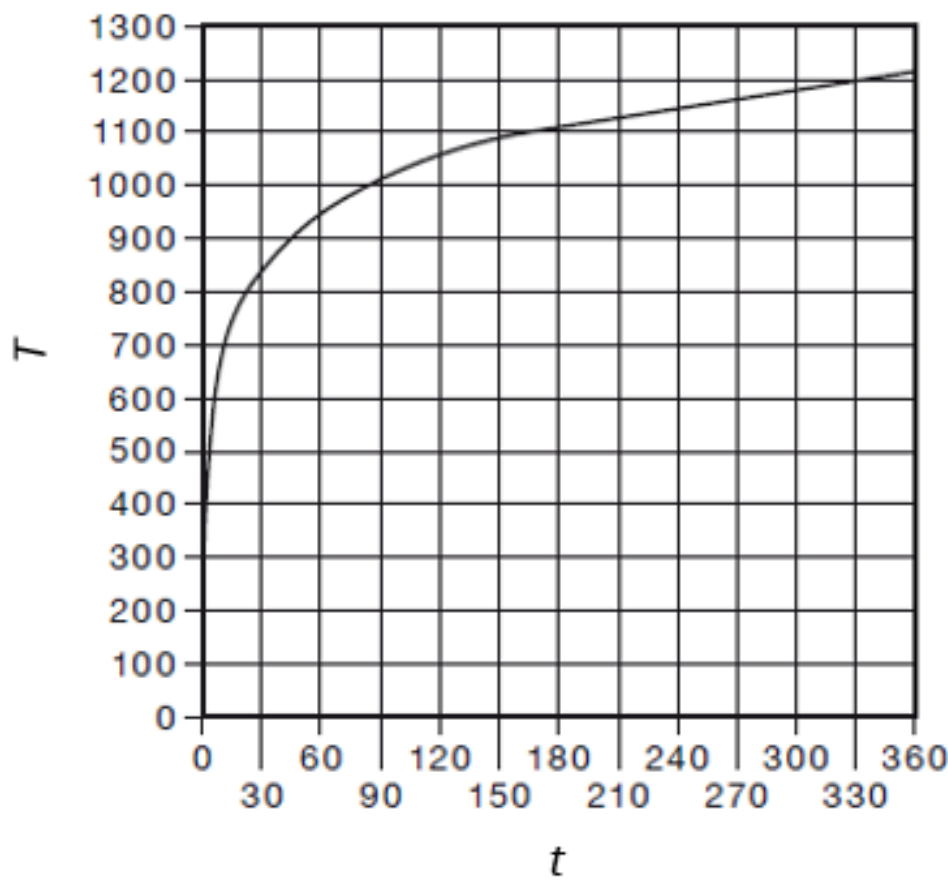

LEGEND:

$T=$ Temperature, ${ }^{\circ} \mathrm{C}$ $t=$ Time, minutes

Figure 1.8 - Standard fire time-temperature curve from AS 1530.4:2014 [5] 
The time-temperature relationship of the ISO 834 standard curve is described in the Equation (1.3).

$$
T=345 \log _{10}(8 t+1)+20
$$

where $T$ and $t$ are the temperature in ${ }^{\circ} \mathrm{C}$ and time in minutes respectively.

In a standard fire-resistance test that is carried out in accordance with Australian Standard AS 1530.4:2014, the performance of the wall specimen is assessed against the following criteria [5];

- Structural adequacy - Failure to resist applied gravity loads during a fire

- Integrity - Passage of flame or hot gases

- Insulation - Unacceptable unexposed face temperature rise

Integrity and insulation failures are determined by observation and temperature measurements on the unexposed side. For load-bearing specimens, structural adequacy failure occurs when axial contraction or the rate of axial contraction exceeds defined limits which are calculated using the Equations (1.4) and (1.5).

$$
\begin{array}{cc}
\text { Limiting axial contraction, } C=\frac{h}{100} \mathrm{~mm} & \text { (Equation 1.4) } \\
\text { Limiting rate of axial contraction, } \frac{d C}{d t}=\frac{3 h}{1000} \mathrm{~mm} / \mathrm{min} & \text { (Equation 1.5) }
\end{array}
$$

where $h$ is the initial height of the wall specimen in millimetres.

The standard fire-resistance wall test thus represents the scenario where a load-bearing gypsum plasterboard wall, which is acting as a separation element, is exposed to fire on one side only. However, load-bearing walls are not always fire separations and, like a structural column or beam supporting a floor above, they can be exposed to fire from two sides simultaneously when they are located within a fire compartment [6]. Therefore, there exists a need for experimental and numerical analyses to reliably determine and understand the performance of load-bearing gypsum plasterboard walls subjected to two-sided fire exposure and to provide a comparative performance assessment with walls subjected to one-sided fire exposure.

\subsection{Research aim and objectives}

The aim of this research is to provide a comparative performance assessment of load-bearing gypsum plasterboard walls subjected to two-sided fire exposure and to formulate a design methodology to accurately predict the structural adequacy of walls subjected to fire exposures 
from both sides simultaneously. The scope of this research is limited to investigating loadbearing timber-framed gypsum plasterboard lined walls with consideration of the limited number of fire-resistance tests in the experimental program and time constraints. To permit comparison with existing test data, the ISO 834 standard fire time-temperature curve is adopted in this research.

The key research objectives are:

- To understand the structural and fire behaviour of load-bearing timber-framed gypsum plasterboard lined walls subjected to two-sided fire exposure using full-scale fireresistance tests

- To conduct a comparative performance assessment of load-bearing timber-framed gypsum plasterboard lined walls subjected to two-sided vs one-sided standard fire exposure

- To develop and validate computational finite element thermal and structural models of load-bearing timber-framed gypsum plasterboard lined walls subjected to two-sided and one-sided fire exposures

- To develop a design methodology that enables the prediction of structural adequacy of load-bearing timber-framed gypsum plasterboard lined walls subjected to two-sided fire exposure based on the experimental findings from fire-resistance tests

\subsection{Outline of thesis}

The outline of this thesis is as follows:

Chapter 1 provides an introduction of the use of gypsum plasterboard as a construction material and typical gypsum plasterboard wall assemblies widely used in residential, commercial and industrial buildings. Standard fire-resistance testing and its limitations are also discussed in this chapter, followed by the research aim and objectives.

Chapter 2 presents a broad literature review of how the fire and structural performance of load-bearing gypsum plasterboard lined walls have been studied numerically and experimentally through computational modelling and experiments respectively as well as other construction elements that have been evaluated and assessed for two-sided fire exposure. It also presents the thermal and mechanical properties of wall assembly components selected by the researcher and summarises the findings. 
Chapter 3 explains the background and development of computational finite element modelling using the Abaqus/CAE finite element software and experimental program implemented in this research to meet the research aims and objectives.

Chapter 4 explains methods of thermal and structural finite element analyses of load-bearing timber-framed gypsum plasterboard lined walls subjected to one and two-sided fire exposures. This is followed by mesh size sensitivity analyses and validation of the developed finite element models using previous experimental results of one-sided fire exposure.

Chapter 5 presents predictions of thermal and structural response of a typical load-bearing timber-framed gypsum plasterboard lined wall assembly when subjected to one and two-sided fire exposure.

Chapter 6 presents details of the experimental program, the testing facilities, the wall specimen details and test configurations designed to expose load-bearing timber-framed gypsum plasterboard lined specimens to fire from both sides simultaneously. Observations of the three modified full-scale fire-resistance experiments, and the analyses of furnace temperatures, loading, axial displacement and structural adequacy performance are also presented.

Chapter 7 presents a finite element model that aligns with the findings from the experiments and provides comparison with experimental results. A comparative performance assessment of the load-bearing timber-framed gypsum plasterboard lined walls subjected to two-sided and one-sided fire exposure is also presented. This is followed by the development of design methods that enable the prediction of structural adequacy of load-bearing timber-framed gypsum plasterboard lined walls subjected to two-sided fire exposure.

Chapter 8 presents the overall findings and conclusions of this research, and makes recommendations for future research. 


\section{Literature Review}

\subsection{Introduction}

This chapter presents a broad literature review of fire and structural performance of loadbearing gypsum plasterboard lined walls. Past research studies on construction elements that have been assessed for two-sided fire exposure are discussed. Thermal and mechanical properties of wall assembly components used by several researchers are summarised, and computational thermo-structural finite element analyses for load-bearing gypsum plasterboard lined walls are investigated.

\subsection{Fire exposure of load-bearing barriers}

The performance of load-bearing gypsum plasterboard lined walls has been extensively studied numerically and experimentally through computational modelling and fire-resistance tests. Studies [7-12] solely investigated the performance of gypsum plasterboard walls subjected to one-sided fire exposure in order to understand the influence of different types of studs, cavity insulation, sheathing, shear membrane and lining orientation. In New Zealand, fire-rated loadbearing wall systems are mainly tested and published by Winstone Wallboards Ltd with Fire Resistance Ratings (FRRs) that range from 30 to 120 minutes [13]. These fire-rated wall systems are based on full-scale fire-resistance tests which have been mainly carried out by the Building Research Association of New Zealand (BRANZ) against the ISO 834 standard timetemperature condition, in accordance with AS 1530.4:2014 [5]. However, these systems are neither tested nor intended for walls that are exposed to fire simultaneously on both sides.

Although no study has been reported on assessing the risk of load-bearing gypsum plasterboard lined walls subjected to two-sided fire exposure, the performance of reinforced concrete walls subjected to two-sided fire exposure has been experimentally and numerically investigated in recent studies by Ryu et al. [14] and Lee and Lee [15]. In [14], it was found that the residual strength of the two-sided exposed walls were less than the one-sided exposed walls but the effect of two-sided fire exposure was not significant with two-sided exposed walls having only 2.2 to $3.2 \%$ more reduction in the residual strength. EN 1992:1-2:2004 [16] and EN 1996-1-2:2005 [17], which are intended for structural fire design of concrete and masonry structures respectively, also distinguish one and two-sided fire exposures. These standards require the two-sided exposed walls to be wider. For concrete structures, an increased concrete 
cover is required for a certain FRR and the width of the two-sided exposed wall needs to be increased by an average of $16.4 \%$ in order to achieve the same FRR. The differences in performance of masonry and concrete structures subjected to one and two-sided fire exposures are not significant, but load-bearing gypsum plasterboard walls are expected to be more susceptible to two-sided exposure due to lower inherent fire-resistant properties than concrete and masonry.

For timber-framed wall assemblies, EN 1995:1-2:2004 [6] provides fire design rules for fire resistance calculation by considering the failure time of gypsum plasterboard and charring rate of timber studs, and suggests charring on both sides to be taken into account when assessing the residual timber section of load-bearing walls with no separating function. However, these design rules are not readily used because the failure times caused by thermal degradation are generally not available from manufacturers of gypsum plasterboard [18]. Thermo-mechanical properties of gypsum plasterboard can vary depending on the type and manufacturer, and hence EN 1995:1-2:2004 [6] suggests the failure times of gypsum plasterboard due to mechanical degradation of the material to be determined on the basis of product specific experiments which can be costly and time consuming.

\subsection{Previous experimental studies}

Experimental work on the performance of load-bearing gypsum plasterboard lined walls under fire conditions, has been carried out in several studies [7, 10-12]. Exposure was against the standard fire time-temperature curve in accordance with either ISO 834:1975 or CAN/ULC-S101.

In the full-scale fire-resistance tests conducted by König [10], three load-bearing timberframed walls consisting of $145 \mathrm{~mm}$ x $45 \mathrm{~mm}$ studs and various thicknesses of gypsum plasterboard were tested to understand their behaviour under fire conditions and to develop a model for designing typical timber-framed housing. The test specimens were $2.5 \mathrm{~m}$ in height and $3.0 \mathrm{~m}$ in width, and consisted of five load-bearing timber studs spaced at $600 \mathrm{~mm}$ centres and two non-load-bearing timber studs at each end. A $50 \mathrm{~mm}$ gap was provided at the top of the non-load-bearing studs to achieve an equal axial load distribution to the load-bearing timber studs as shown in Figure 2.1. 


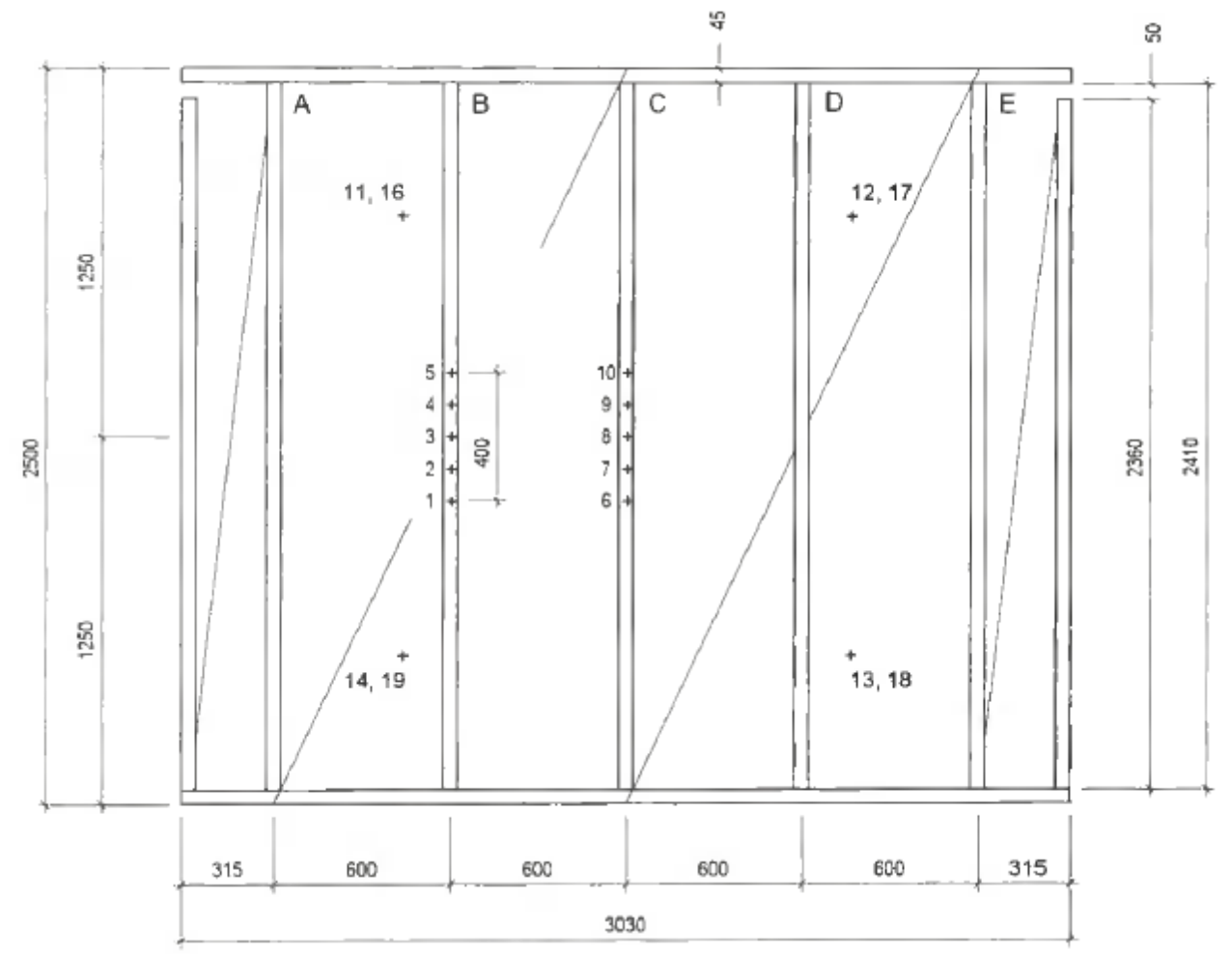

Figure 2.1 - LB wall specimen arrangement by König [10]

The test specimens were then subjected to standard fire exposure on one side to assess their performance as fire separations. The one-sided fire exposure was evident from the recorded residual cross-section of timber studs (shown in Figure 2.2) which showed no sign of char on the unexposed side.

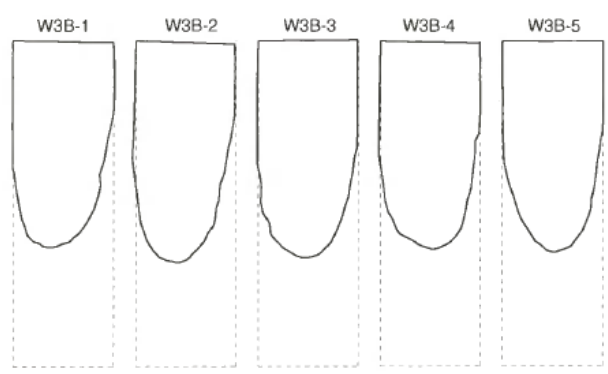

Figure 2.2 - Residual cross-section of timber studs from standard fire-resistance tests by König [10]

\section{(Original dimension in dotted lines)}

It was observed that both horizontal and vertical deflections rapidly increased and failure occurred by buckling towards the ambient side. The failure was due to the softening of the timber when subjected to heat and the effect of eccentricity once timber chars on the exposed side. Thomas [19], who performed nine full-scale and pilot-scale fire-resistance tests of loadbearing timber-framed gypsum plasterboard lined walls, also observed buckling failure towards the ambient side due to timber shrinkage on the fire side of the stud. Tension failures 
of the timber stud did not occur before structural adequacy failure but was considered likely if the test carried on [19].

The performance of load-bearing light-gauge steel-framed gypsum plasterboard lined walls was also investigated by Gerlich and Buchanan [7] and Gunalan [20] who each conducted three full-scale fire-resistance tests against the standard ISO 834 fire time-temperature curve, consisting of a variety of steel stud dimensions, axial loads and gypsum plasterboard thicknesses. In order to achieve an equal axial load distribution to the load-bearing studs, Gerlich and Buchanan [7] used four load-bearing light-gauge steel studs at $600 \mathrm{~mm}$ centres and two non-load-bearing studs at each end as shown in Figure 2.3. Gunalan [20] also used four load-bearing light-gauge steel studs but glass fibre or rock fibre insulation was used to fill a stud bay at each end without end studs.

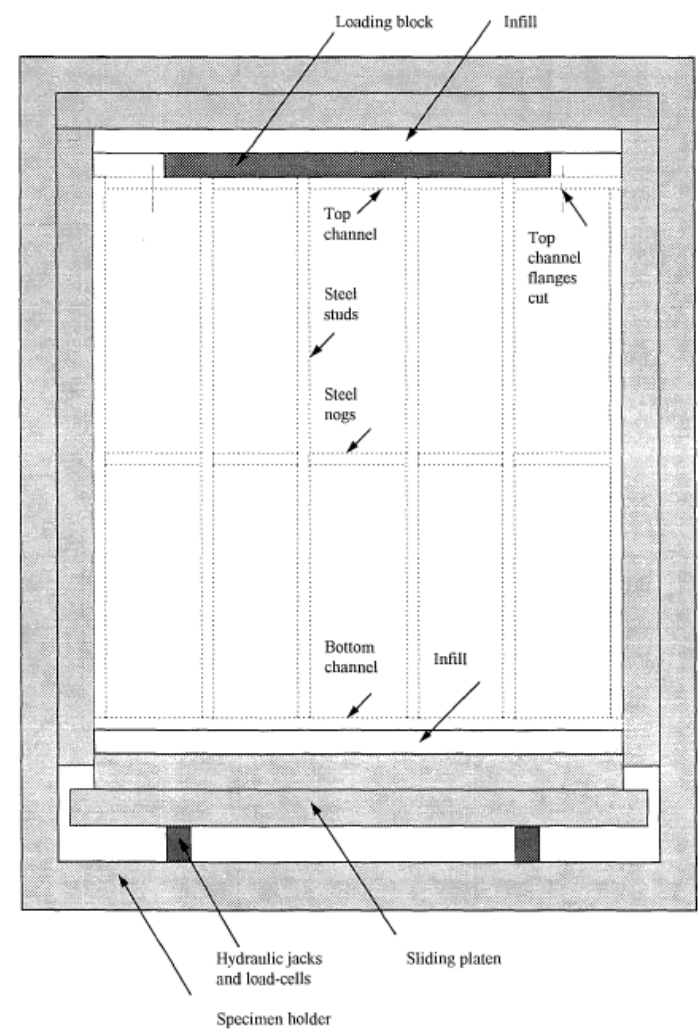

Figure 2.3 - Test arrangement for LB wall assemblies by Gerlich and Buchanan [7]

The failure mode for most experiments was flexural buckling which was initiated by local buckling of the flange on the unexposed side near mid height. The buckling failure occurred towards the furnace side due to thermal bowing which was related to the thermal expansion of the flange on the exposed side, resulting in high compressive stresses on the flange on the unexposed side. 
In recent studies by Lee et al. [21] and Ryu et al. [14], the performance of reinforced concrete walls subjected to two-sided ISO 834 standard fire was investigated. Lee et al. [21] and Ryu et al. [14] exposed the test specimens simultaneously from two sides using a horizontal furnace and two-zone heating chamber as shown in Figure 2.4.
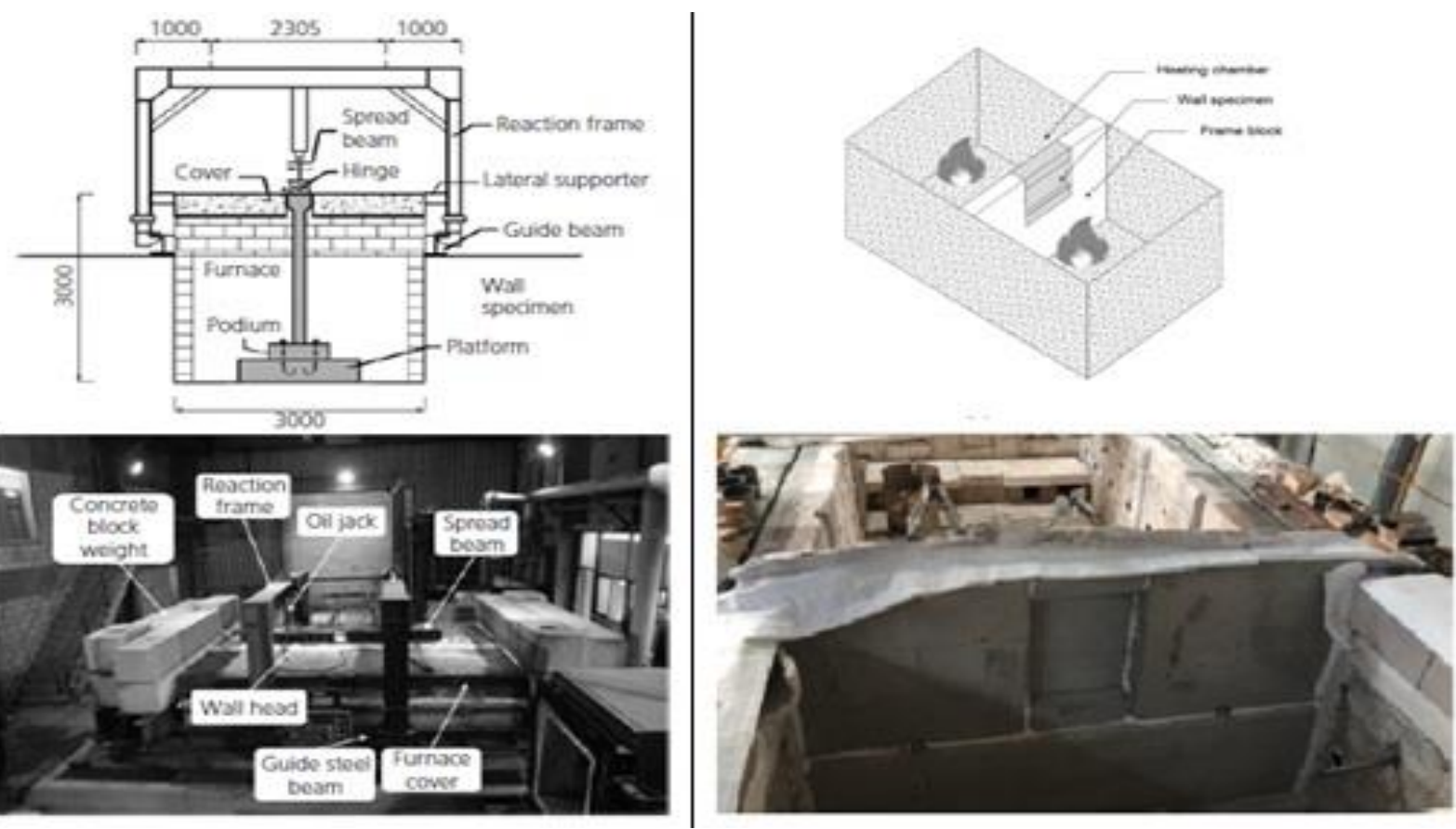

(a)

(b)

Figure 2.4 - Horizontal fire-resistance test furnace and vertical heating chamber set-up by (a) Lee et al. [21] and (b) Ryu et al. [14]

Lee et al. [21] conducted tests for a total of eight reinforced concrete walls which were 1.1 to 1.2 metres wide and 1.75 metres high. As shown in Figure 2.4(a), the specimens were first placed on a reinforced concrete platform located in the horizontal fire furnace which was generally used for evaluating the fire resistance of horizontal construction elements. The furnace was then covered with a $360 \mathrm{~mm}$ thick concrete cover to maintain the furnace condition. The test configuration by Lee et al. [21] allowed a constant fire exposure to flourish and expose the specimen from all sides simultaneously.

A total of eleven reinforced concrete walls were tested by Ryu et al. [14] to investigate the effect of compressive strength of concrete, fire exposure time and fire exposure areas. The test specimens were $600 \mathrm{~mm}$ in width, $800 \mathrm{~mm}$ in height and $200 \mathrm{~mm}$ in thickness. Three test specimens were exposed from two sides simultaneously by placing the test specimen inside a heating chamber which was divided into two zones using a frame block as shown in 
Figure 2.4(b). The heating chamber temperature in each zone was controlled and monitored separately.

\subsection{Fire exposure conditions}

Several studies by Benichou and Sultan [22], Nyman et al. [23], Chen et al. [24], Jones et al. [25] and Rahmanian [26] have investigated the effect of various fire exposure conditions on gypsum plasterboard lined walls including the ISO 834 standard fire time-temperature curve, an external fire exposure curve, a hydrocarbon curve, and a made-up design fire curve. Figure 2.5 shows these four types of fire exposure conditions which Chen et al. [24] used to investigate the behaviour of cold-formed steel-framed gypsum plasterboard lined walls subjected to other fire conditions than the ISO 834 standard fire.

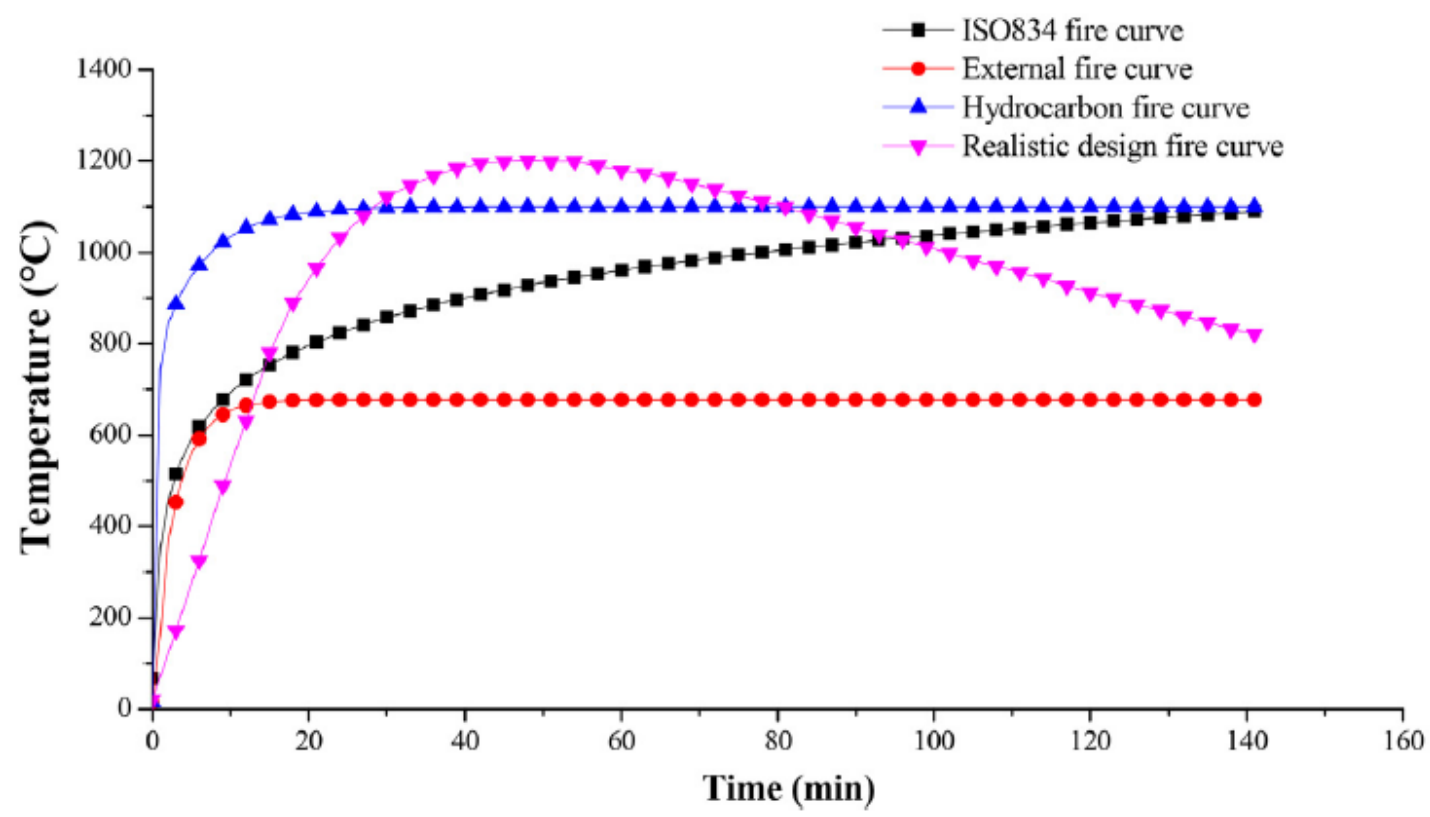

Figure 2.5 - Various fire exposure conditions investigated by Chen et al. [24]

These studies [22-26] have found that the failure of these walls occurs earlier if the fire exposure is more severe than the standard fire curve. Although the effect of various fire exposure conditions has been investigated in many studies, there is limited testing and validation of factors for approximating their time-temperature curves. 


\subsection{Typical timber-framed wall assemblies}

Light timber framing construction, an example of which is shown in Figure 2.6, is widely used in residential construction and is commonly used as partitions in commercial and industrial buildings. Most timber-framed residential houses and low-rise buildings in New Zealand are designed and constructed in accordance with NZS 3604:2011 [27].

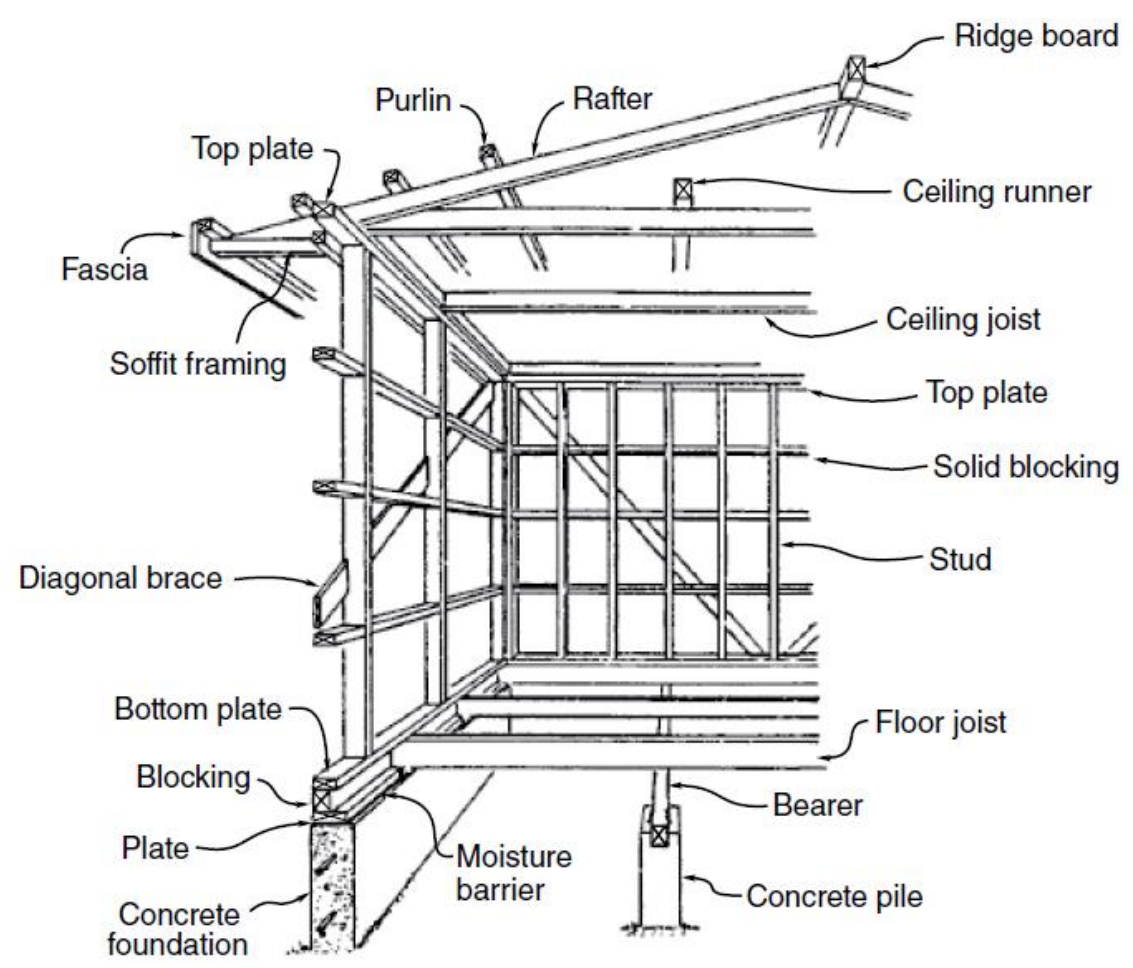

Figure 2.6 - Typical light timber-framed house [1]

Timber-framed wall assemblies consist of sawn timber studs at certain spacing fixed to top and bottom plates with horizontal solid timber blockings between the studs, which are known as nogs or dwangs. In New Zealand, timber-framed walls are commonly constructed with Radiata pine which is grown extensively in the southern hemisphere, mainly in New Zealand, Australia, South Africa and Chile [28].

NZS 3604:2011 stipulates that only verified timber grades can be used within the scope and requires all structural timber to have a structural grade (SG), which is identified by its elastic modulus in GPa. The most common structural grade used for light timber framing construction in New Zealand is SG 8 (dry), which must meet the properties for machine stress-graded MSG 8 or visually stress-graded VSG 8 stated in NZS 3603-1993 A4 [29]. 
In terms of the timber stud dimension, approximately $90 \%$ of new dwellings in New Zealand for year ending December 2010 had 90 mm x 45 mm timber studs (actual minimum dried size), and approximately $6 \%$ had $140 \mathrm{~mm}$ x $45 \mathrm{~mm}$ timber studs (actual minimum dried size) according to the BRANZ New Dwellings Survey [30].

\subsection{Thermal properties of timber-framed wall assemblies}

In order to adequately model the thermal behaviour of load-bearing timber-framed gypsum plasterboard lined walls under fire conditions, thermal properties of wall assembly components such as timber and gypsum plasterboard at elevated temperatures must be accounted for. Mechanical properties of timber discussed in Section 2.7 are temperature-dependent, and hence it is important that the thermal properties are well defined to accurately model the structural behaviour of such walls.

The thermal properties required for heat transfer calculations include density, specific heat and thermal conductivity. These properties have been investigated in several studies $[6,19,22,25$, 31-35]. Although most models have some limitations with property values not being well defined due to the lack of the experimental data for various assembly components [22], these studies are a principal source for comparing and selecting reasonable temperature-dependent thermal properties for the numerical study of this research.

\subsubsection{Density of timber}

Density of timber is a measure of the weight of timber per unit of volume. The timber density is generally reported with moisture content as the weight is highly dependent on the moisture content in the wood.

The temperature-dependent density ratio of softwood attained from Annex B of Eurocode 5: Part 1-2 is provided in Figure 2.7. The density ratio is defined as a ratio of density to oven-dry density, and hence the density ratio below $100{ }^{\circ} \mathrm{C}$ is shown as 1.12 based on an assumed moisture content of $12 \%$. The density ratio remains at 1.0 until $200{ }^{\circ} \mathrm{C}$ when it starts to reduce significantly. 


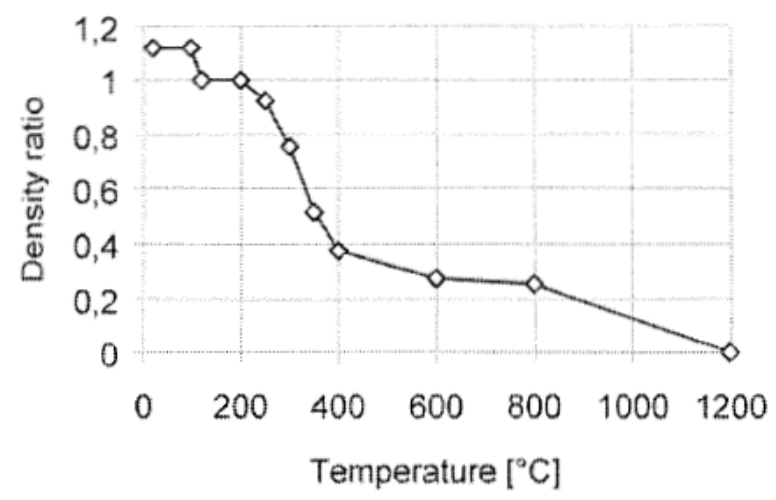

Figure 2.7 - Density loss of softwood with increasing temperatures at a moisture content of 12\% [6]

The density of timber varies significantly between species of timber. In addition, a given species can vary due to anatomical characteristics of timber such as the ratio of earlywood to latewood and heartwood to sapwood [28]. For instance, the density of Radiata pine species varies from $460 \mathrm{~kg} / \mathrm{m}^{3}$ to $560 \mathrm{~kg} / \mathrm{m}^{3}$ at moisture content of $12 \%$ [36].

\subsubsection{Specific heat of timber}

Specific heat is the amount of heat needed to raise the temperature of a unit mass of the material by one degree [1]. The temperature-dependent specific heat values for softwood attained from Eurocode 5: Part 1-2 are provided in Figure 2.8.

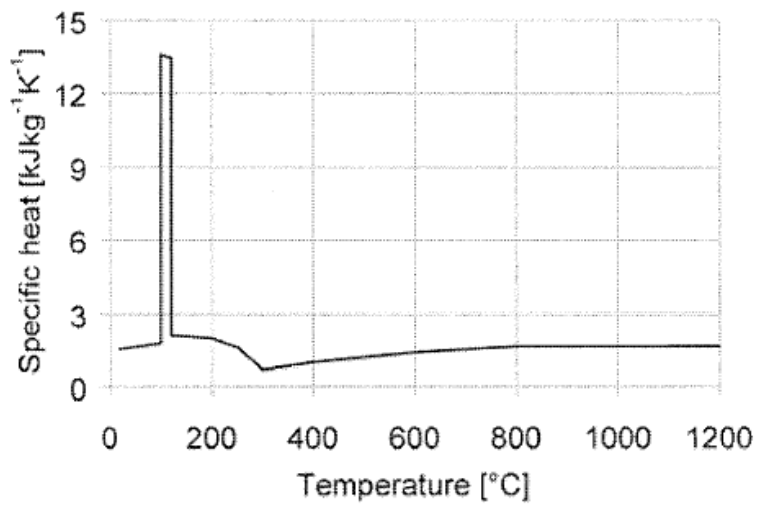

Figure 2.8 - Specific heat of softwood with increasing temperatures [6]

There is a major specific heat peak up to $13.6 \mathrm{~kJ} \cdot \mathrm{kg}^{-1} \mathrm{~K}^{-1}$ between $100{ }^{\circ} \mathrm{C}$ and $120{ }^{\circ} \mathrm{C}$. This peak is related to the dehydration of moisture in timber where more energy is required to evaporate the moisture which delays the temperature rise. 


\subsubsection{Thermal conductivity of timber}

Thermal conductivity measures the ability of material to transmit heat. It represents the amount of transmitted heat through a unit thickness of the material per unit temperature difference [1]. The temperature-dependent thermal conductivity values for softwood attained from Eurocode 5: Part 1-2 is shown in Figure 2.9.

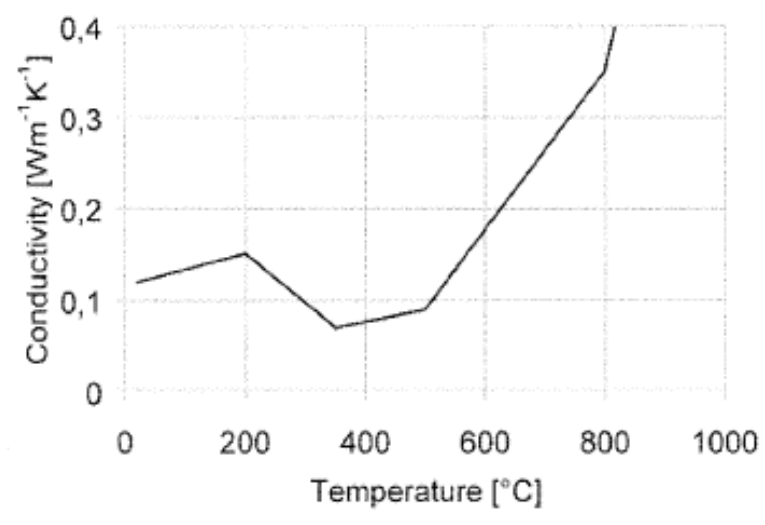

Figure 2.9 - Thermal conductivity of softwood with increasing temperatures [6]

There are two measured values at $20^{\circ} \mathrm{C}$ and $200{ }^{\circ} \mathrm{C}$ for softwood and three measured values at $350{ }^{\circ} \mathrm{C}, 500{ }^{\circ} \mathrm{C}$ and $800{ }^{\circ} \mathrm{C}$ for the timber char layer. The variation of thermal conductivity with temperature is only shown up to $0.4 \mathrm{~W} \cdot \mathrm{m}^{-1} \cdot \mathrm{K}^{-1}$ in Figure 2.9 but it linearly increases to $1.5 \mathrm{~W} \cdot \mathrm{m}^{-1} \cdot \mathrm{K}^{-1}$ at $1200{ }^{\circ} \mathrm{C}$ from $0.35 \mathrm{~W} \cdot \mathrm{m}^{-1} \cdot \mathrm{K}^{-1}$ at $800{ }^{\circ} \mathrm{C}$.

\subsubsection{Density of gypsum plasterboard}

The reduction in density of gypsum plasterboard with increasing temperature, selected by various researchers $[19,25,31,33-35]$, is provided in Figure 2.10. The density ratio of gypsum plasterboard decreases at around $100{ }^{\circ} \mathrm{C}$ due to free water and water of crystallisation being driven off. However, the mass loss of gypsum plasterboard, once it is fully dehydrated, varies a lot. This is due to differences in formulation of the gypsum plasterboard. 


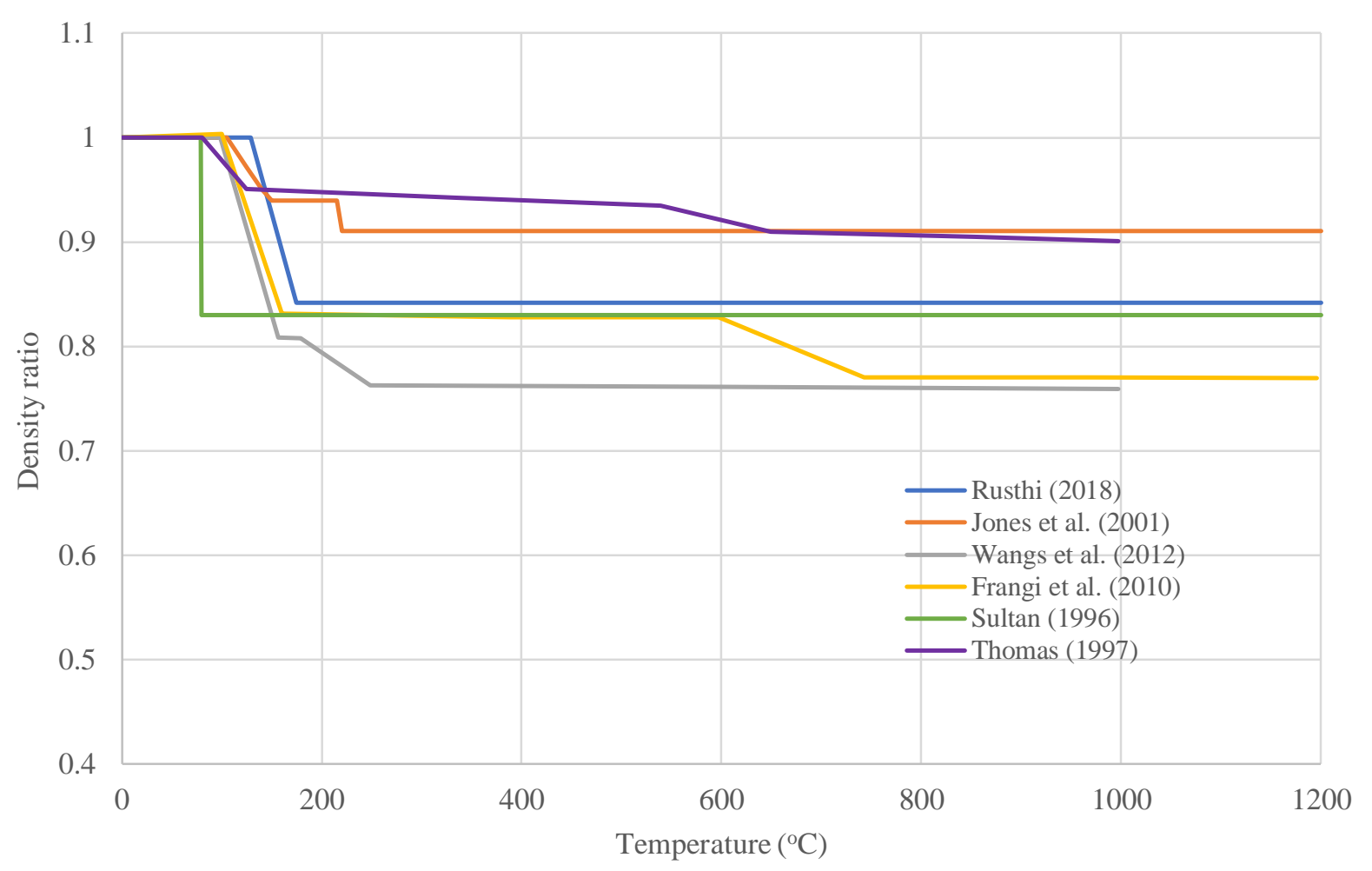

Figure 2.10 - Density loss of gypsum plasterboard with increasing temperatures proposed by various researchers [19, 25, 31, 33-35]

In this research, the relative density of gypsum plasterboard proposed by Wang et al. [35] is selected for the calibration. It has been found to be more generic and widely used in this field of research. Wang et al. [35] considered a mass loss of approximately $25 \%$ at $200{ }^{\circ} \mathrm{C}$ after the complete dehydration process.

However, it was determined in the calibration process, which is provided in Appendix A, that the computational finite element thermal modelling results showed temperatures of the plasterboard and timber stud increasing earlier compared with previous experimental data. This indicated that the selected density ratio of gypsum plasterboard at elevated temperatures was low, resulting in a heat transfer through gypsum plasterboard to occur early. Therefore, in order to achieve good correlation between the experimental and modelling results, the thermal model was calibrated using other relative density values which did not have the mass loss of those proposed by Wang et al. [35] after the complete dehydration process. It was found that the density ratio of gypsum plasterboard proposed by Thomas [19], who also used New Zealand gypsum plasterboard manufactured by Winstone Wallboards Ltd, provided good agreement between the experimental and model results even at the elevated temperatures. 


\subsubsection{Specific heat of gypsum plasterboard}

Similar to the reduction in density of gypsum plasterboard with increasing temperatures, the selected values for specific heat of gypsum plasterboard by researchers [19, 25, 31, 33-35], as shown in Figure 2.11, were inconsistent especially around the peak value and the second dehydration reaction.

There were no measured temperature-dependent specific heat values available for proprietary fire-rated gypsum plasterboard manufactured by Winstone Wallboards Ltd.

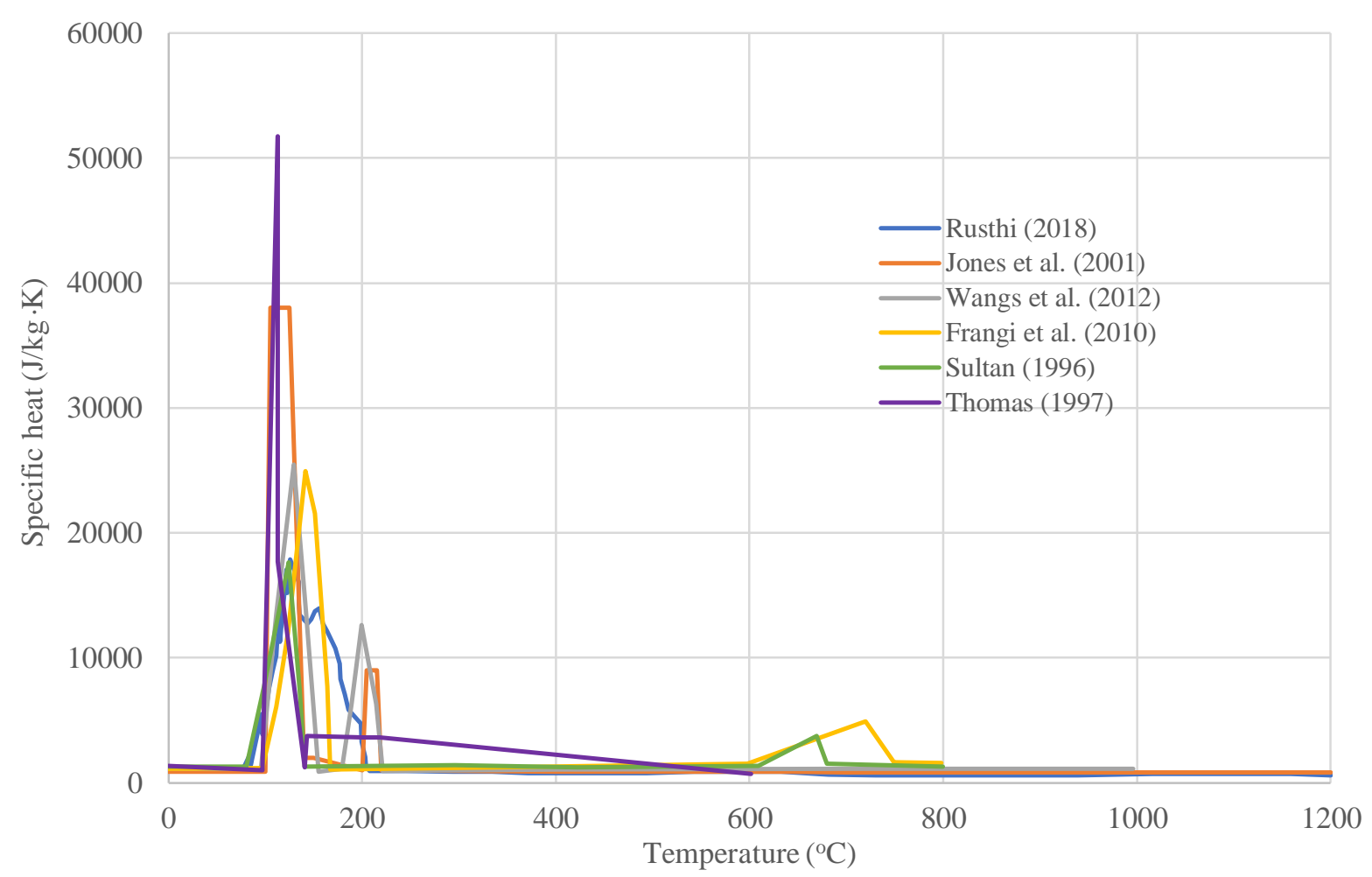

Figure 2.11 - Specific heat of gypsum plasterboard with increasing temperatures proposed by various researchers $[19,25,31,33-35]$

Jones et al. [25] report peak values of $38000 \mathrm{~J} / \mathrm{kg} \cdot \mathrm{K}$ between $105{ }^{\circ} \mathrm{C}$ and $125{ }^{\circ} \mathrm{C}$ and $9000 \mathrm{~J} / \mathrm{kg} \cdot \mathrm{K}$ between $205^{\circ} \mathrm{C}$ and $215^{\circ} \mathrm{C}$. Rusthi [33] also reports that gypsum plasterboard exhibited two peak values of $17500 \mathrm{~J} / \mathrm{kg} \cdot \mathrm{K}$ and $13500 \mathrm{~J} / \mathrm{kg} \cdot \mathrm{K}$ at $145{ }^{\circ} \mathrm{C}$ and $175{ }^{\circ} \mathrm{C}$ respectively. Frangi et al. [31] showed the first and second dehydration reaction to occur between $100{ }^{\circ} \mathrm{C}$ and $170{ }^{\circ} \mathrm{C}$, and $600{ }^{\circ} \mathrm{C}$ and $750{ }^{\circ} \mathrm{C}$ respectively. The first peak occurs due to an endothermic decomposition reaction of gypsum plasterboard and the second peak occurs due to remaining water of crystallisation being driven off [19]. However, Thomas [19] provided one peak value of $52500 \mathrm{~J} / \mathrm{kg} \cdot \mathrm{K}$ at $110{ }^{\circ} \mathrm{C}$ and the second reaction was accounted for by using high baseline values after the first peak at $110^{\circ} \mathrm{C}[25]$. 
In this research, the proposed values for specific heat by Wang et al. [35] were selected. As shown in Figure 2-11, the proposed values were based on an assumption that the first and second dehydration processes occurred between $95{ }^{\circ} \mathrm{C}$ and $155{ }^{\circ} \mathrm{C}$, and $180{ }^{\circ} \mathrm{C}$ and $220{ }^{\circ} \mathrm{C}$, respectively, and reached peak values of 25300 and $12700 \mathrm{~J} / \mathrm{kg} \cdot \mathrm{K}$ assuming a triangular distribution.

\subsubsection{Thermal conductivity of gypsum plasterboard}

Figure 2.12 shows the selected values for thermal conductivity of gypsum plasterboard by the researchers $[19,25,31,33-35]$. The thermal conductivity values decrease at approximately $100{ }^{\circ} \mathrm{C}$ during the dehydration process and then increases as a function of temperature. There is good agreement up to approximately $650{ }^{\circ} \mathrm{C}$ but the differences become significant at temperatures above $650{ }^{\circ} \mathrm{C}$.

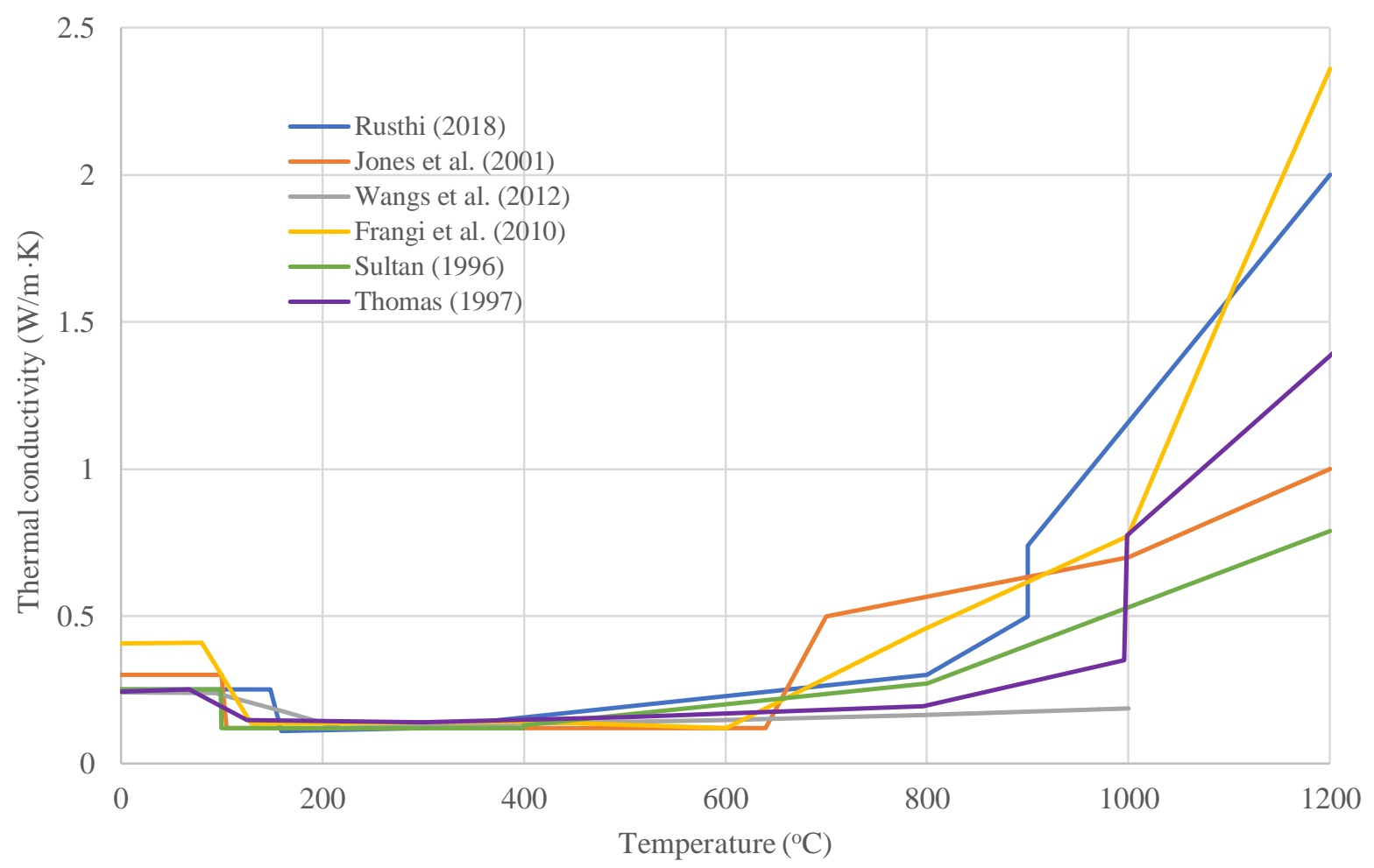

Figure 2.12 - Thermal conductivity of gypsum plasterboard with increasing temperatures proposed by various researchers $[19,25,31,33-35]$

The temperature-dependent thermal conductivity values proposed by Wang et al. [35] were selected for the calibration process. They take reduction during the dehydration process into consideration which increases as a function of temperature depending on the size of gypsum pores. The detailed assumptions that have been made can be found in Wang et al. [35]. 
However, the calibration process provided in Appendix A indicated that the comparison between the experimental data and modelling results was not good. The accuracy of the model started to reduce at more elevated temperatures where the predicted temperatures were lower than the experimental data. This was due to the thermal conductivity values proposed by Wang et al. [35] being low and did not consider the effect of ablation and cracking of gypsum plasterboard. Finite element software is not capable of modelling the behaviour of ablation and opening of cracks in gypsum plasterboard at elevated temperatures. This is generally accounted for by modifying the thermal conductivity values of gypsum plasterboard to mimic its behaviour in the finite element model.

Therefore, the thermal model was calibrated by modelling with higher thermal conductivity values which considered the effect of ablation and cracking of gypsum plasterboard. It was found that the proposed thermal conductivity values by Thomas [19], who also used New Zealand gypsum plasterboard manufactured by Winstone Wallboards Ltd, provided good agreement between the experimental and model results even at the elevated temperatures.

\subsection{Mechanical properties of timber stud}

In many studies, wood is described as an orthotropic material which has unique and independent mechanical properties depending on the directions of three principal axes of timber: longitudinal, radial, and tangential [28, 32, 37]. As shown in Figure 2.13, these axes are determined by fibre direction. The longitudinal axis is parallel to the grain. The radial and tangential axes are both perpendicular to the grain, but normal and tangent to the growth rings respectively. The mechanical properties of wood in the longitudinal direction, which a tree grows, have higher values than those in the radial and tangential directions. Due to its higher load capacity in the direction parallel to the grain, timber is generally sawn into structural timber members with the longitudinal axis aligning parallel to the grain.

Because wood properties are significantly different in each of the three principal axes, it is important to define mechanical properties of timber for each direction for structural applications. 


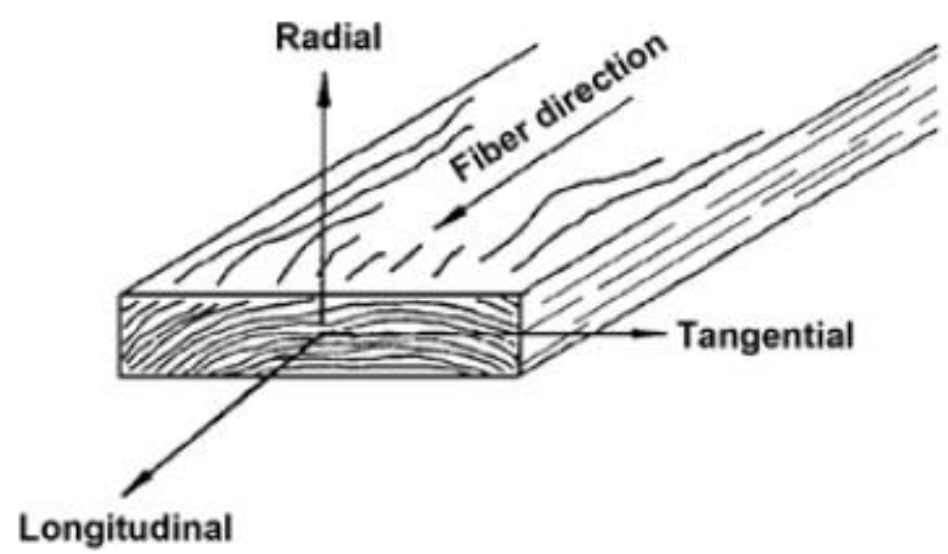

Figure 2.13 - Three principal axes of timber [28]

\subsubsection{Modulus of elasticity}

Modulus of elasticity, which is also known as elastic modulus or Young's modulus, is a measure of a material's resistance to elastic deformation. It is an important design value to describe the elastic behaviour of timber which is the ratio between the maximum stress and strain of timber before it reaches plastic deformation or failure.

The modulus of elasticity of softwood is significantly reduced under fire conditions even at low temperatures. The reduction factors for modulus of elasticity measured for softwood parallel to the grain are provided in Annex B of Eurocode 5: Part 1-2 as shown in Figure 2.14. The reduction factors are available for either tension or compression which is selected by various researchers $[19,32,38]$ depending on the zone of timber member that was largely affected by the temperature. Alternatively, the reduction factor for compression was selected to be conservative.

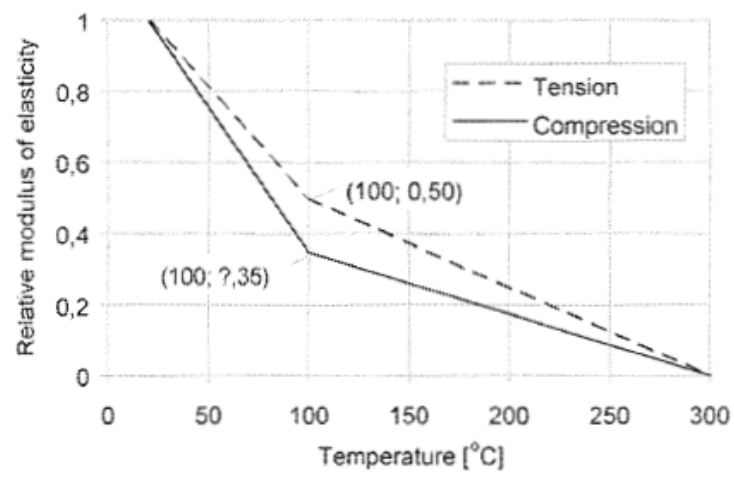

Figure 2.14 - Reduction factors for modulus of elasticity parallel to grain of softwood from Eurocode 5:

Part 1-2 [6]

Page $\mid 24$ 


\subsubsection{Elastic ratio}

The ratio between the moduli of elasticity and rigidity in each orthogonal direction and the moduli of elasticity along the longitudinal axis of timber is called an elastic ratio. It is used to describe the elastic behaviour of timber in each orthogonal direction shown in Figure 2.13. The modulus of rigidity, which is also known as shear modulus, is a measure of a material's resistance to deformation caused by shear stresses [28].

\subsubsection{Poisson's ratio}

Poisson's ratio is defined as the ratio of transverse strain to axial strain of timber. When a timber member is loaded axially, deformation occurs parallel and perpendicular to the direction of the load, and hence six Poisson's ratios are generally used to describe the elastic behaviour of timber. However, the deformation along the longitudinal axis when the timber member is loaded along the radial or tangential axes is very small and often considered negligible [28].

\subsubsection{Compressive and shear strengths}

Plastic behaviour of timber is most commonly described using strength properties which include modulus of rupture, compressive strengths parallel and perpendicular to the grain, and shear strength parallel to the grain [28]. Timber is generally sawn into structural timber members with the longitudinal axis aligned parallel to the grain because strength properties parallel to the grain are more desirable than those perpendicular to grain.

The strength properties of softwood are significantly reduced under fire conditions even at low temperatures. The reduction factors for yield compressive and shear strengths measured for softwood parallel to the grain are provided in Annex B of Eurocode 5: Part 1-2 as shown in Figure 2.15.

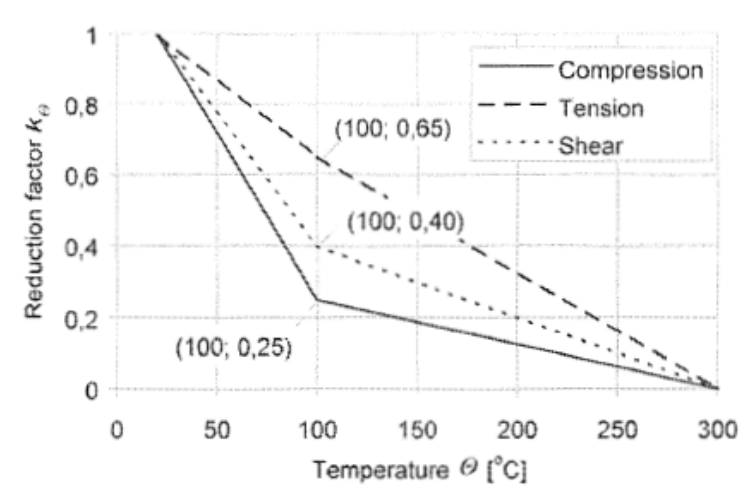

Figure 2.15 - Reduction factors for strength parallel to grain of softwood from Eurocode 5: Part 1-2 [6] 
Thomas [19] assumed the behaviour of timber-framed walls in compression only and the tension strength was not defined in the structural wall model for fire conditions. This was because a timber-framed wall generally fails in compression on the fire side and tension failure on the ambient side is unlikely to occur.

\subsection{Computational thermal modelling}

A full-scale fire-resistance test is both costly and time-consuming, and hence the behaviour of various construction elements under fire conditions is often modelled using finite element software. Thermal finite element analyses have been conducted in several studies substantially to investigate their suitability and to validate capabilities for predicting the behaviour of timberframed or steel-framed gypsum plasterboard lined walls. The thermal behaviour of such walls has been predicted using Abaqus/CAE (Feng et al. [39] and Rusthi [33]), SAFIR (Thomas [40]), and TASEF (Thomas [19]).

Rusthi [33] conducted three-dimensional thermal analyses using Abaqus/CAE for five lightgauge steel-framed gypsum plasterboard lined wall assemblies to obtain time-temperature profiles of $90 \times 40 \times 15 \times 1.15$ mm lipped channel steel studs and gypsum plasterboards. The dimensions of the modelled wall assembly were $1.8 \mathrm{~m}$ in length and $2.4 \mathrm{~m}$ in height, and the wall consisted of two studs at $600 \mathrm{~mm}$ centres as shown in Figure 2.16. The element type of an 8-node linear heat transfer brick elements (DC3D8) was selected for all wall components with a mesh size of $50 \mathrm{~mm}$ on the $\mathrm{x}-\mathrm{y}$ plane and $2 \mathrm{~mm}$ through the thickness of gypsum plasterboard. The wall components were connected using tie constraints and then subjected to the ISO 834 standard fire conditions on one side. A constant convective film coefficient of $25 \mathrm{~W} / \mathrm{m}^{2} \cdot \mathrm{K}$ was used to model the standard fire on the exposed face and $10 \mathrm{~W} / \mathrm{m}^{2} \cdot \mathrm{K}$ on the unexposed face to model losses of radiation and convection. A radiation emissivity of 0.9 was used on all the wall surfaces including in the closed cavity for wall assemblies without insulation. Comparisons between the measured and predicted time-temperature profiles of one of the test specimens are provided in Figure 2.17 which shows good agreement until 53 minutes when the measured temperatures started to rapidly increase due to a failure. 

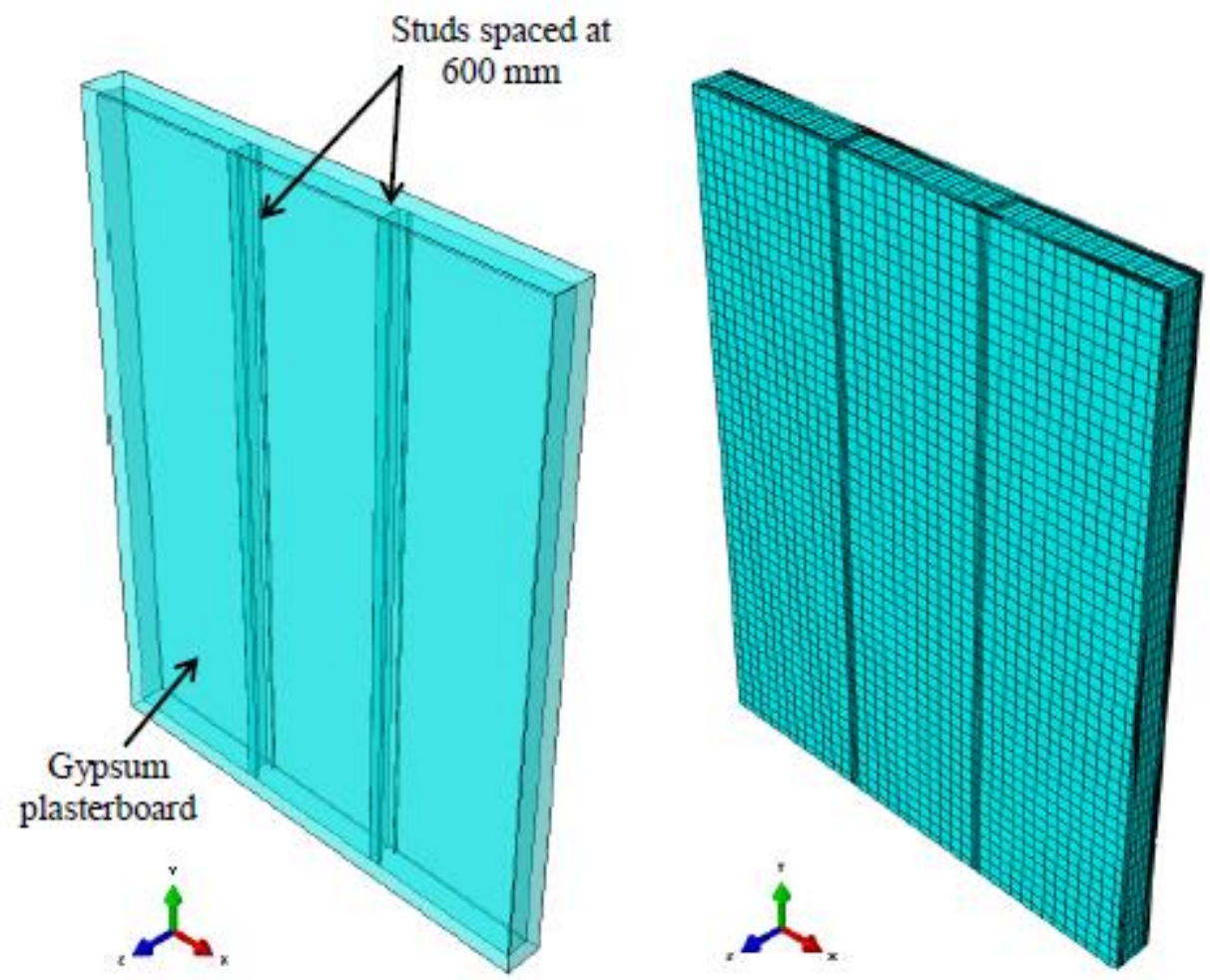

Figure 2.16 - Three-dimensional thermal model of light-gauge steel-framed gypsum plasterboard lined wall developed by Rusthi [33]

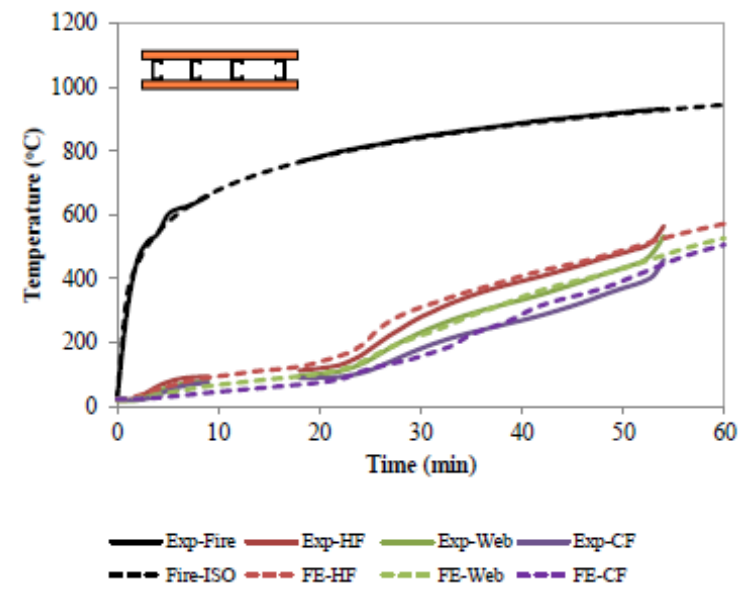

(a)

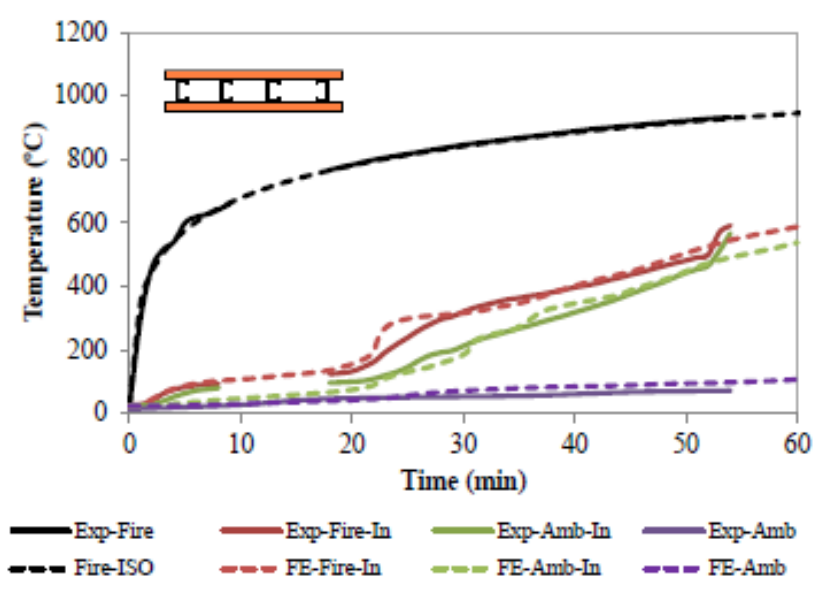

(b)

Figure 2.17 - Time-temperature profiles of (a) light-gauge steel stud and (b) gypsum plasterboards by

\section{Rusthi [33]}

Thomas [19] developed a two-dimensional thermal model using TASEF to predict heat transfer through twelve light timber-framed gypsum plasterboard lined walls consisting of three different lining thicknesses and stud dimensions. As shown in Figure 2.18(a), symmetry was used in the model by considering half of a timber stud with gypsum plasterboard each side for simplicity similar to the finite element model shown in Figure 2.18(b) which was developed 
by Mehaffey et al. [41]. A fine mesh was used across the depth of the wall assembly whilst the mesh was widely spaced across the length of the wall. The ISO 834 standard fire on one side was modelled by Thomas [19] with heat transfer coefficients summarised in Table 2.1 whilst Mehaffey et al. [41] used a constant convective film coefficient of 25 and $9 \mathrm{~W} / \mathrm{m}^{2} \cdot \mathrm{K}$ for the exposed and unexposed surfaces respectively with a radiation emissivity of 0.9 being used for all surfaces of wall cavity, timber stud and gypsum plasterboard. Figure 2.19 shows comparisons between the measured and predicted time-temperature profiles for one of the timber-framed gypsum plasterboard lined walls tested by Mehaffey et al. [41]. The overall comparison for both gypsum plasterboard and timber stud was good.

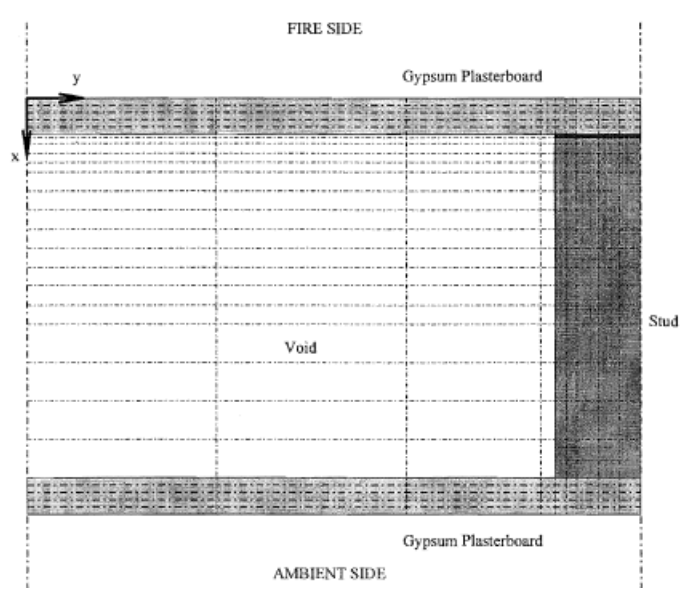

(a)

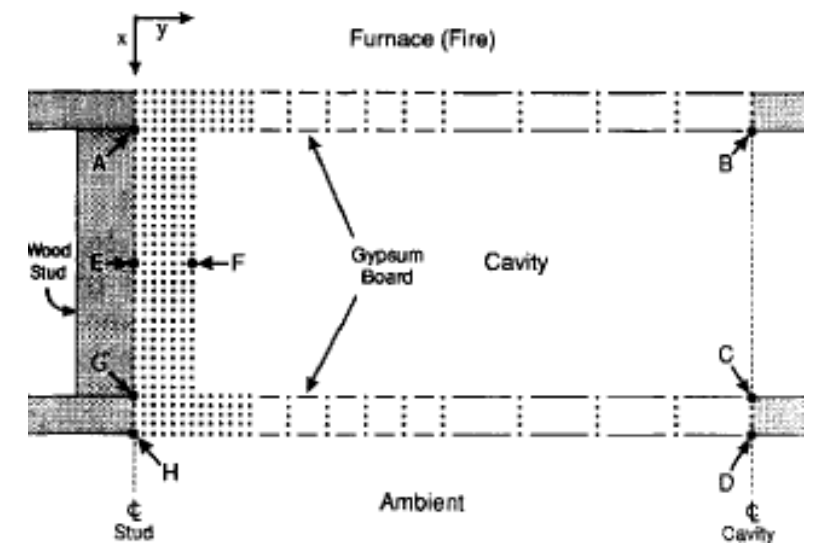

(b)

Figure 2.18 - Two-dimensional thermal models of light timber-framed gypsum plasterboard lined walls developed by (a) Thomas [19] and (b) Mehaffey et al. [41]

Table 2.1 - Heat transfer coefficients selected by Thomas [19]

\begin{tabular}{|c|c|c|c|}
\hline Position & $\varepsilon$ & $\beta$ & $\gamma$ \\
\hline Fire Side & 0.8 & 1.0 & 1.33 \\
Lining, Fire Side of Cavity & 0.6 & 1.0 & 1.33 \\
Lining, Ambient Side of Cavity & 0.6 & 1.0 & 1.33 \\
Wood Stud Side of Cavity & 0.6 & 1.0 & 1.33 \\
Ambient Side & 0.6 & 2.2 & 1.33 \\
\hline
\end{tabular}




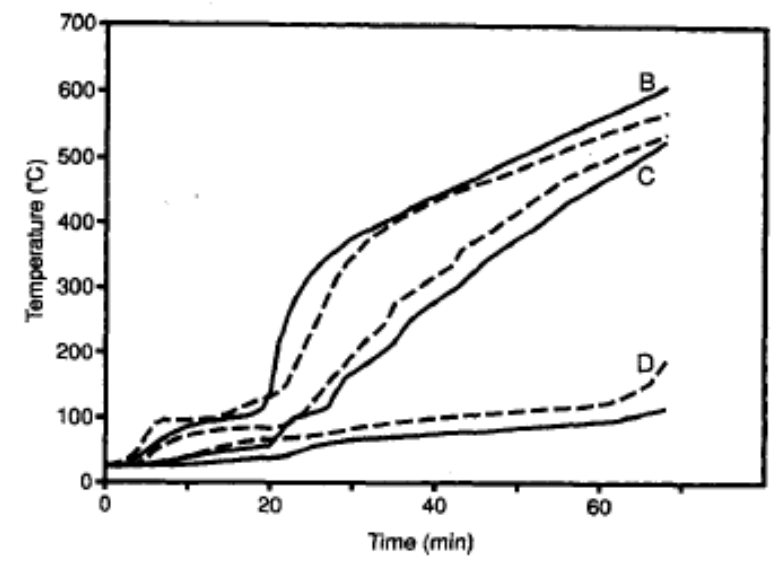

(a)

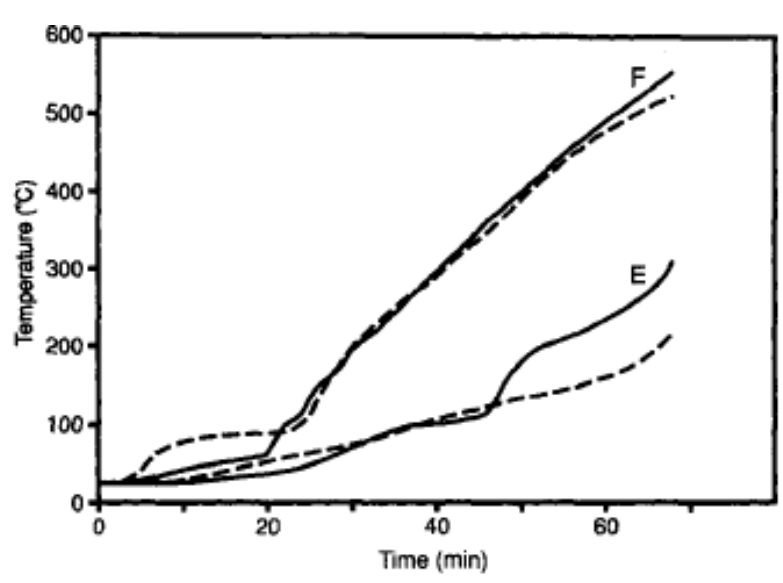

(b)

Figure 2.19 - Time-temperature profiles of (a) gypsum plasterboards and (b) timber stud by Mehaffey et al. [41] (model - solid line, experiment - dashed line)

Feng et al. [39] conducted two-dimensional thermal analyses using Abaqus/CAE for eight coldformed steel-framed gypsum plasterboard lined wall assemblies consisting of different types of steel studs and insulation, and different gypsum plasterboard arrangements. A layout of the finite element model incorporated a single cold-formed steel stud with gypsum plasterboard each side as shown in Figure 2.20. A 4-node linear heat transfer quadrilateral (DC2D4) was selected for gypsum plasterboard and the studs which is most commonly used for performing two-dimensional finite element thermal analyses due to the temperature degree of freedom which can be activated at each node [32]. A sensitivity analysis for selecting the most appropriate mesh size and element type indicated that finer meshes than shown in Figure 2.20 and higher order elements than DC2D4 did not improve the results [39]. The ISO 834 standard fire time-temperature curve was used to expose the wall on one side. A constant convective film coefficient of $25 \mathrm{~W} / \mathrm{m}^{2} \cdot \mathrm{K}$ was used on the exposed face and $10 \mathrm{~W} / \mathrm{m}^{2} \cdot \mathrm{K}$ on the unexposed face. Radiation emissivity values of 0.0 and 0.8 were assigned to the exposed and unexposed surfaces respectively, and the attenuation of cavity radiation was considered by assuming isothermal and iso-emissive cavity facets. The predicted time-temperature profiles aligned reasonably well with the test results as shown in Figure 2.21. 


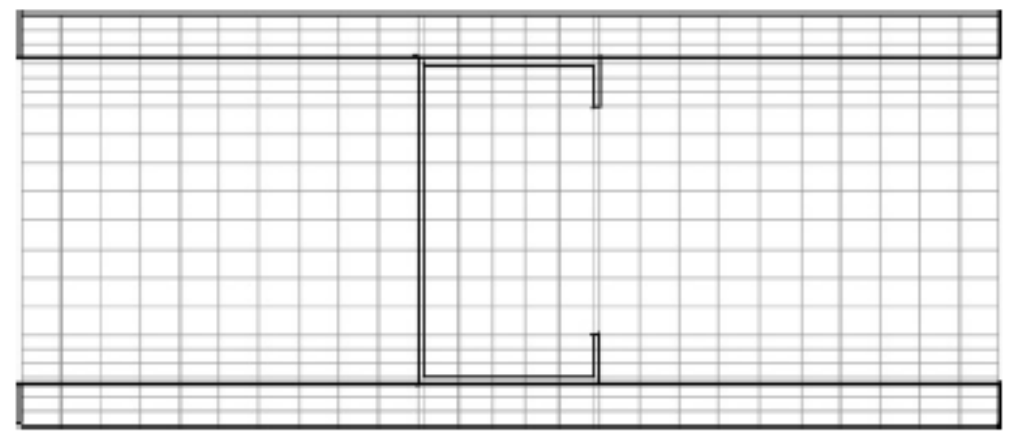

Figure 2.20 - Two-dimensional thermal model mesh of light-gauge steel-framed gypsum plasterboard lined walls developed by Feng et al. [39]

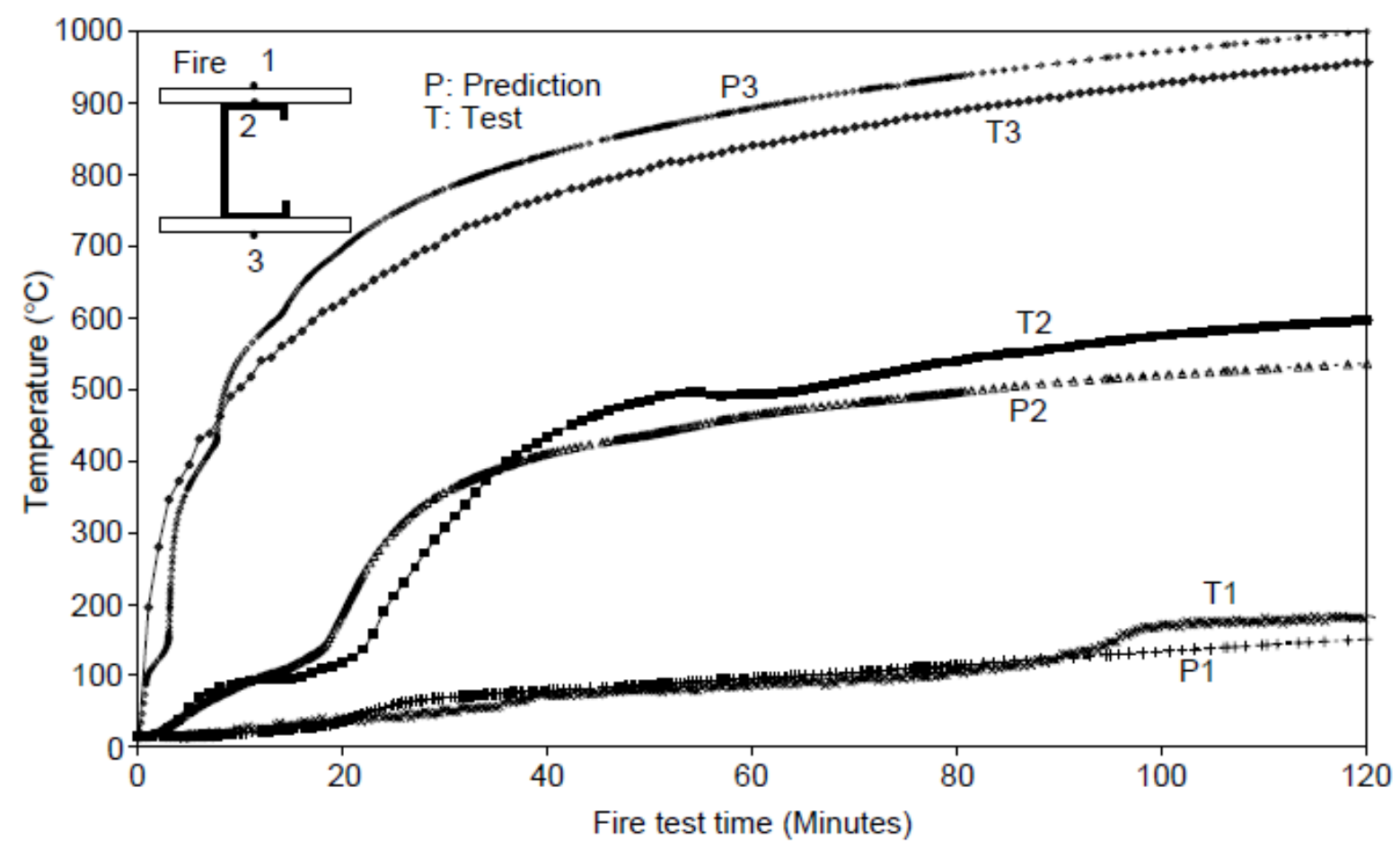

Figure 2.21 - Time-temperature profiles of gypsum plasterboards by Feng et al. [39]

\subsection{Computational structural modelling}

Computational finite element structural analyses have been conducted in several studies to investigate their suitability and to validate capabilities for predicting the structural behaviour of timber-framed or steel-framed gypsum plasterboard lined walls. Rusthi [33], Thomas [19] and Gunalan [20] were able to successfully predict structural response using Abaqus/CAE, and modelling results agreed relatively well with the experimental results. 
Rusthi [33] developed sequentially coupled and fully coupled temperature-displacement finite element models using Abaqus/CAE as shown in Figures 2.22 and 2.23 to simulate the structural behaviour of light-gauge steel-framed gypsum plasterboard lined walls under fire conditions. A comparison was carried out between these two types of analyses as shown in Table 2.2. The fully coupled analysis required longer time even with larger mesh sizes and less elements and very high computational resources. The sequentially coupled analysis was more efficient given time and modelling accuracy. It is expected that the analysis time will be further extended for the timber-framed wall assemblies which have more elements than steel assemblies. For the steel stud assembly, a 4-node general-purpose shell element type (S4RT) was selected with a $4 \mathrm{~mm}$ mesh size in the length and cross-section of the stud. Mechanical boundary conditions are shown in Figure 2.22. Time-temperature profiles of the steel stud were assigned to the nodes as thermal boundary conditions as shown in Figure 2.24. A general eigenvalue buckling analysis was carried out to predict the critical buckling load of the steel stud under ambient conditions from the first collapse mode shape. The results were then added to the sequentially coupled analysis with an appropriate geometric imperfection factor value to account for lack of verticality, flatness and fit of steel studs that are often caused by possible variances in manufacturing, transporting and handling processes. Overall, the predicted failure times from the sequentially coupled analysis were similar to those measured from the experiment but some discrepancies were observed in the predicted and measured deflections.

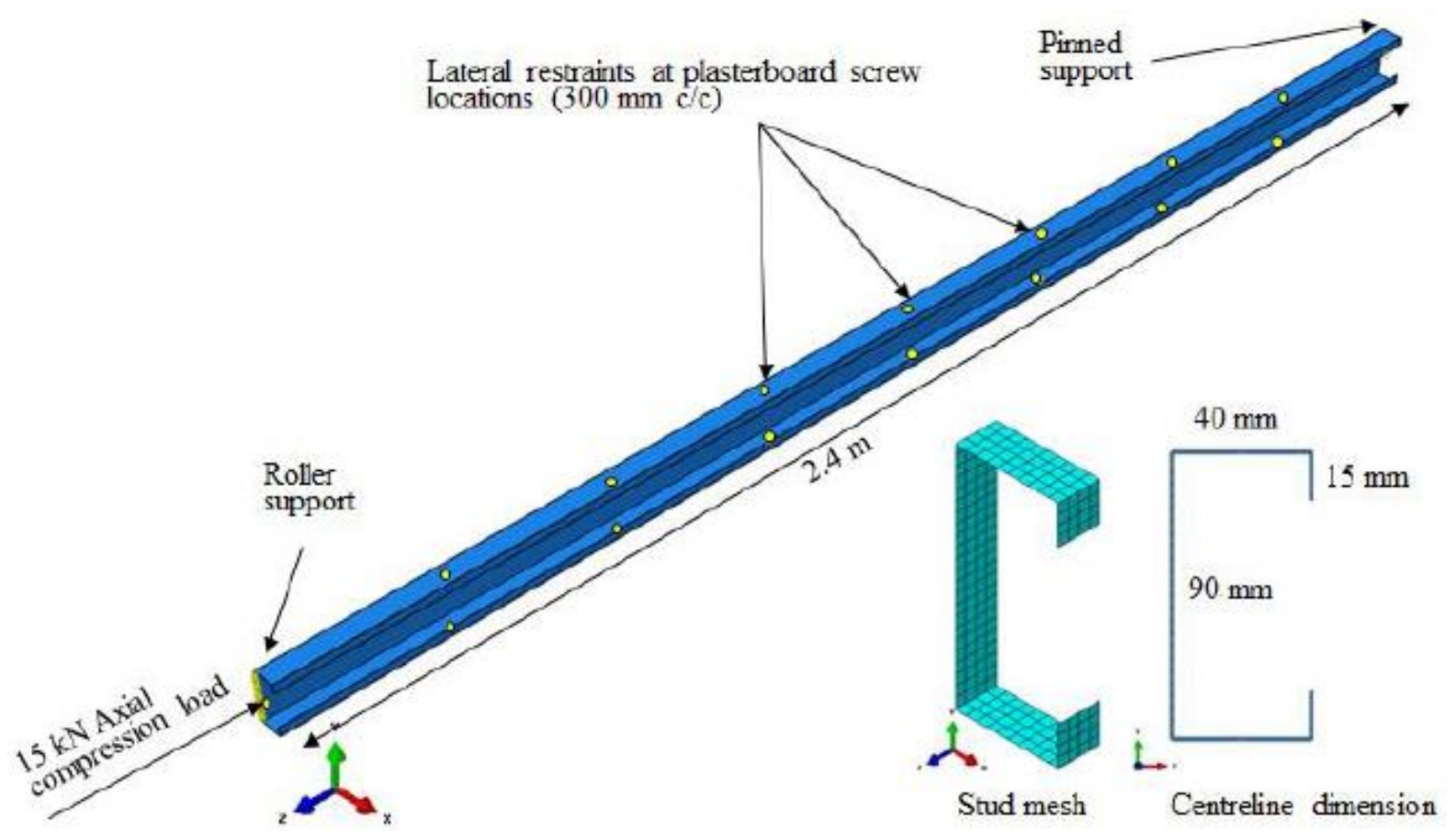

Figure 2.22 - Sequentially coupled temperature-displacement model developed by Rusthi [33] 


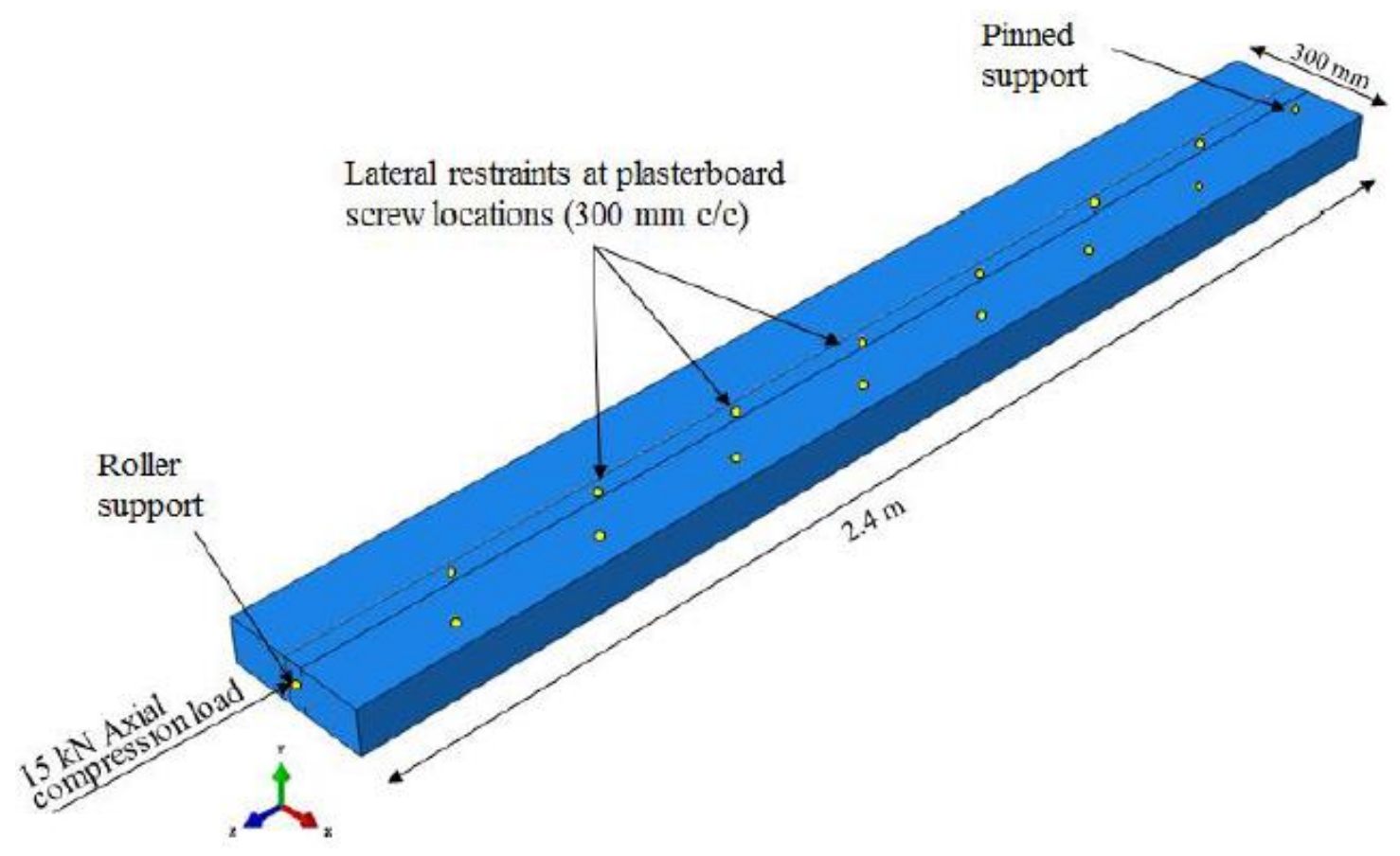

Figure 2.23 - Fully coupled temperature-displacement model developed by Rusthi [33]

Table 2.2 - Comparison between the sequentially coupled and fully coupled analyses by Rusthi [33]

\begin{tabular}{|c|c|c|}
\hline & Sequentially coupled analysis & Fully coupled analysis \\
\hline Model component & Stud & Stud and plasterboard \\
\hline Temperature input & $\begin{array}{l}\text { Stud time-temperature profile } \\
\text { measured during the fire test assigned } \\
\text { to each node separately }\end{array}$ & $\begin{array}{l}\text { Fire curve time-temperature } \\
\text { profile assigned to the } \\
\text { plasterboard surface }\end{array}$ \\
\hline Boundary conditions & Mechanical & Thermal-Mechanical \\
\hline Properties & Mechanical properties & $\begin{array}{l}\text { Mechanical and material } \\
\text { (thermal) properties }\end{array}$ \\
\hline Mesh size & $4 \times 4 \mathrm{~mm}$ & $10 \times 10 \mathrm{~mm}$ \\
\hline Total elements & 30,600 & 24,300 \\
\hline Analysis time & 3 hours & 401 hours \\
\hline Failure time prediction & 53 minutes (similar to fire test) & 58 minutes \\
\hline Failure mode & $\begin{array}{l}\text { Local buckling failure similar to test } \\
\text { observations }\end{array}$ & $\begin{array}{l}\text { Local buckling failure similar to } \\
\text { test observations }\end{array}$ \\
\hline
\end{tabular}
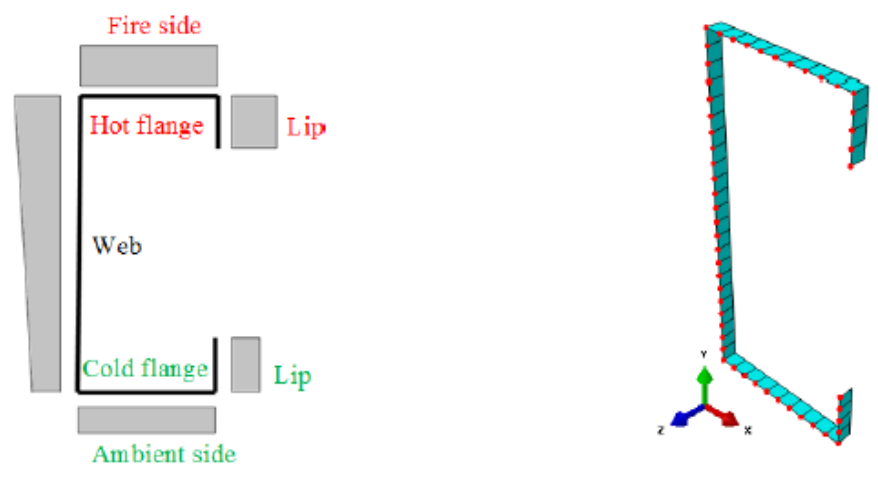

Figure 2.24 - Steel stud temperature variation assigned to nodes by Rusthi [33] 
Thomas [19] developed a three-dimensional structural model using Abaqus (Version 5.4). As shown in Figure 2.25, symmetry was used including half a single timber stud and half the height of the timber-framed gypsum plasterboard lined walls. The length of the top plate was also half the stud spacing, and the gypsum plasterboard was not considered to contribute to the strength and stiffness of the timber-framed wall. The axial load was applied to the top plate directly above the stud, and the time-temperature profiles of the timber stud from a two-dimensional TASEF thermal model were applied by assuming a constant cross-section temperature along the length of the timber stud. An element type assigned for the wall components was not provided, but an 8-node linear brick element (C3D8) or an 8-node thermally coupled brick element (C3D8T) was selected for timber substrate in several studies [32, 42-44], most commonly used for performing three-dimensional finite element stress-strain analyses. This element is stress governed and the analysis terminates when deformations become excessive and lateral deflections rapidly increase signifying buckling of the timber stud [19]. The developed structural model was calibrated by comparison with nine fire-resistance wall tests supplied by the Building Research Association of New Zealand (BRANZ). The details of the wall tests and comparison between the predicted and measured structural failure times are summarised in Table 2.3 which shows good agreement and an average difference of only $2.2 \%$.

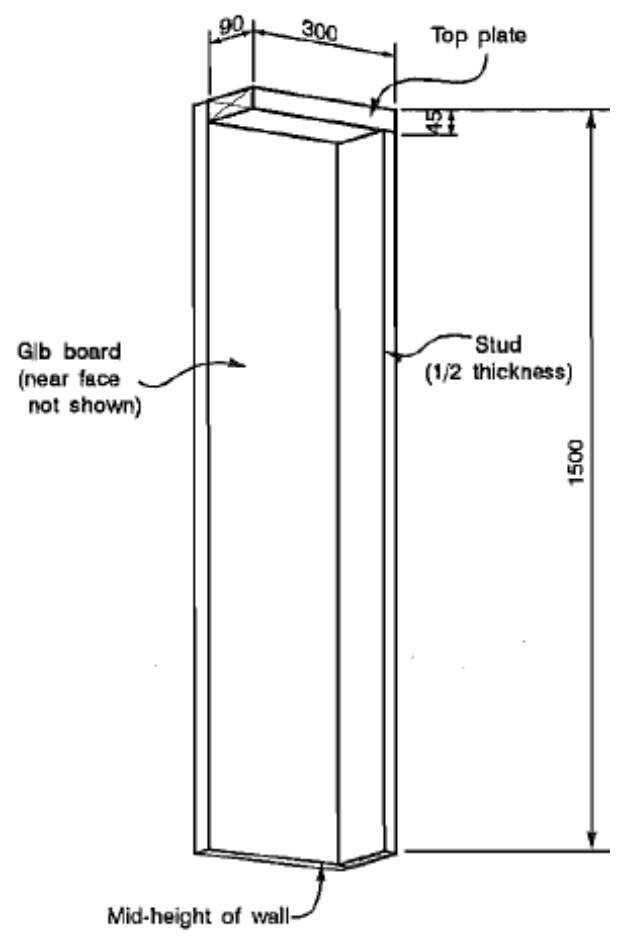

Figure 2.25 - Three-dimensional structural model developed by Thomas [19] 
Table 2.3 - Test wall details and comparison between the predicted and measured structural failure times by Thomas [19]

\begin{tabular}{|c|c|c|c|c|c|c|c|}
\hline \multirow[t]{2}{*}{ Test Code } & \multirow{2}{*}{$\begin{array}{c}\text { Lining } \\
\text { Thickness } \\
(\mathrm{mm})\end{array}$} & \multirow{2}{*}{$\begin{array}{c}\text { Stud Depth } \\
(\mathrm{mm})\end{array}$} & \multirow{2}{*}{$\begin{array}{c}\text { Stud Width } \\
(\mathrm{mm})\end{array}$} & \multirow{2}{*}{$\begin{array}{c}\text { Wall Height } \\
\text { (m) }\end{array}$} & \multirow{2}{*}{$\begin{array}{c}\text { Stud Load } \\
(\mathrm{kN})\end{array}$} & \multicolumn{2}{|c|}{ Time to Failure } \\
\hline & & & & & & $\begin{array}{c}\text { Test } \\
\text { (minutes) }\end{array}$ & $\begin{array}{c}\text { Model } \\
\text { (minutes) }\end{array}$ \\
\hline FR1582A & 9.5 & 69 & 45 & 3 & 2.8 & 42 & 44.8 \\
\hline FR1582B & 9.5 & 90 & 45 & 3 & 8 & 42 & 41.2 \\
\hline FP1583A & 9.5 & 69 & 45 & 2.2 & 5 & 39 & 42.0 \\
\hline FP1583B & 9.5 & 90 & 45 & 2.2 & 13 & 44 & 41.4 \\
\hline FR1611 & 12.5 & 69 & 45 & 3 & 2 & 69 & 66.6 \\
\hline FR1515A & 14.5 & 90 & 45 & 3 & 16 & 46 & 38.5 \\
\hline FR1515B & 14.5 & 90 & 45 & 3 & 8 & 70 & 69.6 \\
\hline FR1515C & 14.5 & 90 & 45 & 3 & 10 & 60 & 60.6 \\
\hline FR1777 & 16 & 90 & 35 & 3 & 3 & 84 & 77.4 \\
\hline
\end{tabular}

Gunalan [20] developed finite element structural analyses to simulate the structural behaviour of light-gauge steel-framed gypsum plasterboard lined walls under ambient and fire conditions. A single steel stud was modelled for simplicity with mechanical boundary conditions and loading as shown in Figure 2.26. Time-temperature profiles of steel flanges were obtained from an experiment and a linear distribution was used for assigning temperature to the web as shown in Figure 2.27.

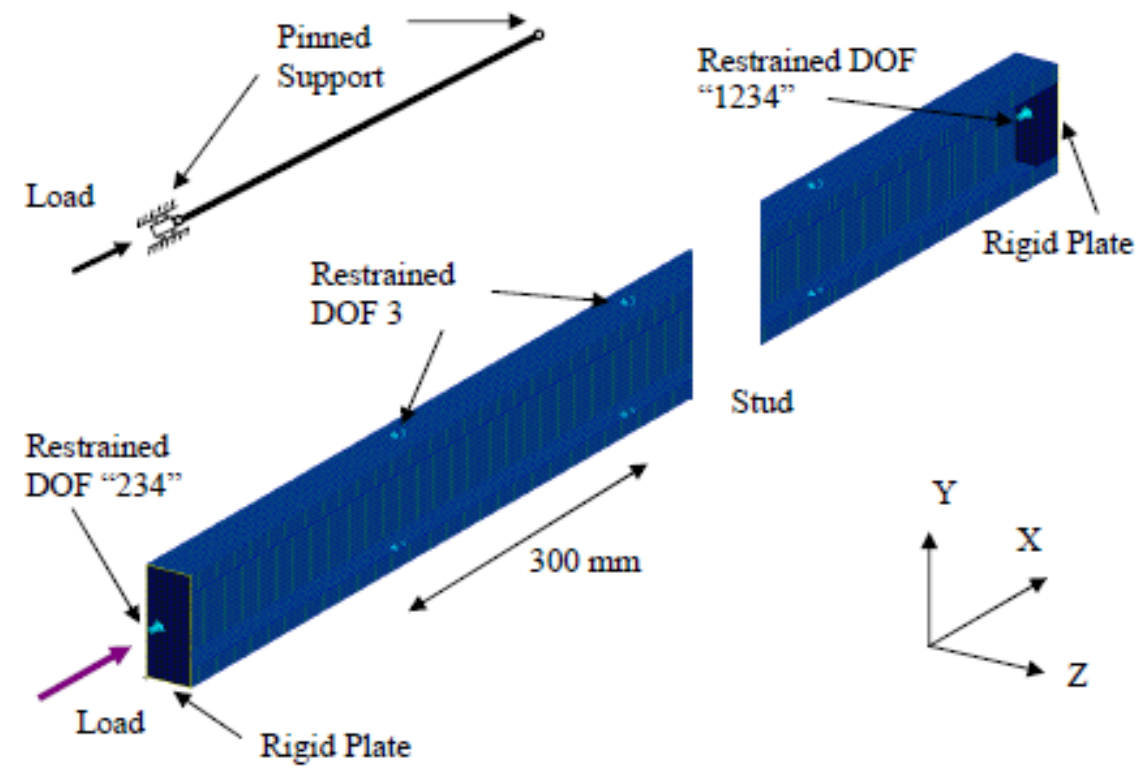

Figure 2.26 - Three-dimensional finite element structural model with mechanical boundary conditions and loading by Gunalan [20] 


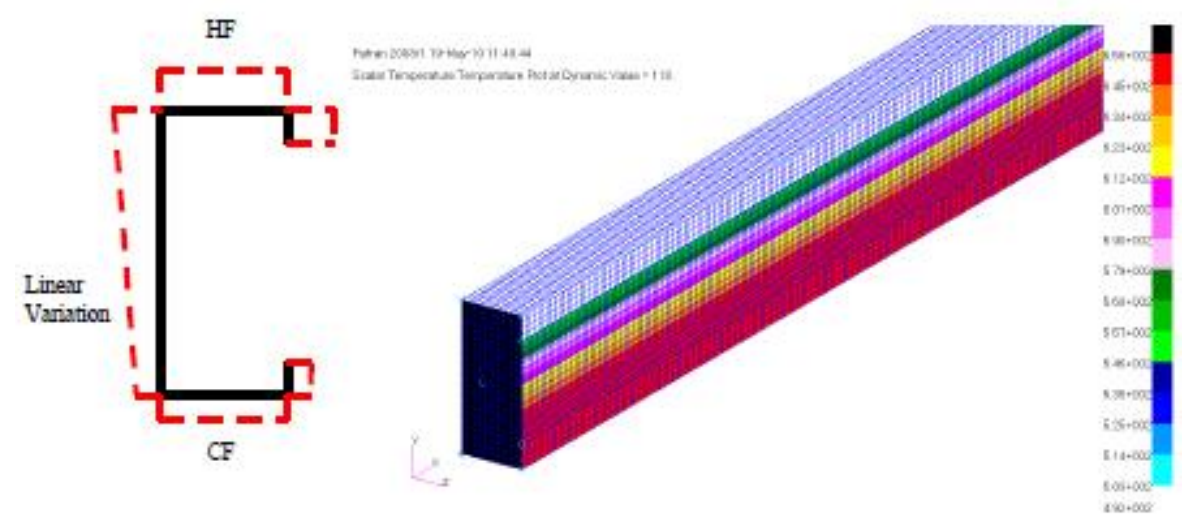

Figure 2.27 - Temperature distribution to the flanges and web of the steel stud

A 4-node general-purpose shell element type (S4R) was selected for the steel stud with a $4 \mathrm{~mm}$ mesh size in the length and cross-section of the stud. Since a structural adequacy failure is dependent on various load ratios, a general eigenvalue buckling analysis was conducted first to estimate the critical buckling load of the stud under ambient conditions. An extensive series of sensitivity analyses were performed by Gunalan [20] to assess the element type, mesh size, influence of eccentric loading, initial geometric imperfections, and plasterboard types.

\subsection{Literature review findings}

A significant number of experimental and numerical studies are related to load-bearing barriers subjected to one-sided fire exposure. Although recent research has focused on understanding the behaviour of reinforced concrete walls subjected to two-sided fire exposure, the behaviour of load-bearing gypsum plasterboard lined walls subjected to two-sided fire exposure remains inconclusive. There exists the need to carry out fire-resistance tests for such walls so that a design approach can be developed enabling the prediction of the structural adequacy of loadbearing plasterboard lined walls.

It is also found that most previously developed finite element models have limitations relating to fire exposure conditions, and thermo-mechanical properties of wall assembly components at elevated temperatures. This is due to inconsistency in extracting relevant material property values, and the discrepancies that exist in values obtained from various studies. Notably the thermal and mechanical properties of gypsum plasterboard showed significant variation in density ratio, specific heat and thermal conductivity values.

Computational finite element modelling was applied in several studies to predict both the thermal and structural behaviour of wall assemblies, and generally showed good correlation 
between experimental and predicted results. However, to improve their accuracy, considerably more numerical studies are required to be undertaken. Input of proprietary material properties, such as for gypsum plasterboard, may also be required to aid the development of reliable fire resistance finite element models.

The ISO 834 standard fire time-temperature curve is adopted in this research as the proposed two-sided fire exposure of load-bearing timber-framed gypsum plasterboard lined walls. This also permits comparison with past fire-resistance tests subjected to one-sided ISO 834 standard fire exposure. Different exposures recorded in the experimental phase of this study will be considered in finite element modelling. This study does not aim to model compartment fire time-temperature conditions other than the ISO 834 standard fire [22] and the experimentally recorded time-temperature conditions. 


\section{Methodology}

\subsection{Introduction}

This chapter explains the method adopted to meet the research aims and objectives. In this research, computational finite element modelling and physical experiments were conducted to formulate a design methodology that predicts the structural adequacy of load-bearing timberframed gypsum plasterboard lined walls subjected to fire exposures from both sides simultaneously.

\subsection{Finite element modelling}

Abaqus/CAE is a generic finite element software package capable of performing thermal and structural analyses under ambient and fire conditions [1]. In this research, Abaqus/CAE was used to analyse the behaviour of load-bearing timber-framed gypsum plasterboard lined walls subjected to one-sided and two-sided fire exposures. The suitability and capabilities of the developed finite element models were then validated by comparing the model predictions with experimental results.

The finite element modelling was carried out as follows:

- Thermal finite element analysis was conducted to obtain time-temperature profiles when subjecting specimens to one and two-sided fire exposure in accordance with the ISO 834 standard fire time-temperature curve

- The thermal model was validated using the measured time-temperature data from past fire-resistance tests and experiments in this research

- Eigenvalue buckling analysis was conducted to estimate the critical buckling load of timber studs

- The eigenvalue buckling analysis model was validated using Euler's critical buckling load method for timber studs in compression

- A sequentially coupled temperature-displacement non-linear static analysis was conducted by applying the time-temperature profiles from the thermal model to studs in compression 
- The structural adequacy failure time of timber studs was predicted and compared with the measured structural adequacy failure time from results of past fire-resistance tests and the experiments in this research

\subsection{Experimental program}

The objective of the experimental program was to obtain the necessary data to validate the computational thermal and structural finite element models developed for two-sided fire exposure, and to formulate a design methodology that predicts the structural adequacy failure time of load-bearing timber-framed gypsum plasterboard lined walls subjected to two-sided fire exposure.

The experimental program was conducted at the fire testing laboratory of the Building Research Association of New Zealand (BRANZ). The three full-scale fire-resistance tests performed in this research were modified in configuration and procedure to achieve exposure of the loadbearing wall specimens from two sides simultaneously. The modified fire-resistance tests were performed on a typical gypsum plasterboard wall assembly that is widely used in residential, commercial and industrial buildings where potential exposure to a fire from both sides is commonly encountered. This type of wall assembly could be potentially exposed to a fire from both sides. Three load-bearing wall specimens were tested and these consisted of two thicknesses of gypsum plasterboard, two different levels of applied axial load per stud, and two widths of wall opening at each end of the load-bearing wall specimen.

\subsection{Development of design methodology}

The computational finite element modelling and experimental results were analysed and compared with a view to identify relationships between the performance of load-bearing timber-framed gypsum plasterboard lined walls subjected to two-sided and one-sided fire exposure.

A simplified design methodology, which is further discussed in Chapter 7, is developed to conservatively predict the structural adequacy failure time of load-bearing timber-framed gypsum plasterboard lined walls subjected to two-sided fire exposure using the one-sided Fire Resistance Rating (FRR) from published manufacturer's literature. 
An advanced design methodology is also developed and requires input of the actual structural adequacy performance and applied stud load from results of standard one-sided ISO 834 fire exposure. In the advanced design methodology, other parameters that also influence the structural adequacy performance, such as thickness of gypsum plasterboard and timber stud dimensions, are also considered. 


\section{Computational Finite Element Modelling}

\subsection{Introduction}

This chapter explains thermal and structural finite element analysis methods for load-bearing timber-framed gypsum plasterboard lined walls subjected to one and two-sided fire exposures. This is followed by validation of the developed finite element models using previous experimental results of one-sided fire exposure.

\subsection{Thermal modelling analysis method}

Abaqus/CAE finite element software was used to carry out two-dimensional finite element analysis of the existing timber-framed wall tests subjected to one-sided fire exposure for validation purposes and to predict the temperature profile for the experiments in this research. It was assumed that there is no temperature gradient along the length of the specimen, and the temperature through the cross-section of the timber stud is constant when modelled against the standard fire-resistance test [19]. Buchanan and Abu [1] also suggest that a two-dimensional analysis of a given cross-section of the structural member is adequate for most fire engineering applications as structural elements are mostly prismatic.

The modelled region of the timber-framed wall is shown in Figure 4.1.

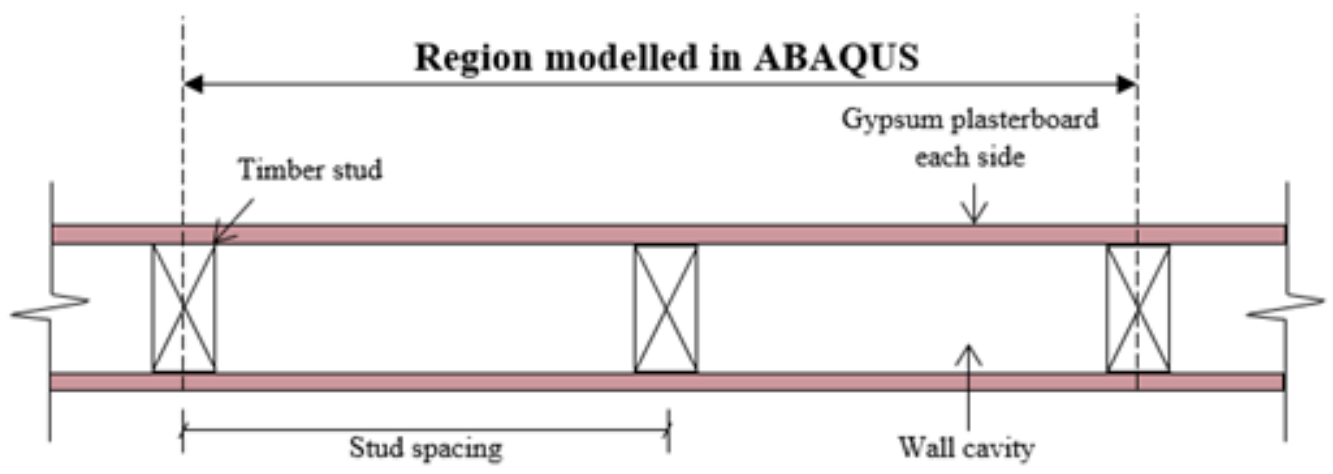

Figure 4.1 - Timber-framed wall section modelled in finite element model

Figure 4.2 is a layout of the geometry for the timber-framed wall assembly model which represents a timber stud, two half-width timber end studs with a closed cavity between, lined with fire-rated gypsum plasterboard each side. 


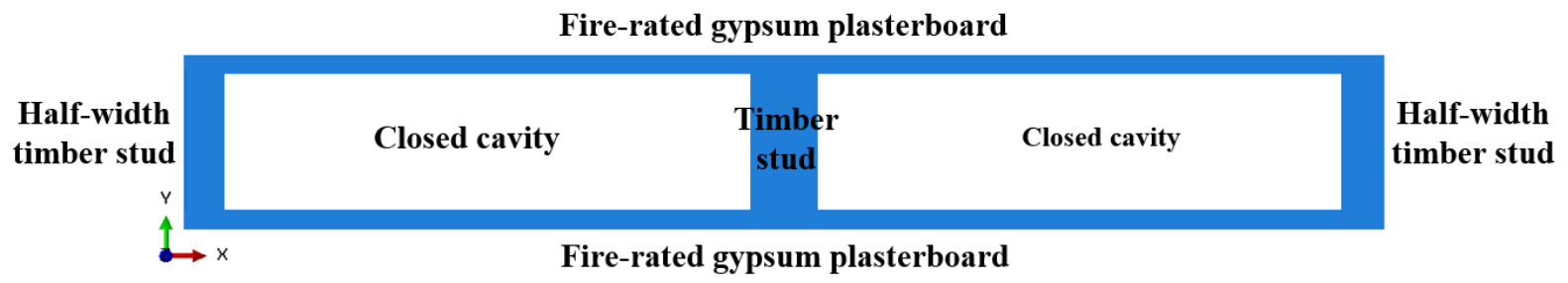

Figure 4.2 - Layout of the geometry for the timber-framed wall assembly model

\subsubsection{Thermal properties of gypsum plasterboard}

As discussed in Chapter 2, the relative density and thermal conductivity of fire-rated gypsum plasterboard proposed by Thomas [19] were selected. The initial density of fire-rated gypsum plasterboard used in this research was $808 \mathrm{~kg} / \mathrm{m}^{3}$ and $925 \mathrm{~kg} / \mathrm{m}^{3}$ for $13 \mathrm{~mm}$ and $16 \mathrm{~mm}$ firerated gypsum plasterboard respectively as published by Winstone Wallboards Ltd and BRANZ [45]. The proposed specific heat values by Wang et al. [35] were selected.

\subsubsection{Thermal properties of timber}

The temperature-dependent density ratio, specific heat and thermal conductivity of light timber were obtained from Eurocode 5: Part 1-2 for use in this research [6]. At a moisture content of $12 \%$, the density of Radiata pine varies from $460 \mathrm{~kg} / \mathrm{m}^{3}$ to $560 \mathrm{~kg} / \mathrm{m}^{3}$ depending on the altitude of growth sites [36]. In this research, the average density of $510 \mathrm{~kg} / \mathrm{m}^{3}$ was used in the finite element thermal and structural models as the growing sites were unknown.

\subsubsection{Thermal model for one-sided fire exposure}

\subsubsection{Element type}

The element type assigned was a 4-node linear heat transfer quadrilateral (DC2D4) for both gypsum plasterboard and the timber studs shown in Figure 4.2. This element is often used for performing two-dimensional finite element thermal analyses due to the temperature degrees of freedom at each node [32].

\subsubsection{Fire input}

The ISO 834 standard fire time-temperature curve was defined using appropriate interactions for radiation and convection heat transfer to the surface of the assembly. This is further discussed in Section 4.2.3.3. The ambient temperature in the thermal analyses was assumed to be $20{ }^{\circ} \mathrm{C}$. 


\subsubsection{Interactions and boundary conditions}

In order to model gypsum plasterboard timber-framed walls subjected to the ISO 834 standard fire exposure, three heat transfer modes of radiation, conduction and convection were considered in the finite element thermal analyses as shown in Figure 4.3.

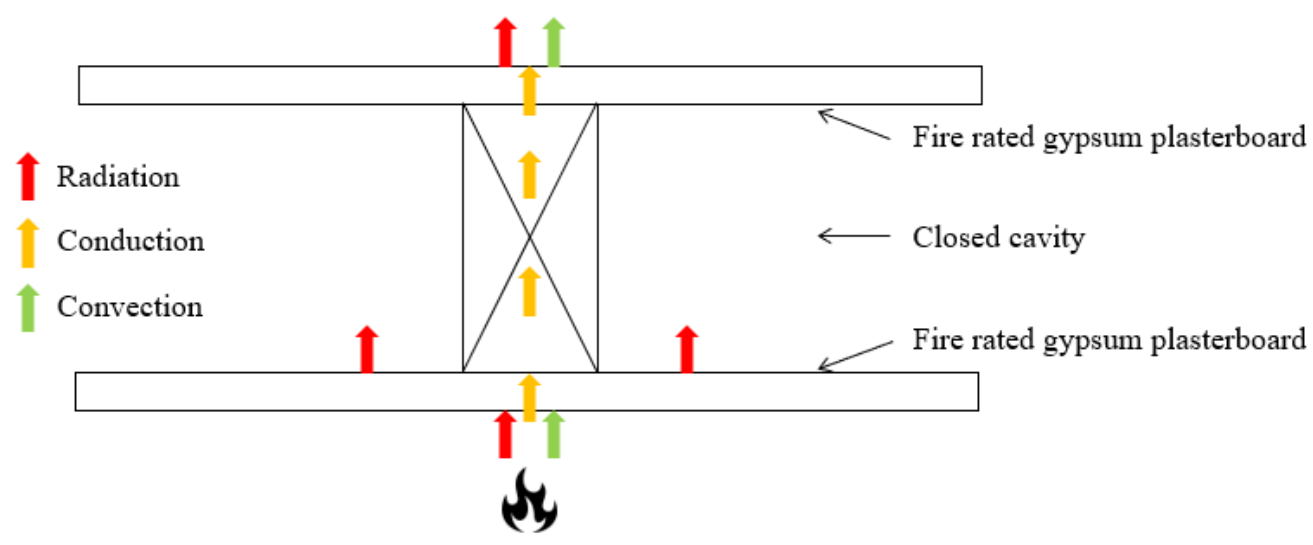

Figure 4.3 - One-sided fire exposure heat transfer modes through timber-framed wall

Figure 4.4 summarises the boundary conditions that were assigned in the thermal analyses to model the ISO 834 standard fire exposure to the wall assembly. A constant convective film coefficient of $25 \mathrm{~W} / \mathrm{m}^{2} \cdot \mathrm{K}$ was used to model the standard fire on the exposed face and $9 \mathrm{~W} / \mathrm{m}^{2} \cdot \mathrm{K}$ on the unexposed face to model losses of radiation and convection. A radiation emissivity of 0.9 was used to model the standard fire on the exposed face, and was also applied to other surfaces of the wall assembly components to model radiation heat transfer. A value of 0.9 was also used for emissivity in the closed cavity.

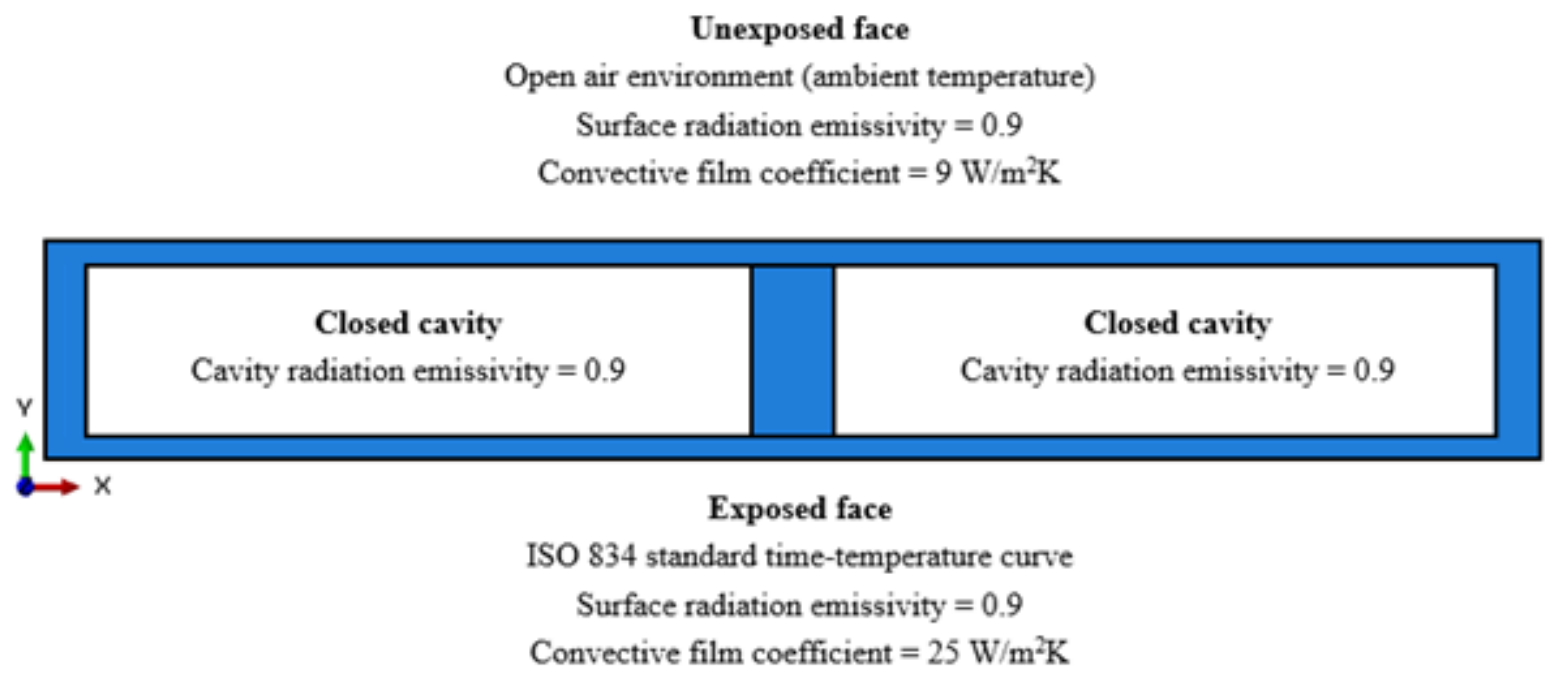

Figure 4.4 - Boundary conditions assigned in one-sided fire exposure heat transfer model

Page $\mid 42$ 
Tie constraints between surfaces of the wall assembly components were defined and used to connect them to ensure heat transfer occurs between the components, and node temperatures at the connected surfaces were equated.

\subsubsection{Mesh size sensitivity analysis}

A sensitivity analysis was carried out for a typical timber-framed wall assembly that consisted of $90 \mathrm{~mm}$ x $45 \mathrm{~mm}$ timber studs lined with $13 \mathrm{~mm}$ fire-rated gypsum plasterboard each side. It is known that a fine mesh size provides more precise and accurate results compared to a coarse mesh size but the simulation run-time and required memory can increase. For this reason, the thermal model was run with four different mesh sizes of 2, 3, 5 and $10 \mathrm{~mm}$ on the $\mathrm{x}$ and $\mathrm{y}$ axis directions shown in Figure 4.4. Table 4.1 summarises the simulation run-time for each mesh size, and for the different mesh sizes. Figure 4.5 shows the time-temperature comparison measured at the back of exposed and unexposed linings and the front face of unexposed lining.

Table 4.1 - Simulation run-time for 2, 3, 5 and $10 \mathrm{~mm}$ square mesh sizes

\begin{tabular}{|c|c|c|c|c|}
\hline Square mesh size $(\mathrm{mm})$ & 2 & 3 & 5 & 10 \\
\hline Modelling run-time $(\mathrm{sec})$ & 7139 & 2333 & 591 & 183 \\
\hline Modelling run-time $(\mathrm{min})$ & 119 & 39 & 10 & 3 \\
\hline
\end{tabular}

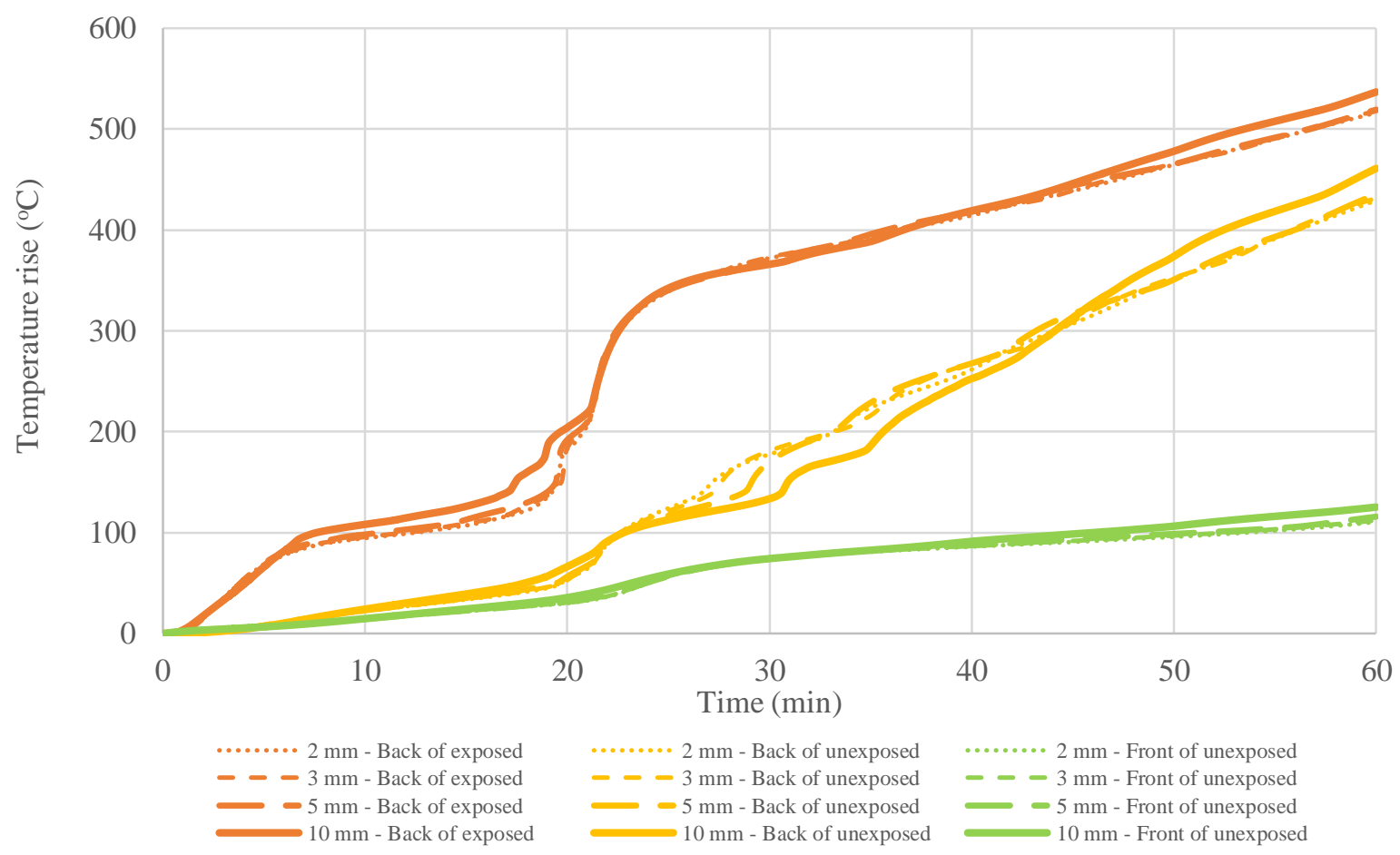

Figure 4.5 - Time-temperature profiles for 2, 3,5 and $10 \mathrm{~mm}$ square mesh sizes 
It can be seen that the predicted temperature based on the $10 \mathrm{~mm}$ square mesh was slightly different to the finer mesh sizes of 2, 3 and $5 \mathrm{~mm}$ and did not agree well with other mesh sizes indicating less accurate results. The finer mesh sizes were observed to be aligned well with no significant difference between them in the predicted temperatures. Therefore, given the accuracy of the modelling results and modelling run-time provided in Table 4.1, it was considered reasonable to select a $5 \mathrm{~mm}$ square mesh size for the thermal analyses.

\subsubsection{Thermal model for two-sided fire exposure}

The thermal finite element model for the two-sided fire exposure was developed by considering three heat transfer modes of radiation, conduction and convection as shown in Figure 4.6 where the ISO 834 standard fire time-temperature curve was applied on both sides of the wall assembly.

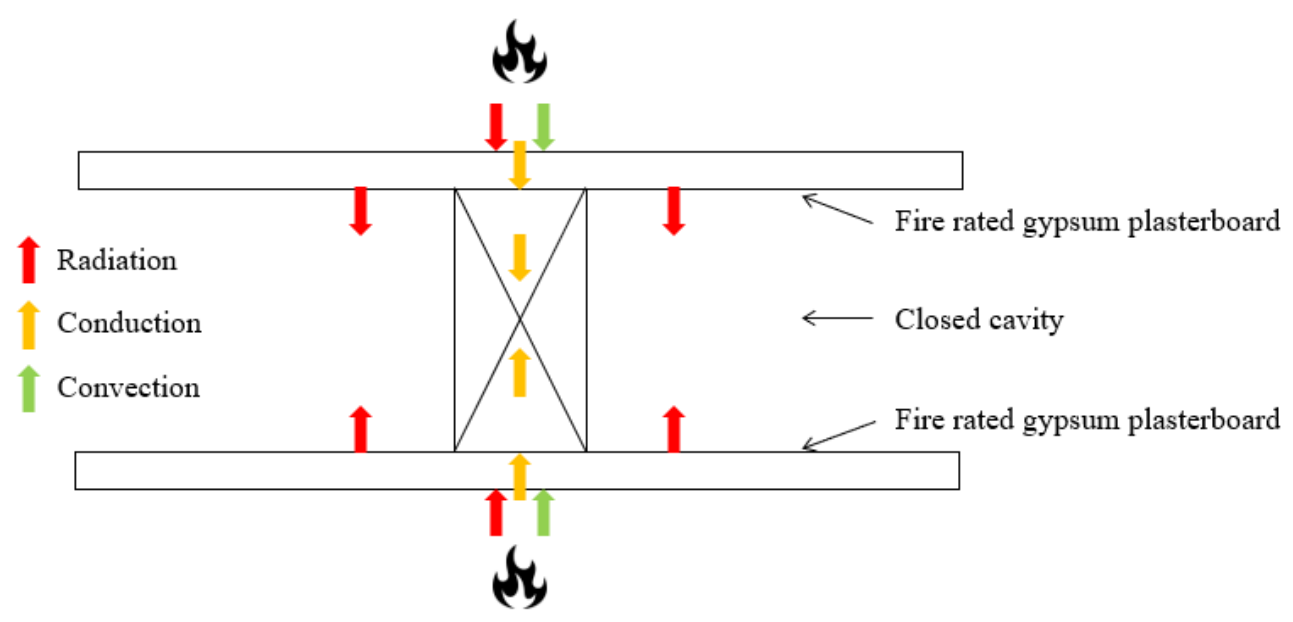

Figure 4.6 - Two-sided fire exposure heat transfer modes through timber-framed wall

Figure 4.7 summarises the boundary conditions that were assigned in the thermal analyses when modelling the ISO 834 standard fire exposure on both sides of the wall assembly. A constant convective film coefficient of $25 \mathrm{~W} / \mathrm{m}^{2} \cdot \mathrm{K}$ and a radiation emissivity of 0.9 were used on both sides. The emissivity of 0.9 was also applied to internal surfaces of the wall assembly to model radiation heat transfer. 


\section{Exposed face}

ISO 834 standard time-temperature curve

Surface radiation emissivity $=0.9$

Convective film coefficient $=25 \mathrm{~W} / \mathrm{m}^{2} \mathrm{~K}$

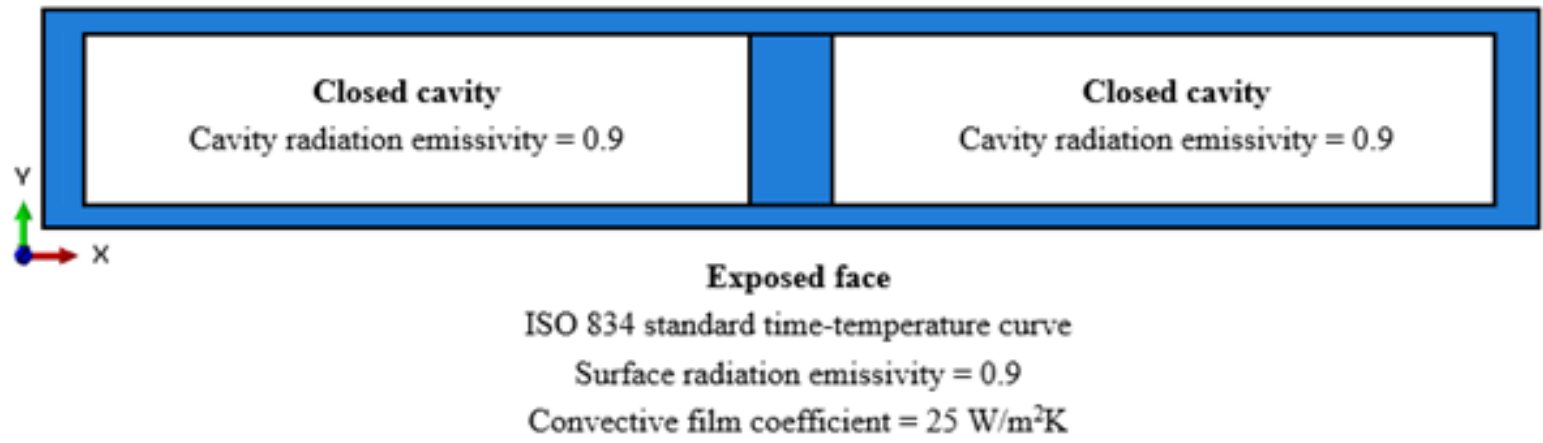

Figure 4.7 - Boundary conditions assigned in two-sided fire exposure heat transfer model

Similar to the developed thermal model for the one-sided fire exposure, tie constraints between surfaces of the wall assembly components were used to connect them to ensure heat transfer between the components, and have equal node temperatures.

\subsection{Structural modelling analysis method}

In order to understand the behaviour of load-bearing timber-framed gypsum plasterboard lined walls under ambient and fire conditions and to predict their structural adequacy failure time as defined in AS 1530.4:2014, the Abaqus/CAE three-dimensional finite element software was utilised to perform a three-dimensional eigenvalue elastic buckling and a sequentially coupled temperature-displacement analysis. A hand calculation was carried out to validate the modelled critical buckling loads, and the past fire-resistance tests of load-bearing timber-framed walls were used to validate the finite element analysis. These are further discussed in Section 4.4.2. Figure 4.8 shows a typical load-bearing timber-framed wall assembly and indicates the region modelled in the three-dimensional finite element structural model. A single timber stud was used for simplicity. 


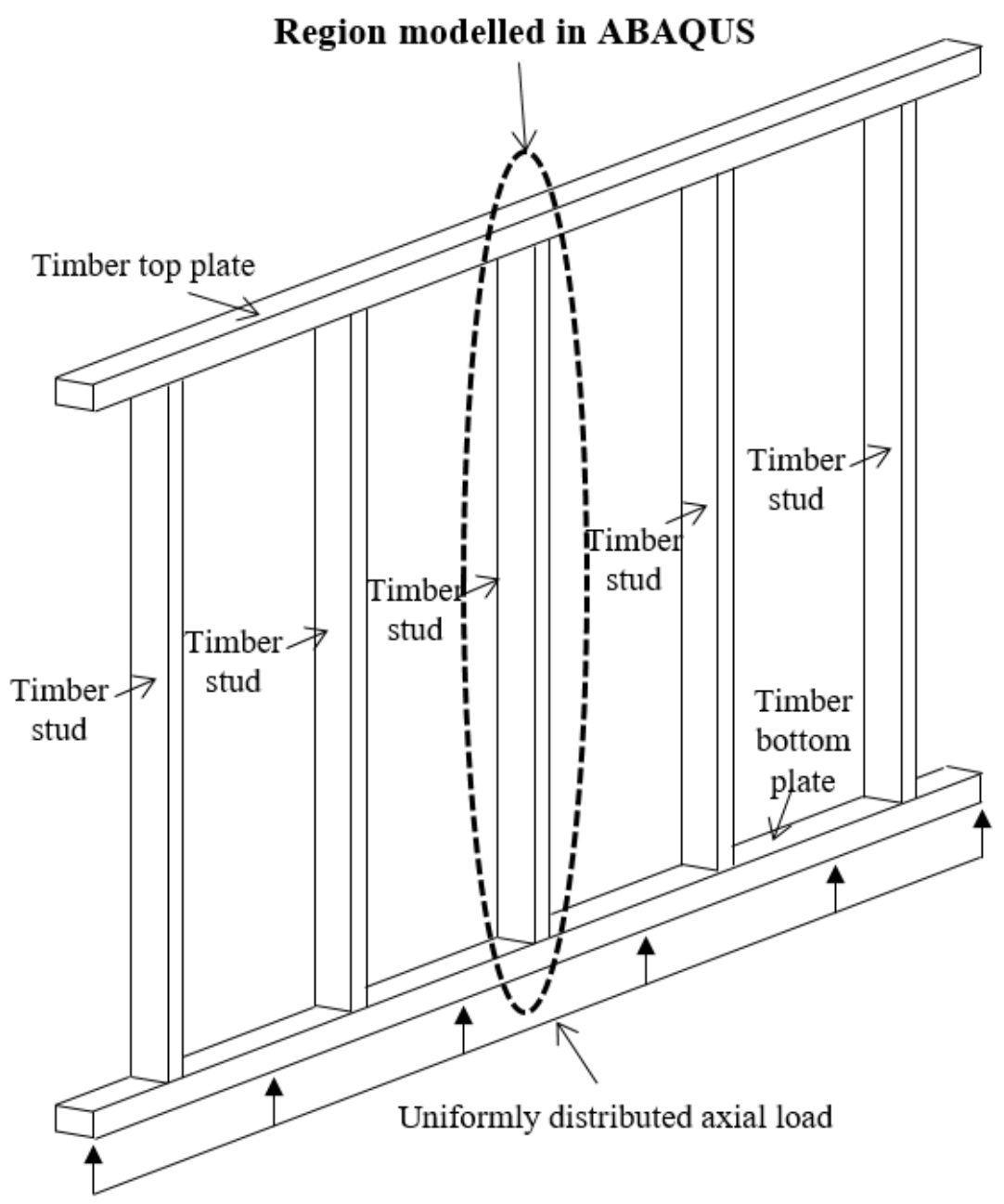

Figure 4.8 - Typical timber-framed wall assembly

\subsubsection{Mechanical properties}

The mechanical properties of light timber studs are significantly reduced under fire conditions even at low temperatures and it was important to input correct temperature-dependent mechanical properties into the Abaqus/CAE software to generate accurate model results. The reduction factors for compression for strength and modulus of elasticity obtained from Annex B of Eurocode 5: Part 1-2 were used as discussed in Section 2.7.

Table 4.2 shows temperature-dependent elastic material properties for structural grade SG8 Radiata pine timber which were defined in the Abaqus/CAE software by specifying the engineering constants. An elastic modulus value of 8 GPa for SG8 Radiata pine under ambient condition was obtained from NZ Wood [36]. A design value of $8 \mathrm{GPa}$ is also stated in NZS 3603-1993 A4. Poisson's ratios and elastic ratios for red pine species, which have comparable strength and elastic behaviour with that of Radiata pine, were used to describe the 
elastic behaviour of SG8 Radiata pine and to obtain the moduli of elasticity and rigidity in each orthogonal direction [28].

The strength and modulus of elasticity of softwood become zero at $300{ }^{\circ} \mathrm{C}$ as shown in Figures 2.14 and 2.15. However, the value input into Abaqus/CAE software was $1 / 100^{\text {th }}$ of the initial value which was the minimum parameter reduction allowed in the Abaqus/CAE. Hence, the elastic engineering constants at $300{ }^{\circ} \mathrm{C}$ were modified as required to satisfy this requirement and to prevent possible numerical issues that could occur in the structural model [19].

Table 4.2 - Temperature-dependent modulus of elasticity, Poisson's ratio and modulus of rigidity of SG8 Radiata pine used for engineering constants orthotropic elasticity

\begin{tabular}{|c|c|c|c|c|c|c|c|c|c|}
\hline $\begin{array}{c}\text { Temperature } \\
\left({ }^{\circ} \mathrm{C}\right)\end{array}$ & \multicolumn{3}{|c|}{$\begin{array}{c}\text { Modulus of elasticity } \\
(\mathrm{MPa})\end{array}$} & \multicolumn{3}{|c|}{ Poisson's ratio } & \multicolumn{3}{c|}{$\begin{array}{c}\text { Modulus of rigidity } \\
(\mathrm{MPa})\end{array}$} \\
\cline { 2 - 10 } & $\mathrm{E}_{1}$ & $\mathrm{E}_{2}$ & $\mathrm{E}_{3}$ & $\mathrm{~V}_{12}$ & $\mathrm{~V}_{13}$ & $\mathrm{~V}_{23}$ & $\mathrm{G}_{12}$ & $\mathrm{G}_{13}$ & $\mathrm{G}_{23}$ \\
\hline 0 & 704.0 & 352.0 & 8000.0 & 0.41 & 0.0 & 0.0 & 88.0 & 768.0 & 648.0 \\
\hline 20 & 704.0 & 352.0 & 8000.0 & 0.41 & 0.0 & 0.0 & 88.0 & 768.0 & 648.0 \\
\hline 100 & 246.4 & 123.2 & 2800.0 & 0.41 & 0.0 & 0.0 & 30.8 & 268.8 & 226.8 \\
\hline 300 & 7.0 & 3.5 & 80.0 & 0.41 & 0.0 & 0.0 & 0.9 & 7.7 & 6.5 \\
\hline
\end{tabular}

Plastic material properties as a function of temperature for SG8 Radiata pine are shown in Table 4.3. The strength for compression parallel and perpendicular to grain for dry Radiata pine were taken as $18 \mathrm{MPa}$ and $8.9 \mathrm{MPa}$ respectively, and a shear strength of 3.8 MPa was used as per NZS 3603-1993 A4.

The following equation suggested by Quiquero et al. [38] was also used to calculated the baseline shear strength.

$$
\tau_{0}=\sigma_{0} / \sqrt{3}
$$

Where: $\quad \tau_{0}=$ Baseline shear strength $(\mathrm{MPa})$

$$
\sigma_{0}=\text { Baseline yield strength }(\mathrm{MPa})
$$

Quiquero et al. [38] investigated five material behaviours in Abaqus/CAE that are suitable to simulate non-linear behaviour of timber. It was found that the Hill's Potential Function 
realistically modelled the behaviour of timber which is also compatible with the engineering constants orthotropic elasticity used in this study. Therefore, the plastic behaviour of the timber stud subjected to axial load was modelled in Abaqus/CAE using the Hill's Potential Function. The temperature-dependent yield and shear strength values in Table 4.3 were used to calculate the strength ratios that were applied in the Hill's Potential Function for plasticity. The strength ratios are shown in Table 4.4.

Table 4.3 - Temperature-dependent compressive and shear strength of SG8 Radiata pine

\begin{tabular}{|c|c|c|c|c|c|c|c|c|}
\hline \multirow{4}{*}{$\begin{array}{c}\text { Temperature } \\
\left({ }^{\circ} \mathrm{C}\right)\end{array}$} & $\begin{array}{c}\text { Baseline } \\
\text { yield } \\
\text { strength, } \\
\sigma_{0}(\mathrm{MPa})\end{array}$ & $\begin{array}{c}\mathrm{f}_{11} \\
(\mathrm{MPa})\end{array}$ & $\begin{array}{c}\mathrm{f}_{22} \\
(\mathrm{MPa})\end{array}$ & $\begin{array}{c}\mathrm{f}_{33} \\
(\mathrm{MPa})\end{array}$ & $\begin{array}{c}\text { Baseline } \\
\text { shear } \\
\text { strength, } \\
\tau_{0}(\mathrm{MPa})\end{array}$ & $\begin{array}{c}\mathrm{f}_{12} \\
(\mathrm{MPa})\end{array}$ & $\begin{array}{c}\mathrm{f}_{13} \\
(\mathrm{MPa})\end{array}$ & $\begin{array}{c}\mathrm{f}_{23} \\
(\mathrm{MPa})\end{array}$ \\
\hline 0 & 18.00 & 8.90 & 8.90 & 18.00 & 10.39 & 3.80 & 3.80 & 3.80 \\
\hline 20 & 18.00 & 8.90 & 8.90 & 18.00 & 10.39 & 3.80 & 3.80 & 3.80 \\
\hline 100 & 4.50 & 2.23 & 2.23 & 4.50 & 2.60 & 1.52 & 1.52 & 1.52 \\
\hline 300 & 0.18 & 0.09 & 0.09 & 0.18 & 0.10 & 0.04 & 0.04 & 0.04 \\
\hline
\end{tabular}

Table 4.4 - Temperature-dependent compressive and shear strength ratios of SG8 Radiata pine used in Hill's Potential Function

\begin{tabular}{|c|c|c|c|c|c|c|}
\hline Temperature $\left({ }^{\circ} \mathrm{C}\right)$ & $\mathrm{R}_{11}$ & $\mathrm{R}_{22}$ & $\mathrm{R}_{33}$ & $\mathrm{R}_{12}$ & $\mathrm{R}_{13}$ & $\mathrm{R}_{23}$ \\
\hline 0 & 0.494 & 0.494 & 1.000 & 0.366 & 0.366 & 0.366 \\
\hline 20 & 0.494 & 0.494 & 1.000 & 0.366 & 0.366 & 0.366 \\
\hline 100 & 0.494 & 0.494 & 1.000 & 0.585 & 0.585 & 0.585 \\
\hline 300 & 0.494 & 0.494 & 1.000 & 0.366 & 0.366 & 0.366 \\
\hline
\end{tabular}

It was assumed that the behaviour of timber material was elastic-perfect-plastic which considers a constant yield strength in the plastic range. A further assumption was made that the use of the characteristic yield strength value was acceptable in the finite element model to predict the worst-case scenario although the Abaqus/CAE required a true stress value to describe the stress-strain relationship. Quiquero et al. [38] also used the characteristic strength values to conservatively demonstrate the behaviour of timber beams. 
Temperature-dependent thermal properties of timber studs such as thermal conductivity, density and specific heat values discussed in Section 4.2.2 were also input into the sequentially coupled temperature-displacement finite element analyses, in addition to the temperaturedependent mechanical properties of timber studs.

\subsubsection{Structural model under ambient conditions}

\subsubsection{Analysis method}

A general eigenvalue buckling analysis was carried out to predict the critical buckling load of stiff structural elements and to provide estimates of collapse mode shapes of the elements under axial load. The elastic buckling load of the timber stud under ambient conditions was obtained from the eigenvalue of the first collapse mode shape. The modelled result was then compared with hand calculation based on Euler's critical load method to validate the prediction and estimate the ambient critical buckling load for the study.

\subsubsection{Element type}

The element type assigned for the timber stud was an 8-node linear brick element (C3D8) with 8 integration points. C3D8 is most appropriate and commonly used for performing threedimensional finite element stress-strain analyses. This analysis is stress governed and terminates when deformations become excessive and lateral deflections rapidly increase, signifying buckling of the timber stud [19].

\subsubsection{Boundary conditions and loading}

Figure 4.9 shows a three-dimensional finite element of a 90 x 45 x $2910 \mathrm{~mm}$ timber stud from Abaqus/CAE which also describes boundary condition applied in the structural model.

The top end of timber stud was modelled to have a pinned support by restraining $\mathrm{x}, \mathrm{y}$ and z-axis translations as well as z-axis rotation. The bottom end had a roller support by restraining $\mathrm{x}$ and $\mathrm{y}$ translations, and $\mathrm{z}$-axis rotation. Rigid body constraints were used to restrict the motion of top and bottom ends of the timber stud about the centre at each end. 


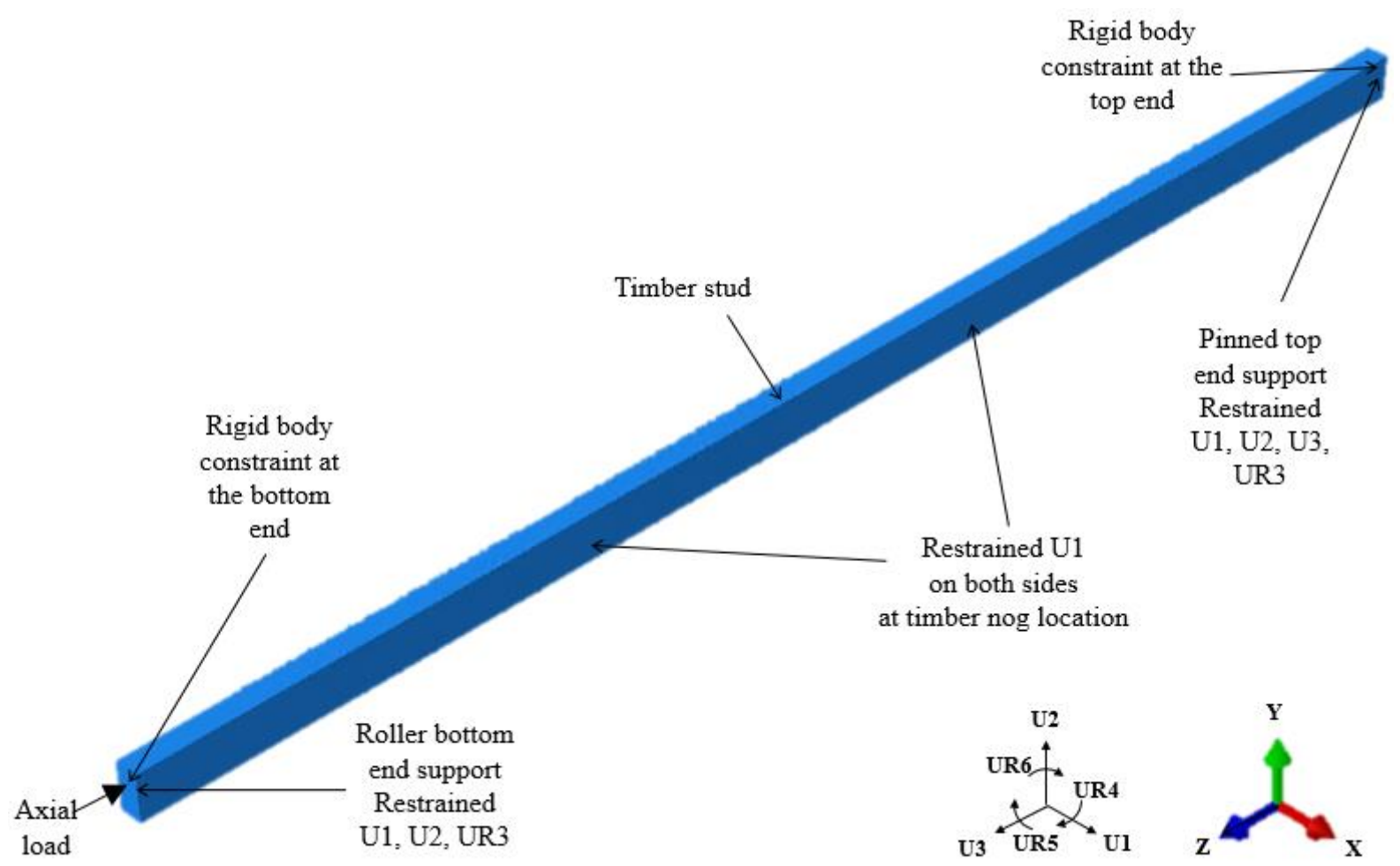

Figure 4.9 - Structural 3-D finite element model of timber stud

A load magnitude of -1 was entered in the load module to define the direction of the axial compression load on the bottom end of timber stud as shown in Figure 4.9. The timber stud was modelled to have lateral restraints at the location of timber nogs as shown in Figure 4.9 so torsional buckling and flexural buckling about the y-axis would not occur. The effect of gypsum plasterboard on lateral restraints was also investigated by restraining the node at plasterboard screw locations at $300 \mathrm{~mm}$ centres along the $\mathrm{x}$-axis. However, there was no reduction in the elastic buckling load which is normally expected to occur in the model. Hence, the effect of gypsum plasterboard lining and screw was considered negligible.

\subsubsection{Mesh size sensitivity analysis and results}

A sensitivity analysis was carried out for a $90 \times 45 \times 2910 \mathrm{~mm}$ timber stud in the general eigenvalue buckling analysis. As discussed in Section 4.2.3.4, a finer mesh size provides more accurate results compared to a coarse mesh size. However, it is also important to consider the simulation run-time and required memory which increase significantly with a finer mesh size. As the general eigenvalue buckling analysis model was developed in a three-dimensional space, the sensitivity analysis was carried out with various mesh sizes in length of the timber stud. Table 4.5 summarises the simulation run-time and modelled critical elastic buckling load for $5,10,50,100 \mathrm{~mm}$ mesh sizes in length with $5 \mathrm{~mm}$ mesh size in cross-section. 
Table 4.5 - Simultion run-time for 5, 10, 50, 100 and $200 \mathrm{~mm}$ mesh size in length

\begin{tabular}{|c|c|c|c|c|}
\hline Mesh size in length $(\mathrm{mm})$ & 5 & 10 & 50 & 100 \\
\hline Mesh size in cross-section (mm) & \multicolumn{5}{|c|}{5} \\
\hline Critical elastic buckling load (kN) & 23.7 & 23.7 & 24.3 & 26.1 \\
\hline Modelling run time (sec) & 65 & 38 & 7 & 3 \\
\hline
\end{tabular}

It can be seen that the simulation run-time for the general eigenvalue buckling analysis was relatively short despite the fact that the model had a three-dimensional solid shape using C3D8 elements. Table 4.5 shows that the model with $10 \mathrm{~mm}$ mesh size in length produced the same estimated critical elastic buckling load as the one with $5 \mathrm{~mm}$ mesh size and resulted in almost two times longer simulation run-time. Therefore, it was considered reasonable to select a $10 \mathrm{~mm}$ mesh size in length with $5 \mathrm{~mm}$ mesh size in cross-section to obtain ideal modelling results.

Figure 4.10 shows the general eigenvalue buckling analysis result for a 90 x 45 x $2910 \mathrm{~mm}$ timber stud under ambient conditions from Abaqus/CAE. The estimated critical elastic buckling load (eigenvalue) was $23.7 \mathrm{kN}$ from the first collapse mode shape which agreed well with the hand calculation result of $24.0 \mathrm{kN}$ based on Euler's critical load method. Detailed hand calculations can be found in Appendix C.

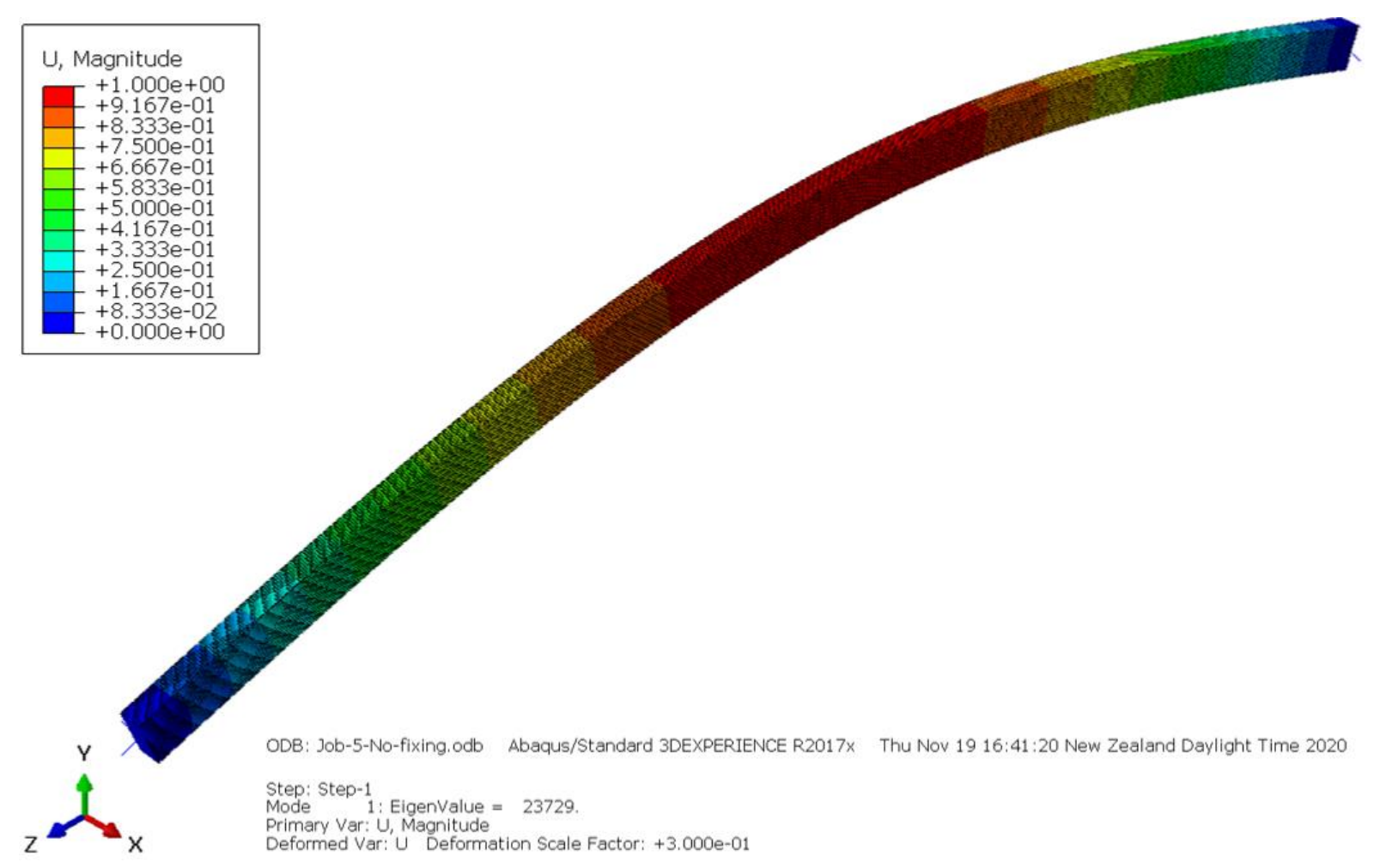

Figure 4.10 - General eigenvalue buckling analysis results of 90 x 45 x $2910 \mathrm{~mm}$ timber stud 


\subsubsection{Structural model under fire conditions}

\subsubsection{Analysis method}

The structural behaviour of the load-bearing timber stud under fire conditions was modelled using the sequentially coupled temperature-displacement non-linear static finite element analysis. A thermal analysis was required to obtain modelled time-temperature profiles of timber stud for input into the structural model to perform this analysis.

A predicted structural adequacy failure time of the timber stud was considered to occur when axial contraction or the rate of axial contraction exceeded defined limits in AS 1530.4:2014. The limiting axial contraction and rate of axial contraction for a 3 metres high wall specimen were $30 \mathrm{~mm}$ and $9 \mathrm{~mm} / \mathrm{min}$ respectively using the Equations (1.4) and (1.5) in Chapter 1.

\subsubsection{Element type}

The element type assigned for timber stud was an 8-node thermally coupled brick, trilinear displacement and temperature (C3D8T) that has full integration. C3D8T is most appropriate for performing three-dimensional finite element thermal stress-strain analyses.

\subsubsection{Boundary conditions and loading}

The boundary conditions adopted for the structural model under fire conditions were similar to the model under ambient condition. The boundary conditions described in Figure 4.9 for the ambient condition model remained the same, but the standard fire transient time-temperature profiles of the timber stud from the thermal model were applied in addition.

The proposed timber stud temperature distribution when subjected to one and two-sided fire exposure is shown in Figures 4.11(a) and 4.11(b) respectively. The average time-temperature profiles for two faces and sides of the timber stud were determined from the thermal model. Then, these were defined using the amplitude temperature data option in Abaqus/CAE software, and temperature boundary conditions were created to specify the time-temperature profiles for each region of the timber stud. 


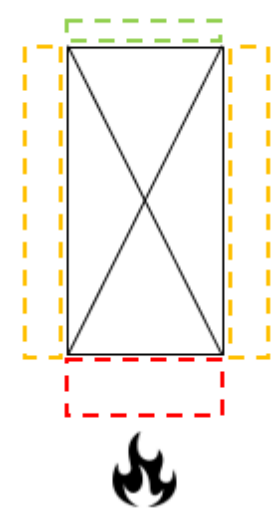

Average unexposed face temperature Average side temperature Average exposed face temperature

(a)

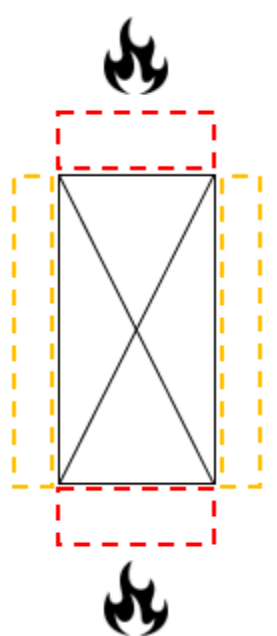

Average exposed face temperature Average side temperature

(b)

Figure 4.11 - Proposed timber stud temperature distribution when subjected to (a) one-sided fire exposure and (b) two-sided fire exposure

The timber stud was subjected to a series of axial loads until the structural adequacy failure occurred. The amount of axial load was either equal to the axial load per stud applied in the experiments or various loadings depending on the proposed load ratios.

\subsubsection{Mesh size sensitivity analysis and results}

A sensitivity analysis was carried out for a 90 x 45 x $2910 \mathrm{~mm}$ timber stud subjected to an axial load of $2 \mathrm{kN}$ in the sequentially coupled temperature-displacement finite element analysis. The time-temperature profiles for the timber stud were obtained from the thermal model discussed in Section 5.2 for the $13 \mathrm{~mm}$ fire-rated gypsum plasterboard lined wall assembly subjected to one-sided fire exposure.

The mesh sizes of $5 \mathrm{~mm}$ in cross-section and $10 \mathrm{~mm}$ in length used for the general eigenvalue buckling analysis were selected first to run the sequentially coupled temperature-displacement finite element model. This resulted in the modelling run time of 13.3 hours as a large analysis such as the sequentially coupled temperature-displacement analysis has a significantly longer run time than the general eigenvalue buckling analysis. Therefore, a sensitivity analysis was carried out with various mesh sizes in length. Figure 4.12 shows vertical displacement-time graphs for 10, 50, 100 and $200 \mathrm{~mm}$ mesh sizes in length and $5 \mathrm{~mm}$ mesh size in cross-section. 


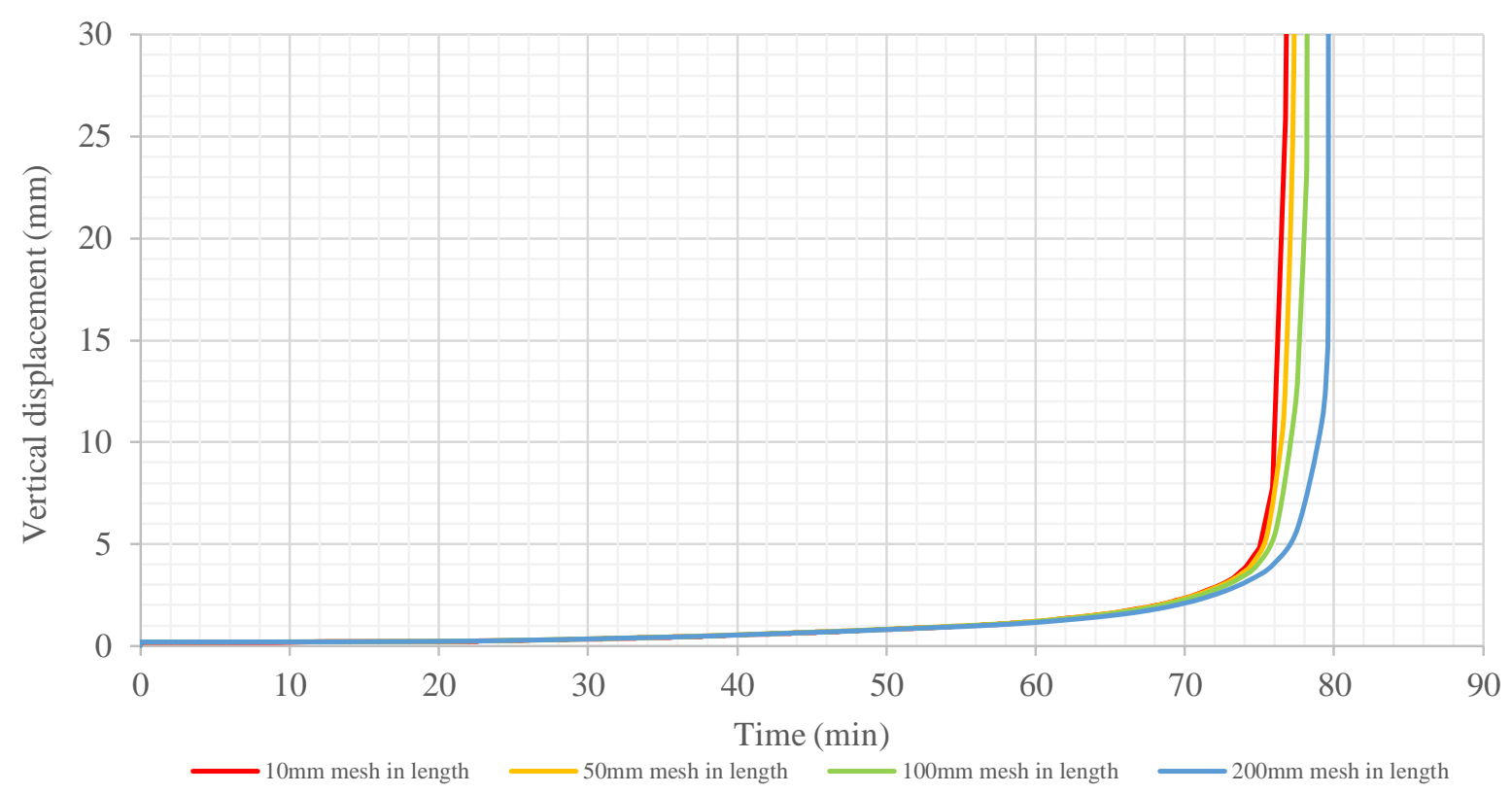

Figure 4.12 - Length mesh size sensitivity analysis

Table 4.6 - Modelling run-time and predicted structural adequacy failure time for each mesh size in length

\begin{tabular}{|c|c|c|c|c|}
\hline Mesh size in length (mm) & 10 & 50 & 100 & 200 \\
\hline Mesh size in cross-section (mm) & \multicolumn{4}{|c|}{5} \\
\hline Predicted structural adequacy failure time (min) & 77 & 77 & 78 & 80 \\
\hline Modelling run time (sec) & 48048 & 9859 & 3585 & 1596 \\
\hline Modelling run time (hours) & 13.3 & 2.7 & 1.0 & 0.4 \\
\hline
\end{tabular}

The predicted structural adequacy failure time and simulation run-times are summarised in Table 4.6. The predicted structural adequacy failure times for the structural model with 10 and $50 \mathrm{~mm}$ mesh sizes in length were same at 77 minutes, but the model with $10 \mathrm{~mm}$ mesh size resulted in the modelling run time of nearly five times of that with $50 \mathrm{~mm}$ mesh size. The modelling run time again dramatically reduced to one hour with the mesh size of $100 \mathrm{~mm}$ in length which slightly over-predicted the structural adequacy failure time, but only by a minute. Therefore, it was considered reasonable to select a $100 \mathrm{~mm}$ mesh size in length with consideration of modelling run time to obtain sufficiently accurate modelling results. The modelling run time also shortened when the axial load increased.

Figure 4.13 shows the sequentially coupled temperature-displacement finite element analysis result for a $90 \times 45 \times 2910 \mathrm{~mm}$ timber stud subjected to an axial load of $2 \mathrm{kN}$. The time- 
temperature profiles simulated one-sided fire exposure behind $13 \mathrm{~mm}$ fire-rated gypsum plasterboard. The failure mode in the model was predicted to be global buckling about the $\mathrm{x}$-axis and buckling towards the ambient side which is commonly observed in the fireresistance tests of light timber-framed wall assemblies.

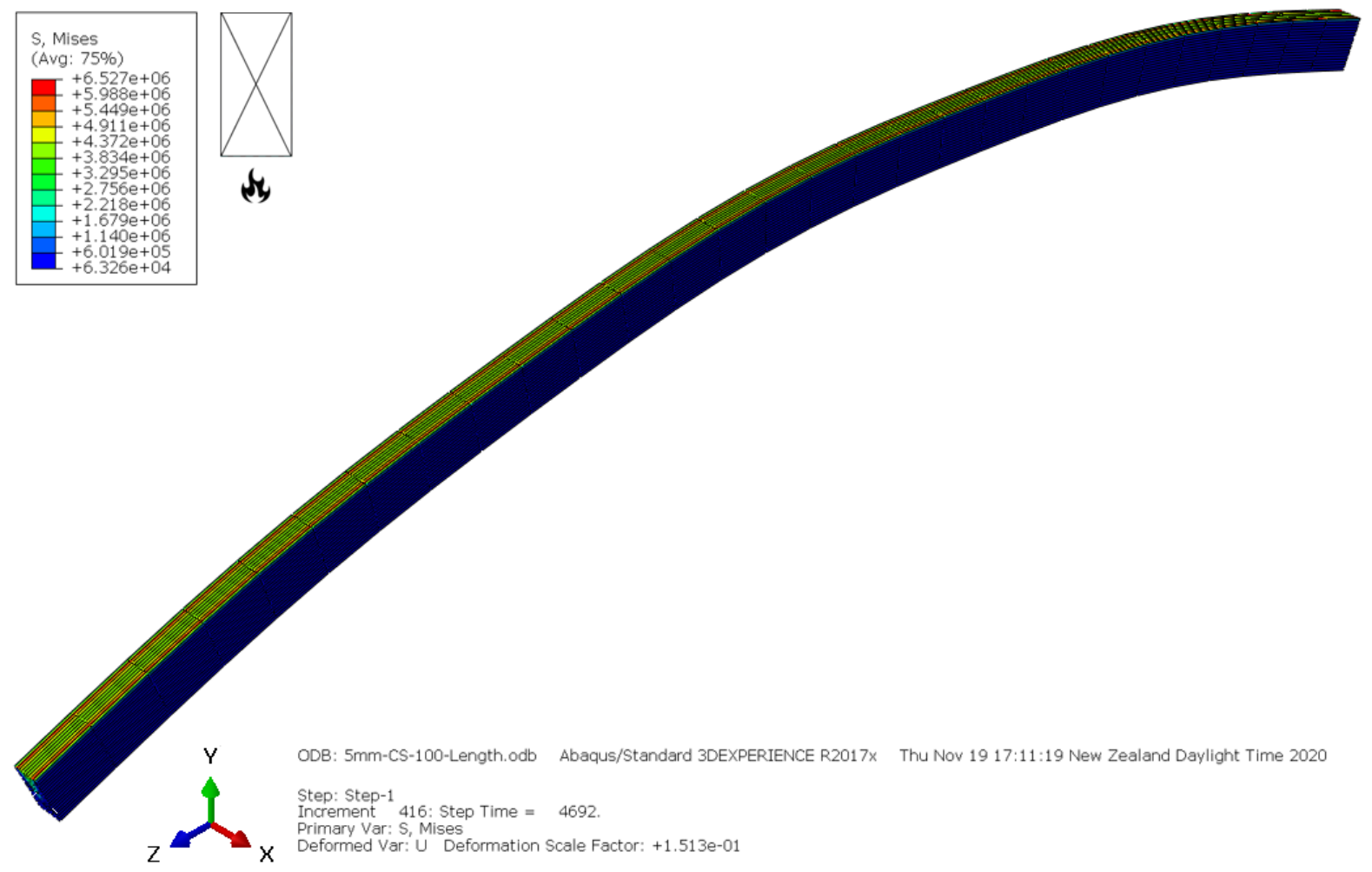

Figure 4.13 - Global buckling failure of $90 \times 45 \times 2910 \mathrm{~mm}$ timber stud subjected to one-sided fire exposure

\subsection{Validation of the model for one-sided fire exposure}

\subsubsection{Thermal model}

To validate the thermal model, outputs were compared with previous experimental results.

The past full-scale fire-resistance tests which incorporated timber-framed walls lined with various thickness of fire-rated gypsum plasterboard were accessed with permission from Winstone Wallboards Ltd. Table 4.7 summarises the past fire-resistance tests used for validation of the thermal model. 
Table 4.7 - Summary of past fire-resistance tests for validation

\begin{tabular}{|c|c|c|c|c|c|}
\hline $\begin{array}{c}\text { Test } \\
\text { Number }\end{array}$ & $\begin{array}{l}\text { Plasterboard thickness } \\
\text { and type }\end{array}$ & $\begin{array}{c}\text { Density of } \\
\text { plasterboard } \\
\left(\mathrm{kg} / \mathrm{m}^{3}\right)\end{array}$ & $\begin{array}{l}\text { Stud depth } \\
\text { and width } \\
\text { (mm x mm) }\end{array}$ & $\begin{array}{l}\text { Density } \\
\text { of studs } \\
\left(\mathrm{kg} / \mathrm{m}^{3}\right)\end{array}$ & $\begin{array}{c}\text { Load- } \\
\text { bearing } \\
\text { capability }\end{array}$ \\
\hline FR1611 & $\begin{array}{l}12.5 \mathrm{~mm} \text { fire-rated } \\
\text { gypsum plasterboard }\end{array}$ & 730.8 & $65 \times 45$ & $510 *$ & $\begin{array}{l}\text { Load- } \\
\text { bearing }\end{array}$ \\
\hline FR1571 & $\begin{array}{l}12.5 \mathrm{~mm} \text { fire-rated } \\
\text { gypsum plasterboard }\end{array}$ & 730.8 & $90 \times 45$ & 477 & $\begin{array}{l}\text { Load- } \\
\text { bearing }\end{array}$ \\
\hline FR1570 & $\begin{array}{c}9.5 \mathrm{~mm} \text { fire-rated gypsum } \\
\text { plasterboard }\end{array}$ & 700.0 & $65 \times 45$ & 567 & $\begin{array}{l}\text { Non- } \\
\text { load- } \\
\text { bearing }\end{array}$ \\
\hline FR1141 & $\begin{array}{c}16 \mathrm{~mm} \text { fire-rated gypsum } \\
\text { plasterboard }\end{array}$ & 856.3 & $90 \times 45$ & 540 & $\begin{array}{l}\text { Load- } \\
\text { bearing }\end{array}$ \\
\hline FR1777 & $\begin{array}{c}16 \mathrm{~mm} \text { fire-rated gypsum } \\
\text { plasterboard }\end{array}$ & 856.3 & $90 \times 35$ & 452 & $\begin{array}{l}\text { Load- } \\
\text { bearing }\end{array}$ \\
\hline FR1142 & $\begin{array}{c}19 \mathrm{~mm} \text { fire-rated gypsum } \\
\text { plasterboard }\end{array}$ & 867.9 & $90 \times 45$ & 414 & $\begin{array}{l}\text { Load- } \\
\text { bearing }\end{array}$ \\
\hline
\end{tabular}

All fire-resistance tests listed in Table 4.7 had specimens that were constructed with five timber studs spaced at nominal $600 \mathrm{~mm}$ centres with two non-load-bearing end studs. This achieved an equal axial load distribution to the studs in between.

There was no measured density of gypsum plasterboard available, and hence the density values published by Winstone Wallboards Ltd [46] at the time were used in the thermal analyses.

Even though the AS 1530.4:2014 test standard does not require these measurements, gypsum plasterboard manufacturers sometime install additional thermocouples within the wall frame cavity, between layers and in a dummy timber stud to collect temperatures for detailed data analysis. The typical location of thermocouples is shown in Figure 4.14. 


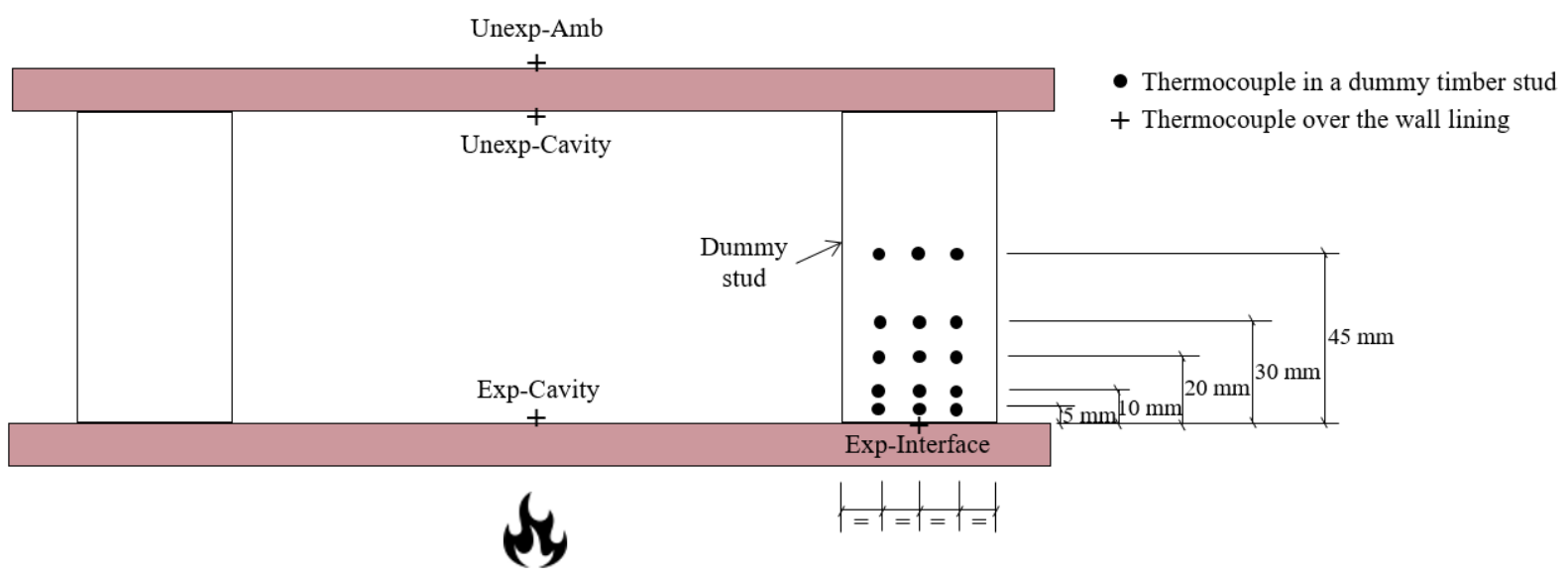

Figure 4.14 - Typical thermocouple location layout

The measured time-temperature data for the timber stud and gypsum plasterboards were used to validate the thermal models. It is noted that not all fire-resistance tests listed in Table 4.7 had thermocouples as per the typical location layout shown in Figure 4.14. The number of thermocouples at each location varied. In all cases thermocouples were placed on the unexposed face close to the centre of the wall and each quarter section in accordance with AS 1530.4:2014 to determine the insulation failure criteria [5].

Tests FR1611, FR1570 and FR1777 had instrumented dummy timber studs included in the experiments with sheathed wire thermocouples. Test FR1611 had three equally spaced thermocouples at depths of 5, 10, 20 and $50 \mathrm{~mm}$. Tests FR1570 and FR1777 had thermocouples along the centreline of the dummy stud at depths of 10 and $20 \mathrm{~mm}$, and at 5, 10, 20 and $30 \mathrm{~mm}$ respectively.

For simplicity, the thermal models developed for validation used the ISO 834 standard fire time-temperature curve rather than the measured furnace temperatures. All fire-resistance tests listed in Table 4.7 showed a variation from the ISO 834 standard fire curve but the difference in the thermal modelling results was negligible as shown in Appendix B.

\subsubsection{FR1611 full-scale fire-resistance test}

Figures 4.15 and 4.16 show the time-temperature profile comparison between test FR1611 and the thermal model output for the wall lining and timber stud respectively. It can be seen that the comparison for the wall lining and timber stud was very good except for the modelled stud 
temperature at the depth of $5 \mathrm{~mm}$ around the simulation time of 50 minutes when the accuracy of the model started to reduce, predicting the temperature lower than the experimental data.

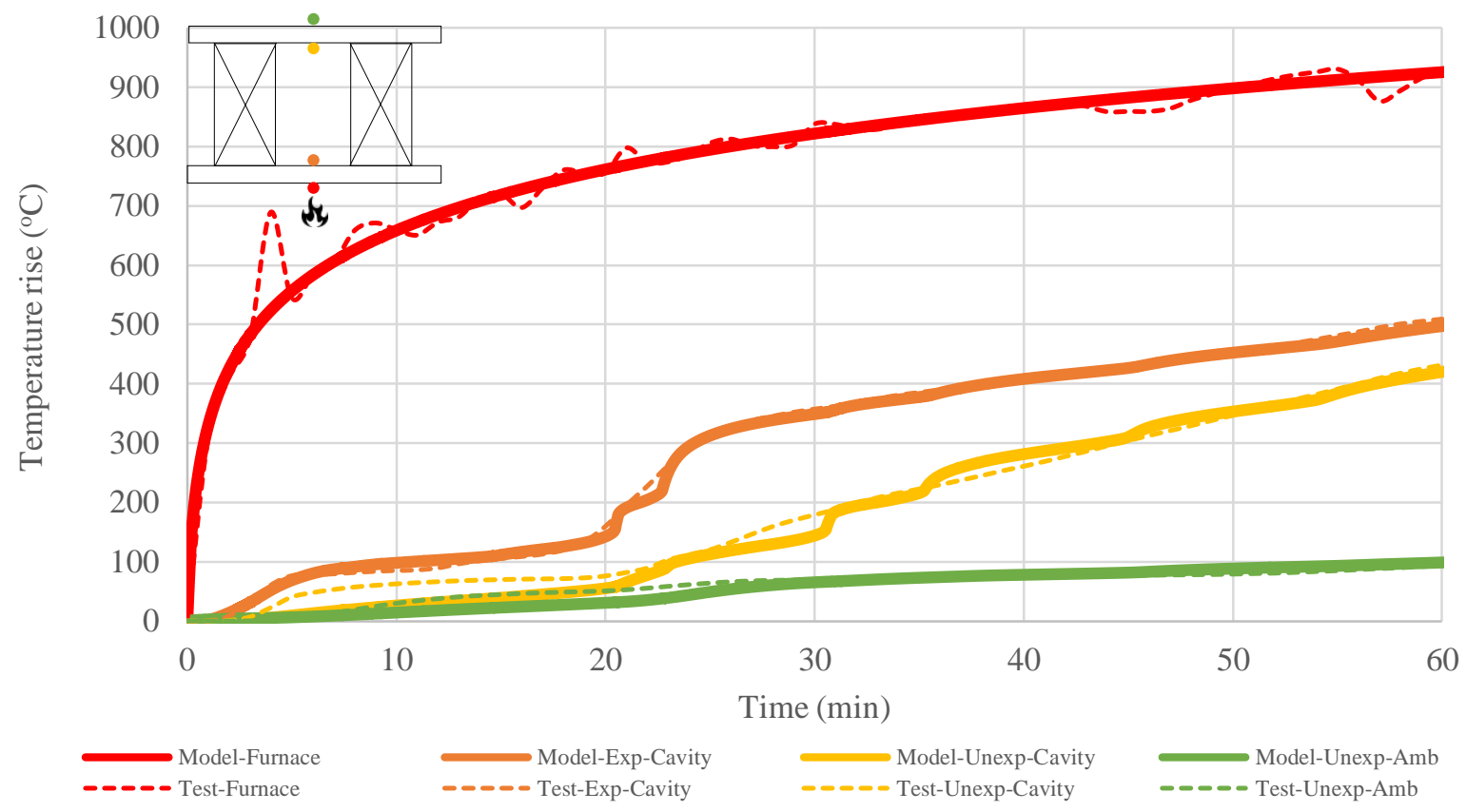

Figure 4.15 - Test FR 1611 time-temperature comparison with thermal model for the wall lining

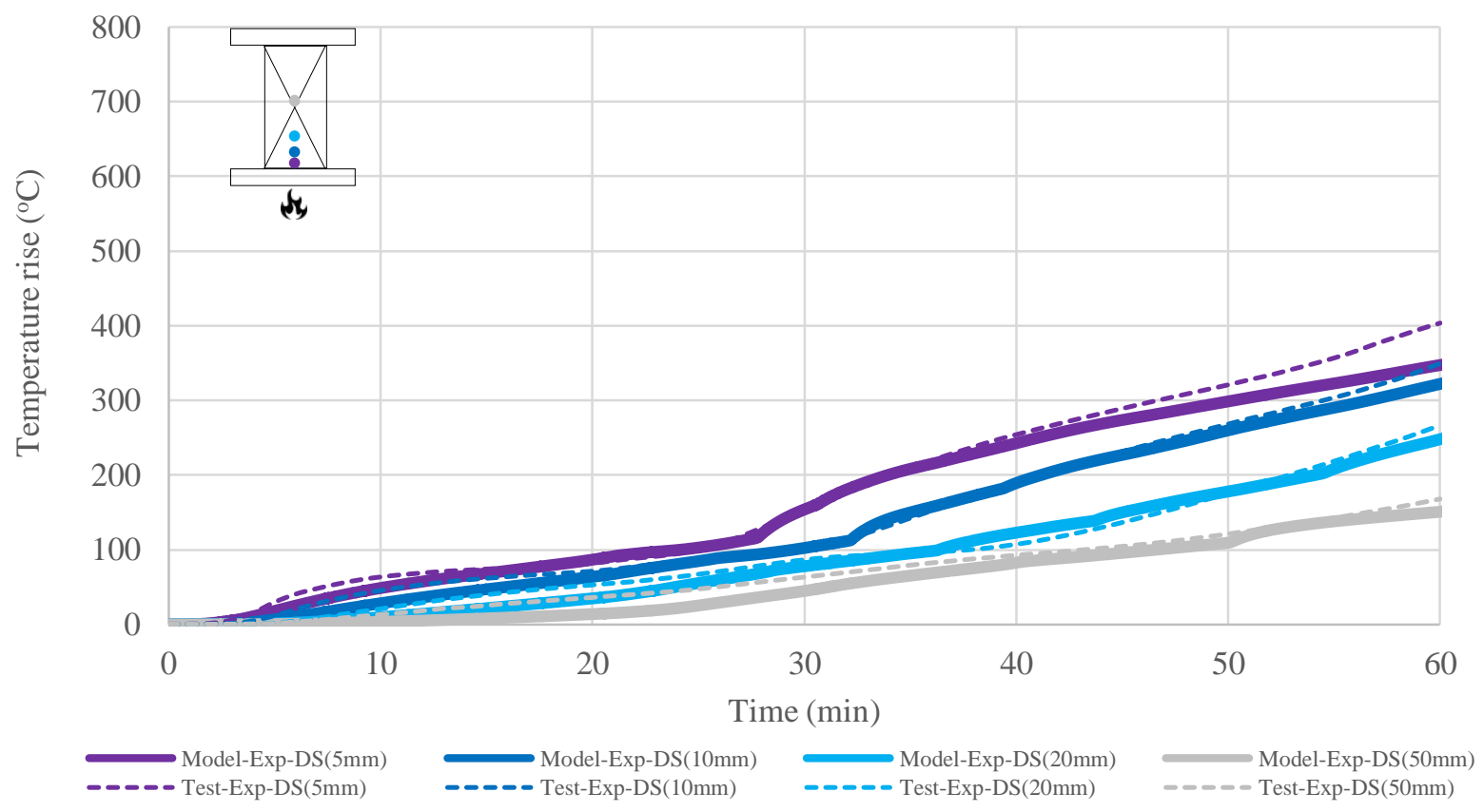

Figure 4.16 - Test FR1611 time-temperature comparison with thermal model for the timber stud 


\subsubsection{FR1571 full-scale fire-resistance test}

Figure 4.17 shows the time-temperature comparison between test FR1571 and the thermal model output for the wall lining and timber stud respectively. The time-temperature data for the cavity side of the unexposed lining was not available for comparison.

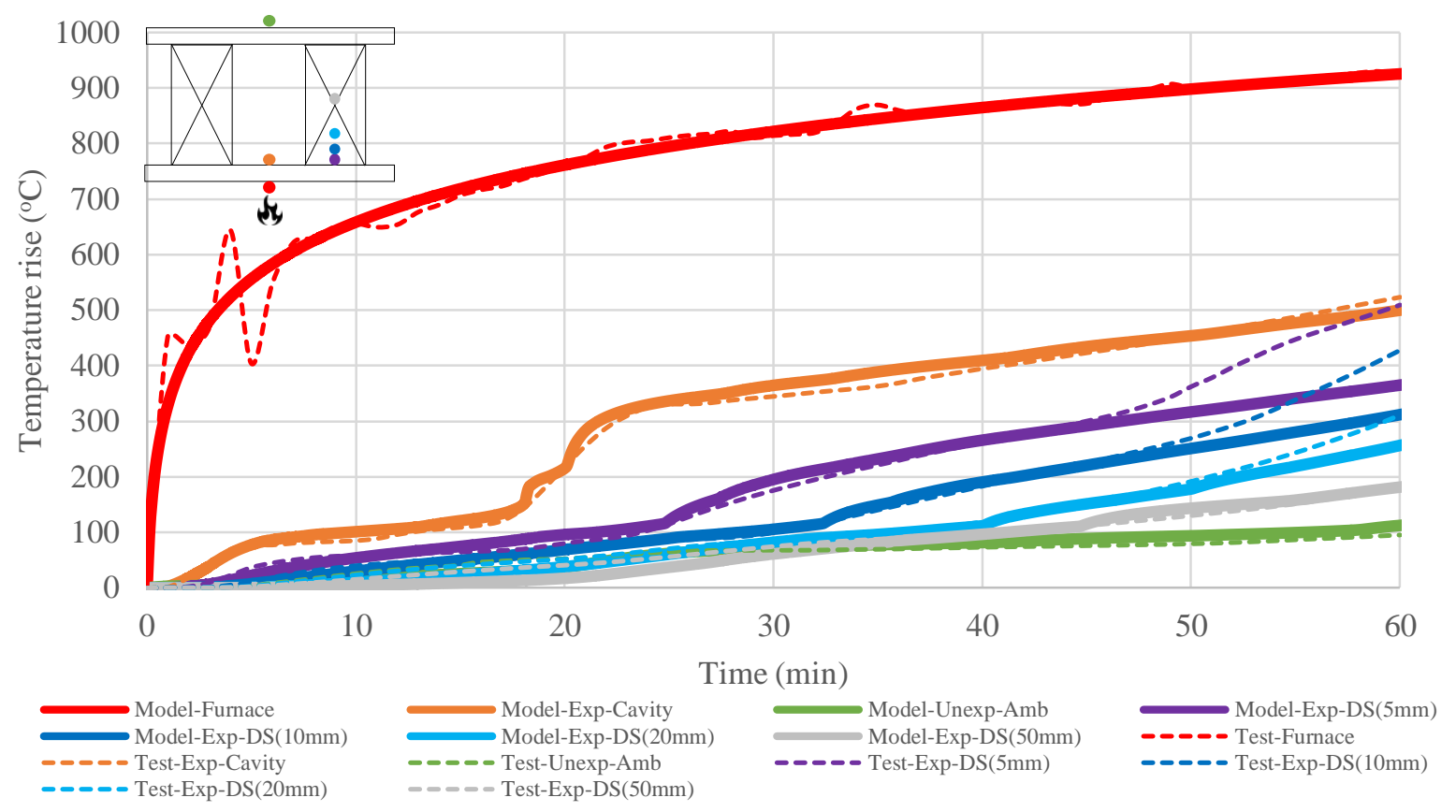

Figure 4.17 - Test FR1571 time-temperature comparison with thermal model

The comparison between the experimental and model results was good except for the modelled stud temperatures at the depth of 5 and $10 \mathrm{~mm}$ which were found lower once simulation time of approximately 50 minutes was reached.

\subsubsection{FR1570 full-scale fire-resistance test}

Figure 4.18 shows the time-temperature comparison between test FR1570 and the thermal model output for the ambient side of unexposed lining, cavity side of exposed lining and dummy studs at depths of 10 and $20 \mathrm{~mm}$. The agreement between the experimental and model results was very good apart from the measured temperature on the cavity side of the exposed lining which was approximately $100{ }^{\circ} \mathrm{C}$ higher in the test after simulation time of 20 minutes. 


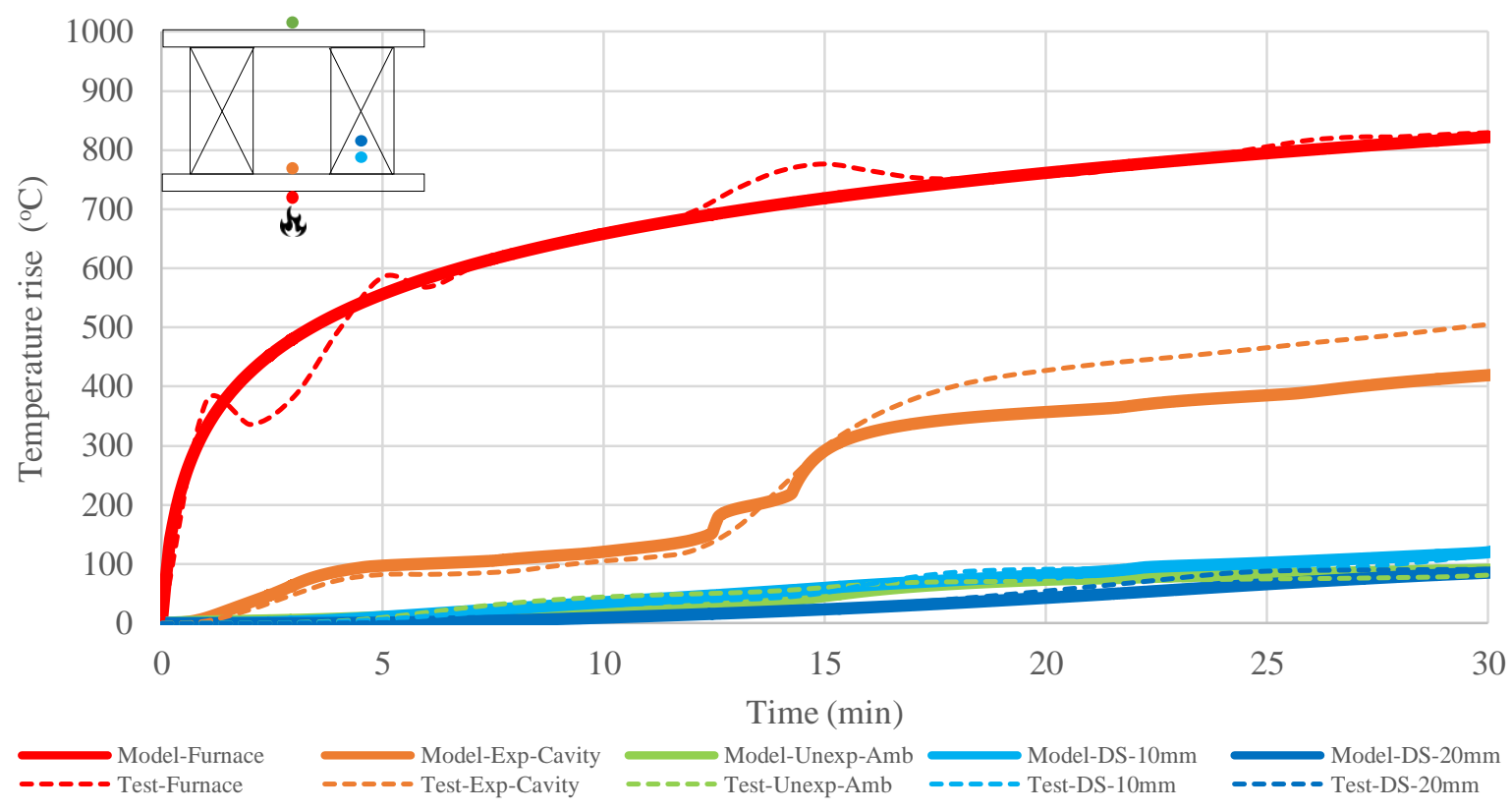

Figure 4.18 - Test FR1570 time-temperature comparison with thermal model

\subsubsection{FR1141 full-scale fire-resistance test}

Figure 4.19 shows the time-temperature comparison between test FR1141 and the thermal model output for the ambient side of unexposed lining which again showed good correlation.

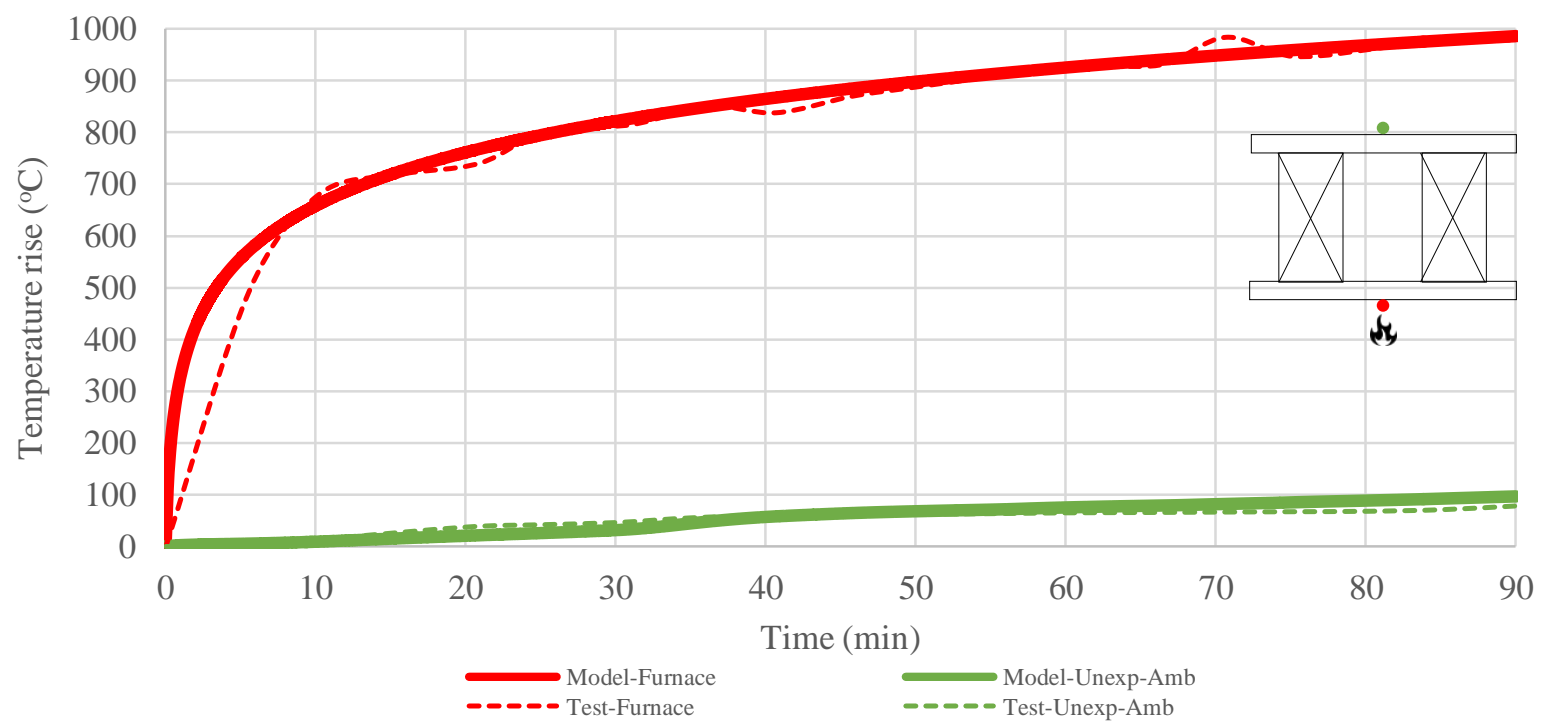

Figure 4.19 - Test FR1141 time-temperature comparison with thermal model

\subsubsection{FR1777 full-scale fire-resistance test}

Figure 4.20 shows the time-temperature comparison between test FR1777 and the thermal model output for the wall linings and timber stud at depths of 5, 10, 20 and $30 \mathrm{~mm}$. The comparison between the experimental and model results is not as good as the previous 
comparisons. The experimental results showed higher temperatures than model results especially in the timber stud. The comparison for the ambient side of unexposed lining and cavity side of unexposed lining was good.

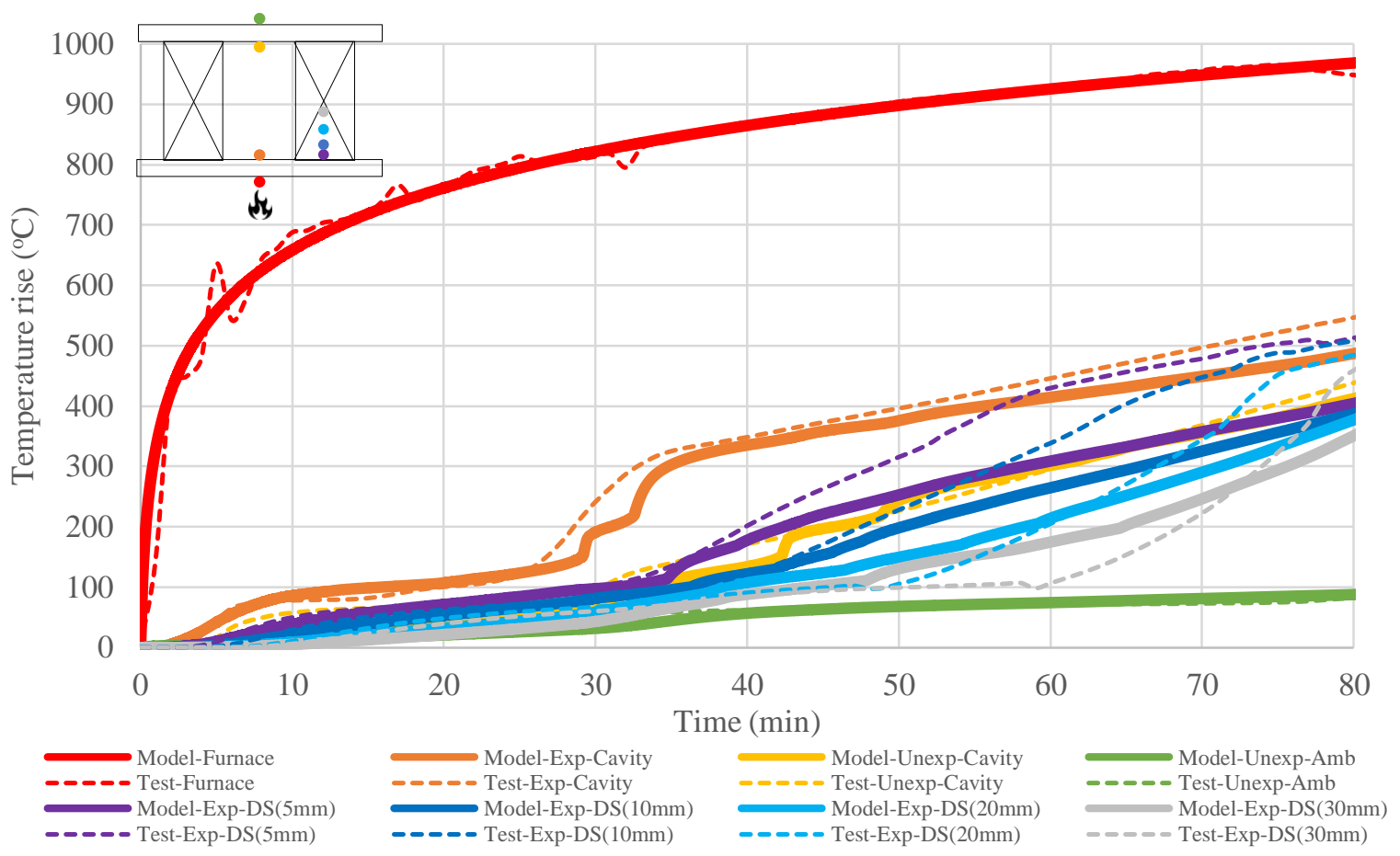

Figure 4.20 - Test FR1777 time-temperature comparison with thermal model

As summarised in Table 4.7, test FR1777 was conducted with 90 x 35 mm timber studs whilst all other tests had $90 \mathrm{~mm}$ x $45 \mathrm{~mm}$ timber studs. The disagreement between the experimental and model results is due to the fact that $35 \mathrm{~mm}$ wide timber studs can allow heat to be transferred to the wall cavity earlier than $45 \mathrm{~mm}$ wide timber stud once sheet joints open up in the test. However, Abaqus/CAE finite element software cannot model the behaviour of ablation and opening of cracks in gypsum plasterboard at elevated temperatures. This is generally accounted for by modifying the thermal conductivity value of gypsum plasterboard to mimic its behaviour in the thermal model as discussed in Section 2.6.6.

\subsubsection{FR1142 full-scale fire-resistance test}

Figure 4.21 shows the time-temperature comparison between test FR1142 and the thermal model output for the interface between the exposed lining and the timber stud, and the ambient side of unexposed lining. 


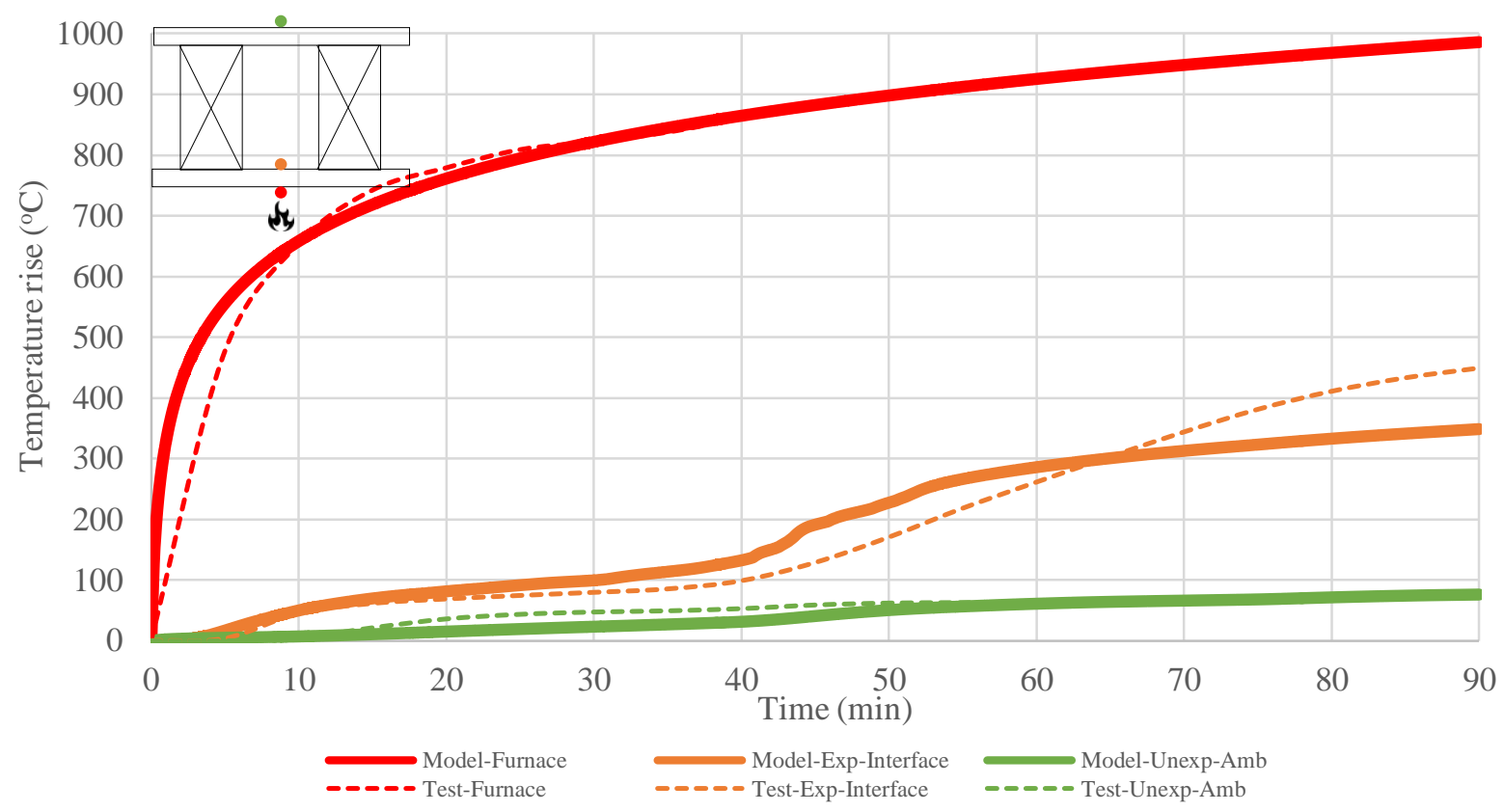

Figure 4.21 - Test FR1142 time-temperature comparison with thermal model

A good correlation can be seen for the ambient side of the unexposed lining. However, the comparison was not as good as previous comparisons where the modelled interface temperature was higher than the measured temperature until approximately 64 minutes, after which the modelled temperatures were lower.

\subsubsection{Structural model}

To accurately predict the failure mode and time of a gypsum plasterboard-lined timber-framed wall, and develop a reliable design methodology, validation of the structural model under fire conditions was required.

The developed structural models under standard fire condition were compared with four past full-scale fire-resistance tests which were also used for validating thermal models. The fireresistance tests were consisted of combinations of two thicknesses of gypsum plasterboard, three stud heights, two stud widths, two stud depths and four different applied axial loads per stud. Table 4.8 describes the four tests used for validation, and provides measured and predicted structural adequacy failure times from the tests and structural models respectively. 
Table 4.8 - Summary of past fire-resistance tests for validation

\begin{tabular}{|c|c|c|c|c|c|}
\hline $\begin{array}{c}\text { Test } \\
\text { Number }\end{array}$ & $\begin{array}{c}\text { Fire-rated } \\
\text { gypsum } \\
\text { plasterboard } \\
\text { thickness } \\
(\mathrm{mm})\end{array}$ & $\begin{array}{c}\text { Stud depth, } \\
\text { width and } \\
\text { height } \\
(\mathrm{mm} \times \mathrm{mm} \times \\
\mathrm{mm})\end{array}$ & $\begin{array}{c}\text { Applied } \\
\text { axial load } \\
\text { per stud } \\
(\mathrm{kN})\end{array}$ & $\begin{array}{c}\text { Measured } \\
\text { structural } \\
\text { adequacy } \\
\text { failure time } \\
(\mathrm{min})\end{array}$ & $\begin{array}{c}\text { Predicted } \\
\text { structural } \\
\text { adequacy } \\
\text { failure time } \\
(\mathrm{min})\end{array}$ \\
\hline FR1611 & 12.5 & $65 \times 45 \times 2575$ & 2 & 69 & 72 \\
\hline FR1571 & 12.5 & $90 \times 45 \times 2910$ & 8 & 49 & 53 \\
\hline FR1141 & 16 & $90 \times 45 \times 2738$ & 4 & 97 & 93 \\
\hline FR1777 & 16 & $90 \times 35 \times 2738$ & 3 & 84 & 80 \\
\hline
\end{tabular}

The difference in structural adequacy failure time between the test and model ranged from 3 to 4 minutes with an average difference of $5.4 \%$. It can be seen that the structural model overpredicted the structural adequacy failure for $12.5 \mathrm{~mm}$ thick fire-rated gypsum plasterboard whereas the model for $16 \mathrm{~mm}$ thick fire-rated gypsum plasterboard was under-predicting. This could be caused by differences in formulation of the gypsum plasterboard or due to the lack of repeatability of the fire-resistance tests. However, overall, the agreement between the measured and predicted structural adequacy failure times was good, and the developed structural model was considered sufficiently accurate in predicting the structural adequacy failure time of the gypsum plasterboard lined timber-framed wall assembly. 


\section{Finite Element Analysis Predictions}

\subsection{Introduction}

The validation analyses, which are provided in Section 4.4, indicated that the developed thermal model for gypsum plasterboard lined timber-framed walls subjected to one-sided fire exposure generally predicted the time-temperature profile of the wall lining and timber stud well. This chapter presents predictions of thermal and structural response of a typical loadbearing timber-framed gypsum plasterboard lined wall assembly when subjected to one and two-sided fire exposure.

\subsection{One-sided fire exposure thermal modelling result}

The developed thermal model was used to predict the performance of a typical fire-rated wall assembly subjected to one-sided fire exposure that consisted of $90 \mathrm{~mm}$ x $45 \mathrm{~mm}$ timber studs and either 13 or $16 \mathrm{~mm}$ fire-rated gypsum plasterboard each side. This wall assembly is commonly constructed as a load-bearing timber-framed wall within apartment units in a multi storey buildings, or as a load-bearing wall supporting a mezzanine floor.

Figure 5.1 shows the predicted time-temperature profile for the cavity side of the exposed and unexposed linings, and the ambient side of the unexposed lining for 13 and $16 \mathrm{~mm}$ fire-rated gypsum plasterboard each side of $90 \mathrm{~mm}$ x $45 \mathrm{~mm}$ timber framing. The wall was subjected to the ISO 834 standard fire time-temperature curve. 


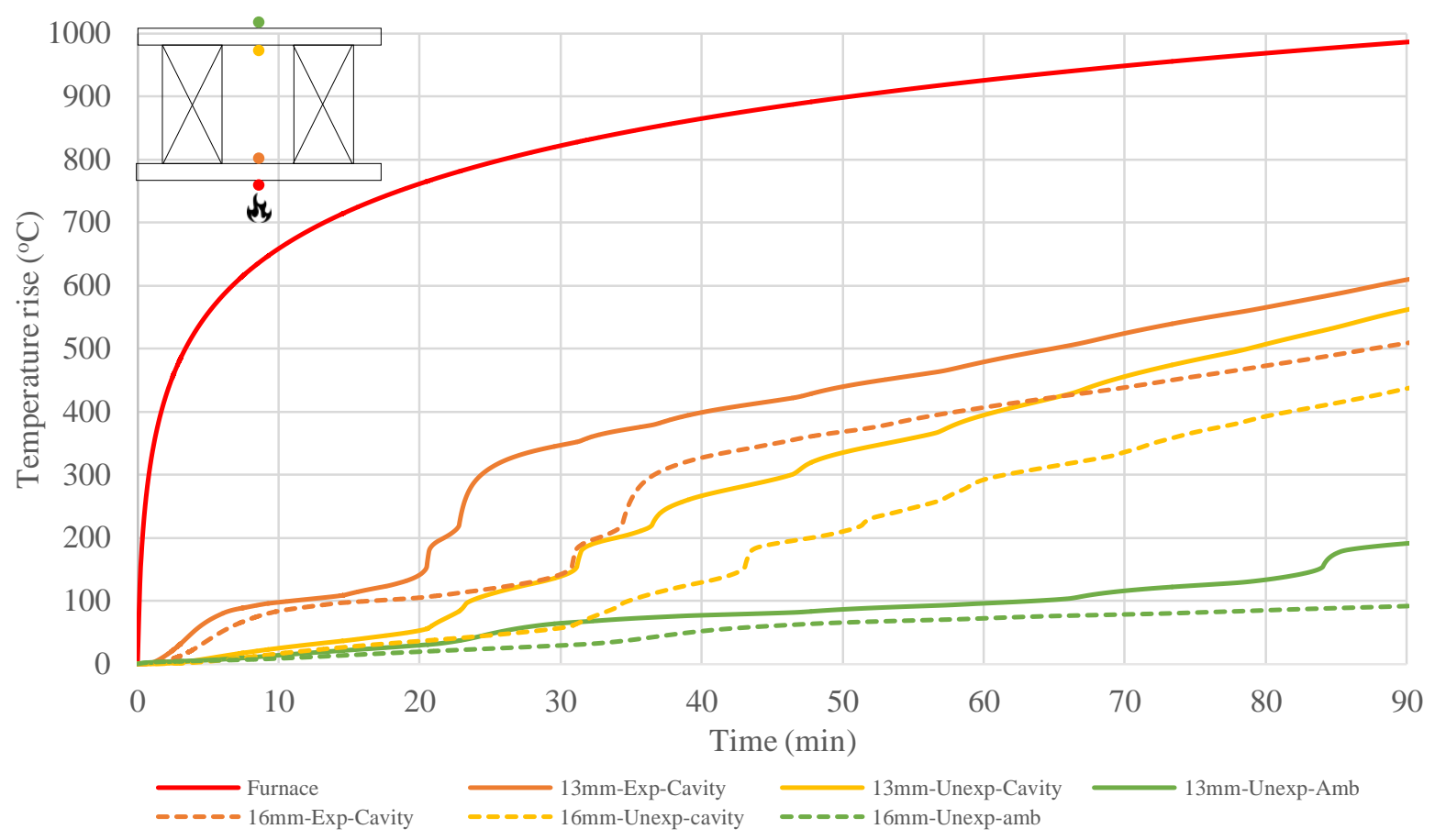

Figure 5.1 - Predicted time-temperature profiles for 13 and $16 \mathrm{~mm}$ fire-rated gypsum plasterboard subjected to one-sided fire exposure

It can be seen that the time-temperature profiles of both thicknesses had a similar trend but the length of plateau for $16 \mathrm{~mm}$ fire-rated gypsum plasterboard was longer than $13 \mathrm{~mm}$ which is a function of the thickness of gypsum plasterboard as well as its density and formulation. The plateau at $100{ }^{\circ} \mathrm{C}$ is due to free water and water of crystallisation being driven off. Once the gypsum plasterboard is fully dehydrated, the temperature increases again.

A plateau for the cavity side of unexposed lining occurs at a lower temperature than the exposed lining due to the wall cavity between the linings. The ambient side of the unexposed lining is at an even lower temperature.

Figures 5.3 and 5.5 show the temperature contours across the modelled wall assembly subjected to one-sided fire exposure for 13 and $16 \mathrm{~mm}$ thicknesses respectively at 15 minute intervals obtained from the Abaqus/CAE. In order to distinguish the position of the 300-degree isotherm on the temperature contours in Figures 5.3 and 5.5 and to easily locate the line of timber char, the maximum contour value was set to $300{ }^{\circ} \mathrm{C}$. It was observed that the thickness of gypsum plasterboard played an important role to delay the heat transfer to the timber stud resulting in a longer structural adequacy failure time with thicker gypsum plasterboard. 


\subsection{Two-sided fire exposure thermal modelling result}

Figure 5.2 shows the predicted time-temperature profiles for the cavity side of the exposed 13 and $16 \mathrm{~mm}$ fire-rated gypsum plasterboard each side of $90 \mathrm{~mm}$ x $45 \mathrm{~mm}$ timber framing when subjected to two-sided ISO 834 standard fire exposure.

It can be seen that the length of plateau for both thicknesses was very similar to those observed in one-sided fire exposure predictions. However, the temperature rapidly increased once the gypsum plasterboard became fully dehydrated, and then it followed the logarithmic trend similar to the ISO 834 standard fire time-temperature curve.

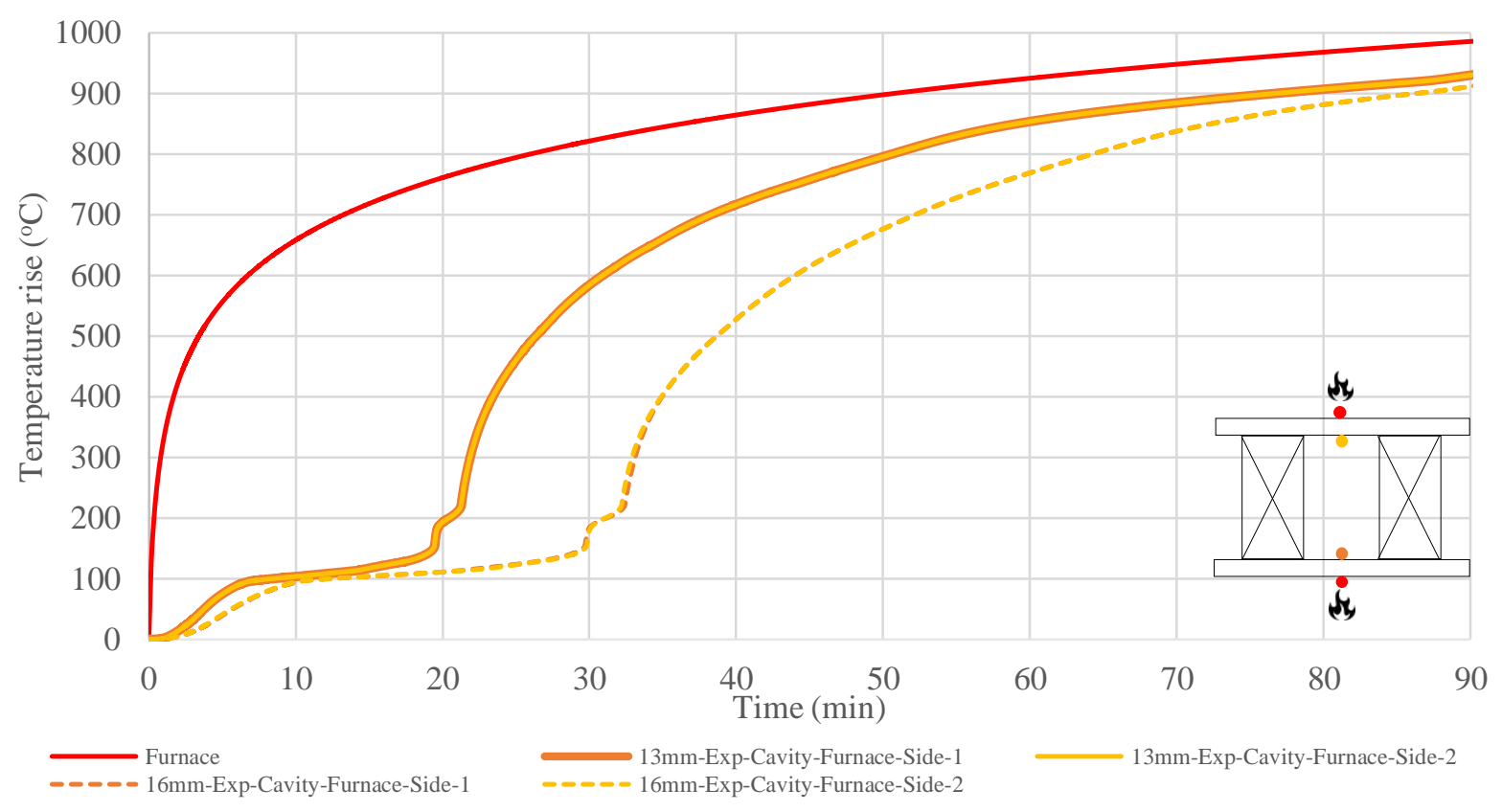

Figure 5.2 - Predicted time-temperature profiles for 13 and $16 \mathrm{~mm}$ fire-rated gypsum plasterboard subjected to two-sided fire exposure

The temperature contours across the gypsum plasterboard lined wall subjected to two-sided fire exposure for 13 and $16 \mathrm{~mm}$ thicknesses respectively at 15 minute intervals are shown in Figures 5.4 and 5.6 which were obtained from the Abaqus/CAE. The residual timber stud sections were found to be larger with thicker gypsum plasterboard at each interval which confirmed that a longer structural adequacy failure time was expected for the timber-framed wall lined with thicker gypsum plasterboard. 

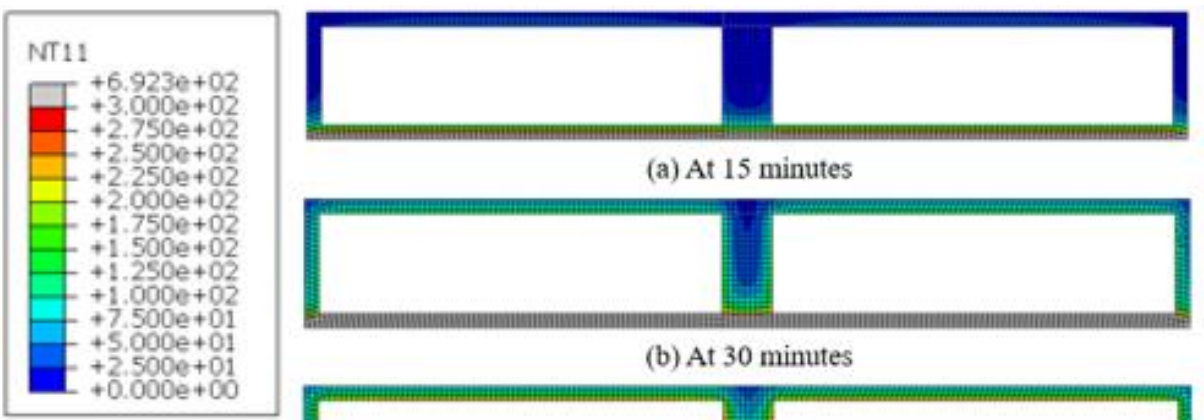

(a) At 15 minutes

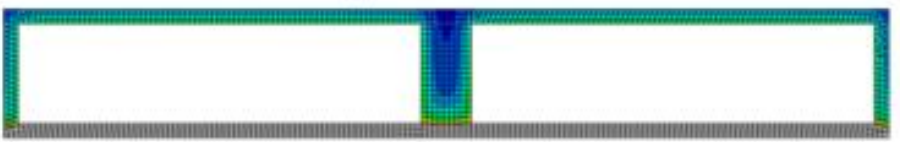

(b) At 30 minutes
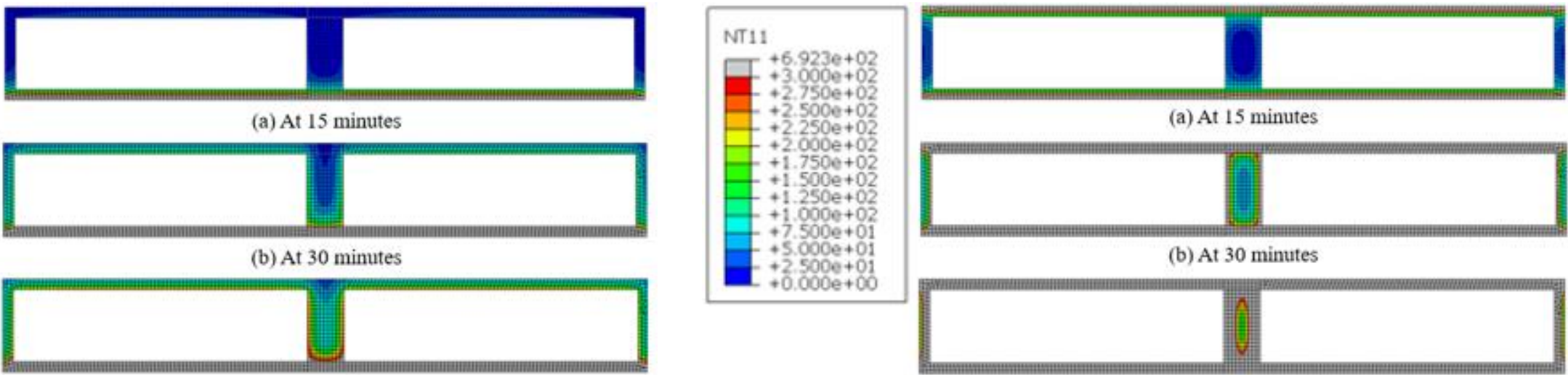

(a) At 15 minutes

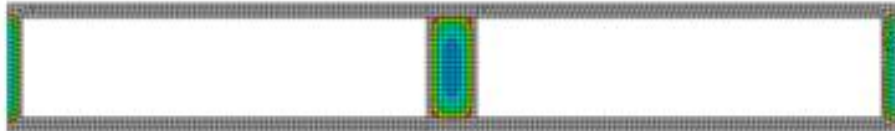

(b) At 30 minutes

(c) At 45 minutes

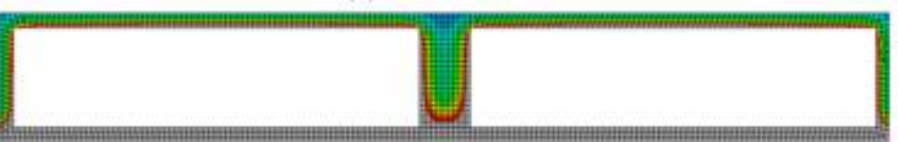

(d) At 60 minutes

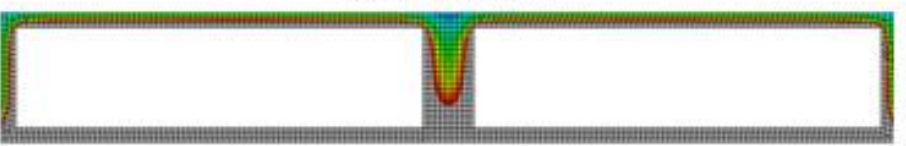

(e) At 75 minutes

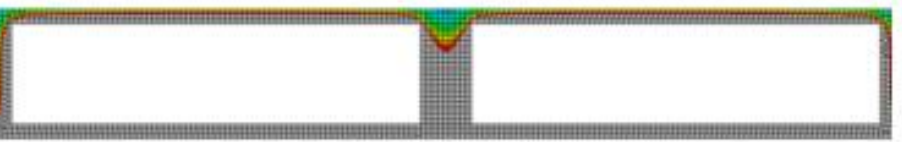

(e) At 90 minutes

Figure 5.3 - Temperature contours across the $13 \mathrm{~mm}$ fire-rated gypsum plasterboard lined wall assembly subjected to one-sided fire exposure

Figure 5.4 - Temperature contours across the $13 \mathrm{~mm}$ fire-rated gypsum plasterboard lined wall assembly subjected to two-sided fire exposure 

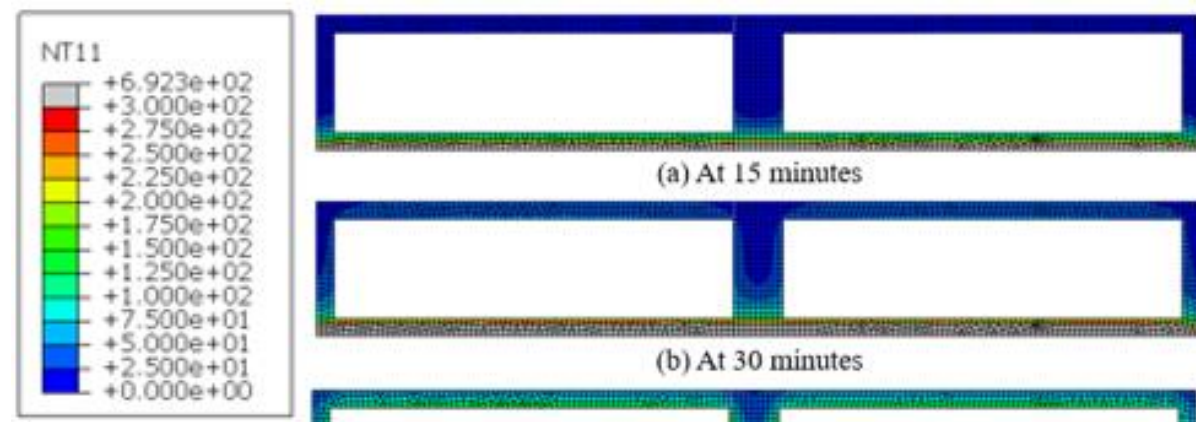

(a) At 15 minutes

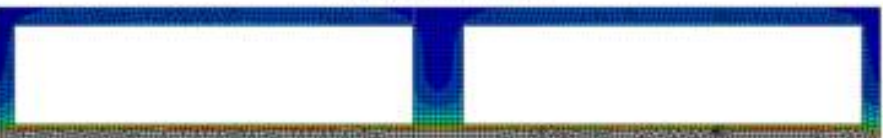

(b) At 30 minutes

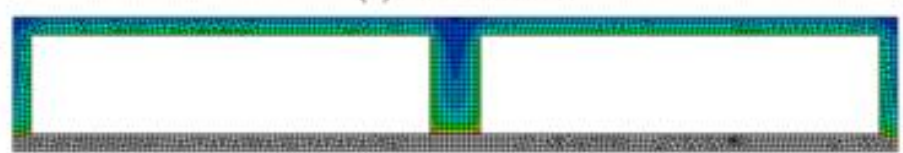

(c) At 45 minutes

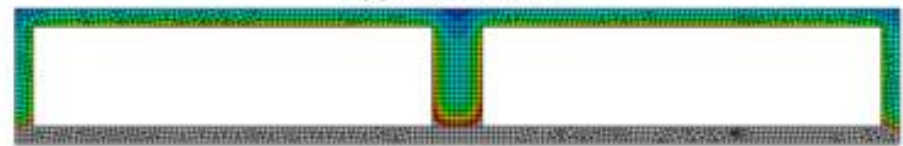

(d) At 60 minutes

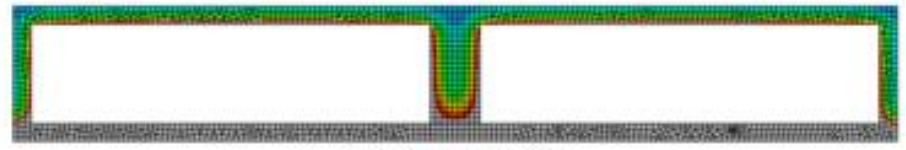

(e) At 75 minutes

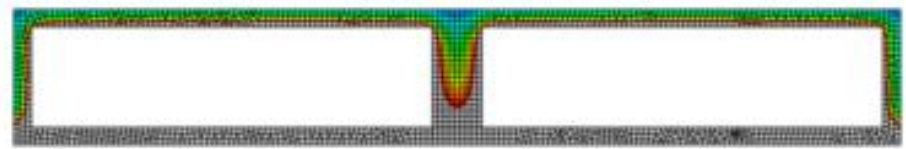

(e) At 90 minutes

Figure 5.5 - Temperature contours across the $16 \mathrm{~mm}$ fire-rated gypsum plasterboard lined wall assembly subjected to one-sided fire exposure
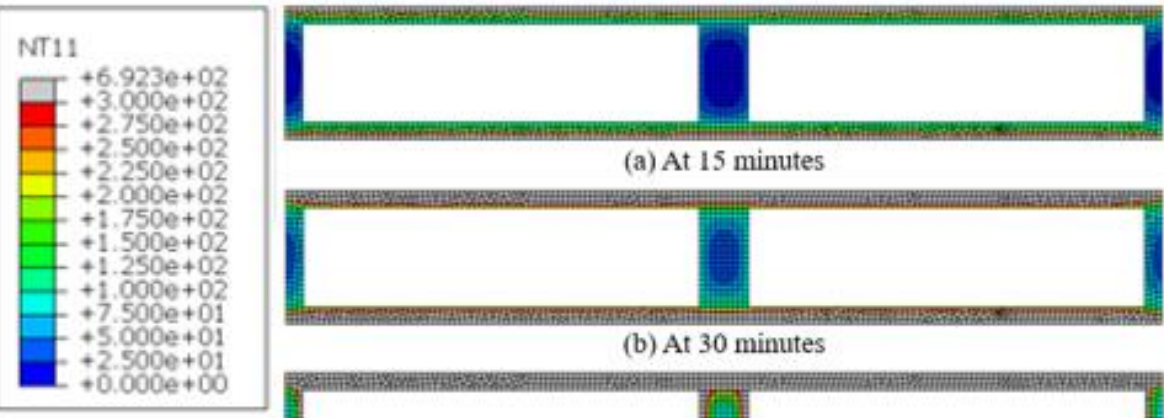

(a) At 15 minutes

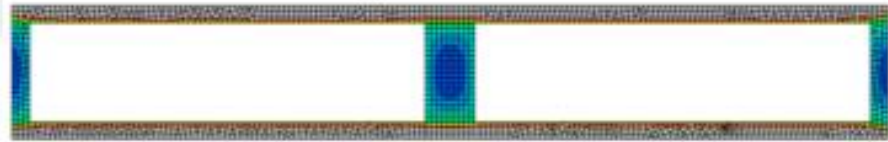

(b) At 30 minutes

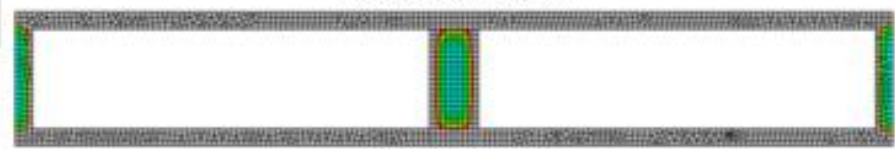

(c) At 45 minutes

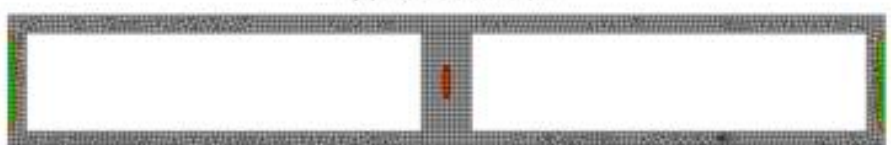

(d) At 60 minutes
Figure 5.6 - Temperature contours across the $16 \mathrm{~mm}$ fire-rated gypsum plasterboard lined wall assembly subjected to two-sided fire exposure 


\subsection{One-sided fire exposure structural modelling result}

The structural model was developed to predict the performance of a typical fire-rated wall assembly subjected to one-sided fire exposure and different axial loads. The predicted structural adequacy failure times for $90 \mathrm{~mm}$ x $45 \mathrm{~mm}$ timber studs lined with 13 and $16 \mathrm{~mm}$ fire-rated gypsum plasterboard are summarised in Tables 5.1 and 5.2. The timber studs were subjected to axial loads based on six different load ratios of 0.8, 0.6, 0.4, 0.2, 0.17 and 0.08. The load ratio is defined as the ratio of applied axial load and critical axial capacity of the timber stud under ambient conditions. The load ratios of 0.17 and 0.08 were included to reflect typical axial loads to load-bearing timber-framed walls designed in accordance with NZS 3604:2011 [27].

Table 5.1 - Predicted structural adequacy failure time of timber stud lined with $13 \mathrm{~mm}$ fire-rated gypsum plasterboard subjected to one-sided fire exposure

\begin{tabular}{|c|c|c|c|}
\hline $\begin{array}{c}\text { Predicted ambient critical } \\
\text { load }(\mathrm{kN})\end{array}$ & Load ratio & $\begin{array}{c}\text { Applied axial load } \\
(\mathrm{kN})\end{array}$ & $\begin{array}{c}\text { Predicted failure time } \\
(\mathrm{min})\end{array}$ \\
\hline 23.7 & 0.8 & 19.0 & 40 \\
\hline 23.7 & 0.6 & 14.2 & 45 \\
\hline 23.7 & 0.4 & 9.5 & 69 \\
\hline 23.7 & 0.2 & 4.7 & 71 \\
\hline 23.7 & 0.17 & 4.0 & 78 \\
\hline 23.7 & 0.08 & 2.0 & 59 \\
\hline
\end{tabular}

Table 5.2 - Predicted structural adequacy failure time of timber stud lined with $16 \mathrm{~mm}$ fire-rated gypsum plasterboard subjected to one-sided fire exposure

\begin{tabular}{|c|c|c|c|}
\hline $\begin{array}{c}\text { Predicted ambient critical } \\
\text { load }(\mathrm{kN})\end{array}$ & Load ratio & $\begin{array}{c}\text { Applied axial load } \\
(\mathrm{kN})\end{array}$ & $\begin{array}{c}\text { Predicted failure time } \\
(\mathrm{min})\end{array}$ \\
\hline 23.7 & 0.8 & 19.0 & 54 \\
\hline 23.7 & 0.6 & 14.2 & 73 \\
\hline 23.7 & 0.4 & 9.5 & 88 \\
\hline 23.7 & 0.2 & 4.7 & 90 \\
\hline 23.7 & 0.17 & 4.0 & 98 \\
\hline 23.7 & 0.08 & 2.0 & \\
\hline
\end{tabular}


Figure 5.7 shows the relationship between predicted structural adequacy failure time and load ratio under one-sided fire exposure. It can be seen that the predicted structural adequacy failure times increased exponentially when the load ratio was reduced. It is also noted that the predicted structural adequacy failure time of timber studs lined with $13 \mathrm{~mm}$ fire-rated gypsum plasterboard increased at almost the same rate as those with $16 \mathrm{~mm}$ fire-rated gypsum plasterboard. Further discussions are presented in Section 7.2.

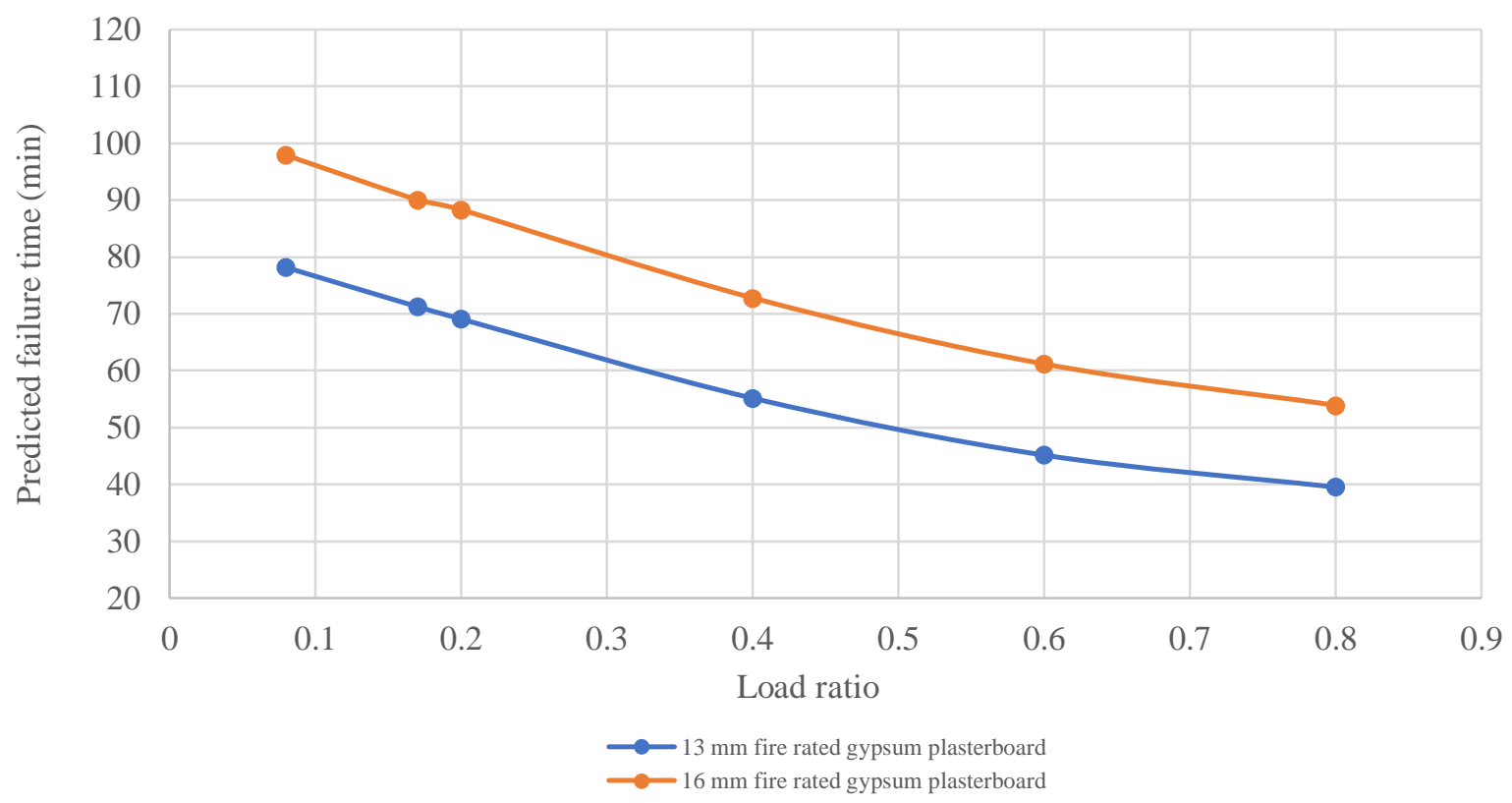

Figure 5.7 - Variation of predicted structural adequacy failure time with load ratio under one-sided fire exposure

\subsection{Two-sided fire exposure structural modelling result}

The structural model was developed to predict the performance of a typical fire-rated wall assembly subjected to two-sided fire exposure and different axial loads. Similar to the finite element structural model for one-sided fire exposure, typical $90 \mathrm{~mm}$ x $45 \mathrm{~mm}$ timber-framed wall assemblies with 13 and 16 mm fire-rated gypsum plasterboard were investigated.

The sequentially coupled temperature-displacement finite element analysis result for a $90 \mathrm{x} 45$ x $2910 \mathrm{~mm}$ timber stud subjected to an axial load of $2 \mathrm{kN}$ and time-temperature profiles behind $13 \mathrm{~mm}$ fire-rated gypsum plasterboard under two-sided fire exposure is shown in Figure 5.8. In contrast to the structural model result for one-sided fire exposure, which showed the failure mode of global buckling about $\mathrm{x}$-axis towards the ambient side, an axial compression failure mode was observed for two-sided fire exposure. 


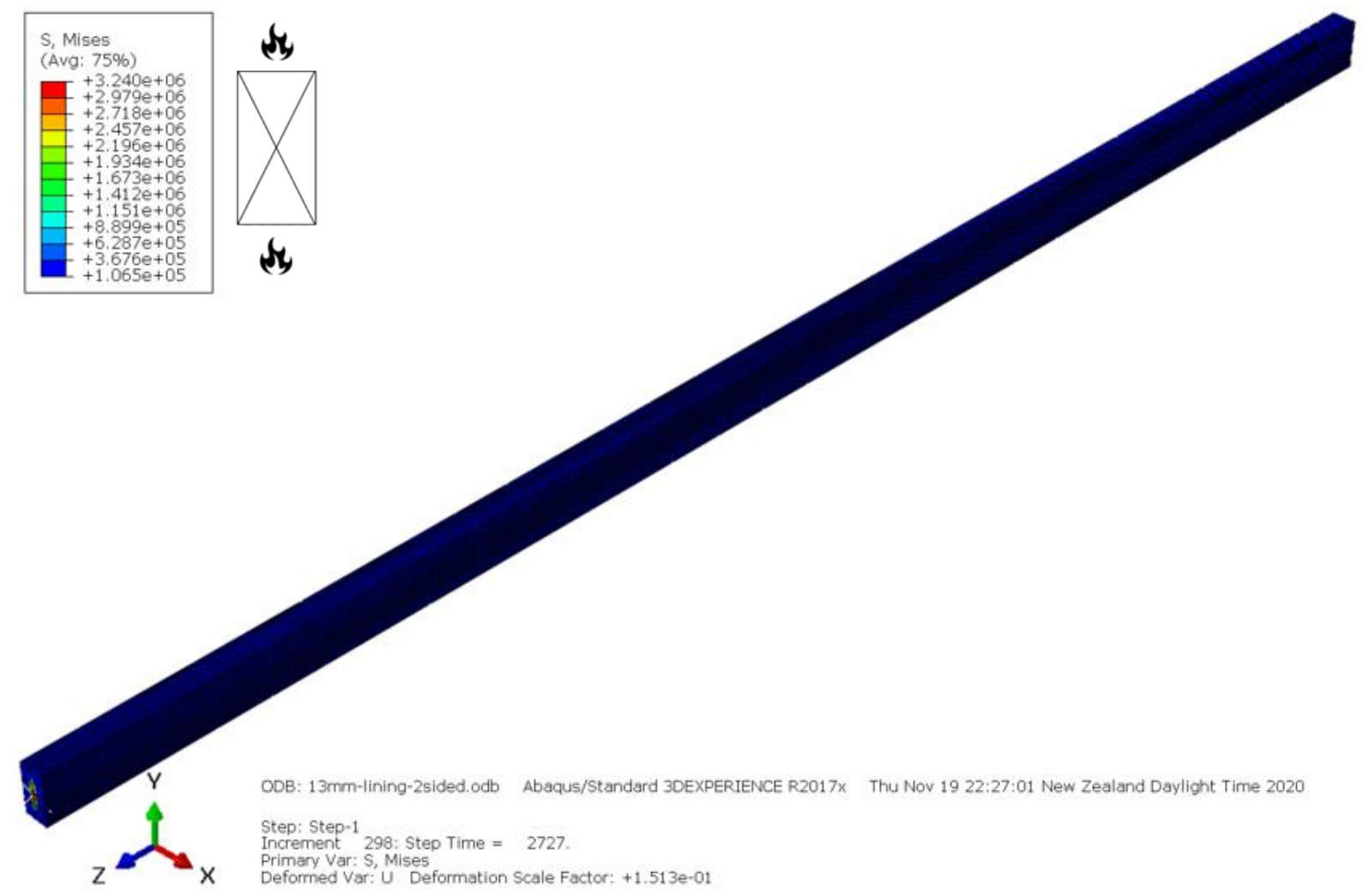

Figure 5.8 - Axial compression failure mode of $90 \times 45 \times 2910 \mathrm{~mm}$ timber stud subjected to two-sided fire exposure

Tables 5.3 and 5.4 show the predicted structural adequacy failure times of timber studs lined with 13 and $16 \mathrm{~mm}$ fire-rated gypsum plasterboard respectively when subjected to two-sided fire exposure. The timber stud was subjected to axial loads based on the same six load ratios as discussed in Section 5.4.

Table 5.3 - Predicted structural adequacy failure time of timber stud lined with $13 \mathrm{~mm}$ fire-rated gypsum plasterboard subjected to two-sided fire exposure

\begin{tabular}{|c|c|c|c|}
\hline $\begin{array}{c}\text { Predicted ambient critical } \\
\text { load }(\mathrm{kN})\end{array}$ & Load ratio & $\begin{array}{c}\text { Applied axial load } \\
(\mathrm{kN})\end{array}$ & $\begin{array}{c}\text { Predicted failure time } \\
(\mathrm{min})\end{array}$ \\
\hline 23.7 & 0.8 & 19.0 & 29 \\
\hline 23.7 & 0.6 & 14.2 & 32 \\
\hline 23.7 & 0.4 & 9.5 & 42 \\
\hline 23.7 & 0.2 & 4.7 & 43 \\
\hline 23.7 & 0.17 & 4.0 & 45 \\
\hline 23.7 & 0.08 & 2.0 & \\
\hline
\end{tabular}


Table 5.4 - Predicted structural adequacy failure time of timber stud lined with 16 mm fire-rated gypsum plasterboard subjected to two-sided fire exposure

\begin{tabular}{|c|c|c|c|}
\hline $\begin{array}{c}\text { Predicted ambient critical load } \\
(\mathrm{kN})\end{array}$ & Load ratio & $\begin{array}{c}\text { Applied axial load } \\
(\mathrm{kN})\end{array}$ & $\begin{array}{c}\text { Predicted failure time } \\
(\mathrm{min})\end{array}$ \\
\hline 23.7 & 0.8 & 19.0 & 39 \\
\hline 23.7 & 0.6 & 14.2 & 42 \\
\hline 23.7 & 0.4 & 9.5 & 56 \\
\hline 23.7 & 0.2 & 4.7 & 54 \\
\hline 23.7 & 0.17 & 4.0 & 57 \\
\hline 23.7 & 0.08 & 2.0 & 53 \\
\hline
\end{tabular}

The relationship between predicted structural adequacy failure time and load ratio under twosided fire exposure is shown in Figure 5.9.

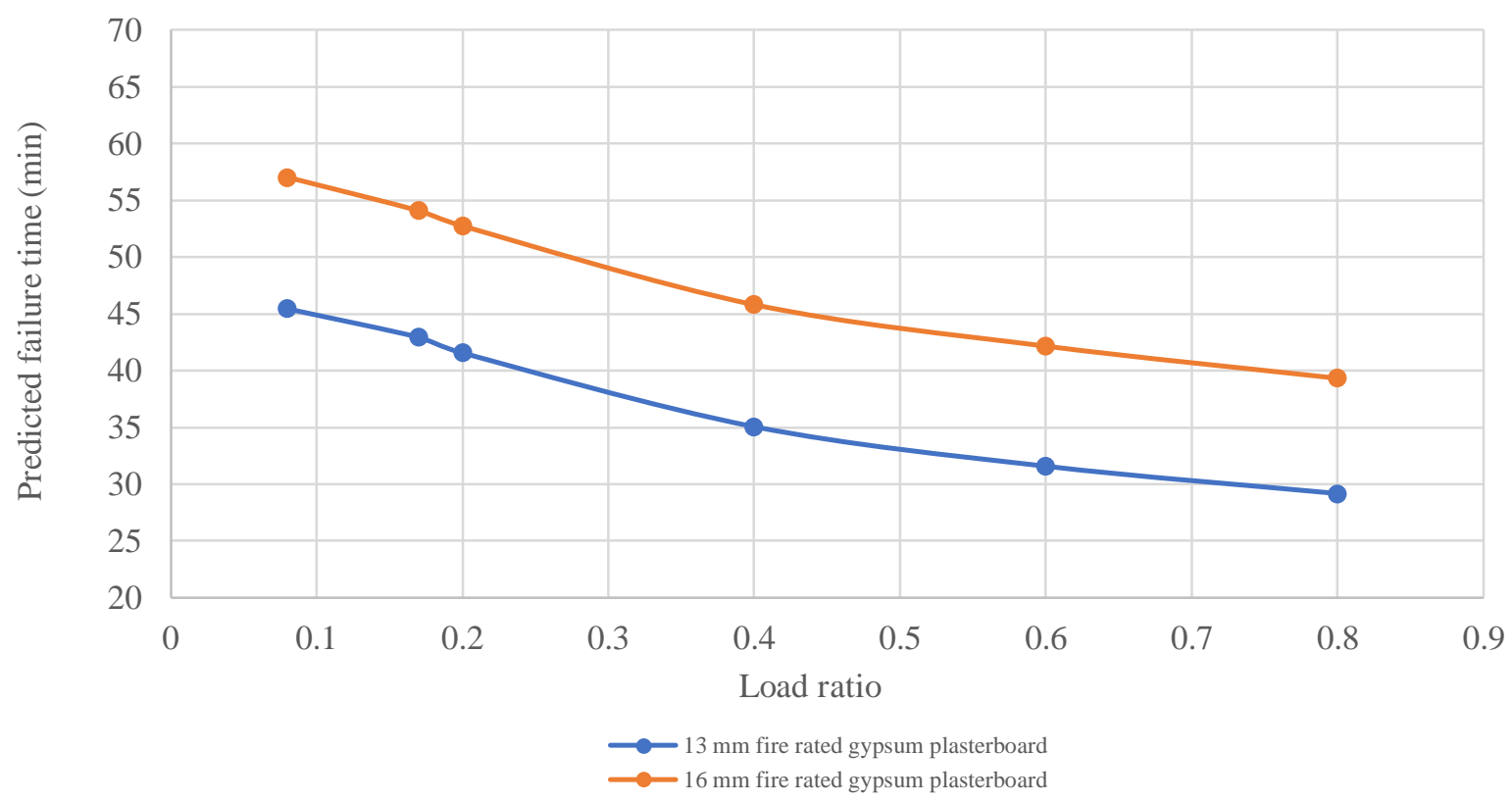

Figure 5.9 - Variation of predicted structural adequacy failure time with load ratio under two-sided fire exposure

It can be seen that predicted structural adequacy failure times significantly reduced as fire exposure increased from one to two-sided as more timber charring occurred on all four sides of the stud which is further discussed in Section 7.2.

It was also observed that the predicted structural adequacy failure time of timber studs lined with thicker gypsum plasterboard were longer as the thickness of gypsum plasterboard plays an important role to delay the cavity temperature rise and heat transfer to the timber stud. 
Similar to the findings from the fire structural model for one-sided fire exposure, the predicted structural adequacy failure times increased exponentially with decreasing load ratios, and the predicted structural adequacy failure time of timber stud lined with 13 and $16 \mathrm{~mm}$ fire-rated gypsum plasterboard increased at almost the same rate. 


\section{Experimental Fire-resistance Tests}

\subsection{Introduction}

As discussed in Chapter 1, neither regulation nor test methods exist to reliably measure the performance of gypsum plasterboard lined timber and steel-framed walls exposed to fire on both sides simultaneously. Extensive numerical and experimental research has been carried out to investigate the performance of gypsum plasterboard lined wall assemblies subjected to onesided fire exposure, but fire-rated wall systems that are currently available from various gypsum plasterboard manufacturers are neither tested nor intended for two-sided fire exposure. This chapter presents details of the experimental program, the testing facilities, the wall specimen details and test configuration, designed to expose load-bearing timber-framed wall specimens on both sides simultaneously. Observations of the three full-scale fire-resistance tests, and the experiment analyses of furnace temperature, loading, axial displacement and structural adequacy are also presented.

The objective of the program was to obtain valuable experimental data to assist with formulating a design methodology that predicts the structural adequacy of load-bearing gypsum plasterboard lined timber-framed walls subjected to two-sided fire exposure.

\subsection{Testing facilities}

The experimental program was conducted at the fire testing laboratory of the Building Research Association of New Zealand (BRANZ). This laboratory is accredited to the ISO/IEC 17025 laboratory standard by International Accreditation New Zealand (IANZ) for testing the fire performance of building elements. BRANZ is also recognised by the National Association of Testing Authorities (NATA) and registered under provisions of the National Construction Code (NCC) of the Building Code of Australia.

The full-scale fire furnace and specimen holder in the BRANZ laboratory are shown in Figure 6.1. The full-scale fire furnace is 3 metres wide and 4 metres high and fuelled by liquefied petroleum gas (LPG). Vertical specimens are built in the specimen holder which is placed on a rail mounted trolley to allow the specimen to roll up to the face of the fire furnace [47]. The furnace temperature is monitored by twelve mineral insulated metal sheathed (MIMS) chromel-alumel thermocouples and manually controlled by a fire laboratory 
technician. These thermocouples are uniformly distributed in a vertical plane as shown in Figure 6.1(a) and located approximately $100 \mathrm{~mm}$ away from the exposed face of the wall specimen. The thermocouples are then connected to a computer-controlled data logging system.

The bottom platen of the specimen holder shown in Figure 6.1(b) is free to move in the vertical axis. Hydraulic jacks located below the platen are used to apply a uniformly distributed axial load to the specimen. The amount of applied axial load is monitored using a load cell that is connected to the computer-controlled data logging system.

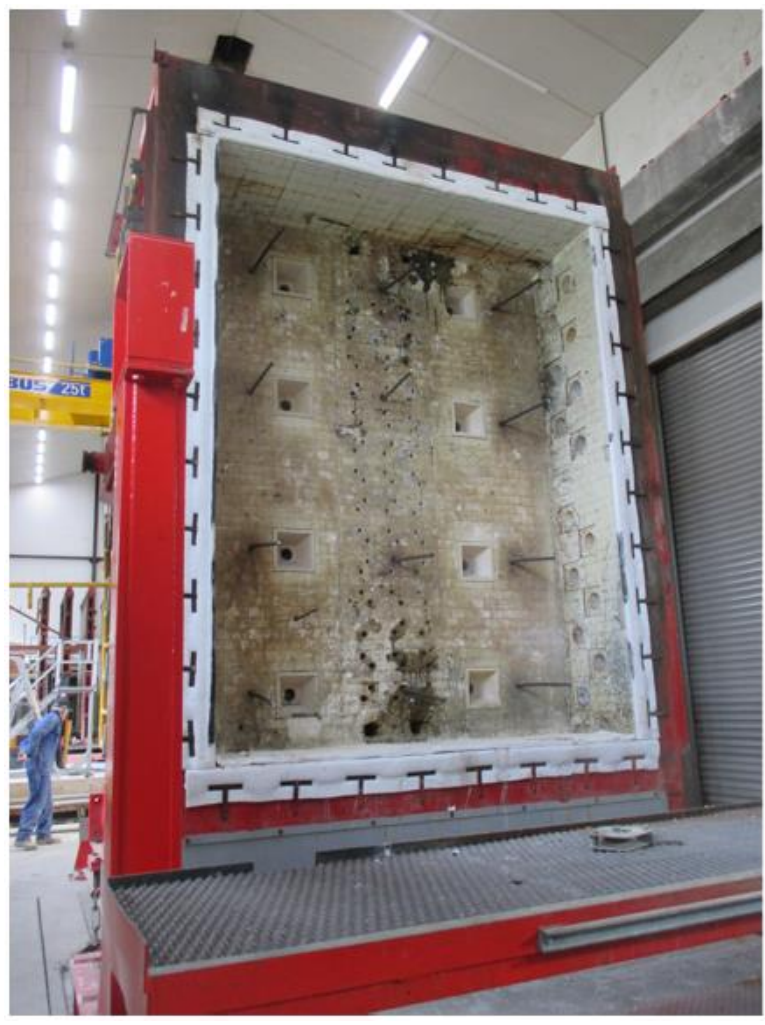

(a)

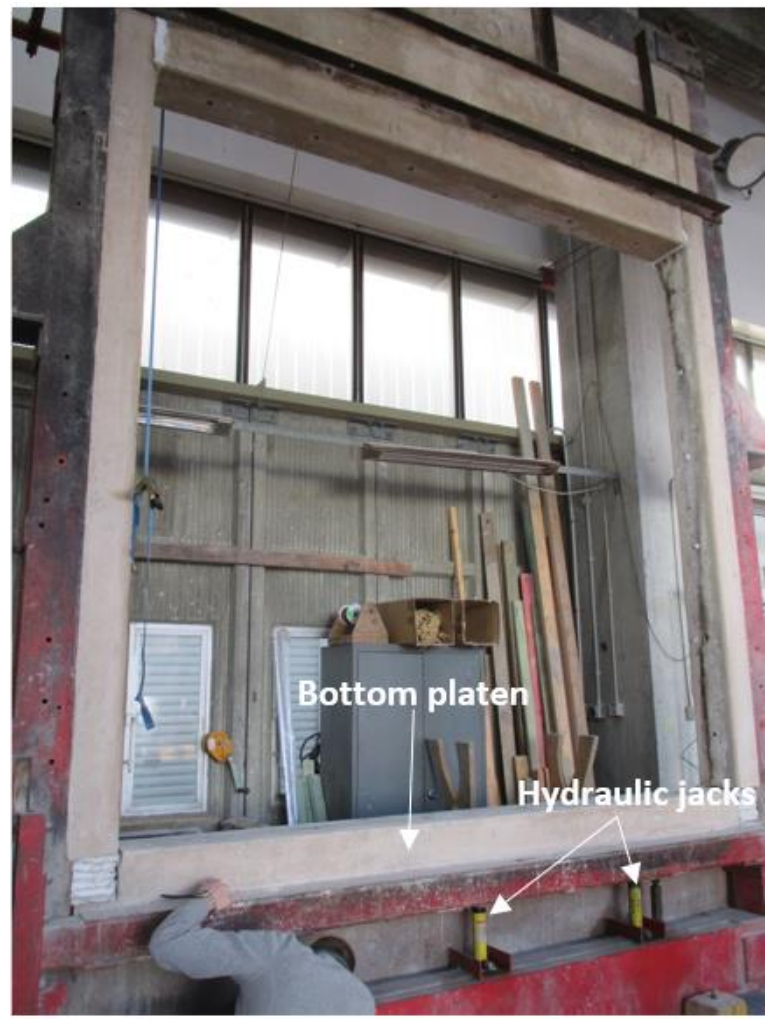

(b)

Figure 6.1 - (a) Full-scale fire furnace and (b) specimen holder in the BRANZ fire testing laboratory

\subsection{Experimental program}

As previously mentioned, the fire-resistance wall test method stipulated in AS 1530.4:2014 does not consider two-sided fire exposure to load-bearing wall specimens, and hence the standard fire-resistance test configuration and procedure must be modified to achieve fire exposure to both sides of the specimen. The fire-resistance test configuration to expose the 
load-bearing wall specimen from two sides simultaneously is shown in Figures 6.2 and 6.3. The detailed specimen drawing for the three full-scale fire-resistance tests is presented in Appendix F.

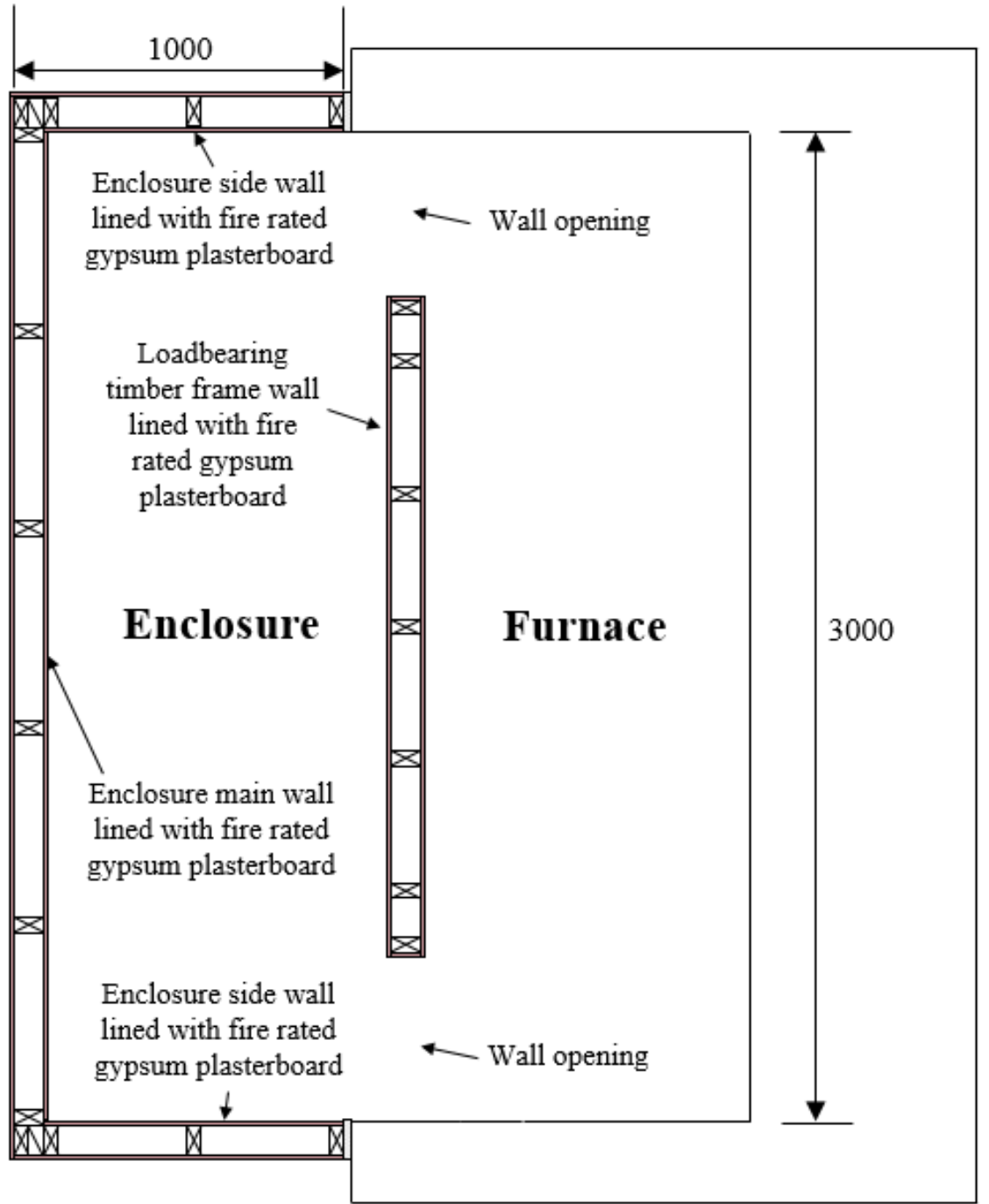

Figure 6.2 - Two-sided fire exposure fire-resistance test configuration (plan view) 


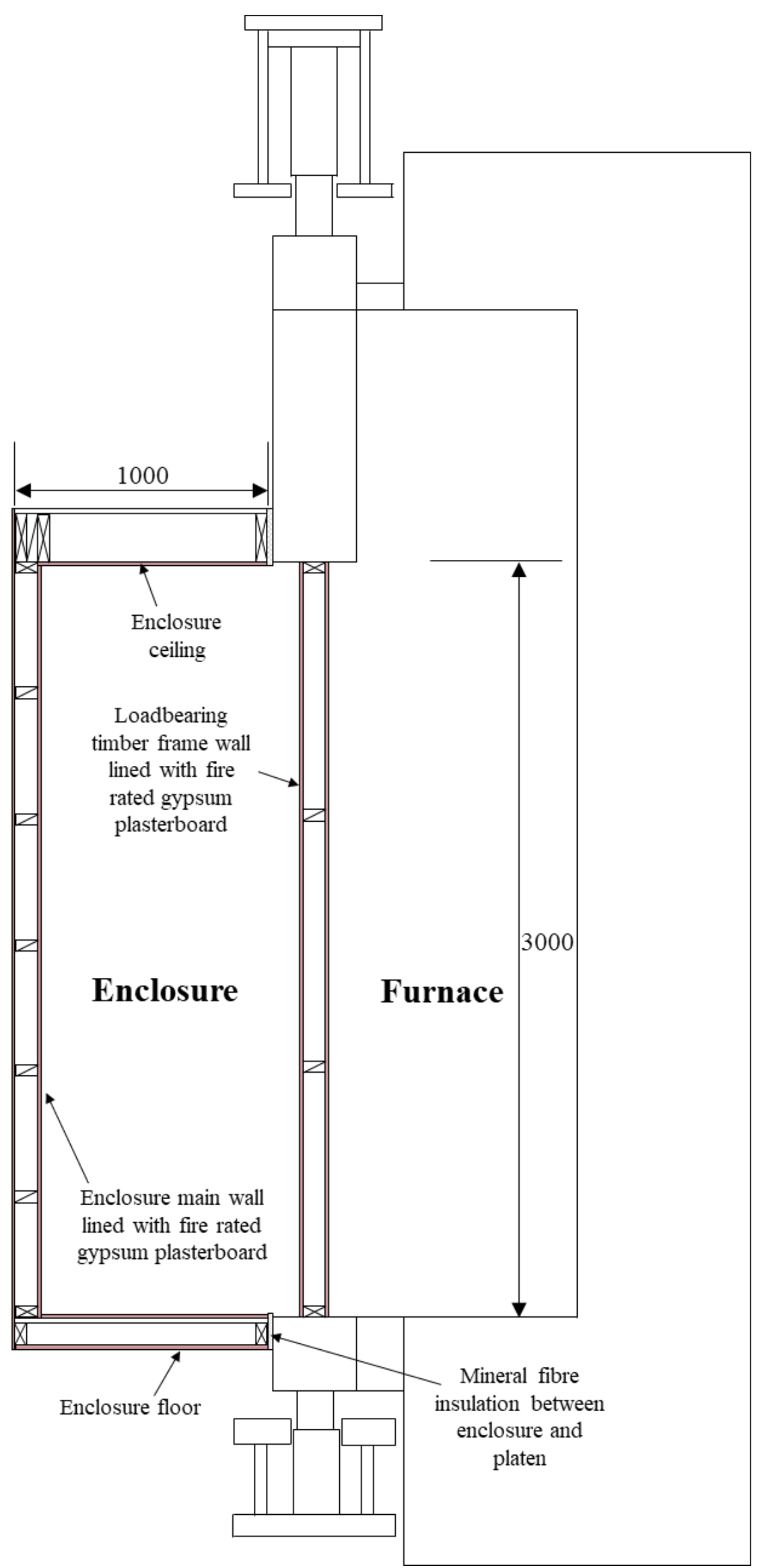

Figure 6.3 - Two-sided fire exposure fire-resistance test configuration (section view) 
The experimental program comprised three full-scale fire-resistance tests. Wall specimens consisted of $90 \mathrm{~mm}$ x $45 \mathrm{~mm}$ timber studs which are typically used in a timber-framed wall assembly according to the BRANZ New Dwellings Survey [30]. The specimen details such as wall dimension, width of wall opening at each end of the specimen, axial loading per stud and thickness of fire-rated gypsum plasterboard are provided in Table 6.1.

Table 6.1 - Full-scale fire-resistance test specimens for two-sided fire exposure

\begin{tabular}{|c|c|c|c|c|}
\hline $\begin{array}{c}\text { BRANZ test } \\
\text { number }\end{array}$ & $\begin{array}{c}\text { Wall dimension, } \\
\text { width } \times \text { height } \\
(\mathrm{m})\end{array}$ & $\begin{array}{c}\text { Width of wall } \\
\text { opening } \\
(\mathrm{mm})\end{array}$ & $\begin{array}{c}\text { Axial } \\
\text { load per } \\
\text { stud }(\mathrm{kN})\end{array}$ & $\begin{array}{c}\text { Fire-rated gypsum } \\
\text { plasterboard thickness } \\
(\mathrm{mm})\end{array}$ \\
\hline QR1810-161 & $2.0 \times 3.0$ & 500 & 2 & 1 layer of $13 \mathrm{~mm}$ each side \\
\hline QR1810-162 & $2.0 \times 3.0$ & 500 & 4 & 1 layer of $16 \mathrm{~mm}$ each side \\
\hline QR1810-163 & $1.5 \times 3.0$ & 750 & 4 & 1 layer of $13 \mathrm{~mm}$ each side \\
\hline
\end{tabular}

The load-bearing wall specimen was subjected to an axial load between 2 to $4 \mathrm{kN}$ per stud, which is the most commonly adopted in load-bearing walls designed in accordance with NZS 3604:2011. The shortened load-bearing wall specimen had a 500 to $750 \mathrm{~mm}$ wide wall opening at each end to achieve exposure from both sides simultaneously.

The first experiment was conducted with the timber-framed wall specimen with five loadbearing studs at $400 \mathrm{~mm}$ centres and one non-load-bearing stud at each end for an equal axial load distribution. The wall specimen was lined with a single layer of $13 \mathrm{~mm}$ fire-rated gypsum plasterboard each side which provides a 60 minute FRR when subjected to one-sided fire exposure [13]. In the second experiment, the thickness of the fire-rated gypsum plasterboard was changed to $16 \mathrm{~mm}$ which provides a 90 minute FRR when subjected to one-sided fire exposure, and the amount of axial load per stud was increased to $4 \mathrm{kN}$. The third experiment was identical to the first experiment except for an increase of applied axial load and width of wall opening to $4 \mathrm{kN}$ and $750 \mathrm{~mm}$ respectively which resulted in the spacing of timber studs at $300 \mathrm{~mm}$ centres.

\subsection{Specimen details and construction}

In the full-scale standard fire-resistance test, $3 \mathrm{~m}$ wide vertical specimens are fully contained in the specimen holder which can be either 3 or $4 \mathrm{~m}$ high as shown in Figure 6.4(a) [47]. The full-scale fire-resistance tests in this research had a full height opening at each end of the 
shortened load-bearing wall specimen and the furnace was extended beyond the specimen with fire-rated walls and a floor/ceiling assembly as shown in Figure 6.4(b). Five plate thermometers were installed each side of the load-bearing wall specimen to monitor the furnace and enclosure conditions, and to measure temperature and radiation applied to both sides of the load-bearing wall specimen.

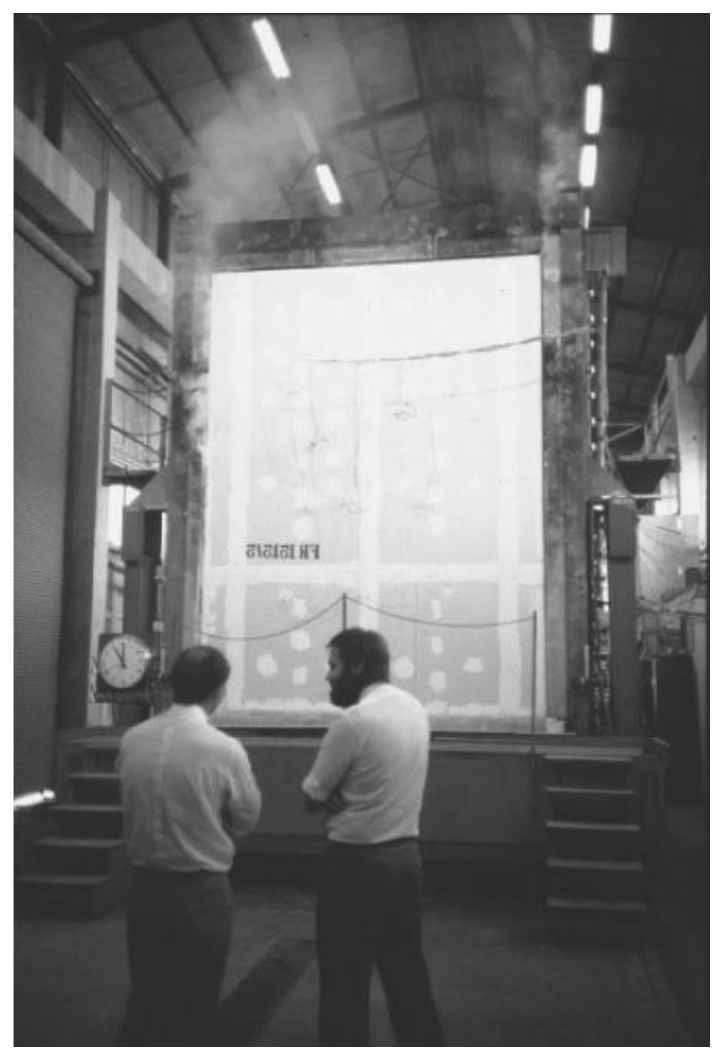

(a)

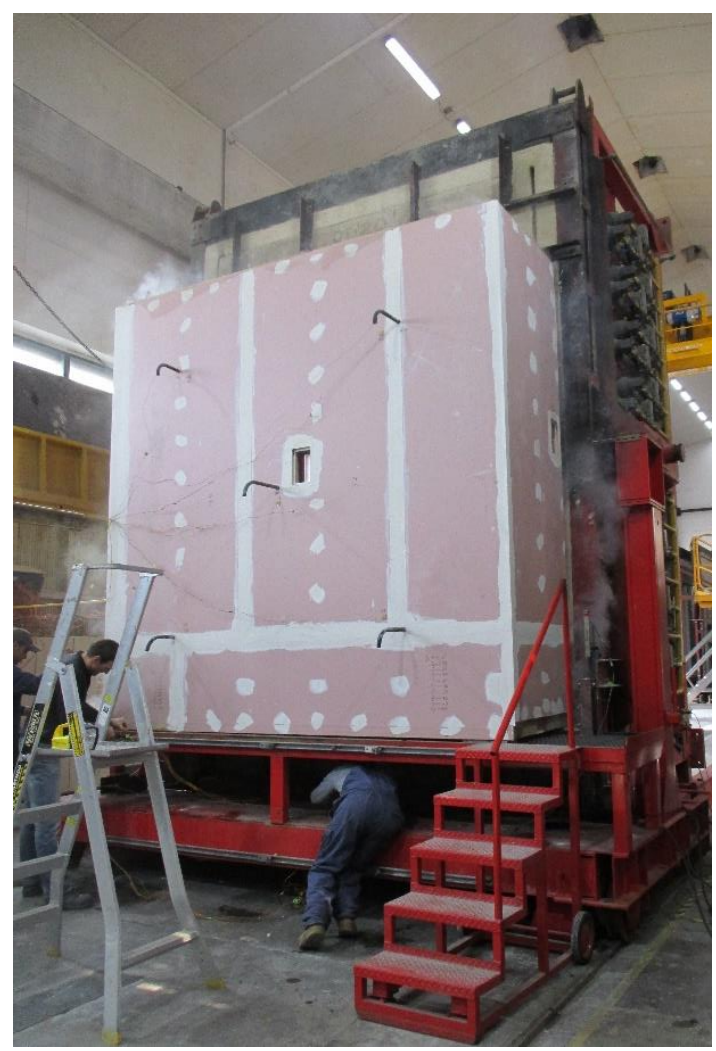

(b)

Figure 6.4 - (a) Full-scale fire-resistance test of a light timber frame wall taken from Buchanan and Abu [1] and (b) modified test for two-sided fire exposure

The enclosure structures, which are further discussed in Section 6.4.1, were fastened to the top and side platens using mechanical screw anchors. The enclosure structures were then placed on the rig trolley for additional support. No mechanical connection was made to the bottom platen and the junction was filled with mineral fibre insulation to allow the bottom platen to freely move when applying the required uniformly distributed axial loading to the specimen.

The load-bearing wall specimen was lined with a suitable fire-rated gypsum plasterboard each side for a 60 or 90 minute FRR when subjected to one-sided fire exposure. However, as failure of the load-bearing wall specimen was anticipated when subjected to two-sided fire exposure, the enclosure was constructed using suitable fire-rated gypsum plasterboard systems that achieve the same FRR as the wall specimen when subjected to one-sided fire exposure. This 
was considered sufficient for the enclosure structures not to reach the failure criteria earlier than the load-bearing wall specimen.

\subsubsection{Specimen and enclosure}

The load-bearing wall specimen and enclosure were constructed of SG8 Radiata pine which complied with the design requirements of NZS 3604:2011 and achieved the engineering properties as specified in NZS 3603:1993 A4.

The load-bearing wall specimen consisted of five load-bearing studs and two non-load-bearing end studs with two rows of timber nogs spaced at 1.0 metre as shown in Figure 6.5(a). This arrangement achieved an equal axial load distribution to the load-bearing studs. As shown in Figure 6.5(c), the non-load-bearing end studs had a $100 \mathrm{~mm}$ gap at mid-height which were temporarily connected using a $200 \mathrm{~mm}$ long $92 \times 32 \times 1.15$ BMT steel channel fixed temporarily with $25 \mathrm{~mm}$ x $6 \mathrm{~g}$ self-tapping drywall screws. Prior to lining the ends of the loadbearing wall specimen, one of the self-tapping drywall screws was removed to ensure the end studs were not loaded during the experiment. The top plate was fastened to the specimen holder using M16 engineering bolts through pre-drilled holes at $500 \mathrm{~mm}$ centres as shown in Figure 6.5(d). The bottom plate was fastened similarly but only at each end, using the inner pre-drilled holes to run thermocouple wires out of the load-bearing wall specimen and connect them to the computer-controlled data logging system.

Figure 6.5(b) shows the enclosure structures consisting of the main wall, two side walls, bottom floor and top floor/ceiling. The continuous boundary joist of the top floor/ceiling and end studs of the two side walls adjacent to the specimen holder were fastened to the top and side platens respectively using $10 \times 140 \mathrm{~mm}$ concrete screw anchors at $1250 \mathrm{~mm}$ centres. Mineral fibre insulation was installed between the timber framing and concrete specimen holder as shown in Figure 6.5(e). Two $150 \times 250 \mathrm{~mm}$ observation windows were installed to observe the loadbearing wall specimen during the experiment. A photo and construction details of the observation window are provided in Figure 6.5(f) and Appendix F respectively. 


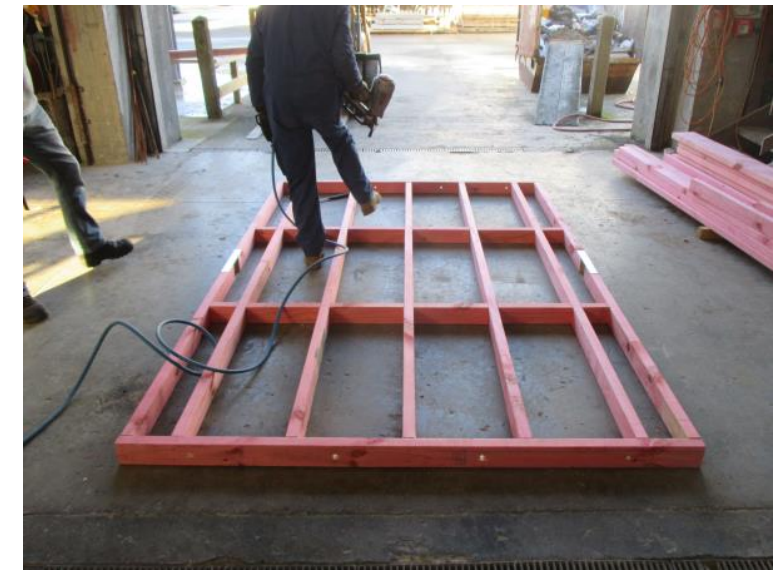

(a) load-bearing wall specimen frame

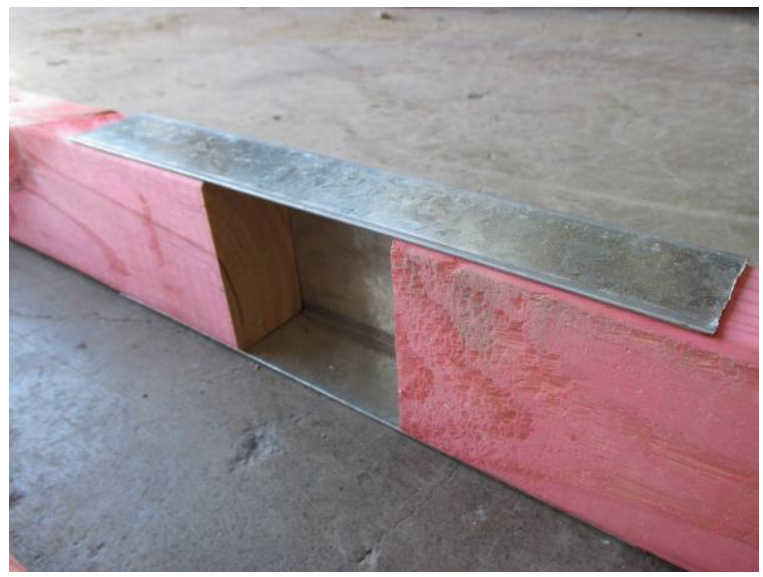

(c) $200 \mathrm{~mm}$ long $92 \times 32 \times 1.15$ BMT steel channel

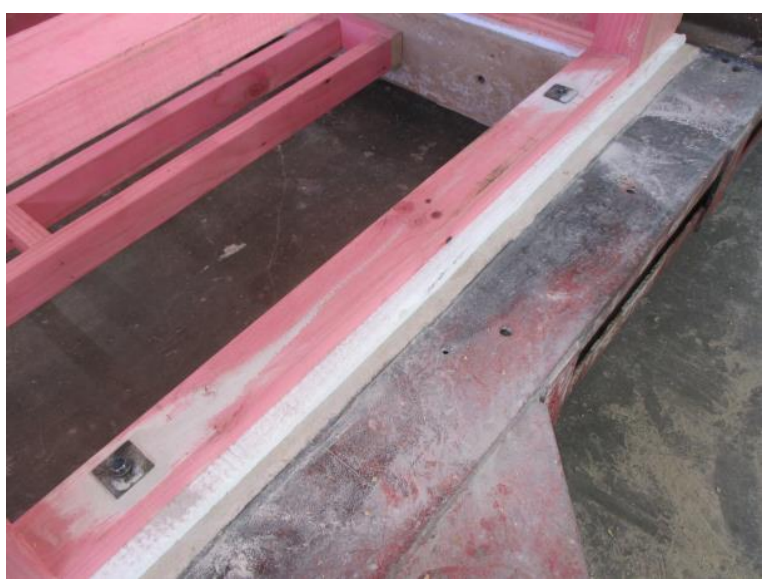

(e) $10 \times 140 \mathrm{~mm}$ screw anchors with square washers

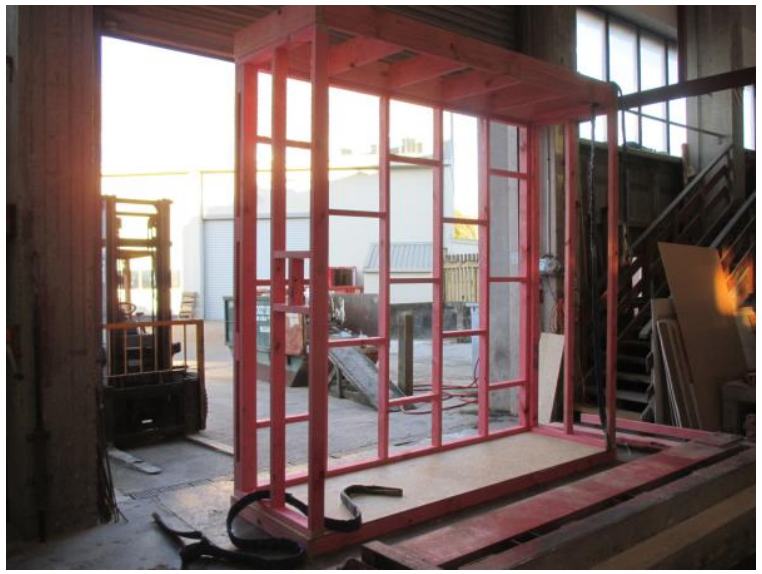

(b) Enclosure structures frames

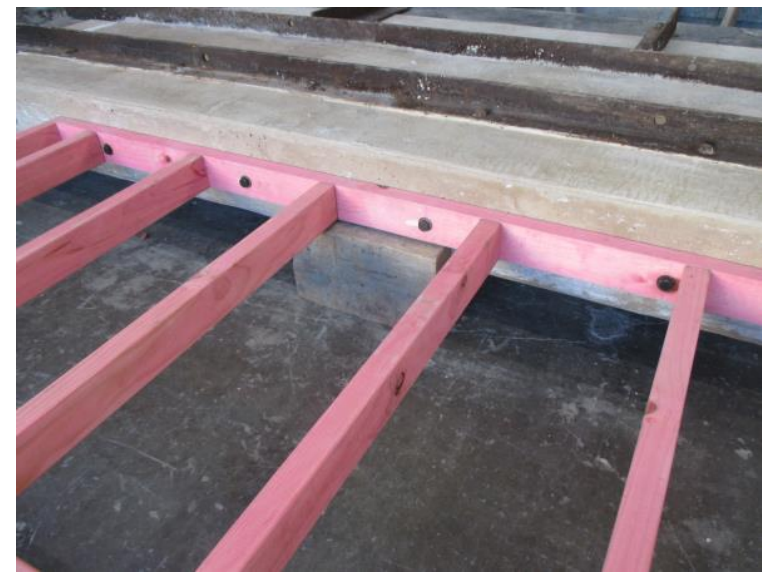

(d) M16 engineering bolts for fastening top plate

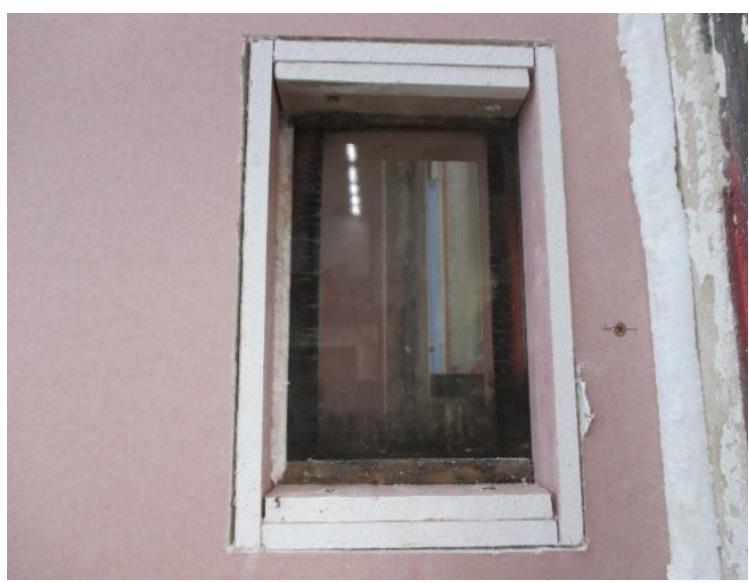

(f) Observation window

Figure 6.5 - Load-bearing specimen and enclosure structures

\subsection{2 'Dummy' stud}

Dummy studs were used to establish an understanding of timber char by monitoring the timetemperature profiles through the timber stud, assuming onset of timber char at $300{ }^{\circ} \mathrm{C}$. 
There were two $90 \times 45 \times 955 \mathrm{~mm}$ dummy timber studs installed in each experiment located within the wall cavity between the timber nogs. Both dummy studs were instrumented with 9 sheathed wire thermocouples which were embedded into one side of the dummy studs at 60 degrees as shown in Figure 6.6(a). The sectioned dummy studs were then glued back together and left to be fully cured as shown in Figure 6.6(b) prior to locating them within the wall cavity. Figure 6.6(c) shows the dummy studs installed within the load-bearing wall specimen cavity.

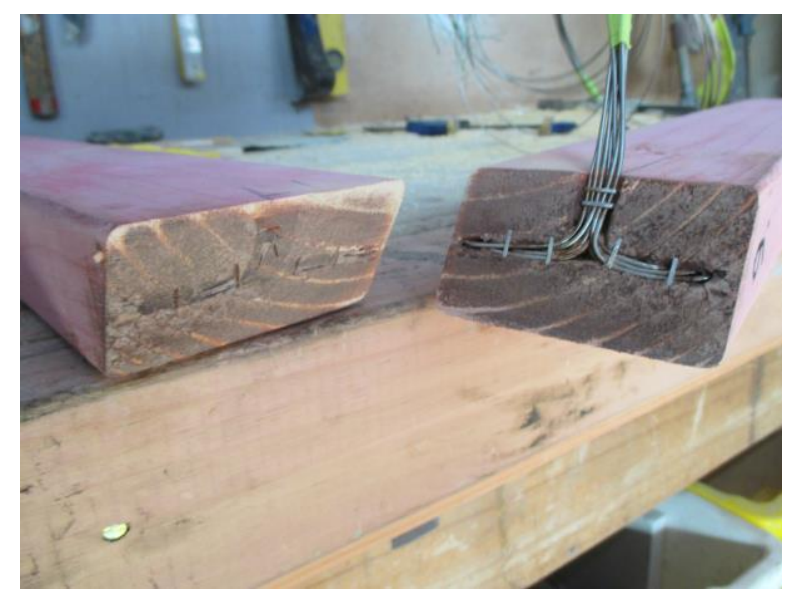

(a) Sectioned dummy stud at $60^{\circ}$ showing embedded sheathed wire thermocouples

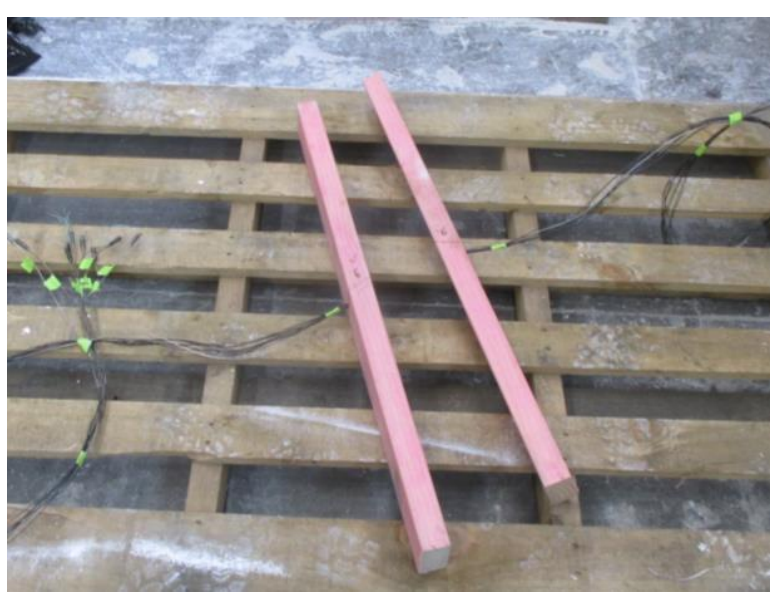

(b) $90 \times 45 \times 955 \mathrm{~mm}$ dummy studs

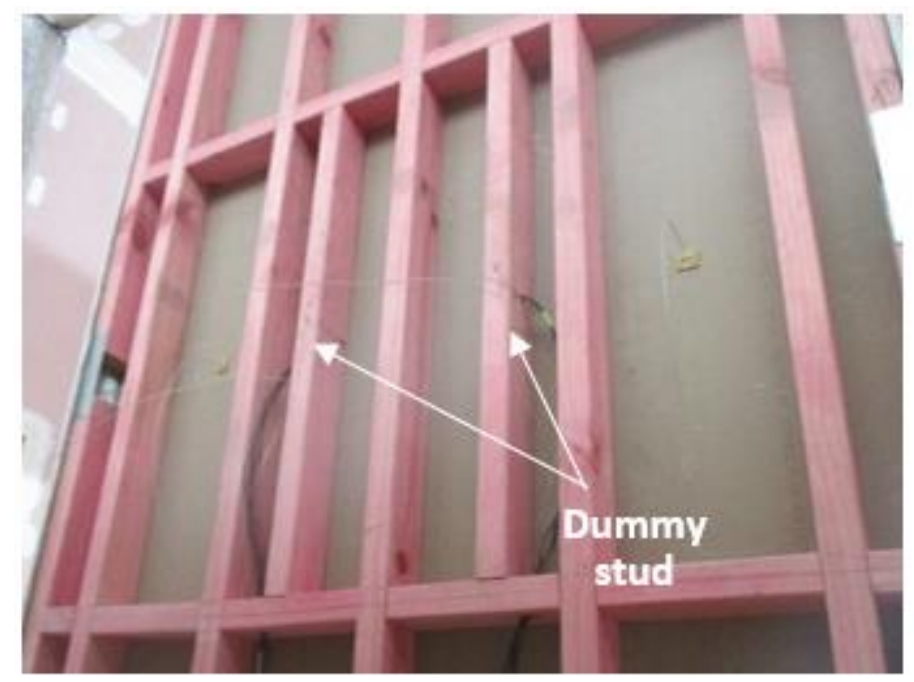

(c) Dummy studs located within the load-bearing wall specimen cavity between timber nogs

Figure 6.6 - Dummy studs for recording time-temperature profiles through the stud 
Figure 6.7 shows the location of 9 sheathed wire thermocouples embedded into a sectioned dummy stud. These thermocouples were embedded along the centreline through the depth of the dummy studs at depths shown in Figure 6.7.

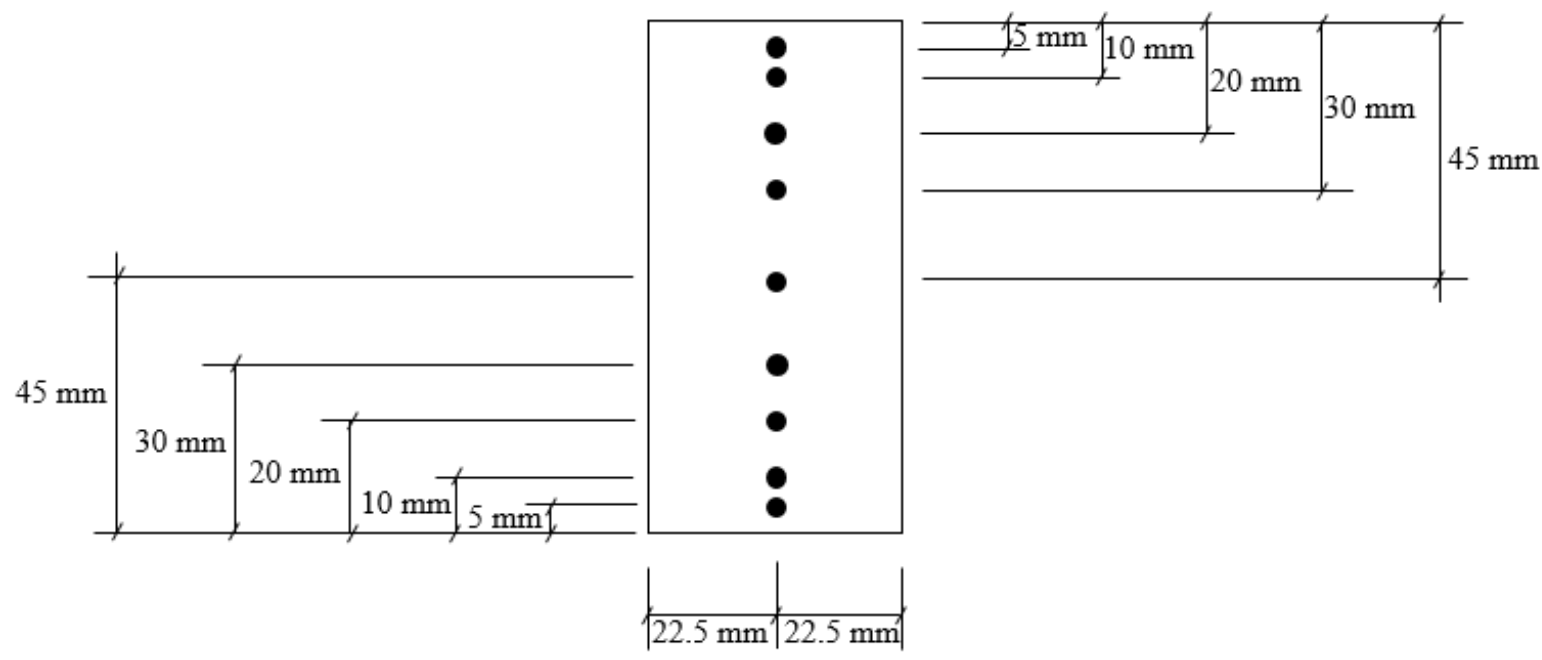

Figure 6.7 - Location of thermocouple embedded into a sectioned dummy stud

\subsubsection{Gypsum plasterboard and flooring}

The load-bearing wall specimen and enclosure walls were lined with a single layer of fire-rated gypsum plasterboard each side and at each end as per manufacturer's specification, as shown in Figures 6.8(a) and 6.8(c) [13]. The $13 \mathrm{~mm}$ thick fire-rated gypsum plasterboard in the first and third experiments was fixed in a vertical orientation with $41 \mathrm{~mm}$ x $6 \mathrm{~g}$ high thread drywall screws at $300 \mathrm{~mm}$ centres around the perimeter of each sheet and along intermediate studs. The $16 \mathrm{~mm}$ thick gypsum plasterboard in the second experiment was installed similarly but with $51 \mathrm{~mm} \times 7 \mathrm{~g}$ high thread drywall screws. All gypsum plasterboard sheet joints were formed over solid timber framing.

$20 \mathrm{~mm}$ thick oriented Strandfloor flooring was fixed to the enclosure floor and ceiling framing with $45 \mathrm{~mm} \times 8 \mathrm{~g}$ self-drilling screws at $150 \mathrm{~mm}$ centres around the perimeter and at $200 \mathrm{~mm}$ centres along intermediate supports as per manufacturer's specification [48]. The underside of the enclosure floor and ceiling were lined with a single layer of $16 \mathrm{~mm}$ fire-rated gypsum plasterboard as shown in Figure 6.8(e), fastened with $51 \mathrm{~mm} \times 7 \mathrm{~g}$ high thread drywall screws at $150 \mathrm{~mm}$ centres around the perimeter of each sheet and $200 \mathrm{~mm}$ centres along intermediate supports. In addition, the flooring on the enclosure floor framing was protected with a single layer of $16 \mathrm{~mm}$ fire-rated gypsum plasterboard to limit possible heat loss. The locations of 
vertical and horizontal plasterboard sheet joints made in the load-bearing wall specimen are provided in Appendix F.

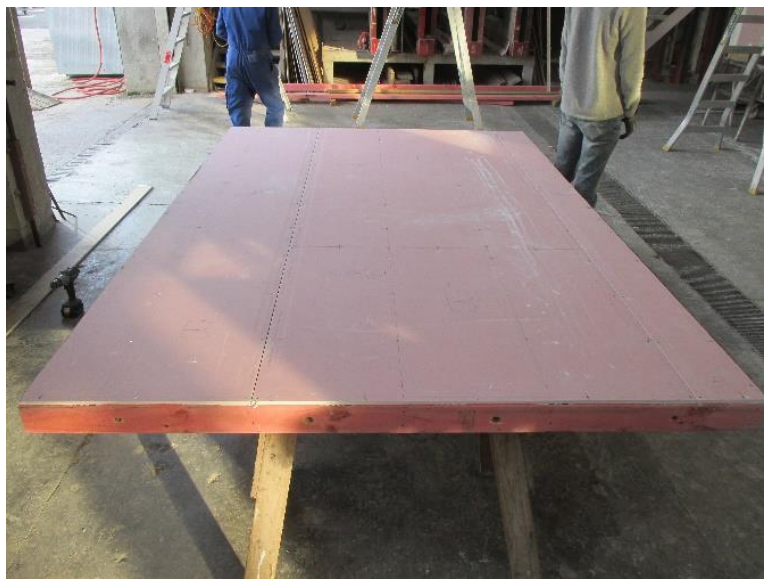

(a) Load-bearing wall specimen lined on one side

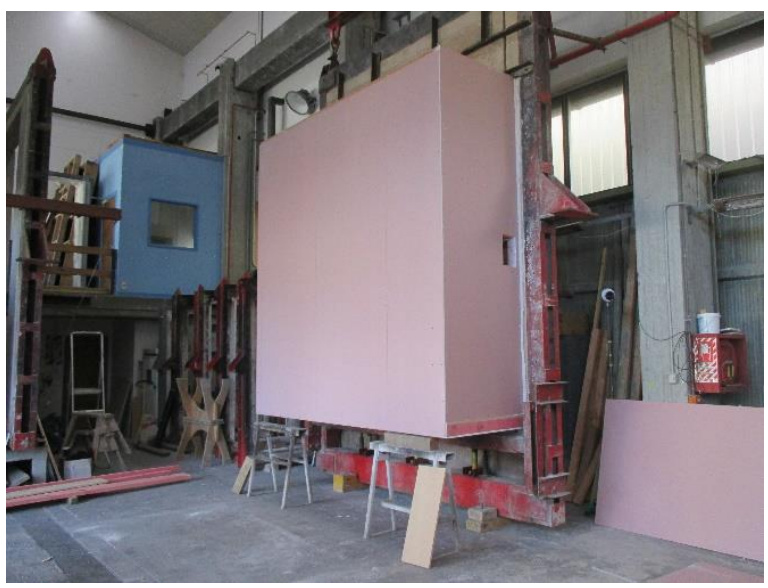

(c) Enclosure structure fully lined

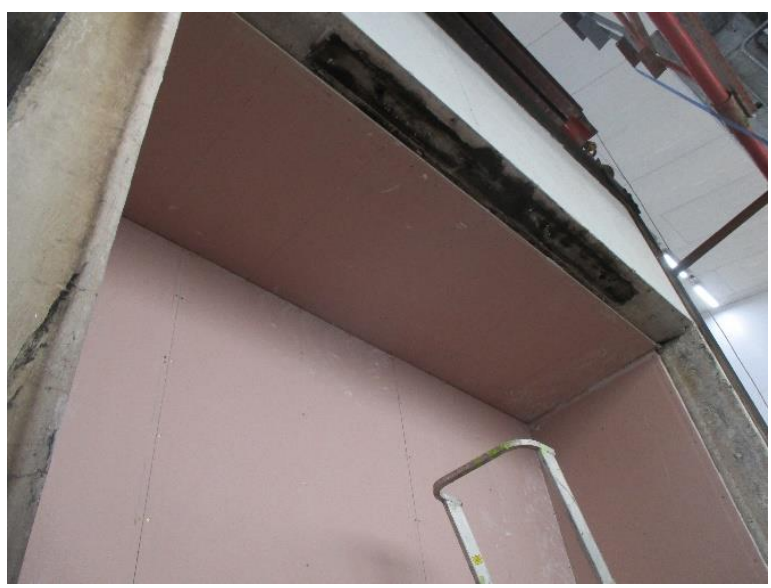

(e) Enclosure ceiling lining

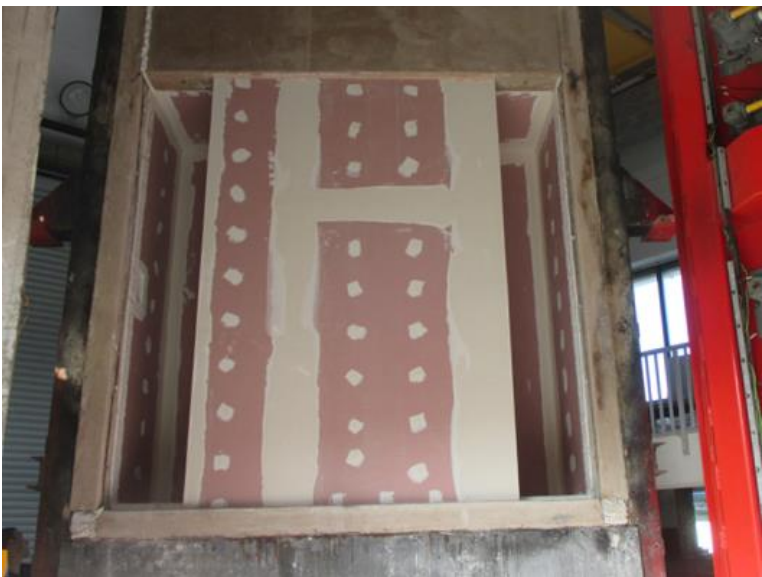

(b) Jointing and fastener heads stopped for load-bearing wall specimen

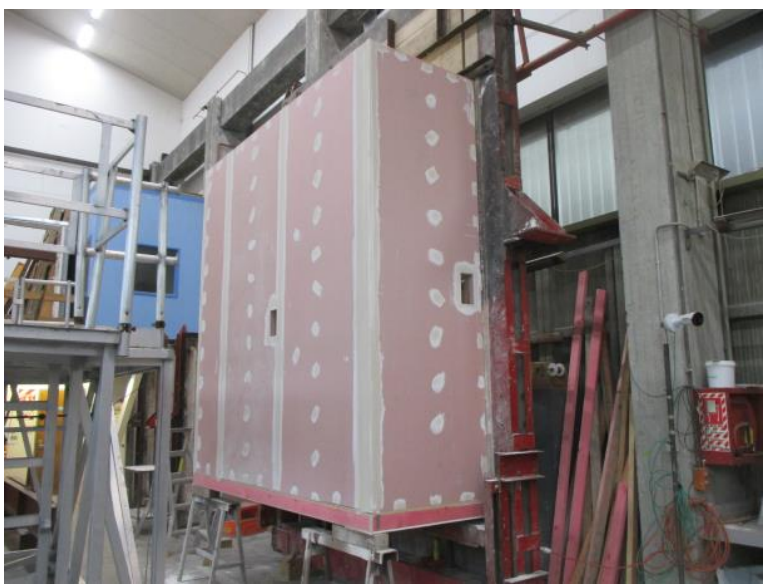

(d) Jointing and fastener heads stopped for enclosure structure

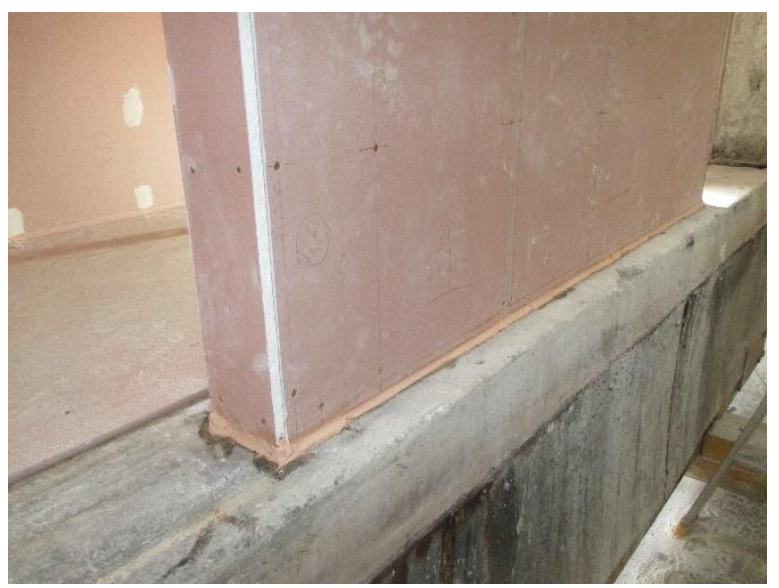

(f) Minor gaps filled with fire-rated sealant

Figure 6.8 - Fire-rated gypsum plasterboard and flooring installation 
All gypsum plasterboard sheet joints were tape-reinforced using a matt fibreglass tape and stopped using a setting compound as per manufacturer's recommendations. Drywall screw heads were also stopped as shown in Figures 6.8(b) and 6.8(d), and minor gaps along the joints between the load-bearing wall specimen and concrete specimen holder were filled with a firerated sealant as shown in Figure 6.8(f).

\subsubsection{Temperature measurement}

Temperature measurements within the furnace were obtained from twelve mineral insulated metal sheathed (MIMS) chromel-alumel thermocouples. Five plate thermometers were also installed on both sides and $100 \mathrm{~mm}$ away from the load-bearing wall specimen faces to monitor conditions on the furnace and enclosure sides. These were located in the centre and near each corner of the load-bearing wall specimen as shown in Figures 6.9(a) and 6.9(b). In order to locate plate thermometers on the enclosure side, five $25 \mathrm{~mm}$ diameter steel tubes were installed as shown in Figure 6.9(b). Wire thermocouples ran through, and were welded to the centre of $100 \times 100 \mathrm{~mm}$ by $0.7 \mathrm{~mm}$ thick stainless steel plates insulated with mineral fibre as shown in Figure 6.9(c) [49].

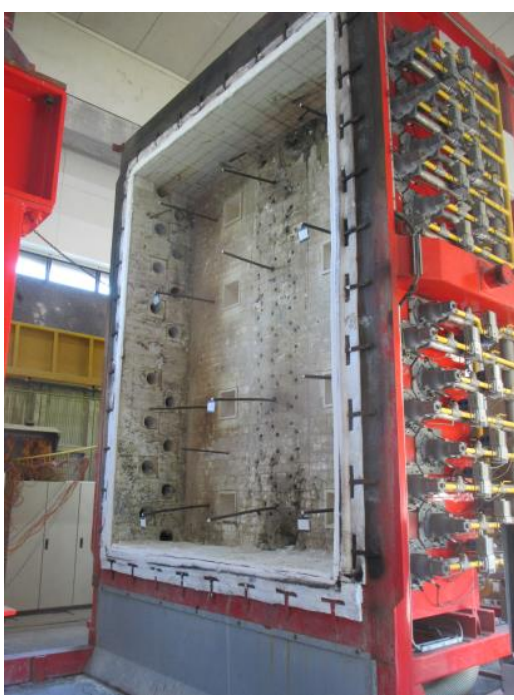

(a) 12 MIMS and 5 plate

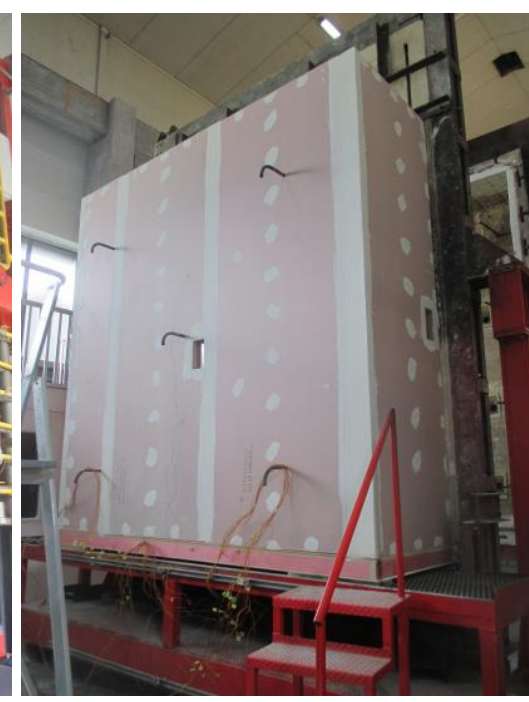

(b) 5 steel tubes to instrument plate

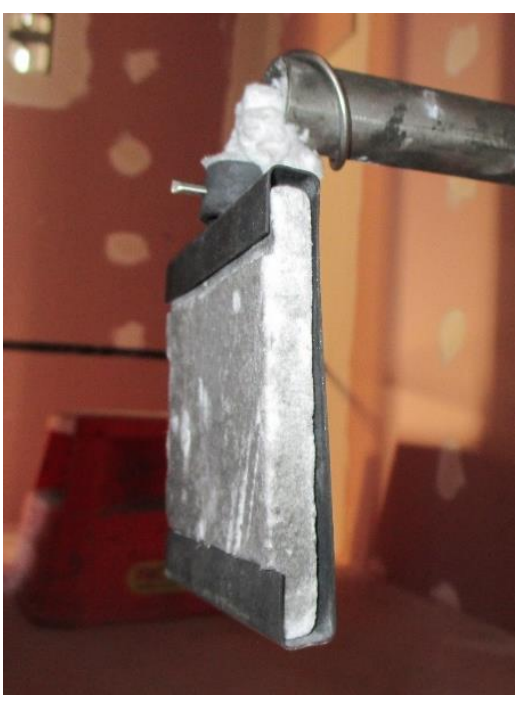

(c) Plate thermometer thermometers on furnace side thermometers on enclosure side

Figure 6.9 - Location of MIMS thermocouple and plate thermometer

Chromel-alumel thermocouples mounted on copper discs and covered with insulating pads as shown in Figure 6.10(a) were attached to the back of the exposed lining and unexposed face of the enclosure structure in various locations in order to measure transient time-temperature 
profiles. Disc-type thermocouples attached within the load-bearing wall cavity and sheathed wire thermocouples used for dummy studs ran through two inner pre-drilled holes in the bottom platen of specimen holder as shown in Figure 6.10(b).

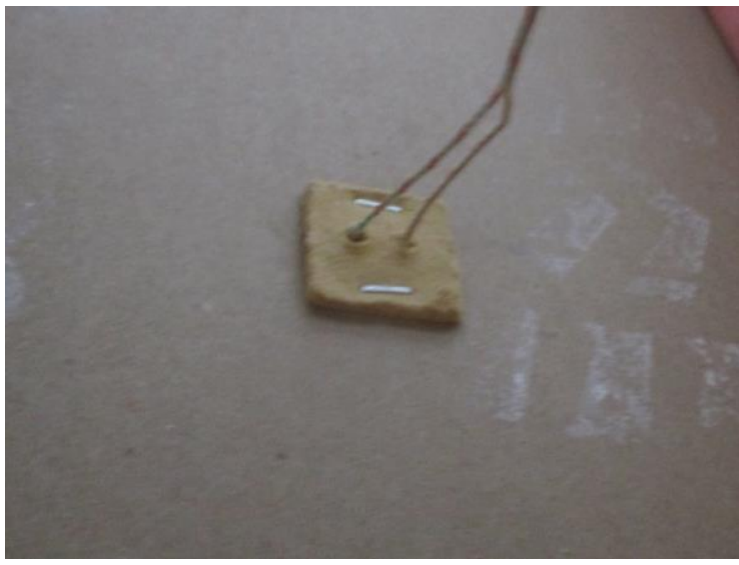

(a) Disc-type thermocouple

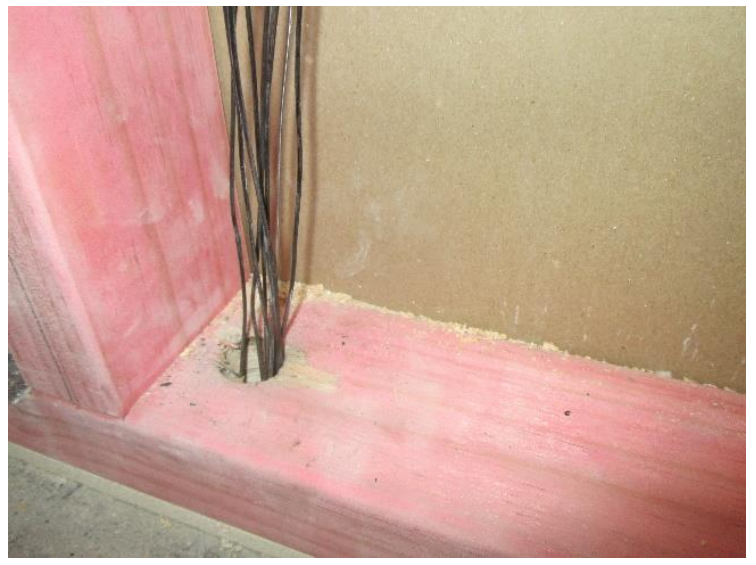

(b) Wire thermocouples through pre-drilled holes

Figure 6.10 - Disc-type thermocouple and wire thermocouples set-up for load-bearing wall specimen

Thermocouple locations for each experiment with corresponding thermocouple numbers are shown in Figure 6.11.

\subsubsection{Load arrangement}

A uniformly distributed axial load was applied to the load-bearing wall specimen by the movable concrete platen loaded by hydraulic jacks connected to a single hydraulic pump as shown in Figure 6.12. The applied load for each jack was monitored using load cells connected to the computer-controlled data logging system.

The total load applied per hydraulic jack was calculated by considering the total target axial load to the load-bearing wall specimen and weights of the concrete beam and the gypsum plasterboard and timber-framed wall. Table 6.2 summarises the applied load per hydraulic jack for each experiment. As the total required load to be applied was low, two hydraulic jacks were used in the experiments.

Table 6.2 - Nominal load per hydraulic jack for each experiment

\begin{tabular}{|c|c|c|}
\hline BRANZ test number & Axial load per stud (kN) & Nominal load per hydraulic jack (kN) \\
\hline QR1810-161 & 2.0 & 9.3 \\
\hline QR1810-162 & 4.0 & 14.5 \\
\hline QR1810-163 & 4.0 & 14.1 \\
\hline
\end{tabular}




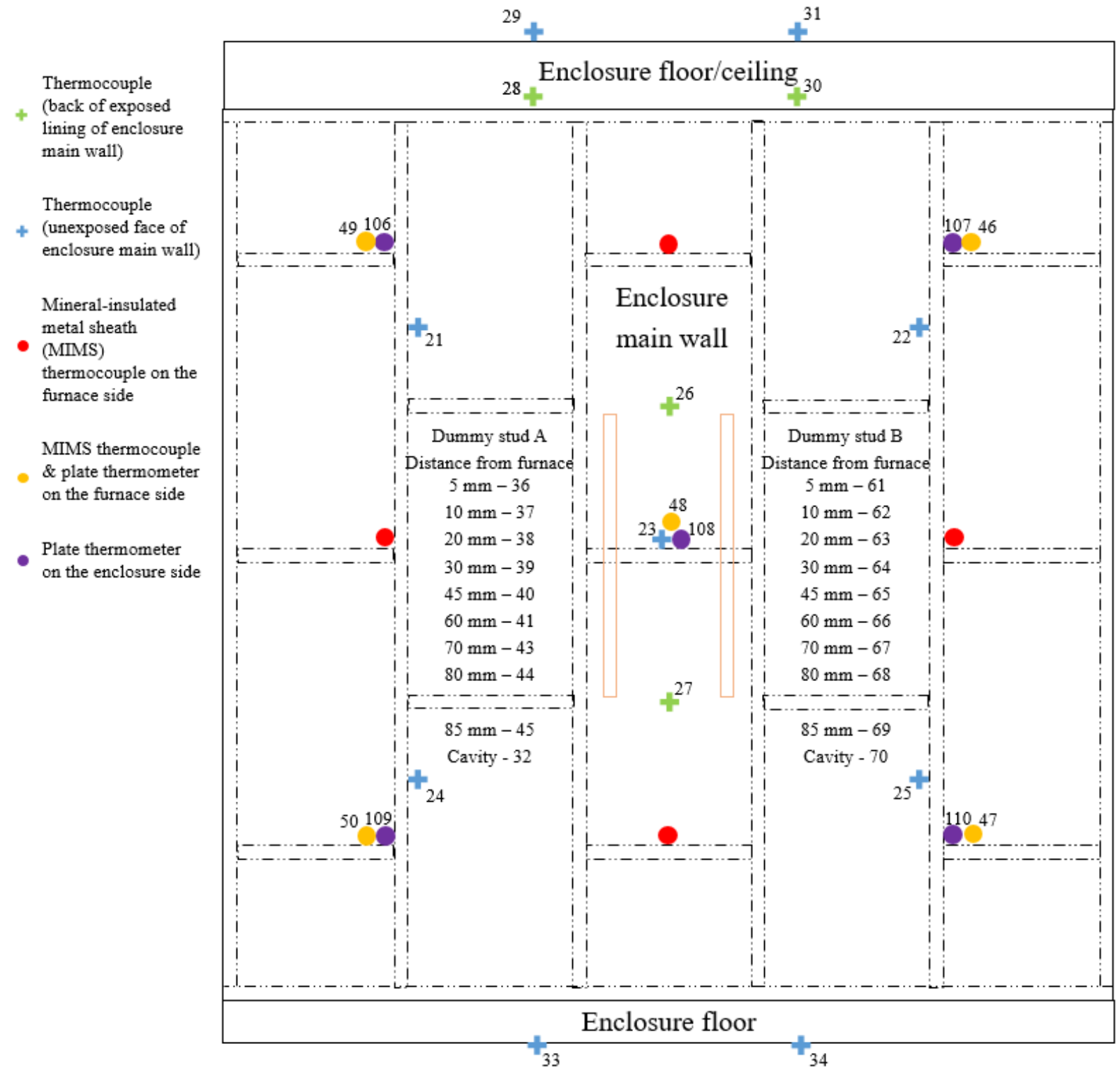

(a) Experiment 1-QR1810-161 
29

30

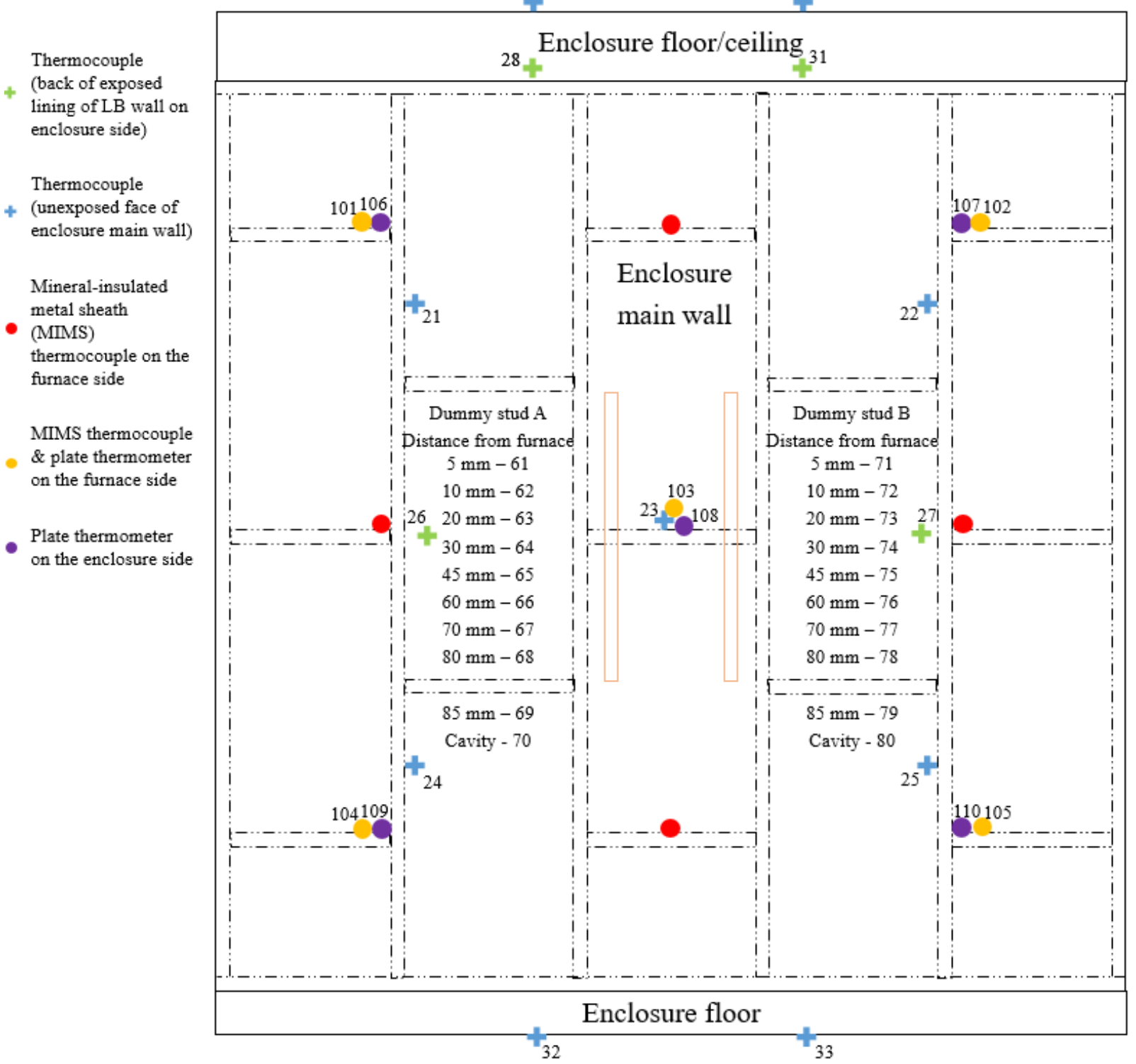

(b) Experiment 2 - QR1810-162 


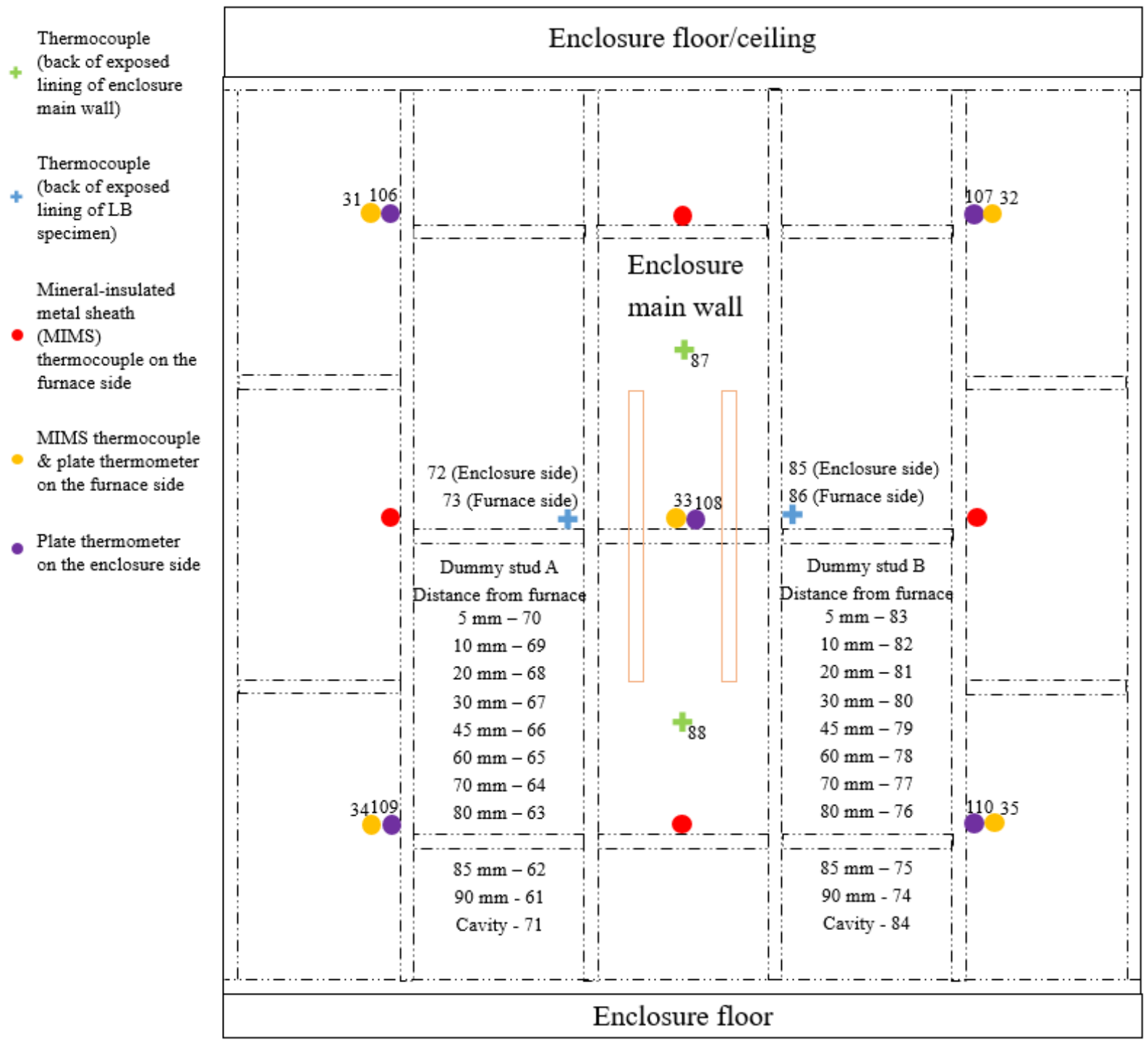

(c) Experiment 3-QR1810-163

Figure 6.11 - Location of thermocouple in experiments

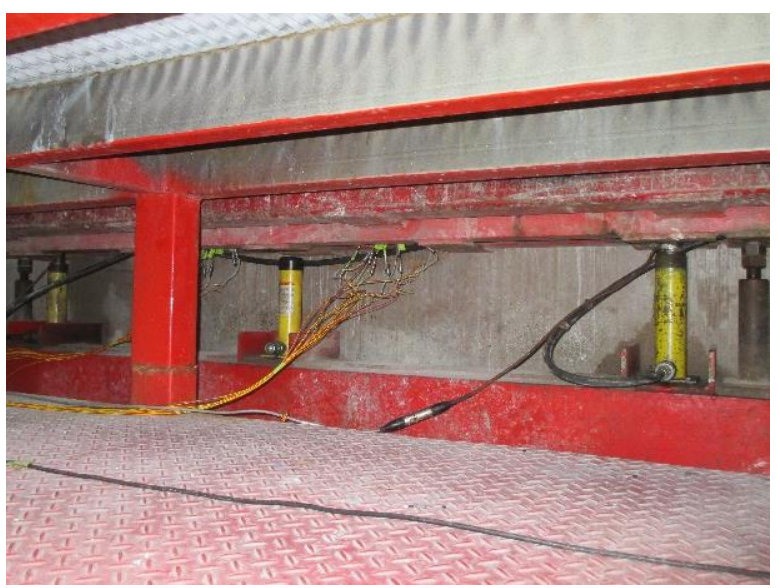

(a)

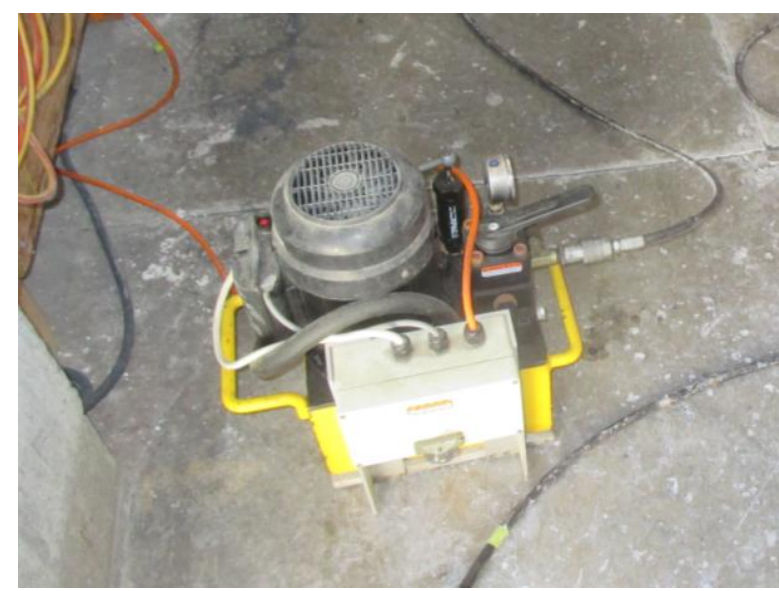

(b)

Figure 6.12 - (a) Hydraulic jacks and (b) a hydraulic pump 


\subsubsection{Displacement measurement}

The vertical displacement of the bottom platen, which is equivalent to the axial displacement of the load-bearing wall specimen, was measured using two linear variable differential transducers (LVDTs) installed at each end of the specimen holder frame as shown in Figure 6.13. The LVDTs were connected to the computer-controlled data logging system for recording.

During the experiments, the vertical displacement of the load-bearing wall specimen was closely monitored to determine when the axial contraction or rate of axial contraction as defined in AS 1530.4:2014 was exceeded. The experiment was terminated once structural adequacy failure was established to prevent further loss of the load-bearing wall specimen and to observe the residual section of timber. The out-of-plane deflection of the load-bearing wall specimen could not be measured due to the specimen being located within the furnace.
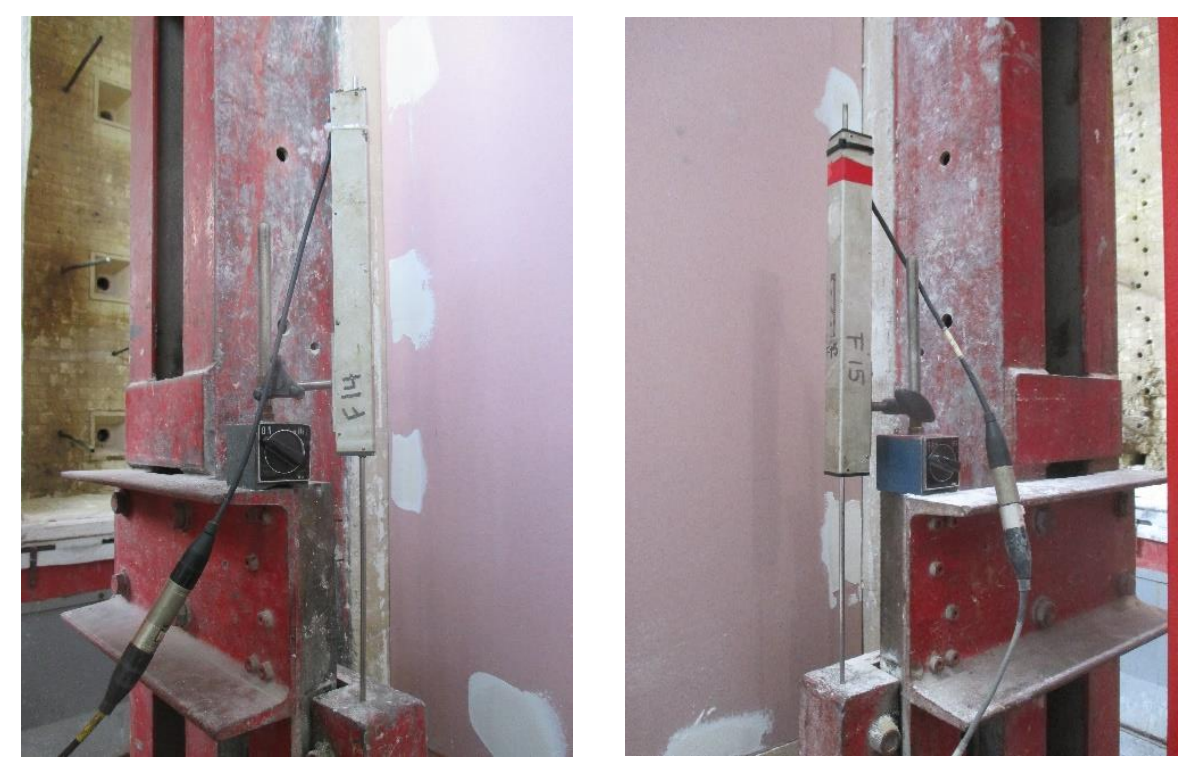

Figure 6.13 - Linear variable differential transducers installed at each end

\subsection{Observations and results}

\subsubsection{Experiment 1 (QR1810-161)}

\subsubsection{Furnace temperature}

Figure 6.14 shows the average time-temperature profile of the furnace measured from the twelve MIMS chromel-alumel thermocouples, in comparison to the ISO 834 standard fire timetemperature curve. These were well aligned and within AS 1530.4:2014 permitted upper and 
lower limits. Furnace temperature measurements from the plate thermometers also provided good agreement with the ISO 834 standard time-temperatures but were slightly lower up to approximately 25 minutes.

However, furnace temperatures on the enclosure side were much lower than the standard conditions especially in the beginning of the experiment, indicating less exposure on the enclosure side. The temperatures increased and were within the AS 1530.4:2014 permitted limits after approximately 48 minutes.

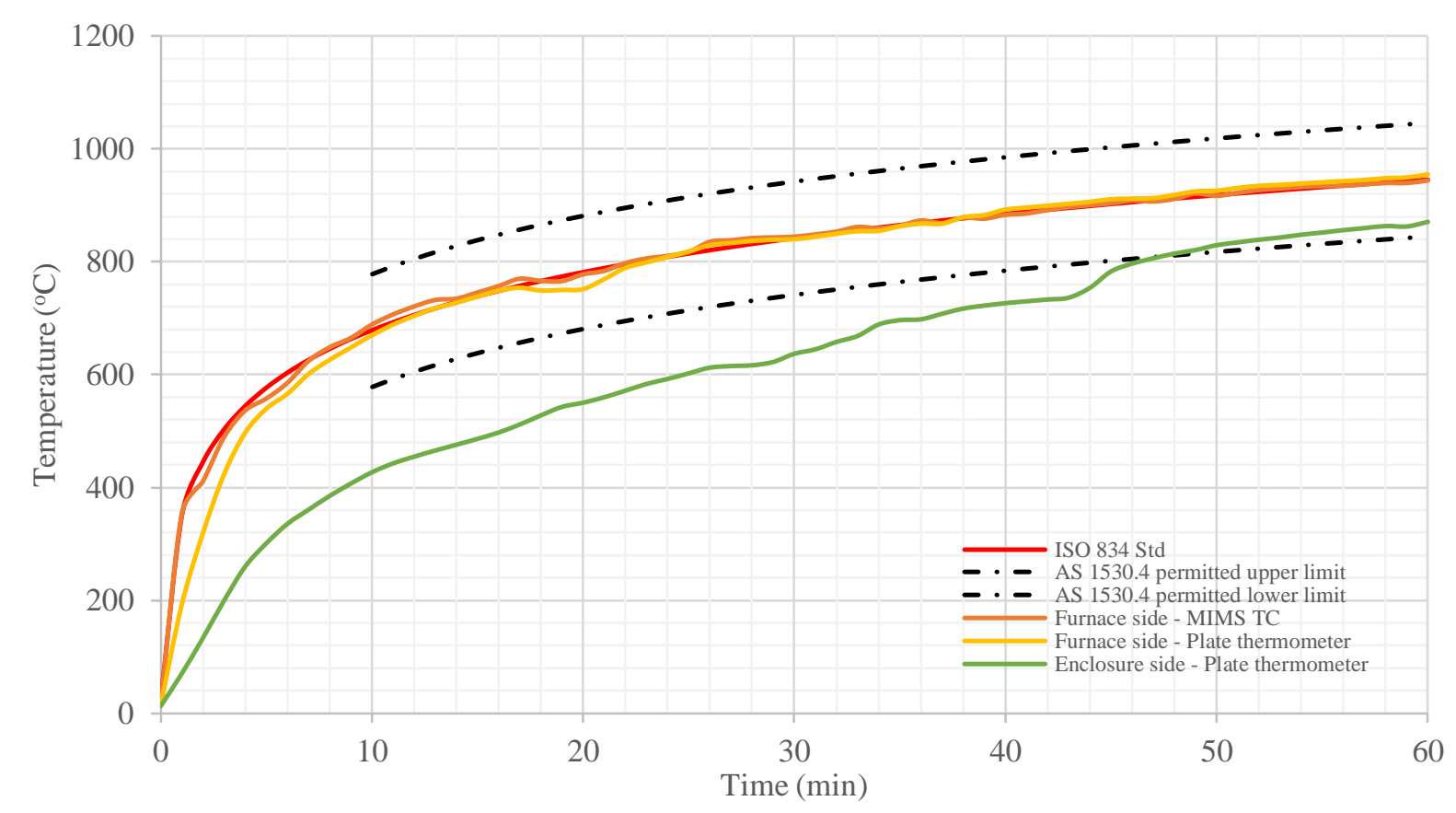

Figure 6.14 - Measured average furnace time-temperature profiles in QR1810-161

Since the measured furnace temperatures on both sides of the load-bearing wall specimen poorly aligned with the fire time-temperature input in the two-sided fire exposure thermal model, the thermal and structural finite element models were re-run based on the measured furnace temperatures to accommodate the lower exposures on the enclosure side. The intention was to validate the model and check its capability to simulate different fire exposures on opposite sides of the load-bearing timber-framed wall. The thermal and structural modelling results and further discussions are provided in Section 7.1. It is probable that the measured fire exposures were more representative of a real fire scenario as it is highly likely for a fire to occur on one side of a wall first, and then spread to the other side through a door opening or similar. 


\subsubsection{Observations}

After about 10 to 15 minutes of fire exposure, small amounts of smoke and steam was visible from the top of the enclosure due to the dehydration reaction that occurs as bound crystalline moisture from gypsum plasterboard is evaporated. At 14 minutes, the gypsum plasterboard joint stopping started to crack and fall, and the opening of a plasterboard sheet joint was visible at about 30 minutes, as shown in Figures 6.15(a) and 6.15(b). As the experiment continued, the size of the plasterboard sheet joint openings on both sides of the load-bearing wall specimen developed significantly, and large amounts of smoke and steam were produced from about 43 minutes of fire exposure.

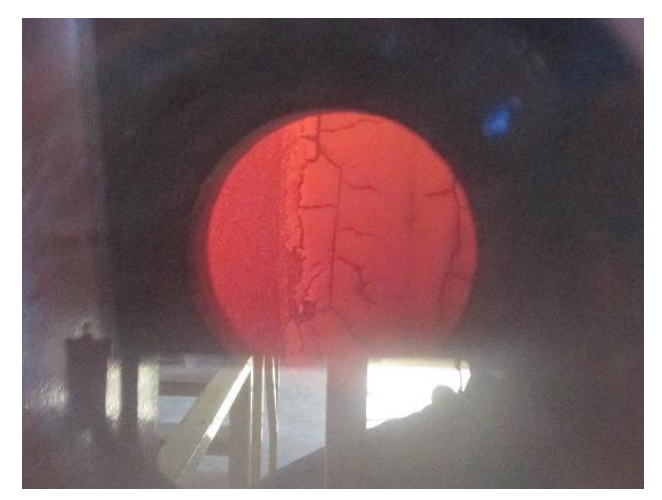

(a) Joint stopping cracking at 14 min

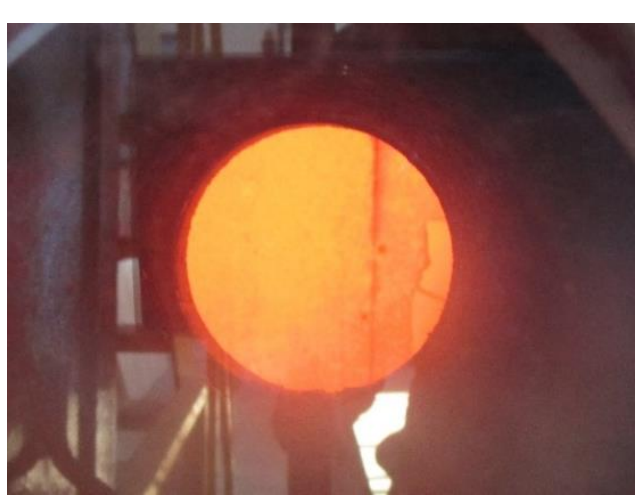

(b) Large opening of joint at $30 \mathrm{~min}$

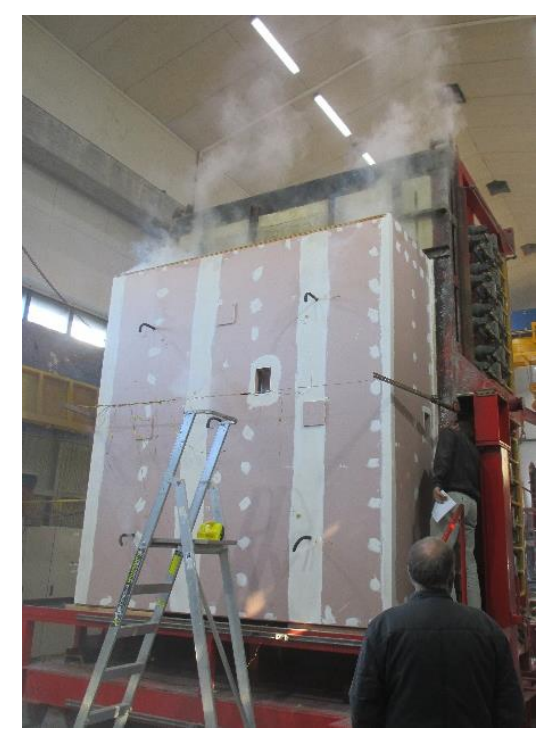

(c) Large amounts of smoke and steam visible from the top of the enclosure at $\mathbf{4 3}$ minutes

Figure 6.15 - Photos of QR1810-161 during the test

There were no signs of discolouration of the gypsum plasterboard lining on the unexposed face of the enclosure. The sheet joints and fastener heads were also observed to remain intact, and no flaming was visible from the outside of enclosure for the duration of the experiment. 
Figure 6.16 shows the cavity temperature rise of the exposed 13 and $16 \mathrm{~mm}$ fire-rated gypsum plasterboard linings of the enclosure walls and floor/ceiling respectively. Thermocouple locations are provided in Appendix F. These temperatures further permitted investigation of the furnace exposure conditions on the enclosure side by comparing them with past experiments tested to standard ISO 834 fire exposure. It can be seen that cavity temperatures measured from QR1810-161, behind these wall linings, were much lower than those measured from FR1611 and FR1370, indicating less exposure on the enclosure side. As heat inside the furnace tends to rise, it was observed that the cavity temperature behind the ceiling lining showed a better comparison than the wall lining.

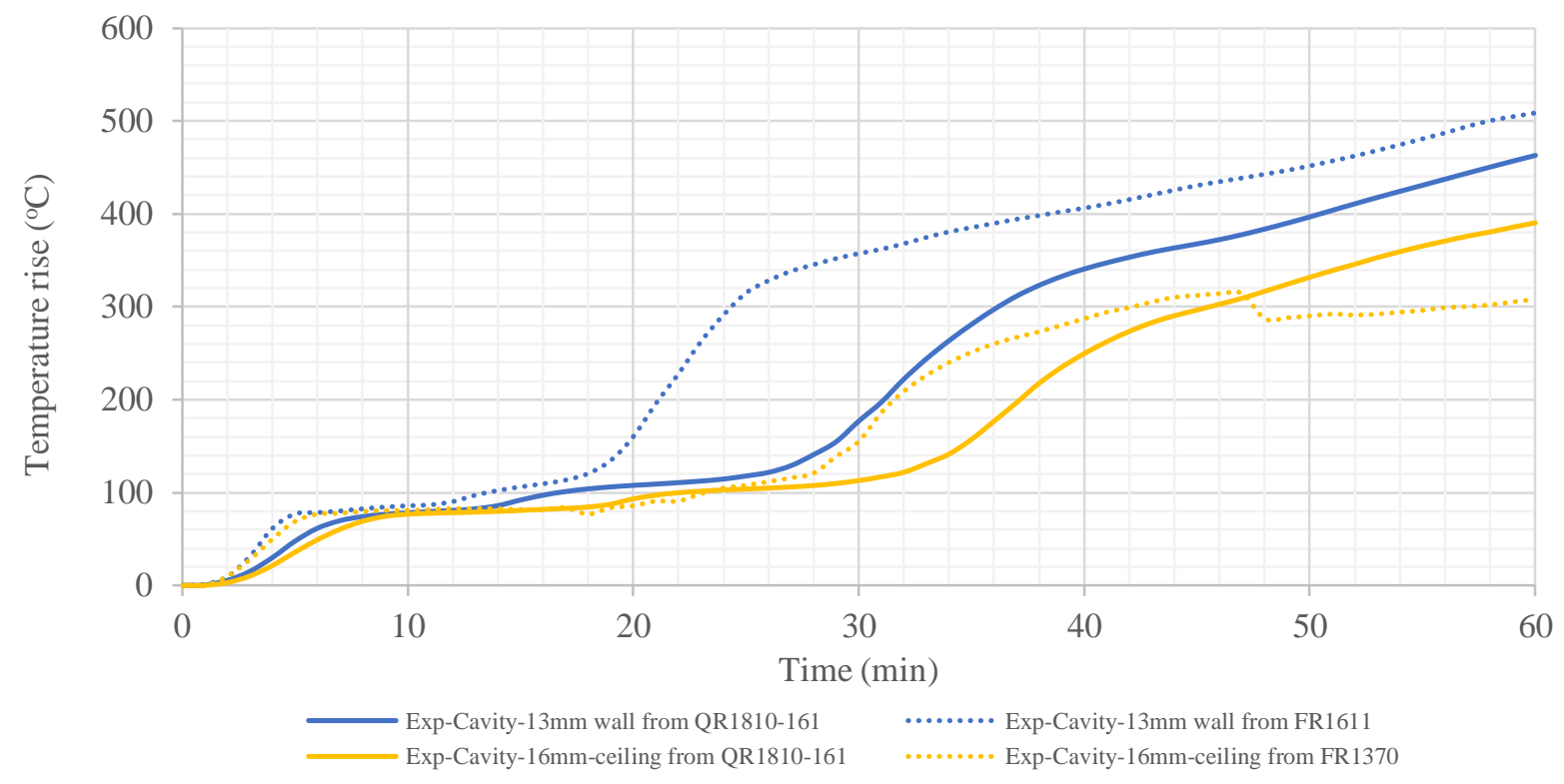

Figure 6.16 - Enclosure exposed cavity temperature comparison with past tests

The average time-temperature rise profile of two dummy studs is shown in Figure 6.17 where the legend indicates the depth of thermocouple locations as measured from the furnace side. The stud temperature remained well below $100{ }^{\circ} \mathrm{C}$ until approximately 20 minutes when the dehydration reaction of gypsum plasterboard ended, and when cracks and joints in gypsum plasterboard started to open up. Then, the temperature of the outer stud thermocouple increased rapidly, which was followed by the deeper temperatures. The stud temperatures measured at equal depth from both sides would show good agreement if the furnace condition on the enclosure side had followed the ISO 834 standard fire time-temperature curve. However, and as expected, it was observed from the dummy stud time-temperature profiles that the exposure on the enclosure side was less than the furnace side. 


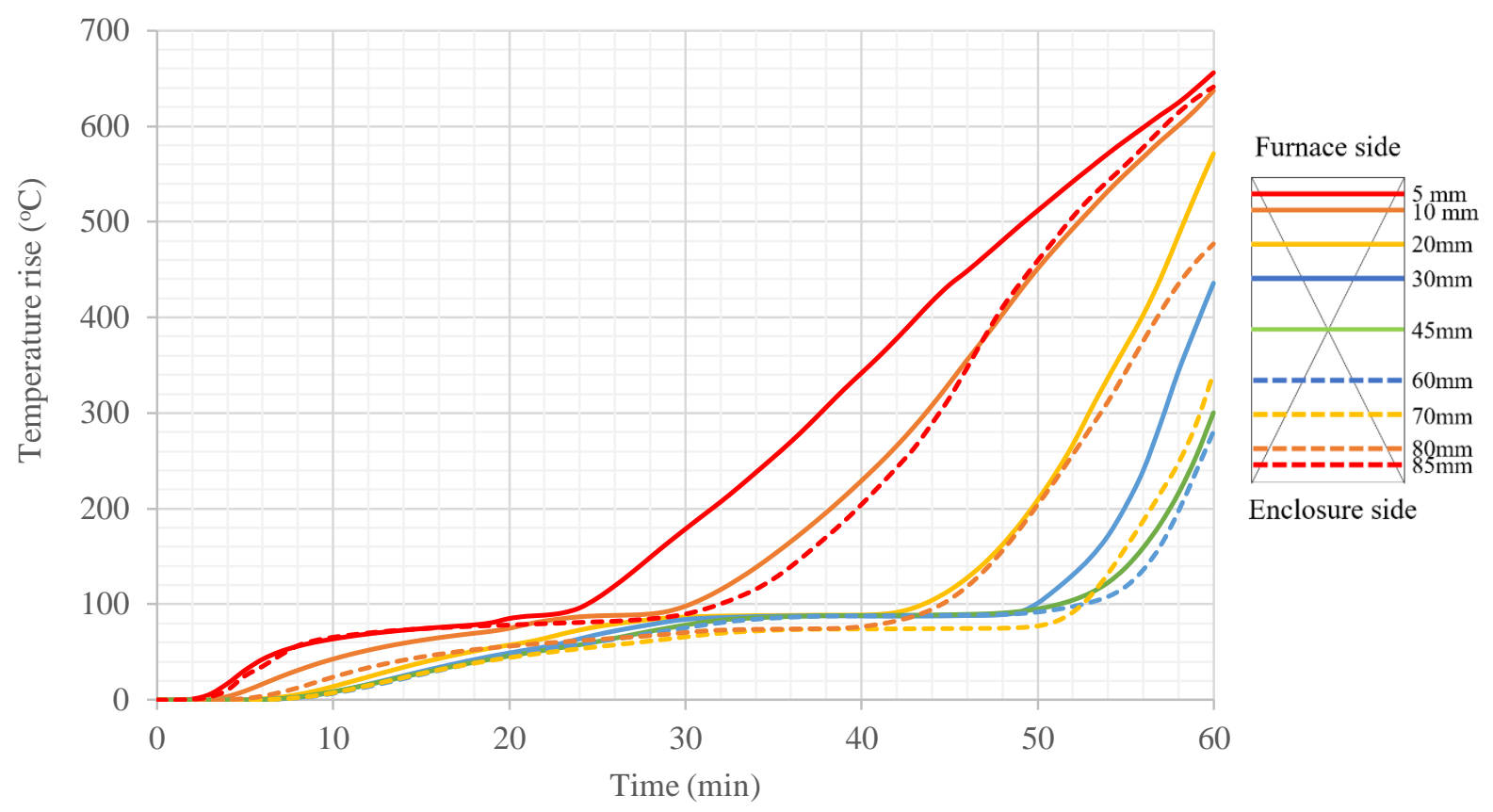

Figure 6.17 - Dummy stud time-temperature profiles of QR1810-161

Figure 6.18 shows the load-bearing wall specimen after the test. By the time the furnace was open for post-fire observations, minutes after the structural adequacy failure, the load-bearing wall specimen collapsed and most of timber studs were lost. This was likely because of the applied axial stud load being very low resulting in much less residual section of timber stud to fail, and the time consumed with disconnecting the instrumentation prior to opening of the furnace.
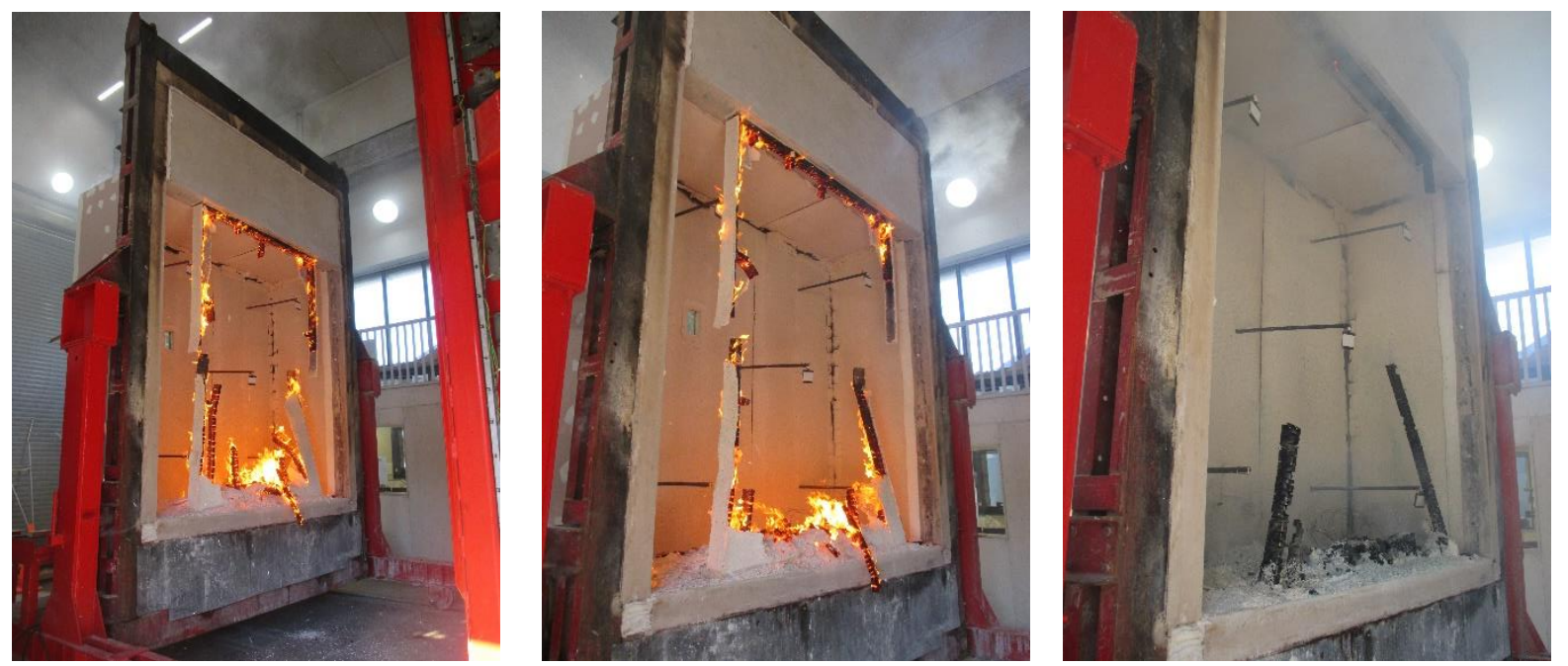

Figure 6.18 - Residual load-bearing wall specimen of QR1810-161 


\subsubsection{Axial displacement and loading}

Figure 6.19 shows the measured axial displacement versus time. The vertical axial displacement of the load-bearing wall specimen was $-1.7 \mathrm{~mm}$ on average at the beginning of the experiment due to the thermal expansion of the specimen, and then it started to increase. The left-hand LVDTs showed an exponential increase of the vertical displacement from 50 minutes whereas the right-hand LVDTs exhibited a much lower displacement which even decreased at 56 minutes. This experimental error was found to be caused by the movement of the concrete bottom platen being restricted on one side possibly due to low axial load applied to the specimen. This resulted in an uneven load spread from 56 minutes.

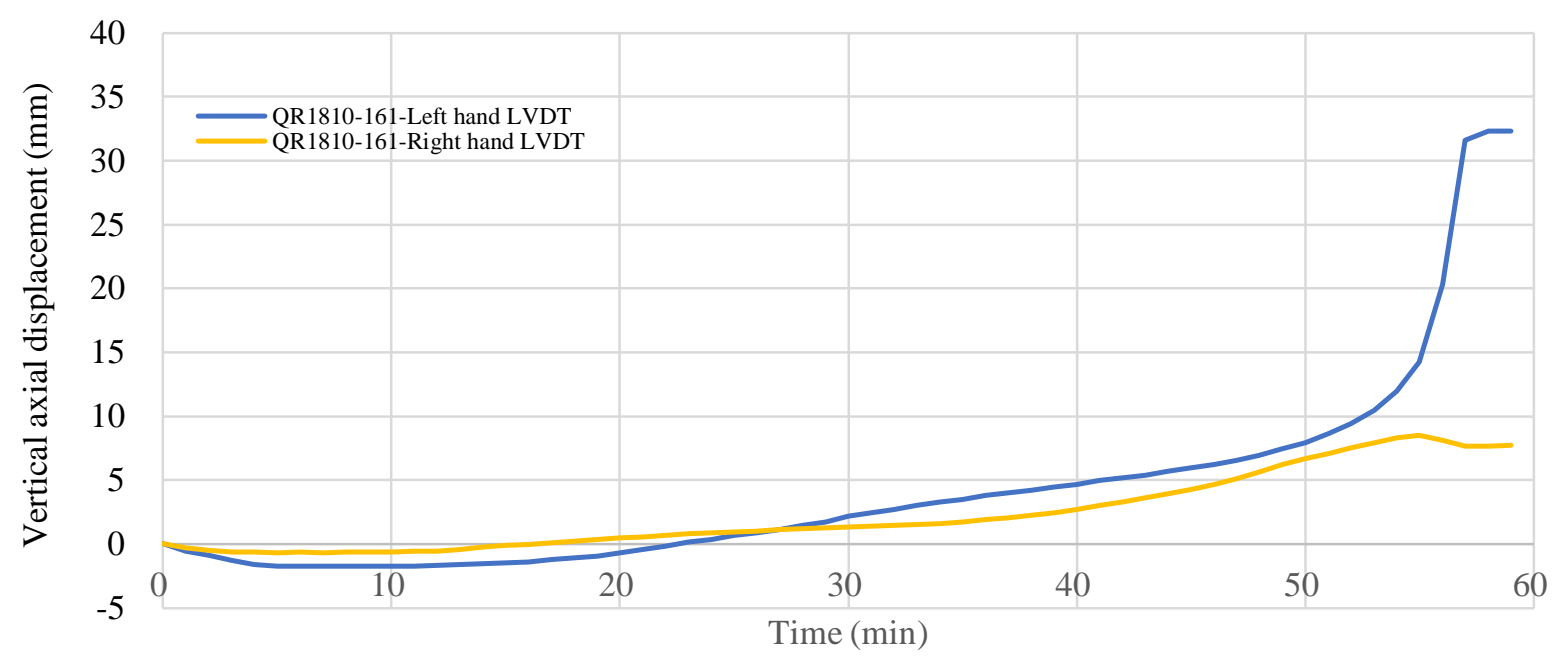

Figure 6.19 - Measured axial displacement in QR1810-161

Figure 6.20 shows the load variation with time applied by two hydraulic jacks. The nominal applied load per hydraulic jack was $9.3 \mathrm{kN}$. In the beginning of the experiment, the measured load from the hydraulic jack on the left-hand side reached close to $11 \mathrm{kN}$ due to the thermal expansion of the specimen applying the pressure to the hydraulic system. This was managed by reducing the hydraulic pressure manually resulting in difficulty controlling the axial load. Both hydraulic jacks maintained the target load satisfactorily from about 8 minutes. At the structural adequacy failure, the load-bearing wall specimen was unloaded to prevent further loss of the specimen. 


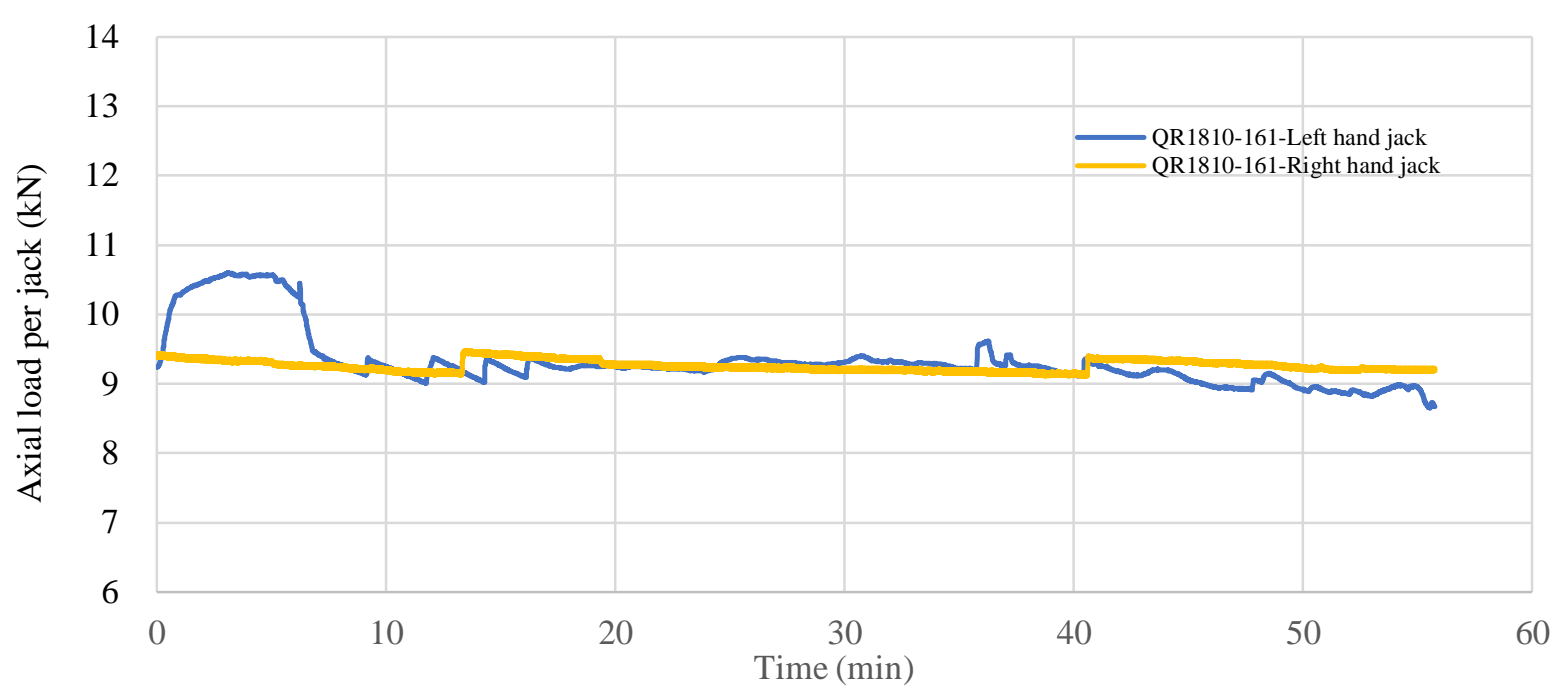

Figure 6.20 - Measured applied load per hydraulic jack in QR1810-161

\subsubsection{Structural adequacy failure}

The limiting axial contraction and rate of axial contraction defined in AS 1530.4:2014 for a 3 metres high wall specimen were calculated to be $30 \mathrm{~mm}$ and $9 \mathrm{~mm} / \mathrm{min}$ respectively using Equations (1.4) and (1.5) in Chapter 1. The rate of axial contraction of $10 \mathrm{~mm} / \mathrm{min}$ was measured from the LVDTs on the left-hand side which exceeded this limit at 56 minutes. The limiting axial contraction of $30 \mathrm{~mm}$ was exceeded at 57 minutes. Therefore, structural adequacy failure was adjudged to have occurred at 56 minutes.

The uneven load spread to the load-bearing wall specimen due to the platen being restricted was not considered to affect the structural adequacy failure time result as the restriction was observed at 56 minutes when the structural adequacy failure occurred.

\subsubsection{Experiment $2(\mathrm{QR} 1810-162)$}

\subsubsection{Furnace temperature}

The average furnace time-temperature profile from twelve MIMS chromel-alumel thermocouples and five plate thermometers is shown in Figure 6.21 and was within AS 1530.4:2014 permitted upper and lower limits. The furnace temperature measurement from the plate thermometers on the furnace side was found to be lower up to approximately 40 minutes. The furnace temperature on the enclosure side was lower than the AS 1530.4:2014 permitted lower limit during the entire period of the experiment. 


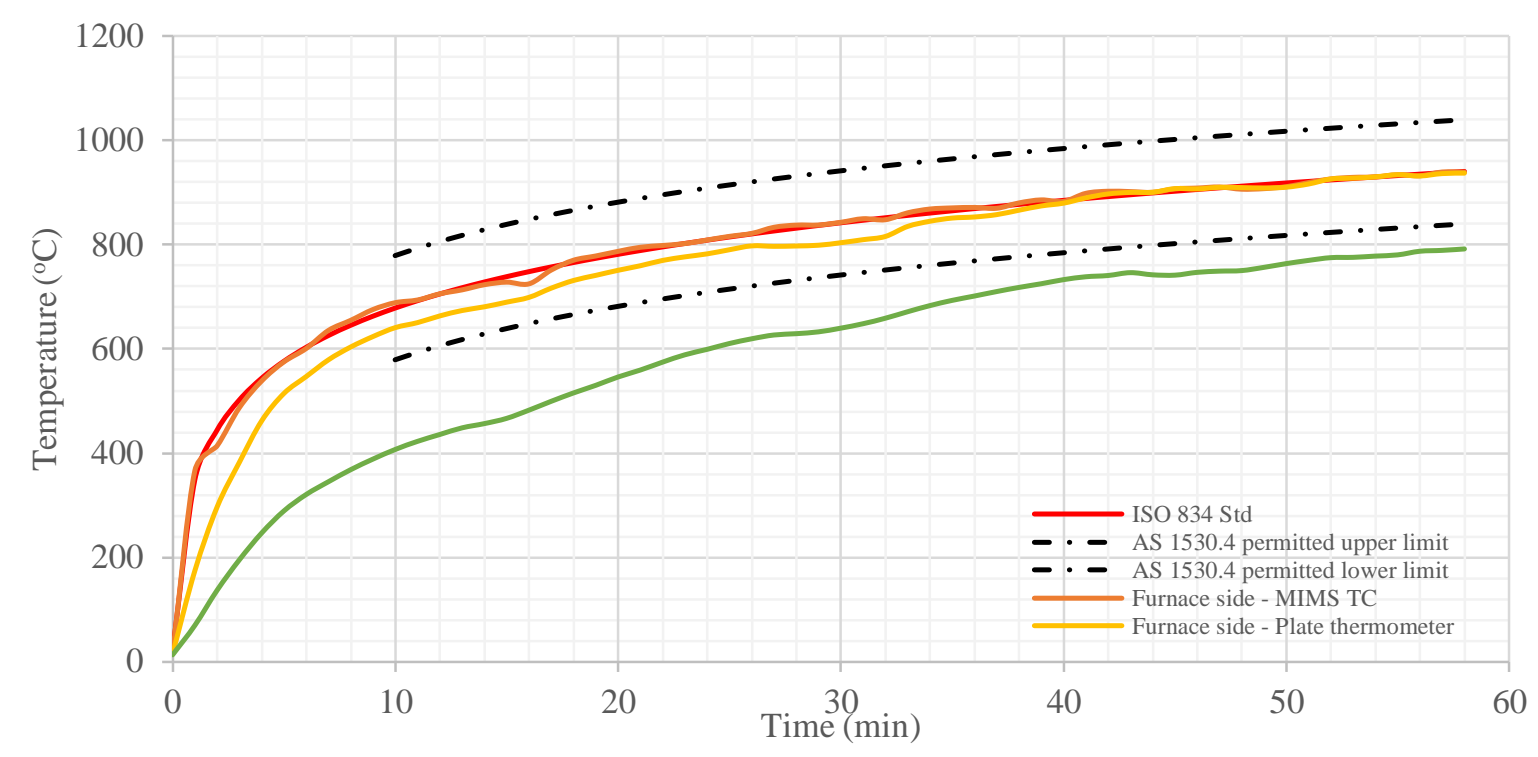

Figure 6.21 - Measured average furnace time-temperature profiles in QR1810-162

\subsubsection{Observations}

Visual observations similar to the first experiment were recorded in the second experiment. Small amounts of smoke and steam were visible from the top of the enclosure from approximately 15 minutes and the cracking of plasterboard sheet joint stopping was observed at 20 minutes as shown in Figure 6.22(a). As the experiment continued, the volume of steam from the top of the enclosure developed as more chemically bound water evaporated which led to water dripping from the enclosure as shown in Figure 6.22(b).

Figure 6.22(c) shows the load-bearing wall specimen at 49 minutes through the observation window in the enclosure side wall indicating a large opening of vertical sheet joints, exposing timber studs. It was observed that the gypsum plasterboard protecting the load-bearing wall specimen became fully dehydrated and quite loose, but it did not fall off during the experiment. Lateral deflection could not be established by visual observation and the wall appeared to remain reasonably straight at 49 minutes. 


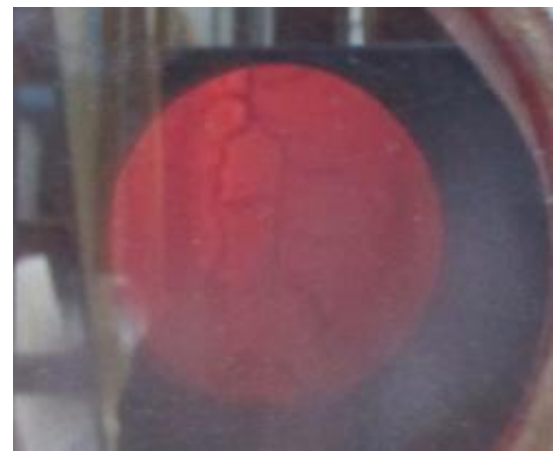

(a) Joint stopping cracking at 20 min

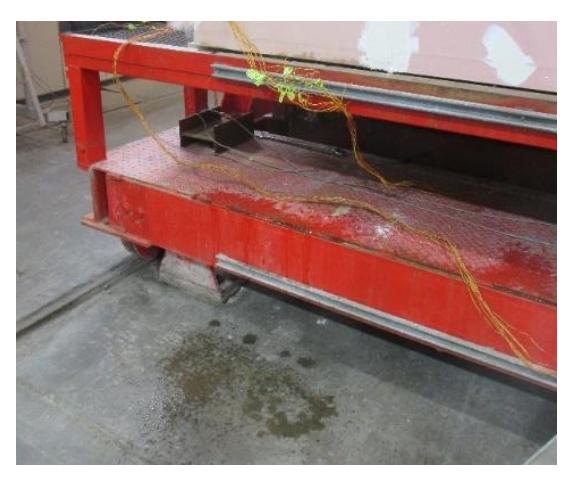

(b) Water dripping from the enclosure

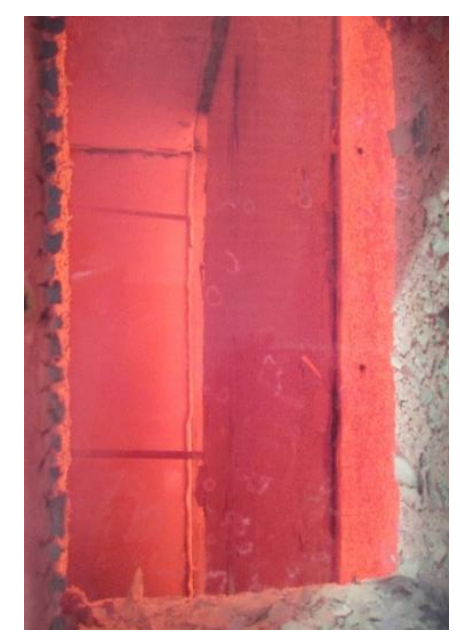

(c) Load-bearing wall specimen at 49 minutes showing large opening of sheet joints

Figure 6.22 - Photos of QR1810-162 during the test

Due to the lower exposure inside the furnace on the enclosure side, no discolouration of gypsum plasterboard lining was observed on the outside of the enclosure. The sheet joints and fastener heads were also observed to remain intact during the experiment.

Figure 6.23 shows the average temperature rise of the unexposed face of the $16 \mathrm{~mm}$ fire-rated gypsum plasterboard lined enclosure wall and floor/ceiling compared with past experiments tested to the standard ISO 834 exposure. Thermocouple locations are provided in Appendix F. Despite the lower exposure in the experiment, the comparison of the unexposed face wall temperatures was found to be good. However, the unexposed ceiling face temperatures measured from QR1810-162 were much lower than those from FR1370. 


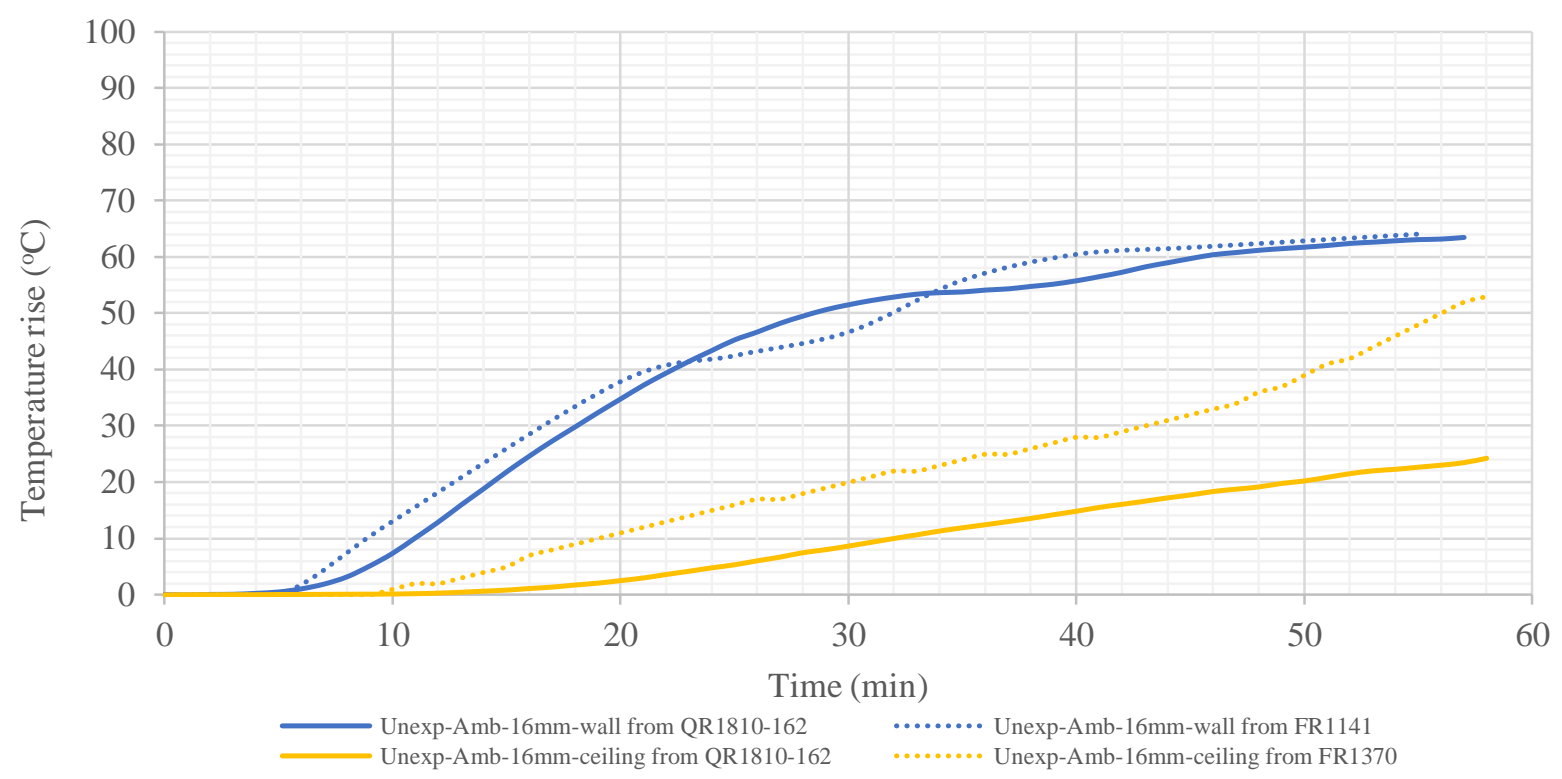

Figure 6.23 - Enclosure unexposed face temperature comparison with past tests

Figure 6.24 shows the average time-temperature rise profiles for the two dummy studs, where the legend indicates the depth of thermocouple locations measured from the furnace side. The stud temperatures remained below $100{ }^{\circ} \mathrm{C}$ for approximately 30 minutes which was about 10 minutes longer than the first experiment due to thicker gypsum plasterboard delaying the stud temperature rise. The stud temperatures on the furnace side rose rapidly from 30 minutes, whereas stud temperature from the enclosure side rose from approximately 42 minutes. This delay is as a result of the lower exposure on the enclosure side.

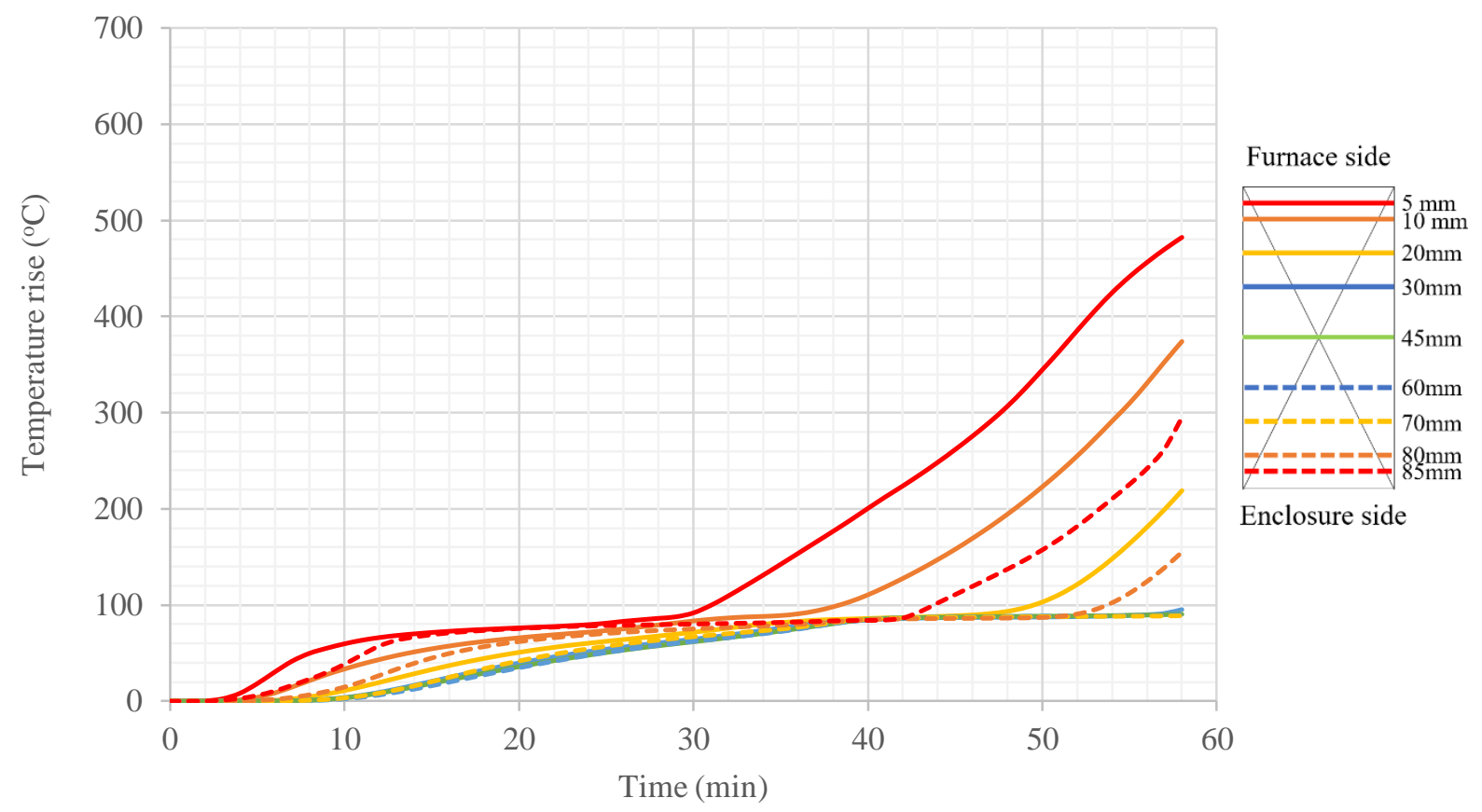

Figure 6.24 - Dummy stud time-temperature profiles of QR1810-162

Page $\mid 99$ 
Post-fire observation of the residual load-bearing wall specimen shown in Figure 6.25 indicated a global buckling failure towards the enclosure side. In standard fire-resistance tests, timberframed wall assemblies generally fail by buckling towards the ambient side due to moisture loss and shrinkage on the furnace side, and the effects of eccentricity. This results in the timber stud failing in compression on the furnace side first. Since the fire exposure condition on the enclosure side was much lower than the furnace side, the load-bearing wall specimen was observed to fail by buckling towards the enclosure side. If the fire exposure conditions on both sides were uniform, the timber stud is expected to fail by axial compression as observed in the finite element modelling results. However, because the timber in reality is not homogeneous with defects and natural variations, the stud would have failed by buckling.
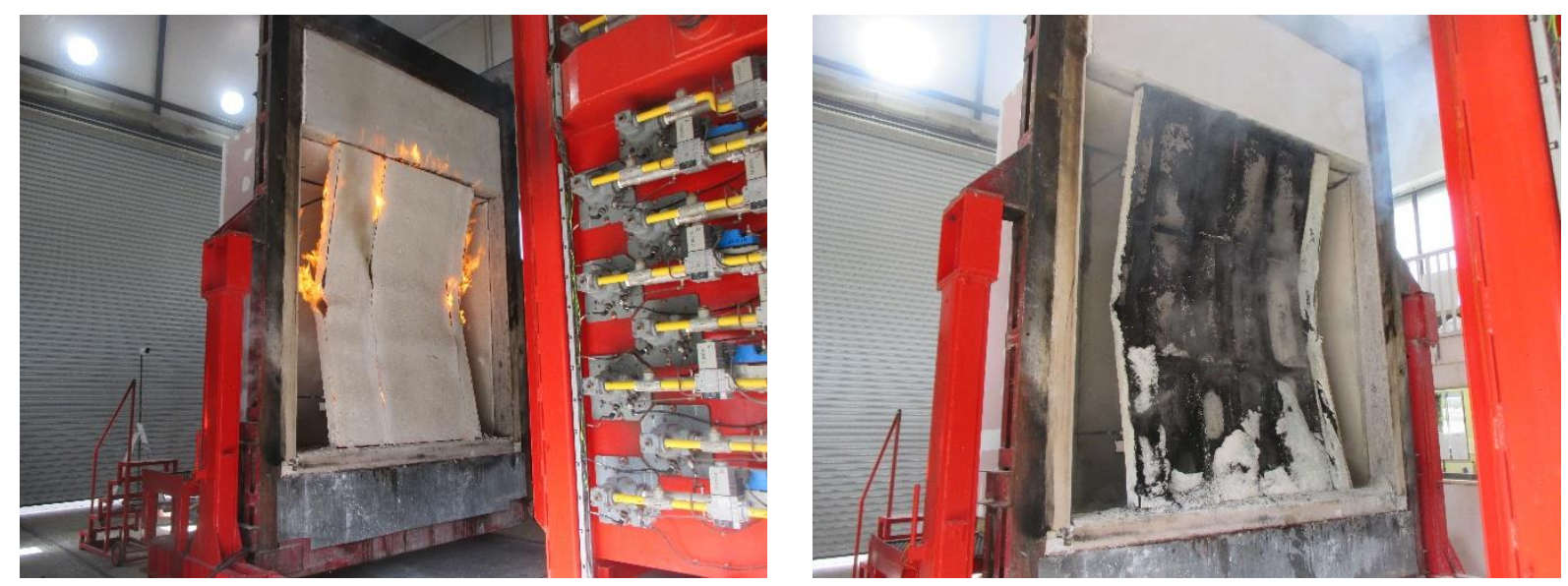

Figure 6.25 - Residual load-bearing wall specimen of QR1810-162

\subsubsection{Axial displacement and loading}

As shown in Figure 6.26, the vertical axial displacement of the load-bearing wall specimen was $-1.2 \mathrm{~mm}$ on average at the beginning of the experiment due to the thermal expansion of the specimen. Displacement moved back to zero at approximately 24 minutes and then increased gradually before ramping up from 53 minutes. 


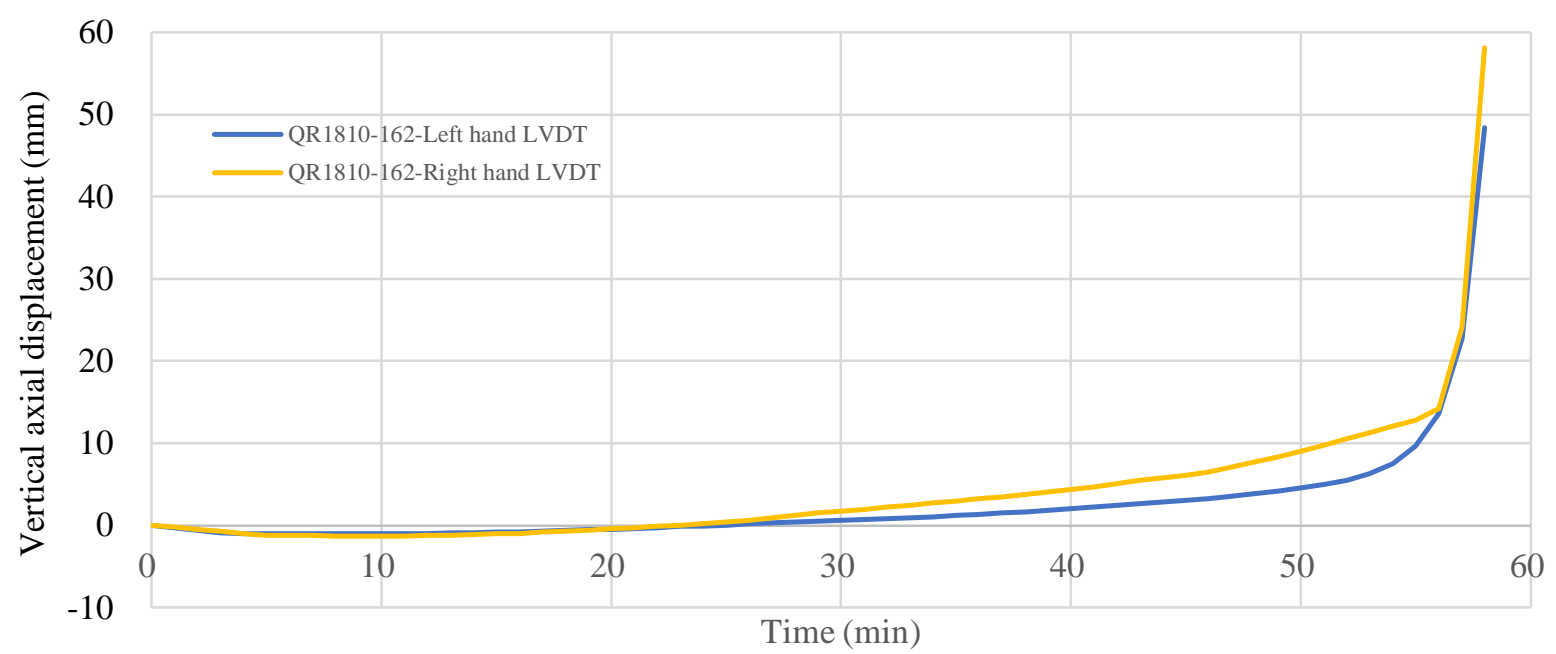

Figure 6.26 - Measured axial displacement in QR1810-162

Figure 6.27 shows the load variation with time applied by the two hydraulic jacks. The target load per hydraulic jack was $14.5 \mathrm{kN}$. At the beginning of the experiment, the measured load reached more than $16 \mathrm{kN}$ but was maintained at the target load satisfactorily after 10 minutes. At the structural adequacy failure, the load-bearing wall specimen was unloaded to prevent further loss of the specimen.

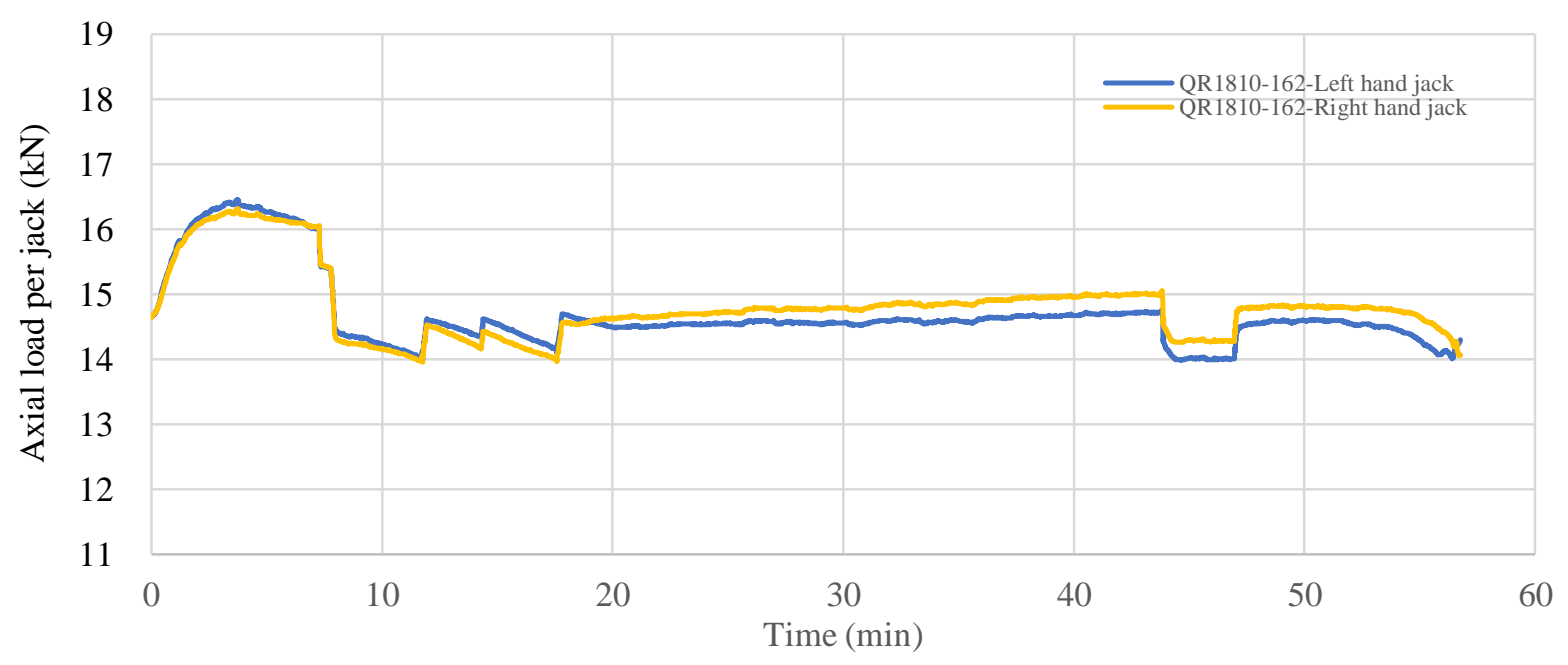

Figure 6.27 - Measured applied load per hydraulic jack in QR1810-162

\subsubsection{Structural adequacy failure}

A rate of axial contraction of $10.5 \mathrm{~mm} / \mathrm{min}$ and $9.2 \mathrm{~mm} / \mathrm{min}$ was measured from the LVDTs on the left-hand and right-hand side respectively at 57 minutes when they both exceeded the limit. The limiting axial contraction of $30 \mathrm{~mm}$ was exceeded at 58 minutes. Therefore, the structural adequacy failure was considered to occur at 57 minutes. 


\subsubsection{Experiment 3 (QR1810-163)}

\subsubsection{Furnace temperature}

Figure 6.28 shows the average time-temperature profile of the furnace measured from twelve MIMS chromel-alumel thermocouples and five plate thermometers to be in very good agreement with the AS 1530.4:2014 permitted upper and lower limits. It is noted that the width of wall opening at each end of the load-bearing wall specimen was increased from $500 \mathrm{~mm}$ to $750 \mathrm{~mm}$ in this experiment which improved the exposure on the enclosure side. The temperatures on the enclosure side fell within the AS 1530.4:2014 permitted limits relatively early at approximately 30 minutes compared with the first two experiments.

It can be seen in Figure 6.28 that a sudden decrease in furnace temperature occurred at approximately 45 minutes. This was due to an error with the LPG fuel supply when an automatic changeover valve did not switch from an empty gas cylinder to the next.

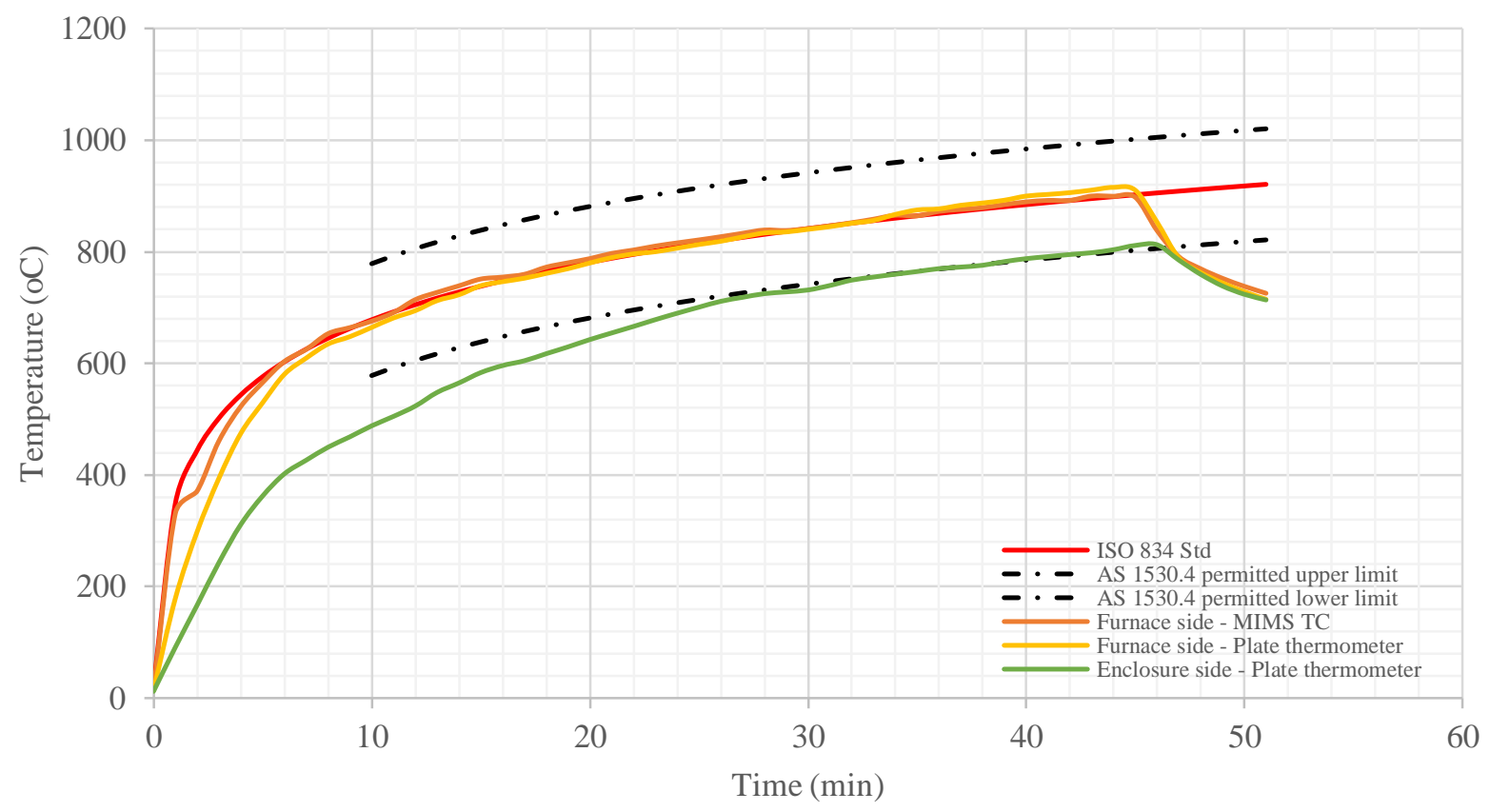

Figure 6.28 - Measured average furnace time-temperature profiles in QR1810-163

Although the LPG fuel supply stopped, the experiment was continued for another five minutes until the structural adequacy failure occurred. The measured furnace temperatures from the experiment were once again used as input into the thermal model, and the output results were used to predict the time to structural adequacy failure for this experiment. Detailed results and further discussions are provided in Section 7.1. 


\subsubsection{Observations}

Similar visual observations to the first two experiments were recorded in the third experiment. However, due to the increased exposure on the enclosure side in this experiment, it was observed that cracking of plaster stopping and plasterboard sheet joints as shown in Figures 6.29(a) and 6.29(b) occurred earlier than in the first two experiments. Also, the volume of smoke and steam in the beginning of the experiment was noticeably increased. Similar to the second experiment, the gypsum plasterboard did not fall during the experiment, and from visual observation, the load-bearing wall specimen remained standing reasonably straight when observed at 43 minutes as shown in Figure 6.29(d).

Although the exposure on the enclosure side increased slightly, there was still no discolouration of the gypsum plasterboard lining or cracking observed on the unexposed face of enclosure.

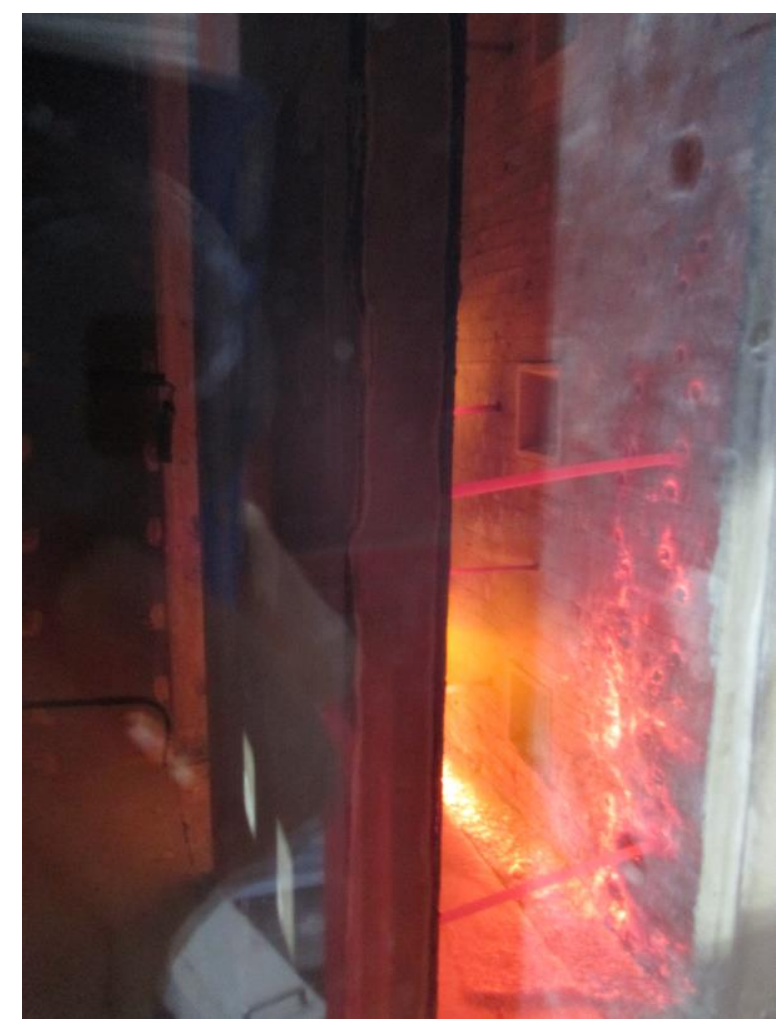

(a) Load-bearing wall specimen at $10 \mathrm{~min}$

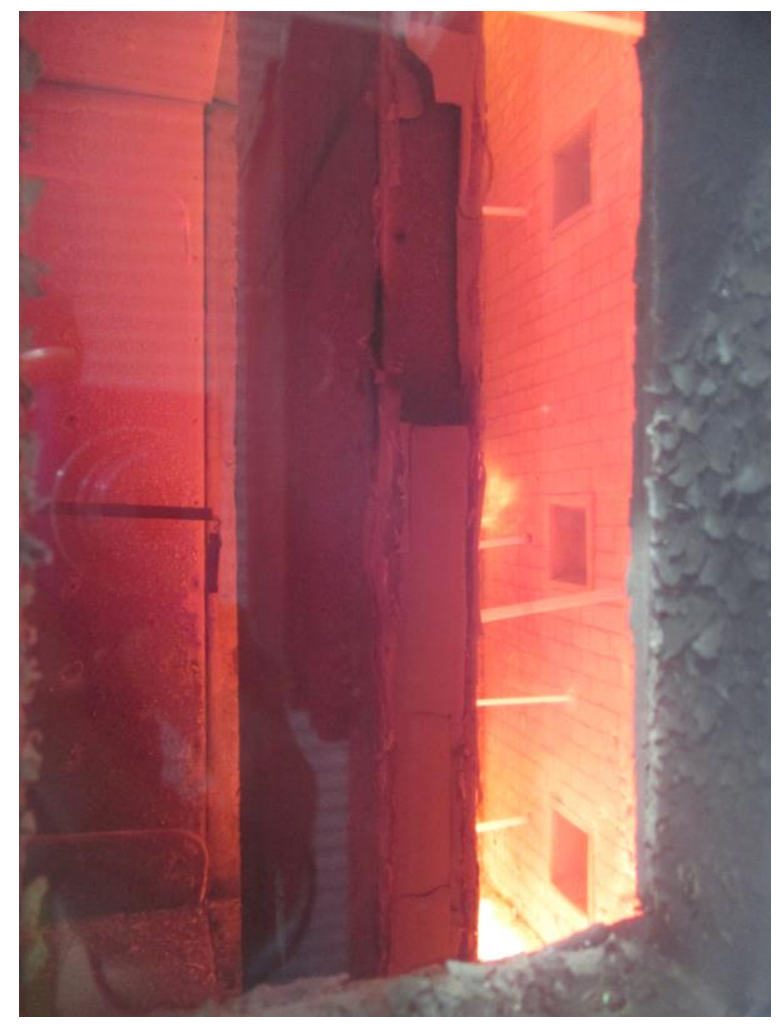

(b) Load-bearing wall specimen at 26 min 


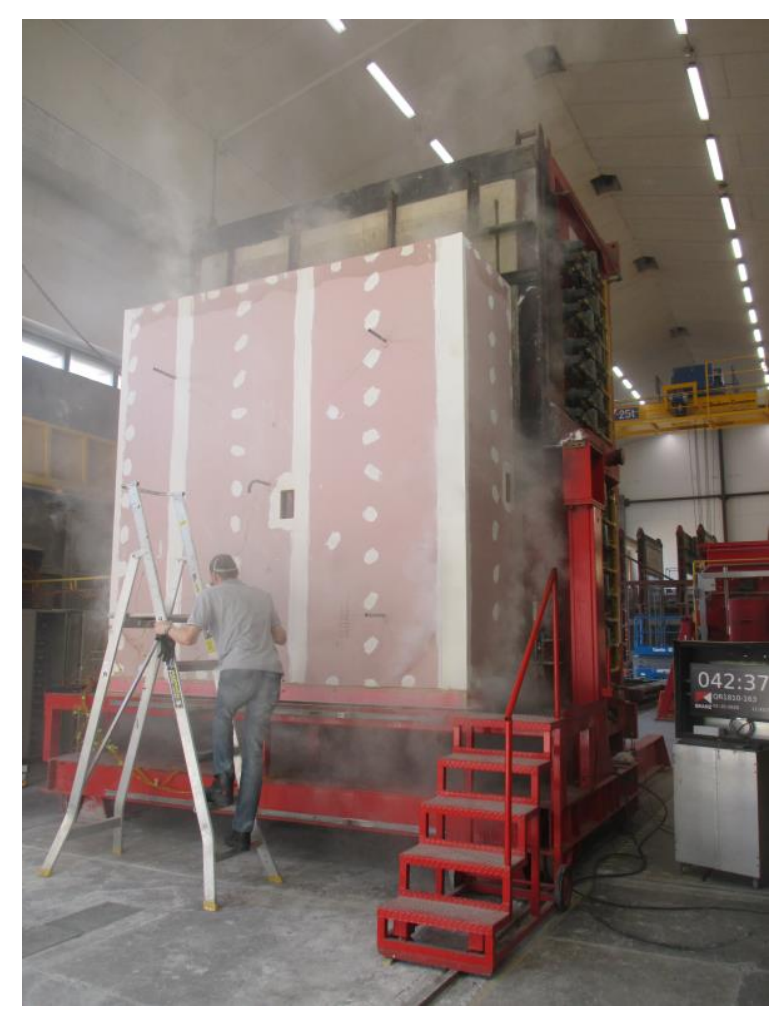

(c) Enclosures at 43 min

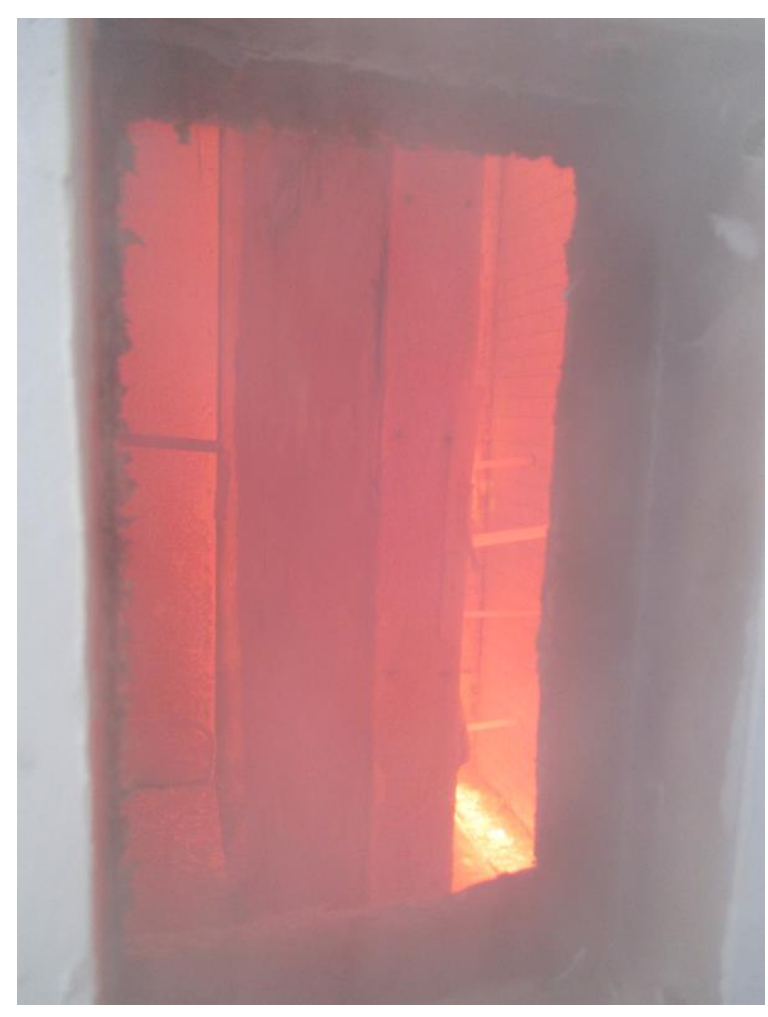

(d) Load-bearing wall specimen at 43 min

Figure 6.29 - Photos of QR1810-163 during the test

Figure 6.30 shows the average cavity temperature rise behind the exposed $13 \mathrm{~mm}$ fire-rated gypsum plasterboard of the load-bearing wall specimen on the furnace and enclosure side. Thermocouple locations are provided in Appendix F. As expected, the temperatures behind the exposed lining on the enclosure side had a longer plateau than those on the furnace side due to the lower exposure.

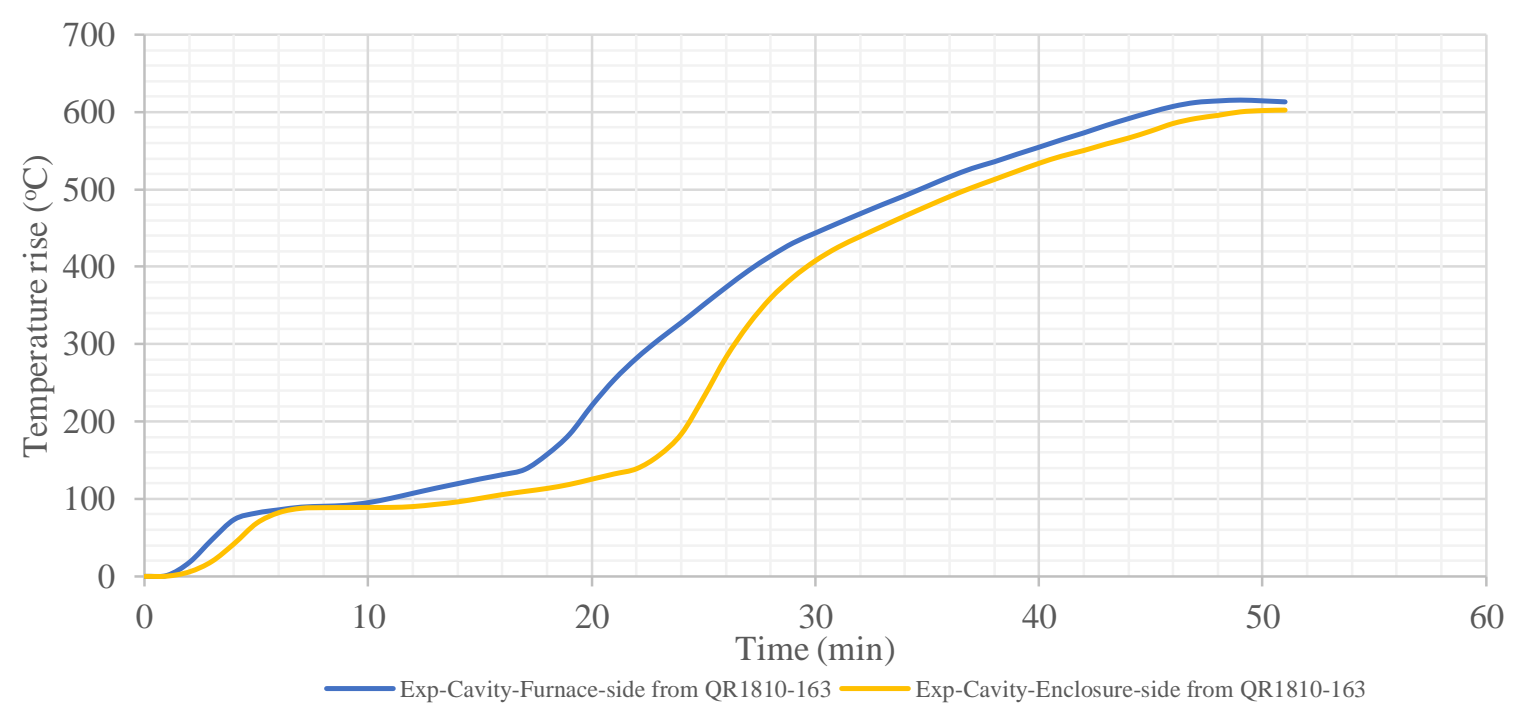

Figure 6.30 - Load-bearing wall specimen exposed cavity temperature 
The average time-temperature rise profile of the two dummy studs is shown in Figure 6.31, where the legend indicates the thermocouple depths measured from the furnace side. The stud temperatures remained below $100{ }^{\circ} \mathrm{C}$ for approximately 20 minutes and rapidly rose from 25 minutes starting from the outer to inner stud temperatures. With the increased exposure on the enclosure side, the stud temperatures measured at the equal depth from the furnace and enclosure sides showed good agreement although the enclosure side still showed slightly lower temperatures.

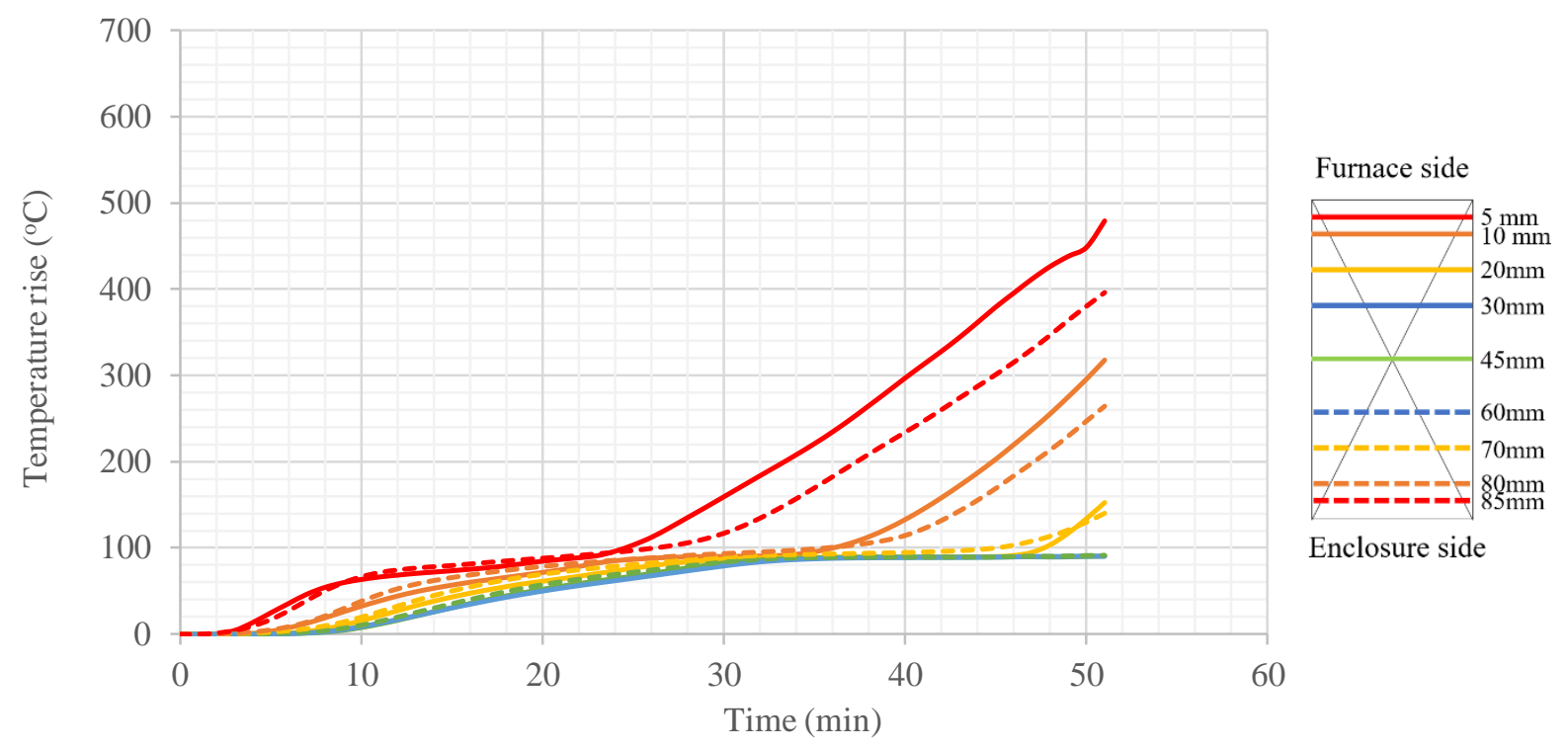

Figure 6.31 - Dummy stud time-temperature profiles of QR1810-163

Photos of the residual load-bearing wall specimen are provided in Figure 6.32. When the furnace was open for post-fire observations, a few minutes after structural adequacy failure, flaming was still visible inside the cavity of the load-bearing wall specimen as shown in Figure 6.32(a). After hosing down the flames and fully dehydrated gypsum plasterboard, it was observed that the load-bearing wall specimen had buckled towards the enclosure side similar to the second experiment. The timber studs failed in compression on the furnace side at close to the mid-height as shown in Figures 6.32(c) and 6.32(d). 


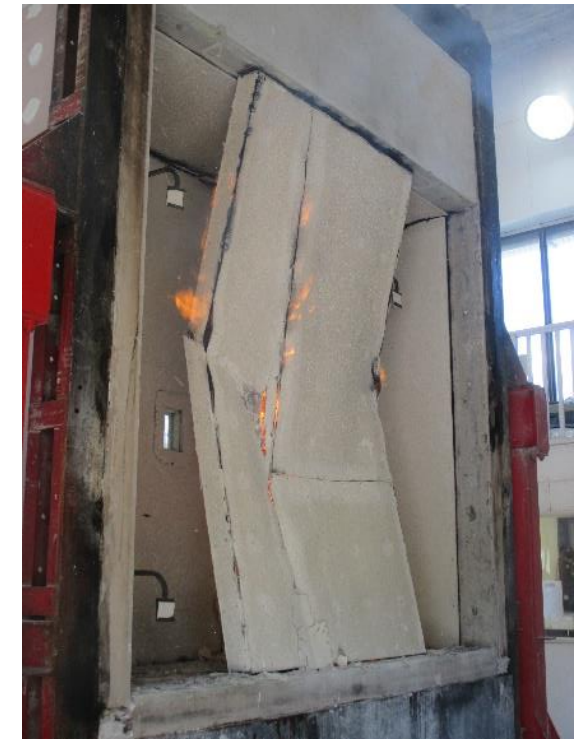

(a) Load-bearing wall specimen with flaming inside the cavity

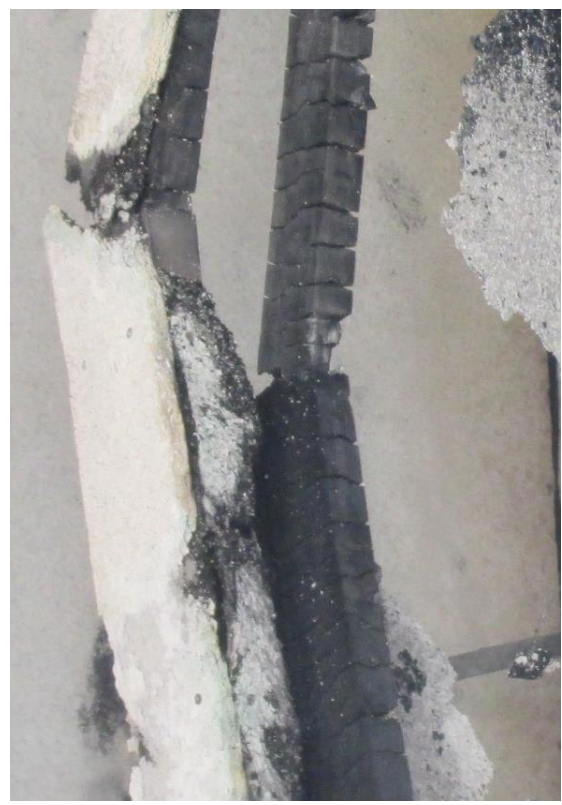

(c) Failure of stud 1

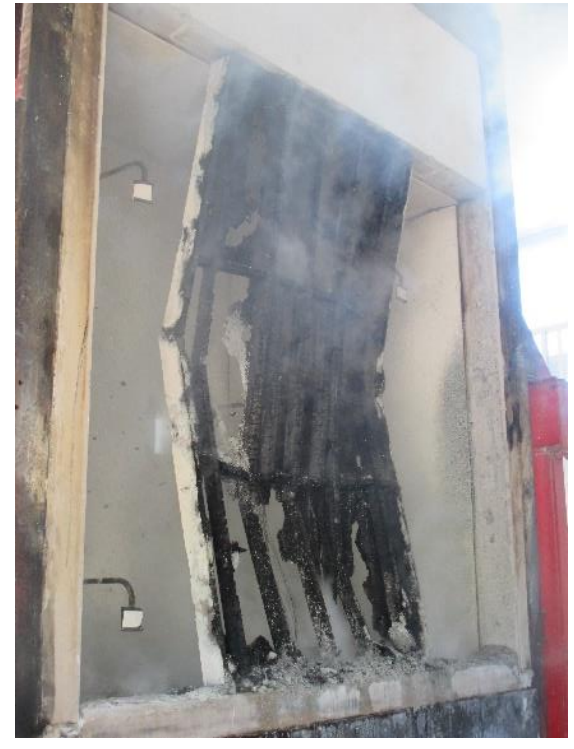

(b) Residual wall frame

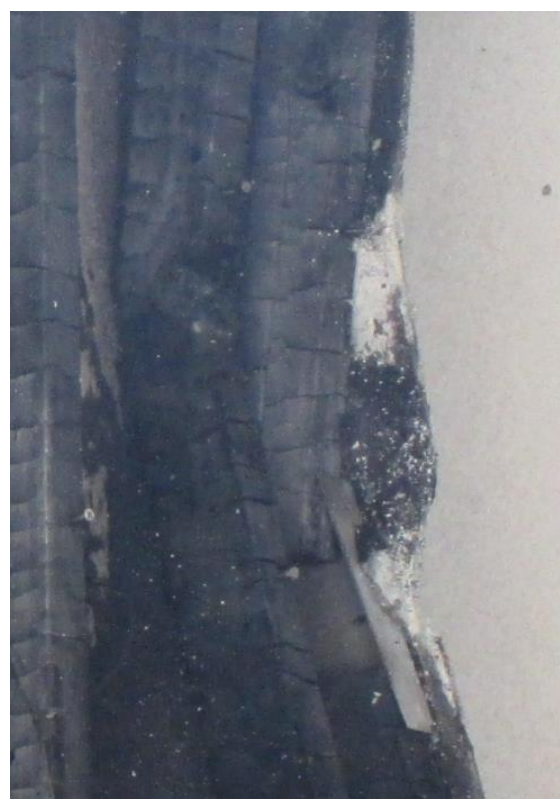

(d) Failure of stud 2

Figure 6.32 - Residual load-bearing wall specimen and failure of timber studs observed in QR1810-163

\subsubsection{Axial displacement and loading}

Figure 6.33 shows the measured axial displacement of the load-bearing wall specimen. The vertical displacement was $-0.3 \mathrm{~mm}$ on average at the beginning of the experiment due to thermal expansion of the specimen. Displacement moved back to zero after 10 minutes. The vertical displacement then started to gradually increase and ramped up after the LPG fuel supply stopped at 45 minutes. 


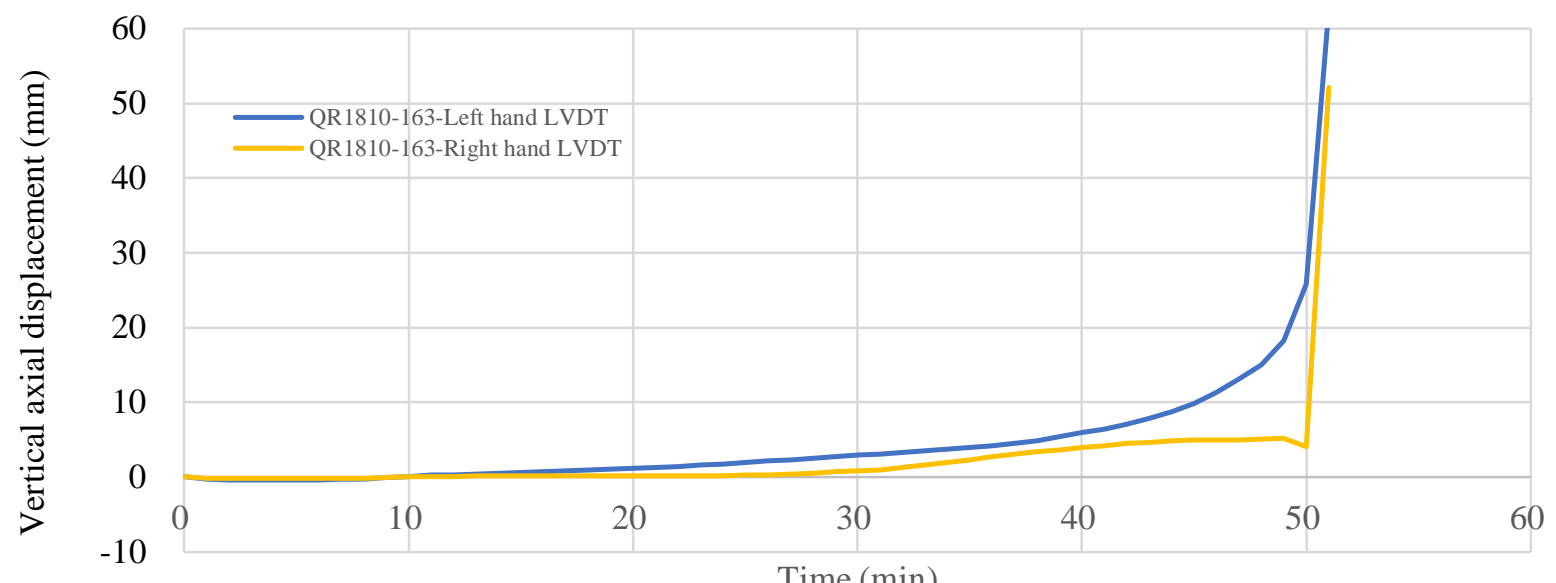

Figure 6.33 - Measured axial displacement in QR1810-163

The nominal applied load per hydraulic jack was $14.1 \mathrm{kN}$. In Figure 6.34, the load variation with time applied by two hydraulic jacks is shown. Like the previous experiments, a slight load increase was observed which was adjusted back to the target applied load at 5 minutes. The load by the hydraulic jack on the right-hand side was well maintained at the target load until the end of the experiment. However, the load by the hydraulic jack on the left-hand side showed approximately $1 \mathrm{kN}$ less than that on the right-hand side. At the time of structural adequacy failure, the load-bearing wall specimen was unloaded to prevent further loss of the specimen.

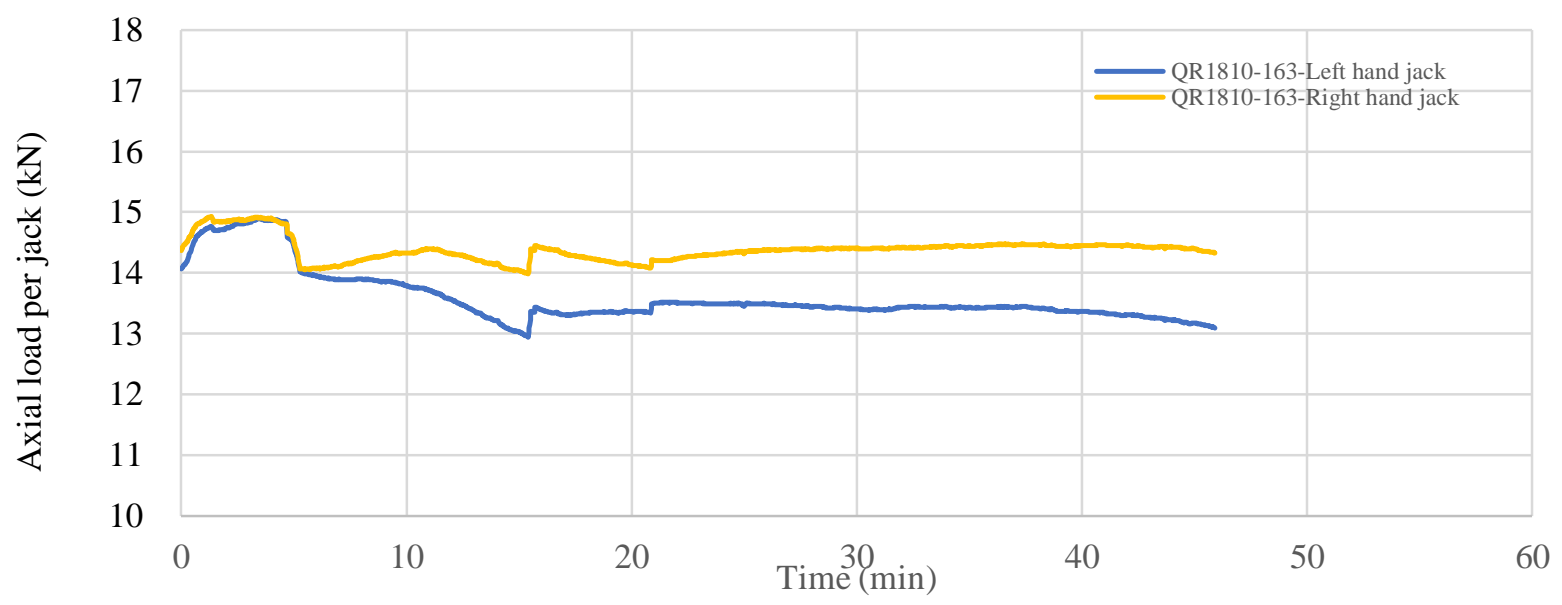

Figure 6.34 - Measured applied load per hydraulic jack in QR1810-163

\subsubsection{Structural adequacy failure}

A rate of axial contraction of $9.2 \mathrm{~mm} / \mathrm{min}$ and $14.6 \mathrm{~mm} / \mathrm{min}$ was measured by the LVDTs on the left-hand and right-hand side at 50 and 51 minutes respectively when both exceeded the limit. The limiting axial contraction of $30 \mathrm{~mm}$ was also exceeded at 51 minutes. Therefore, the structural adequacy failure was considered to occur at 50 minutes. 


\section{Development of Design Methodology}

\subsection{Computational finite element modelling for lower exposure}

As discussed in Chapter 6, the measured furnace temperature on the enclosure side poorly aligned with the ISO 834 standard fire time-temperature curve. Hence, the developed thermal and structural finite element models for two-sided fire exposure were modified to accommodate the furnace temperatures measured from the three experiments. The intention was to validate the developed model and check its predictions using different fire exposures on opposite sides of the load-bearing timber-framed wall, so that the ideal design scenario of twosided ISO 834 standard fire exposure could be modelled.

The three heat transfer modes of radiation, conduction and convection were considered as shown in Figure 7.1, and the measured furnace time-temperature curves were applied on both sides of the wall assembly.

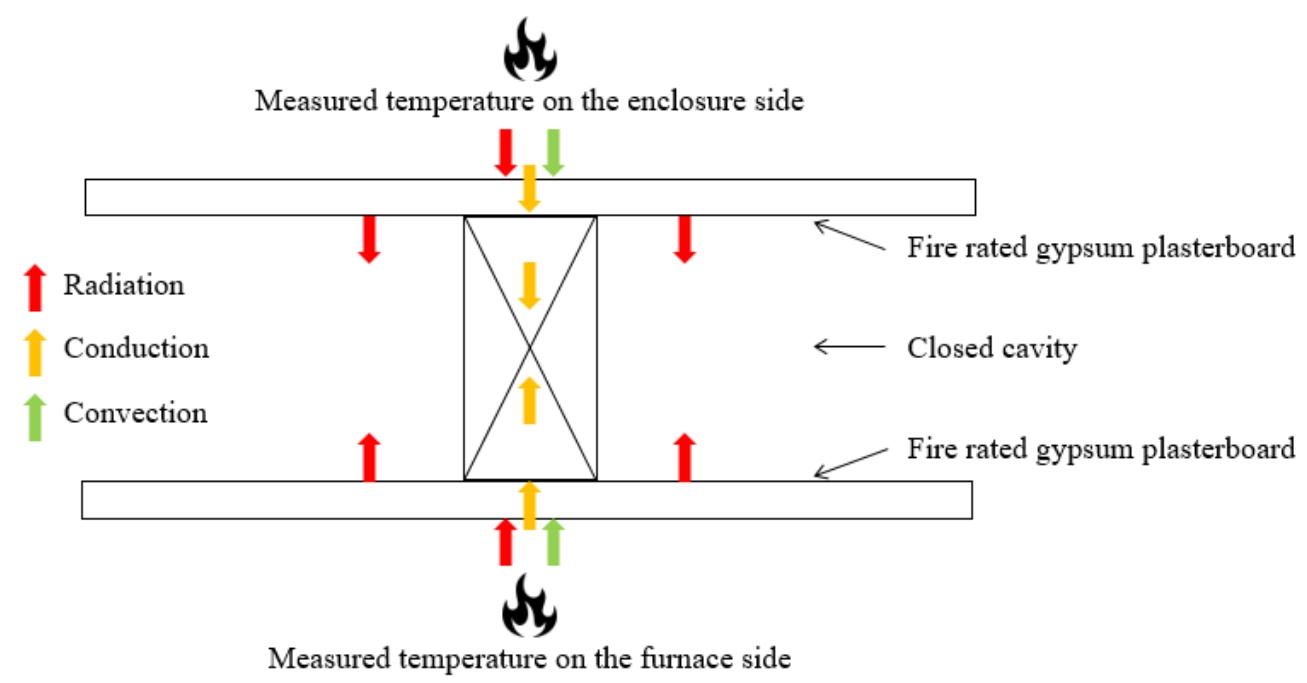

Figure 7.1 - Two-sided fire exposure heat transfer modes with lower exposure on the enclosure side

Figure 7.2 shows the proposed timber stud temperature distribution when subjected to twosided fire exposure with lower exposure on one side. The average time-temperature profiles for the two exposed faces and two sides of the timber stud were determined from the thermal model. All other input parameters and finite element analysis methods remained the same as described in Sections 4.2 and 4.3. 


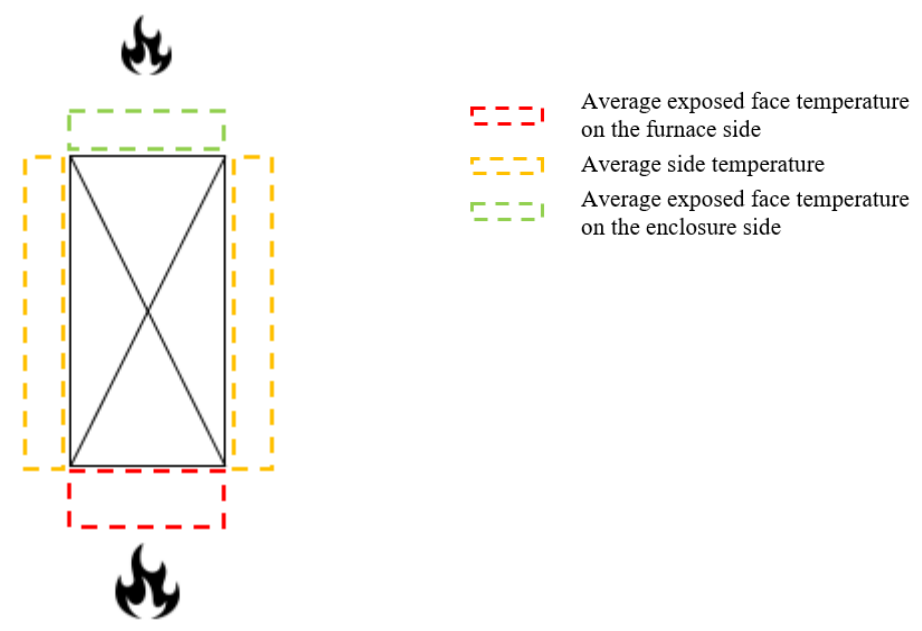

Figure 7.2 - Two-sided fire exposure temperature distribution with lower exposure on enclosure side

\subsubsection{Measured stud temperature comparison with prediction model}

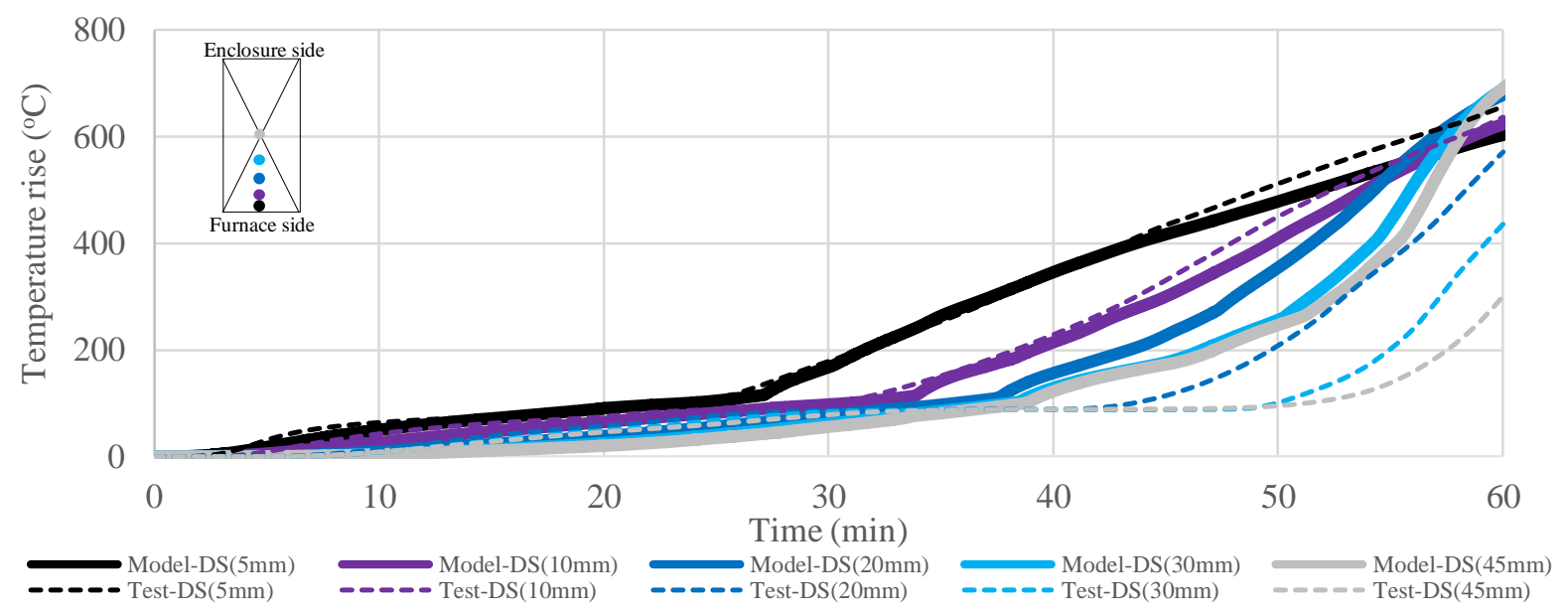

(a) Timber stud temperatures at depths of 5, 10, 20,30 and $45 \mathrm{~mm}$

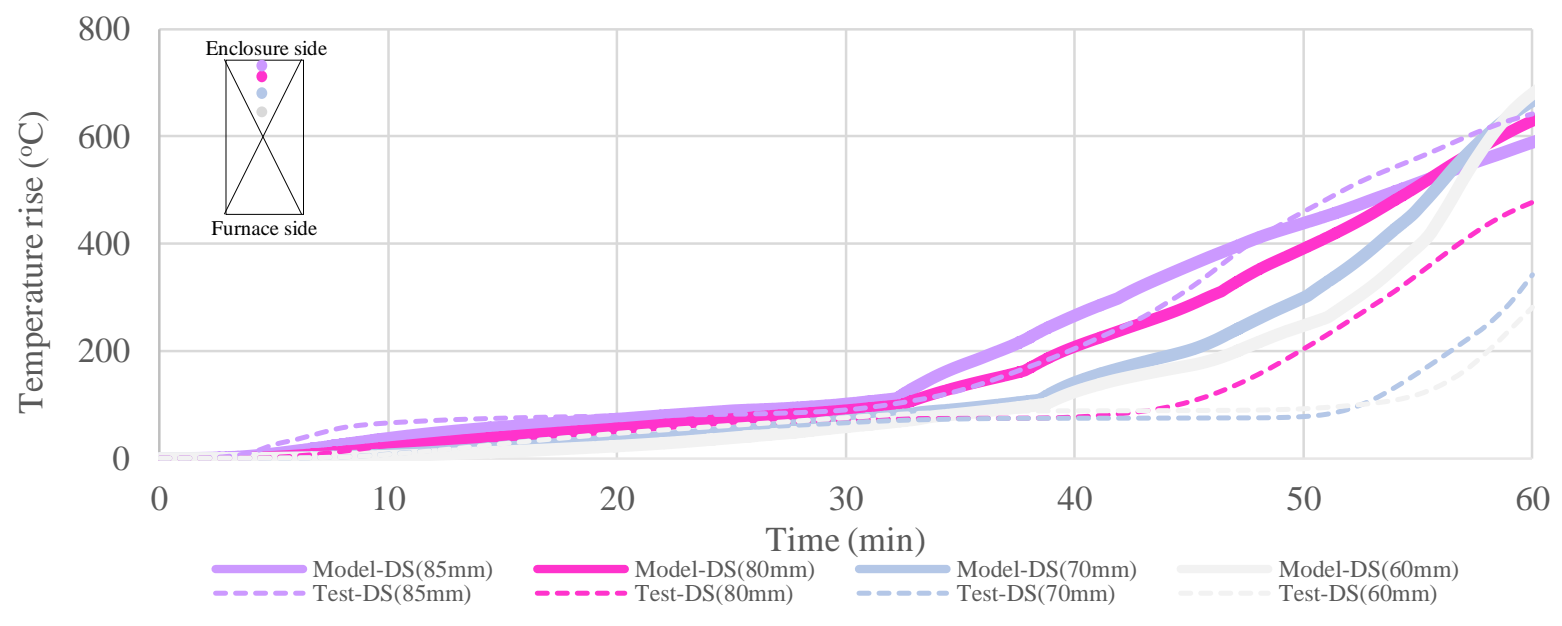

(b) Timber stud temperatures at depths of 60, 70, 80 and $85 \mathrm{~mm}$

Figure 7.3 - Experimental and modelled timber stud temperatures for QR1810-161 
Figure 7.3 shows the time-temperature profile comparison between test QR1810-161 and the thermal model output for the timber stud at depths of 5, 10, 20, 30, 45, 60, 70, 80 and $85 \mathrm{~mm}$ measured from the furnace side. The comparison of outer stud thermocouple temperatures was good. The comparison of inner stud thermocouple temperatures was good until approximately 35 minutes when the modelled temperatures started to rapidly increase approximately 8 minutes earlier than the measured temperatures.

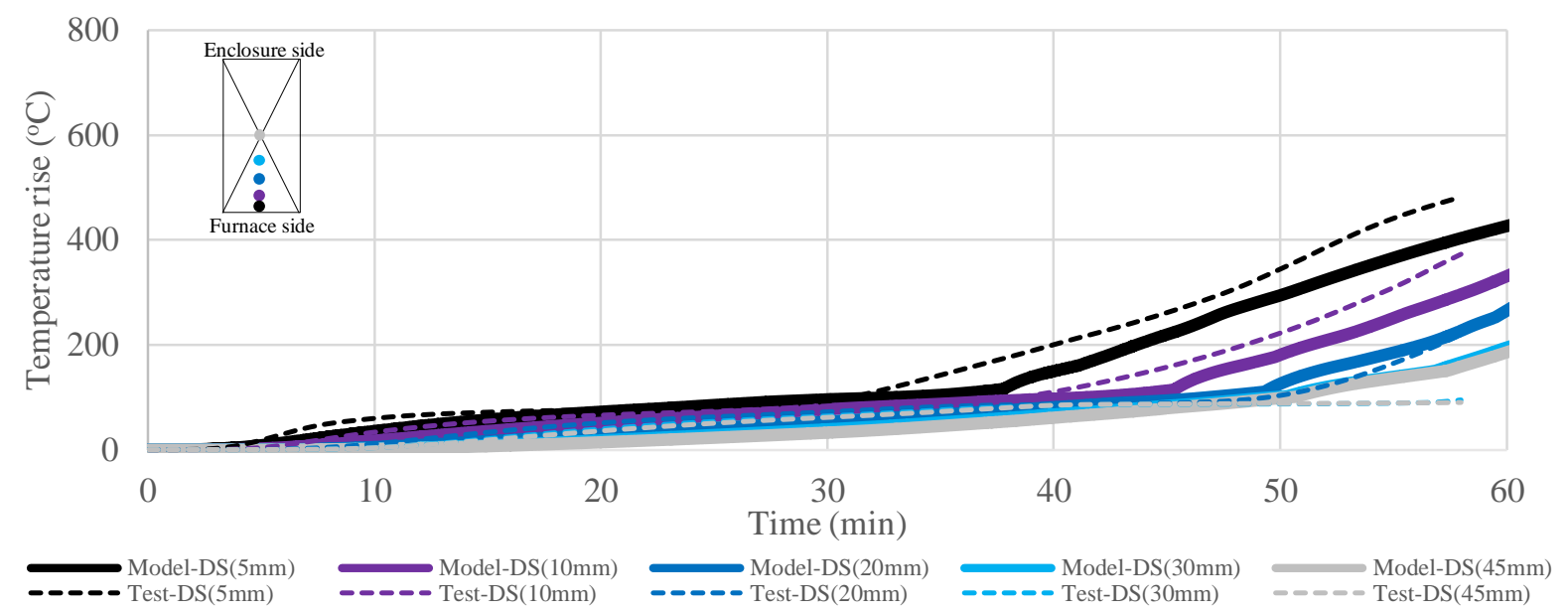

(a) Timber stud temperatures at depths of 5, 10, 20,30 and $45 \mathrm{~mm}$

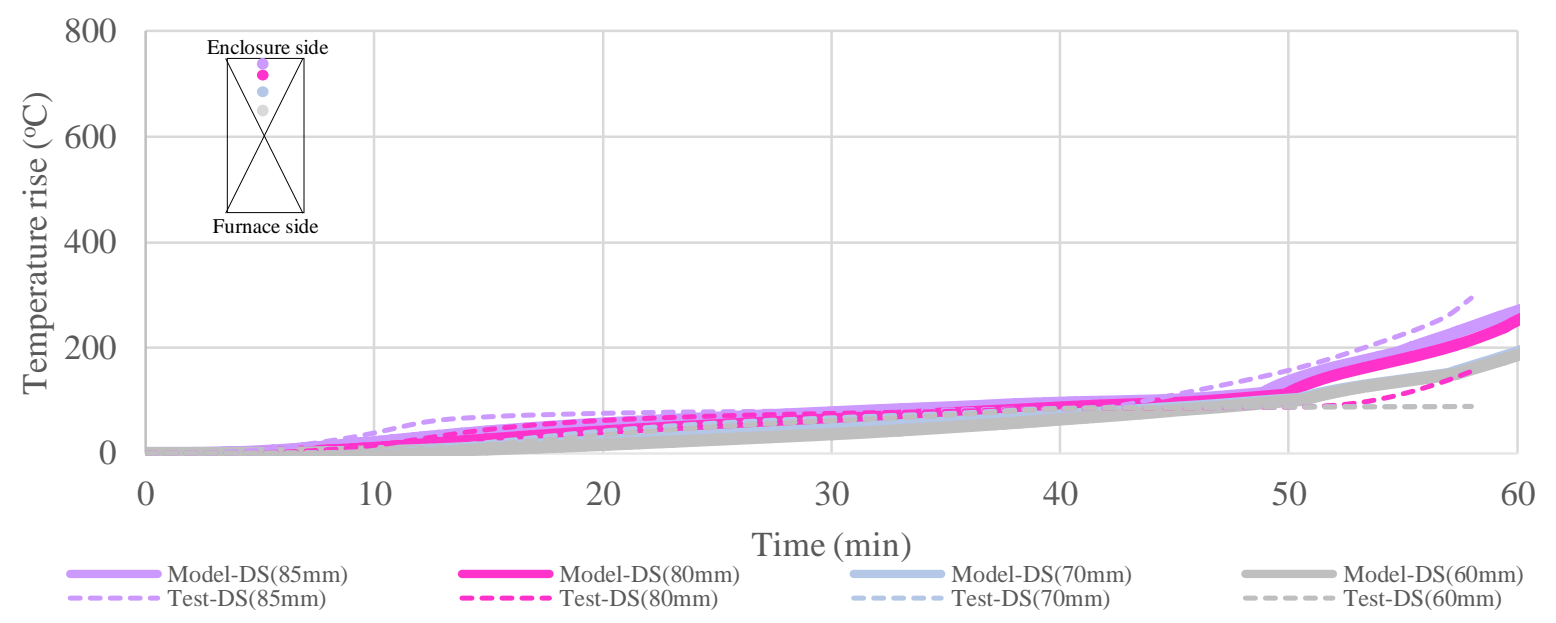

(b) Timber stud temperatures at depths of 60, 70, 80 and $85 \mathrm{~mm}$

Figure 7.4 - Experimental and modelled timber stud temperatures for QR1810-162

The time-temperature comparison between test QR1810-162 and the thermal model output for the timber stud is shown in Figure 7.4. The agreement between the experimental and model results was very good although most predicted stud temperatures were marginally lower than the measured stud temperatures. The test had a timber-framed wall specimen lined with $16 \mathrm{~mm}$ fire-rated gypsum plasterboard. In this test, both the predicted and the measured timber stud temperatures were lower than those shown in Figure 7.3. This indicates that the thicker gypsum 
plasterboard delays the timber stud temperature rise, and hence improves structural adequacy of the fire-rated wall assembly.

Figure 7.5 shows the time-temperature profile comparison between test QR1810-163 and the thermal model output for the timber stud. The comparison was good until approximately 40 minutes when the accuracy of the model started to reduce predicting inner stud temperatures higher than the experimental data similar to the comparison between test QR1810-161 and its thermal model. The modelled outer stud temperatures provided very good agreement with the measured temperatures even after 40 minutes.

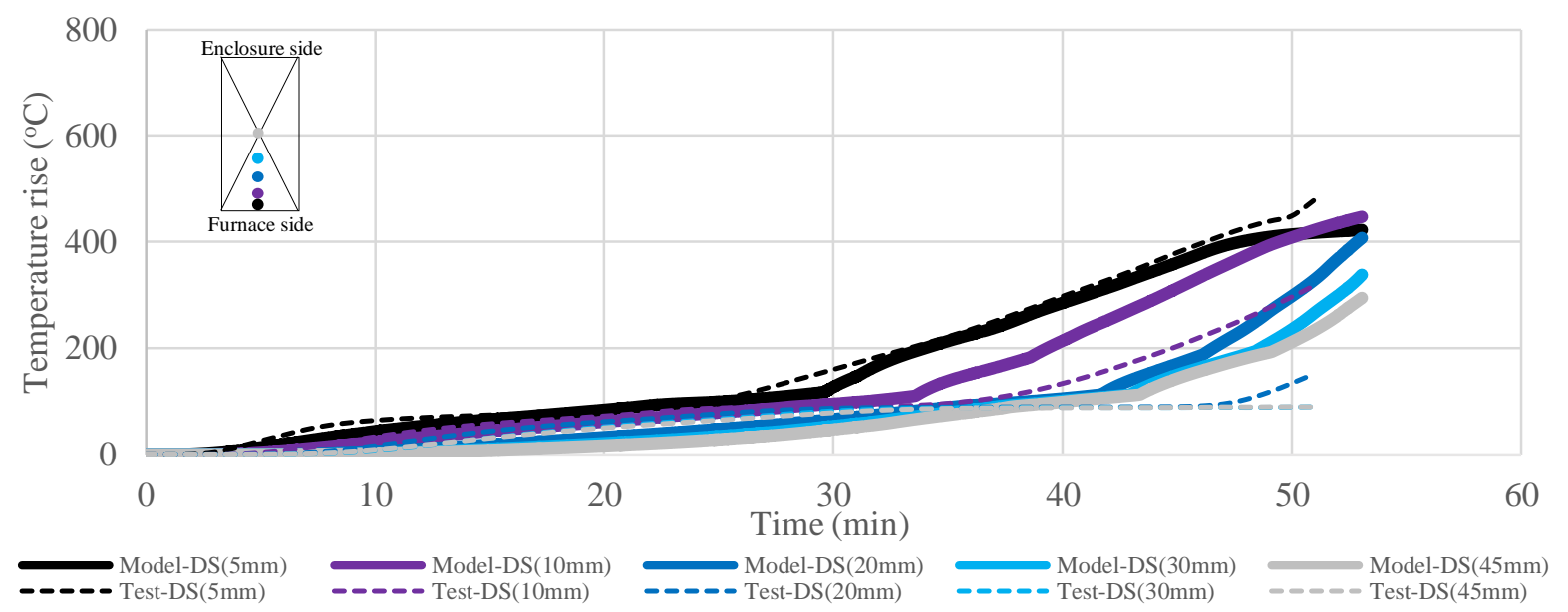

(a) Timber stud temperatures at depths of $5,10,20,30$ and $45 \mathrm{~mm}$

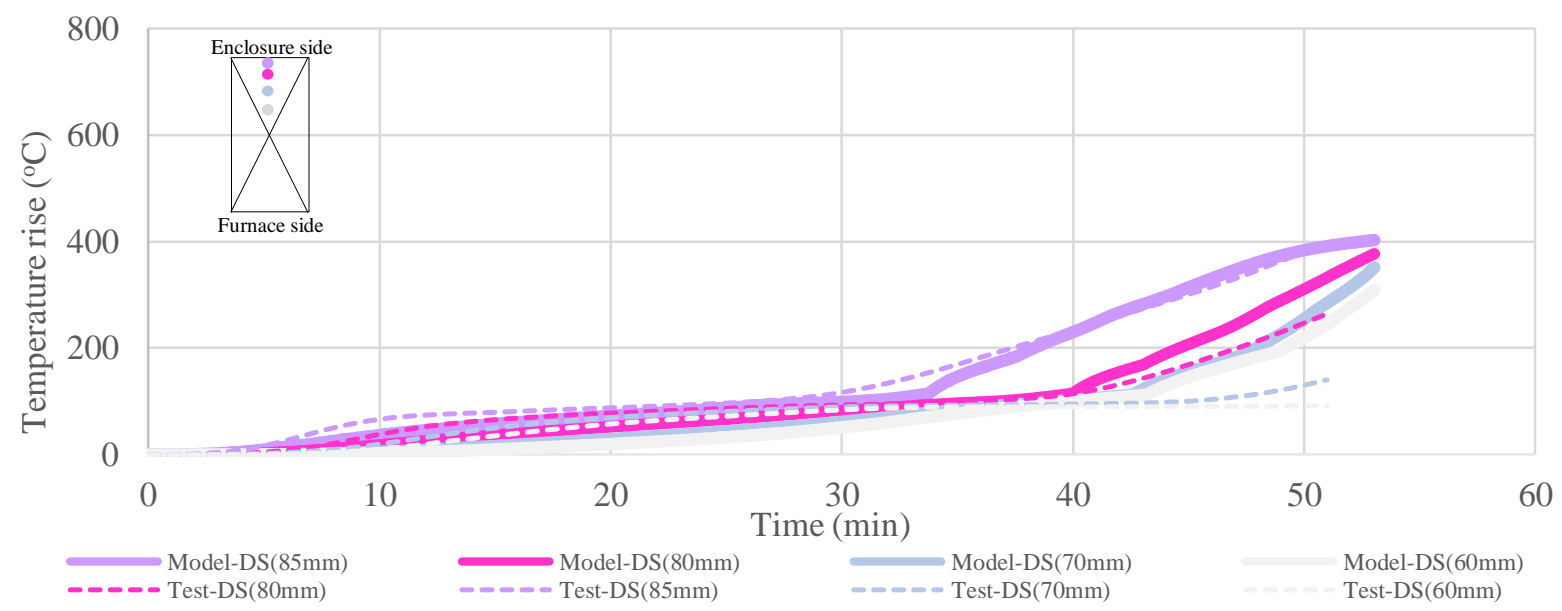

(b) Timber stud temperatures at depths of $60,70,80$ and $85 \mathrm{~mm}$

Figure 7.5 - Experimental and modelled timber stud temperatures for QR1810-163 


\subsubsection{Measured axial displacement comparison with prediction model}

Figure 7.6 shows measured axial displacement-time graphs for tests QR1810-161, QR1810-162 and QR1810-163. The plots also show modelled axial displacement for the walls subjected to one and two-sided ISO 834 standard fire exposures, and two-sided exposure using data measured from the tests with lower exposure on one side.

In all three experiments, it was observed that the predicted axial displacement of timber studs subjected to two-sided ISO 834 standard fire exposure reached the structural adequacy failure criteria earlier than walls subjected to one-sided ISO 834. Walls with lower exposure on one side failed later than walls exposed both sides to the standard ISO 834 conditions.

Measured axial displacements were found to exponentially increase once an axial displacement of approximately $10 \mathrm{~mm}$ was reached, whereas predicted axial displacements rapidly increased once an axial displacement of approximately $5 \mathrm{~mm}$ was reached.

The comparison between the measured and predicted axial displacements was good apart from the comparison for QR1810-161 which had the experimental error of the movement of the concrete bottom platen being restricted on one side. This caused inaccurate measurement of the axial displacement due to the uneven load spread.

\subsubsection{Measured structural adequacy failure with prediction model}

Table 7.1 describes the three full-scale fire-resistance tests conducted in this research and provides measured and predicted structural adequacy failure times from the tests and developed structural models respectively. The predicted failure mode was global buckling towards the lower exposure side as observed in the experiments.

The differences in structural adequacy failure time between the test and model ranged from 3 to 5 minutes with an average difference of $6.0 \%$. The structural model under-predicted the structural adequacy failure for $13 \mathrm{~mm}$ thick fire-rated gypsum plasterboard whereas the model for $16 \mathrm{~mm}$ thick fire-rated gypsum plasterboard was over-predicting the axial displacement. Overall, the comparison between the test and model was good, and the developed models for two-sided fire exposure with lower exposure on one side was considered sufficiently accurate in predicting the structural adequacy failure time of the gypsum plasterboard lined timberframed wall assemblies. 


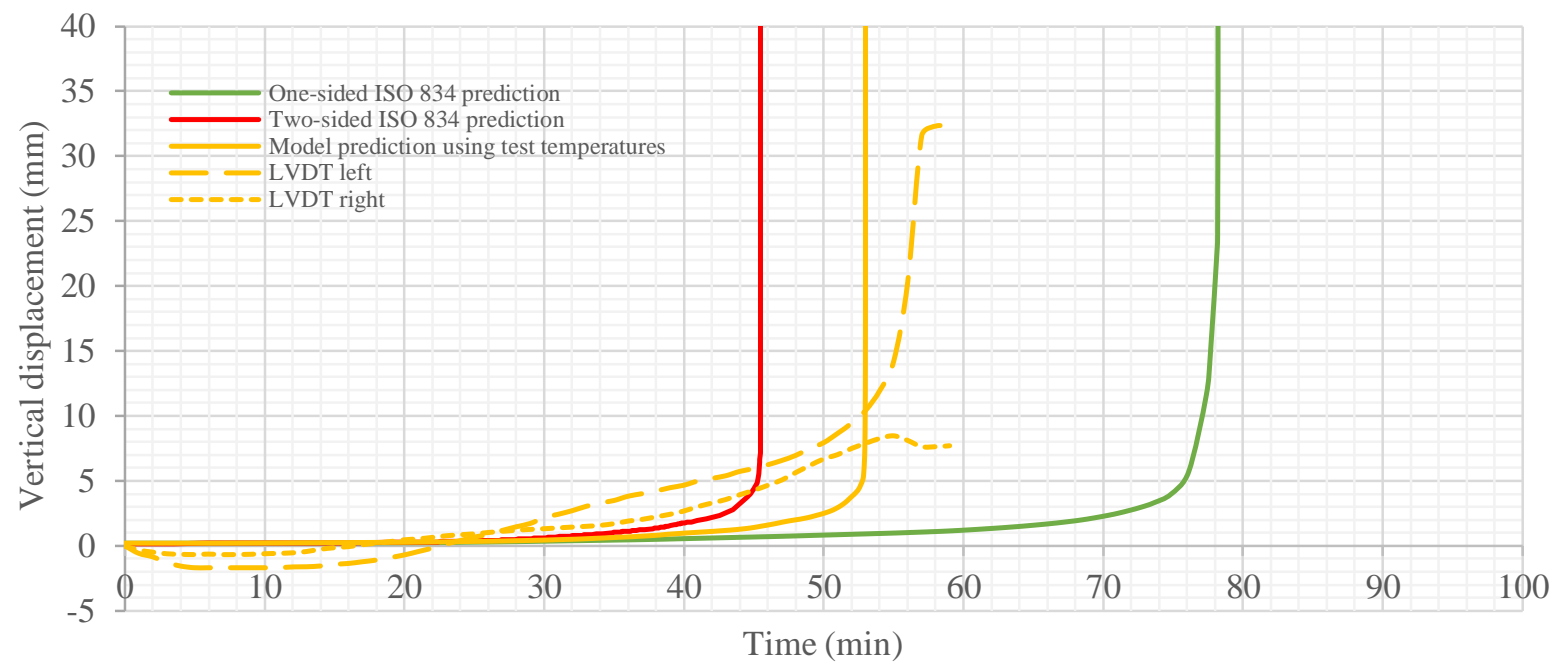

(a) Axial displacement-time plot for QR1810-161

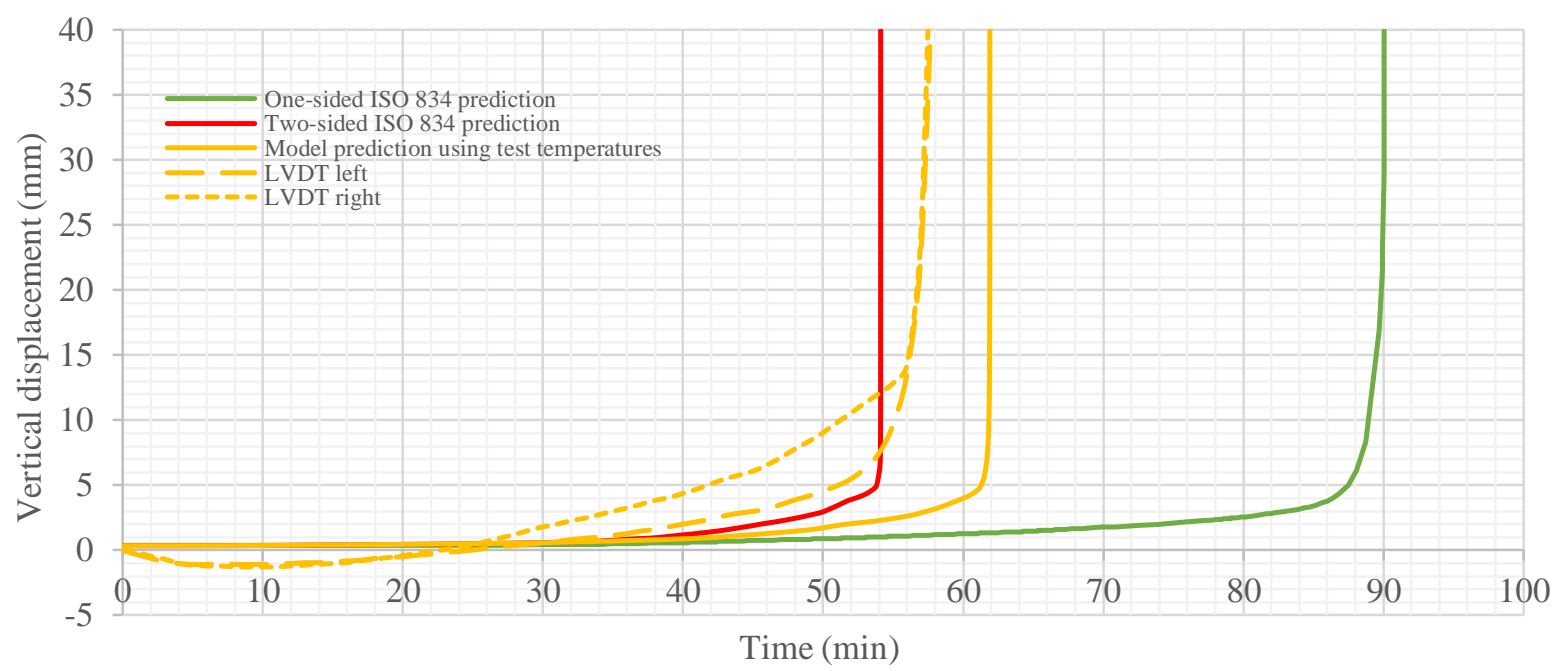

(b) Axial displacement-time plot for QR1810-162

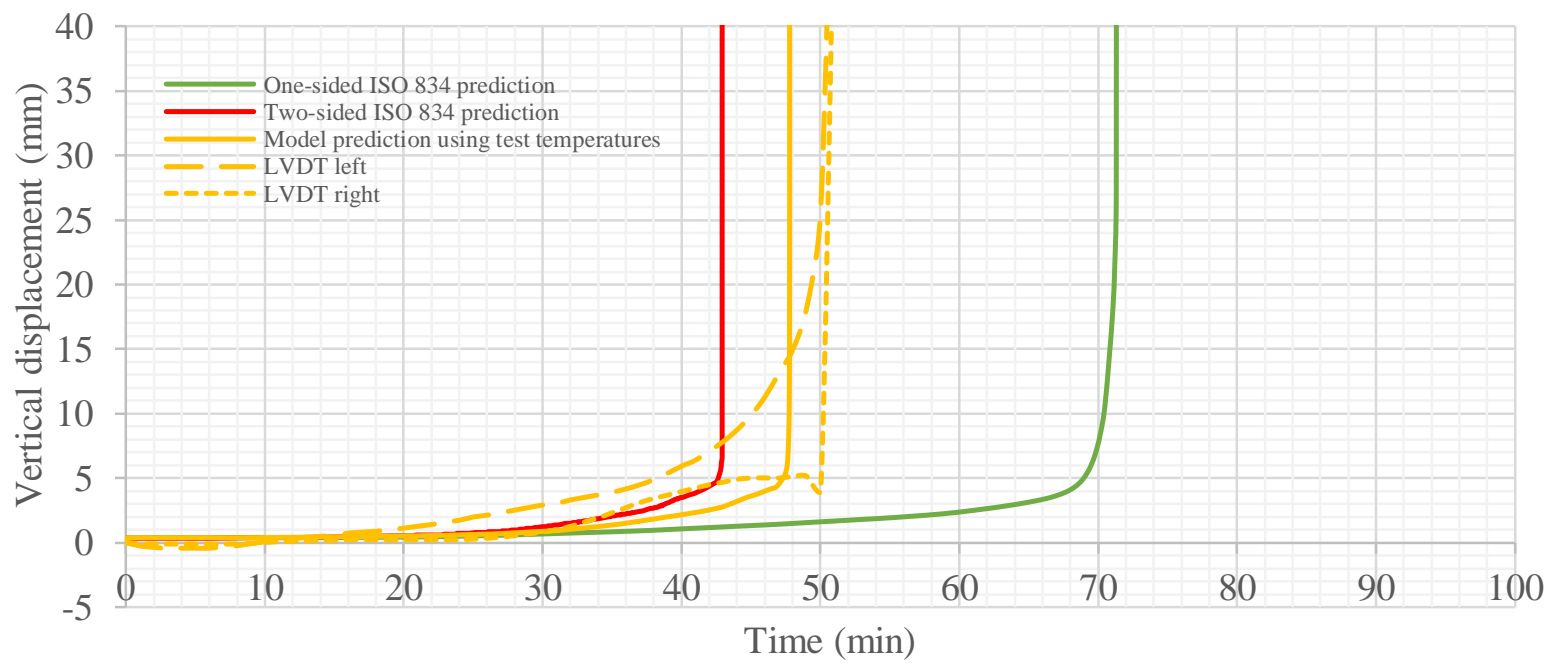

(c) Axial displacement-time plot for QR1810-163

Figure 7.6 - Experimental and modelled vertical axial displacements 
Table 7.1 - Measured and predicted structural adequacy failure times

\begin{tabular}{|c|c|c|c|c|}
\hline $\begin{array}{c}\text { BRANZ test } \\
\text { number }\end{array}$ & $\begin{array}{c}\text { Fire-rated } \\
\text { gypsum } \\
\text { plasterboard } \\
\text { thickness }(\mathrm{mm})\end{array}$ & $\begin{array}{c}\text { Applied axial } \\
\text { load per stud } \\
(\mathrm{kN})\end{array}$ & $\begin{array}{c}\text { Measured } \\
\text { structural } \\
\text { adequacy failure } \\
\text { time (min) }\end{array}$ & $\begin{array}{c}\text { Predicted } \\
\text { structural } \\
\text { adequacy failure } \\
\text { time (min) }\end{array}$ \\
\hline QR1810-161 & 13 & 2 & 56 & 53 \\
\hline QR1810-162 & 16 & 4 & 57 & 62 \\
\hline QR1810-163 & 13 & 4 & 50 & 48 \\
\hline
\end{tabular}

\subsubsection{Measured residual section comparison with prediction model}

The average temperatures of the timber stud measured from QR1810-161, QR1810-162 and QR1810-163 are provided in Tables 7.2, 7.3 and 7.4 respectively. Each table includes the average stud temperature at depths of $5,10,20,30,45,60,70,80$ and $85 \mathrm{~mm}$ measured from the furnace side, for a 5 minute duration around the measured structural adequacy failure time. The depth of timber char was calculated back from the position of the $300{ }^{\circ} \mathrm{C}$ isotherm, and the width of timber char was determined based on the method of calculating the residual stud crosssection suggested by Collier [50]. At structural failure the residual stud cross-sections measured from QR1810-161 were approximately 50 x $20 \mathrm{~mm}$ and from QR1810-162 and QR1810-163 they were $60 \times 30 \mathrm{~mm}$.

Table 7.2 - Average timber stud temperatures measured from QR1810-161

\begin{tabular}{|c|c|c|c|c|c|c|c|c|c|}
\hline $\begin{array}{c}\text { Time } \\
(\mathrm{min})\end{array}$ & \multicolumn{6}{|c|}{ Average timber stud temperatures at various depths measured from the exposed } \\
& \multicolumn{7}{|c|}{ stud face on the furnace side $\left({ }^{\circ} \mathrm{C}\right)$} \\
\cline { 2 - 11 } & $5 \mathrm{~mm}$ & $10 \mathrm{~mm}$ & $20 \mathrm{~mm}$ & $30 \mathrm{~mm}$ & $45 \mathrm{~mm}$ & $60 \mathrm{~mm}$ & $70 \mathrm{~mm}$ & $80 \mathrm{~mm}$ & $85 \mathrm{~mm}$ \\
\hline 53 & 570 & 525 & 315 & 161 & 124 & 114 & 121 & 296 & 537 \\
\hline 54 & 584 & 544 & 349 & 184 & 135 & 120 & 144 & 324 & 555 \\
\hline 55 & 598 & 562 & 382 & 215 & 151 & 130 & 171 & 355 & 572 \\
\hline 56 & 611 & 580 & 415 & 252 & 172 & 148 & 199 & 387 & 590 \\
\hline 57 & 625 & 597 & 453 & 302 & 197 & 174 & 229 & 418 & 609 \\
\hline
\end{tabular}


Table 7.3 - Average timber stud temperatures measured from QR1810-162

\begin{tabular}{|c|c|c|c|c|c|c|c|c|c|}
\hline $\begin{array}{c}\text { Time } \\
(\mathrm{min})\end{array}$ & \multicolumn{6}{|c|}{ Average timber stud temperatures at various depths measured from the exposed } \\
& \multicolumn{7}{|c|}{ stud face on the furnace side $\left({ }^{\circ} \mathrm{C}\right)$} \\
\cline { 2 - 11 } & $5 \mathrm{~mm}$ & $10 \mathrm{~mm}$ & $20 \mathrm{~mm}$ & $30 \mathrm{~mm}$ & $45 \mathrm{~mm}$ & $60 \mathrm{~mm}$ & $70 \mathrm{~mm}$ & $80 \mathrm{~mm}$ & $85 \mathrm{~mm}$ \\
\hline 54 & 438 & 304 & 161 & 101 & 101 & 101 & 100 & 114 & 403 \\
\hline 55 & 455 & 323 & 177 & 102 & 101 & 101 & 100 & 124 & 414 \\
\hline 56 & 470 & 343 & 194 & 103 & 102 & 101 & 100 & 137 & 424 \\
\hline 57 & 483 & 366 & 212 & 104 & 102 & 101 & 100 & 151 & 435 \\
\hline 58 & 496 & 387 & 232 & 108 & 103 & 102 & 100 & 167 & 455 \\
\hline
\end{tabular}

Table 7.4 - Average timber stud temperatures measured from QR1810-163

\begin{tabular}{|c|c|c|c|c|c|c|c|c|c|}
\hline $\begin{array}{c}\text { Time } \\
(\mathrm{min})\end{array}$ & \multicolumn{6}{|c|}{ Average timber stud temperatures at various depths measured from the exposed } \\
& \multicolumn{7}{|c|}{ stud face on the furnace side $\left({ }^{\circ} \mathrm{C}\right)$} \\
\cline { 2 - 11 } & $5 \mathrm{~mm}$ & $10 \mathrm{~mm}$ & $20 \mathrm{~mm}$ & $30 \mathrm{~mm}$ & $45 \mathrm{~mm}$ & $60 \mathrm{~mm}$ & $70 \mathrm{~mm}$ & $80 \mathrm{~mm}$ & $85 \mathrm{~mm}$ \\
\hline 47 & 423 & 248 & 106 & 100 & 101 & 101 & 119 & 209 & 319 \\
\hline 48 & 438 & 266 & 115 & 100 & 100 & 101 & 124 & 224 & 336 \\
\hline 49 & 450 & 286 & 128 & 100 & 101 & 101 & 132 & 240 & 358 \\
\hline 50 & 460 & 307 & 145 & 100 & 101 & 102 & 140 & 258 & 374 \\
\hline 51 & 491 & 329 & 164 & 101 & 101 & 102 & 151 & 275 & 390 \\
\hline
\end{tabular}

Figure 7.7 shows the temperature contours from the structural finite element model across the timber stud where a red line indicates the position of the 300-degree isotherm. The predicted equivalent residual stud cross-sections were approximately $50 \times 16 \mathrm{~mm}, 60 \times 25 \mathrm{~mm}$ and 65 x $20 \mathrm{~mm}$ for QR1810-161, QR1810-162 and QR1810-163 respectively at structural adequacy failure.

The comparison between the measured and predicted residual stud cross-sections showed good agreement. 


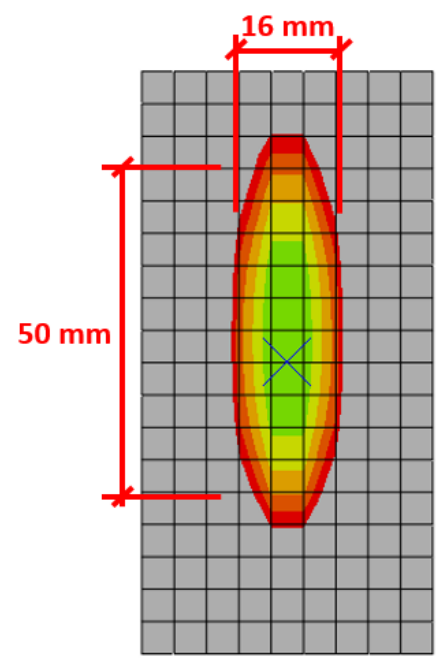

Predicted failure time of 53 minutes under $2 \mathrm{kN}$

(a) QR1810-161

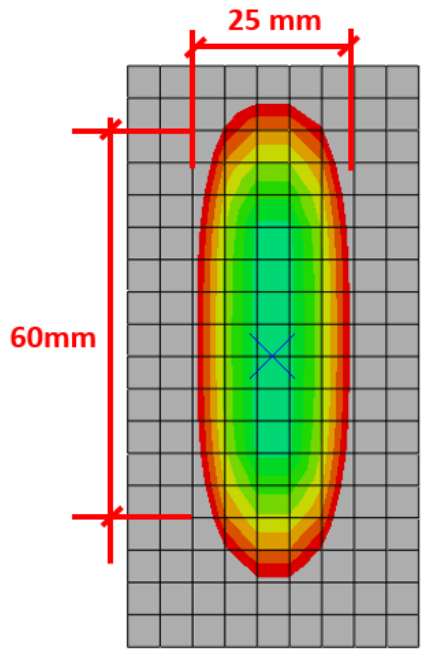

Predicted failure time of 62 minutes under $4 \mathrm{kN}$

(b) QR1810-162

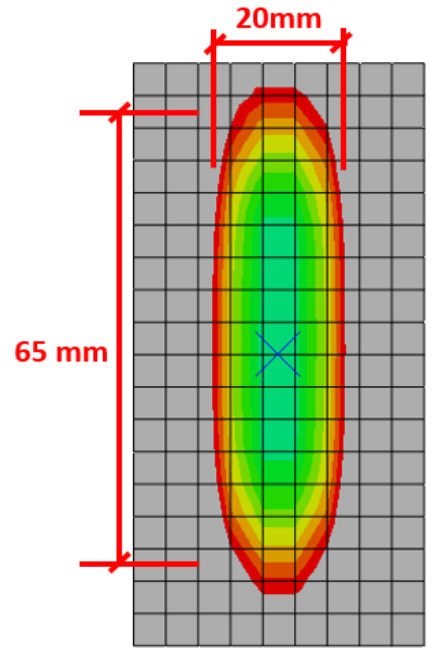

Predicted failure time of 48 minutes under $4 \mathrm{kN}$

(c) QR1810-163

Figure 7.7 - Modelled residual timber stud section at failure

\subsection{Comparative performance assessment between one and two- sided fire exposures}

As discussed in Chapter 5, the differences in wall cavity and timber stud temperatures between one and two-sided fire exposures were significant. The predicted time-temperature profiles for two-sided fire exposure showed similar length of plateau to those for one-sided fire exposure. However, under the two-sided fire exposure, the wall cavity and timber stud temperatures were found to rapidly increase once the gypsum plasterboard became fully dehydrated. Then, the temperatures followed a logarithmic trend similar to the ISO 834 standard fire timetemperature curve.

Figure 7.8 shows the sequentially coupled temperature-displacement finite element analysis result for a 90 x 45 x $2910 \mathrm{~mm}$ timber stud subjected to one and two-sided fire exposures. Regardless of the amount of applied axial load and thickness of fire-rated gypsum plasterboard, the predicted failure mode observed in the one-sided fire exposure model was always global buckling about the $\mathrm{x}$-axis and buckling towards the ambient side which is commonly observed in fire-resistance tests of light time frame wall assemblies. On the other hand, the predicted failure mode observed for the two-sided fire exposure model was an axial compression failure. These observations are also evident in Figure 7.9 which shows modelled lateral displacement- 
time graphs at mid-height of the $90 \times 45 \times 2910 \mathrm{~mm}$ timber stud subjected to axial load of $2 \mathrm{kN}$ and lined with $13 \mathrm{~mm}$ fire-rated gypsum plasterboard each side.

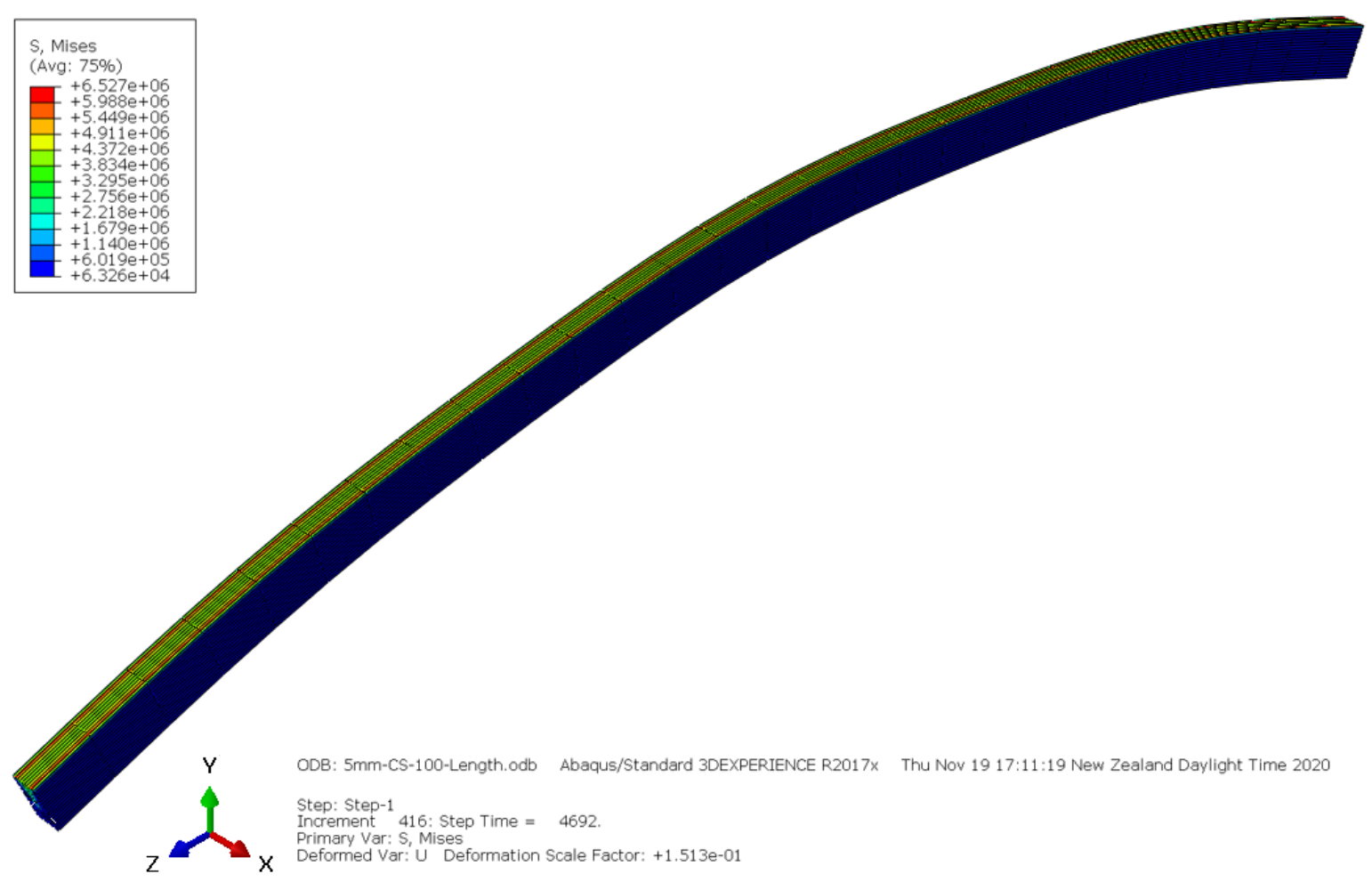

(a)

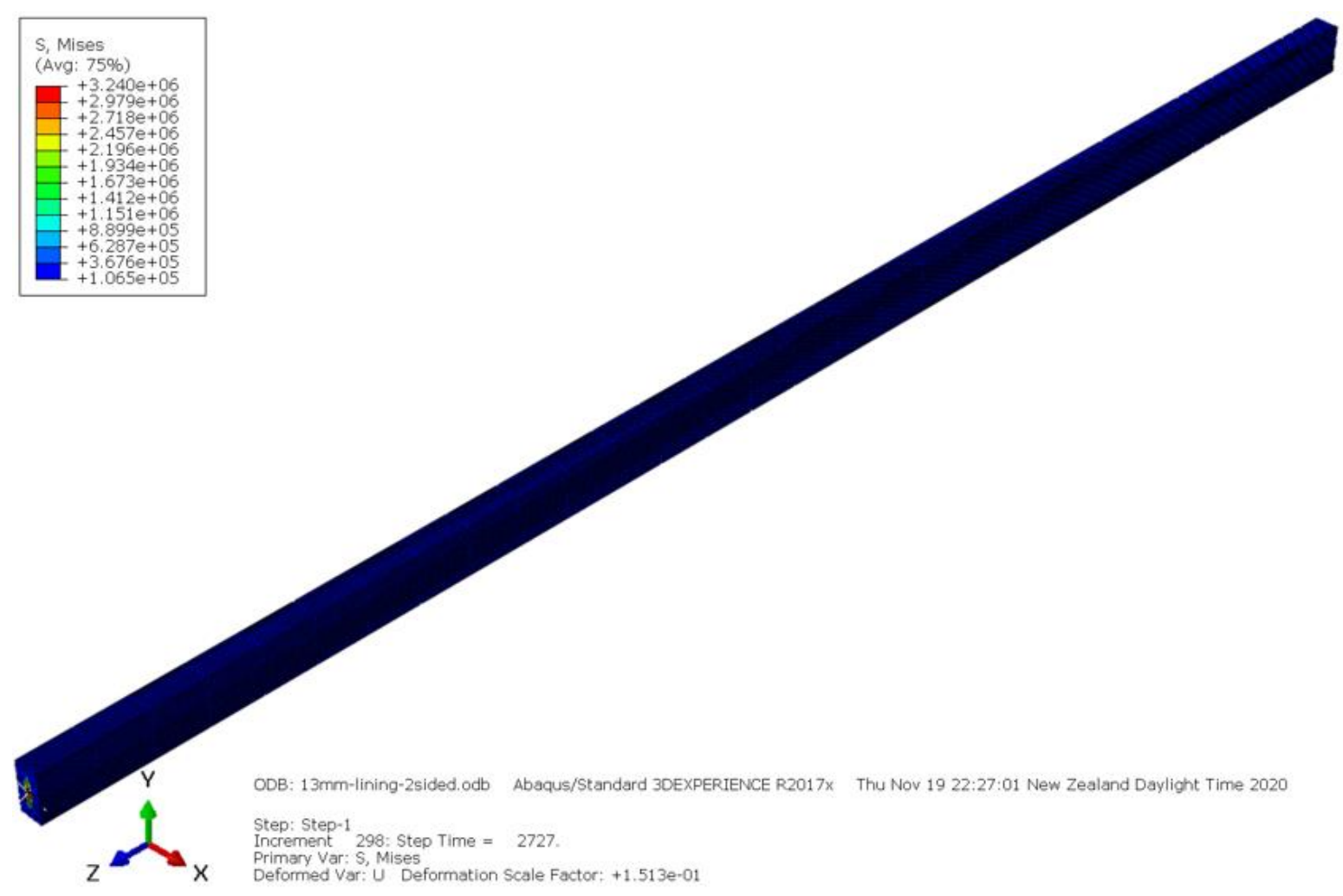

(b)

Figure 7.8 - Predicted buckling failure comparison between (a) one and (b) two-sided fire exposure 


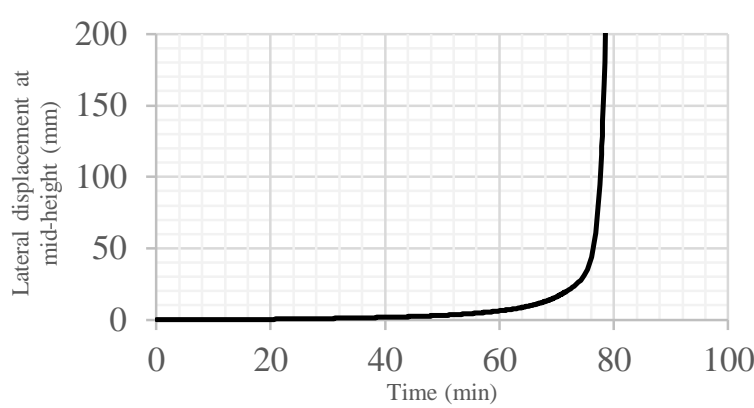

(a)

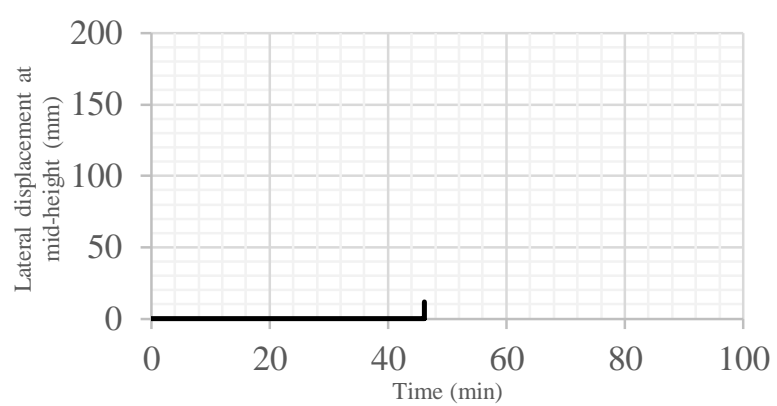

(b)

Figure 7.9 - Modelled lateral displacement at mid-height when subjected to (a) one and (b) two-sided fire exposure

In order to increase the accuracy of the proposed design methodology, the developed thermal and structural finite element models were used again to predict the structural adequacy failure times of 13 and $16 \mathrm{~mm}$ fire-rated gypsum plasterboard lined $140 \mathrm{~mm}$ x $45 \mathrm{~mm}$ SG8 timber framing. Deeper studs are commonly used to provide enough depth for thicker wall insulation. Detailed hand calculation results for the critical elastic buckling load of the $140 \mathrm{~mm}$ x $45 \mathrm{~mm}$ timber studs based on Euler's critical load method can be found in Appendix D. The general eigenvalue buckling analysis results are provided in Appendix E.

The predicted structural adequacy failure times for $90 \mathrm{~mm}$ x $45 \mathrm{~mm}$ timber studs lined with 13 and $16 \mathrm{~mm}$ fire-rated gypsum plasterboard are summarised in Tables 7.5 and 7.6 respectively. A retention factor, defined as the ratio between the two and one-sided predicted structural adequacy failure times, is also included in each table. Tables 7.7 and 7.8 show the predicted structural adequacy failure times for $140 \mathrm{~mm}$ x $45 \mathrm{~mm}$ timber studs.

Table 7.5 - Predicted failure times of $90 \mathrm{~mm}$ x $45 \mathrm{~mm}$ stud with $13 \mathrm{~mm}$ fire-rated gypsum plasterboard

\begin{tabular}{|c|c|c|c|c|c|}
\hline $\begin{array}{c}\text { Predicted } \\
\text { ambient critical } \\
\text { load }(\mathrm{kN})\end{array}$ & \multirow{2}{*}{$\begin{array}{c}\text { Load } \\
\text { ratio }\end{array}$} & $\begin{array}{c}\text { Applied axial } \\
\text { load }(\mathrm{kN})\end{array}$ & \multicolumn{2}{|c|}{ Predicted failure time (min) } & $\begin{array}{c}\text { Retention } \\
\text { factor }\end{array}$ \\
\cline { 4 - 5 } & & & $\begin{array}{c}\text { One-sided } \\
\text { exposure }\end{array}$ & $\begin{array}{c}\text { Two-sided } \\
\text { exposure }\end{array}$ & \\
\hline 23.7 & 0.8 & 19.0 & 40 & 29 & 0.74 \\
\hline 23.7 & 0.6 & 14.2 & 45 & 32 & 0.70 \\
\hline 23.7 & 0.4 & 9.5 & 55 & 35 & 0.63 \\
\hline 23.7 & 0.2 & 4.7 & 69 & 42 & 0.60 \\
\hline 23.7 & 0.17 & 4.0 & 71 & 43 & 0.60 \\
\hline 23.7 & 0.08 & 2.0 & 78 & 45 & 0.58 \\
\hline
\end{tabular}


Table 7.6 - Predicted failure times of $90 \mathrm{~mm}$ x $45 \mathrm{~mm}$ stud with $16 \mathrm{~mm}$ fire-rated gypsum plasterboard

\begin{tabular}{|c|c|c|c|c|c|}
\hline $\begin{array}{c}\text { Predicted } \\
\text { ambient critical } \\
\text { load }(\mathrm{kN})\end{array}$ & $\begin{array}{c}\text { Load } \\
\text { ratio }\end{array}$ & $\begin{array}{c}\text { Applied axial } \\
\text { load }(\mathrm{kN})\end{array}$ & \multicolumn{2}{|c|}{ Predicted failure time (min) } & $\begin{array}{c}\text { Retention } \\
\text { factor }\end{array}$ \\
\cline { 4 - 5 } & & $\begin{array}{c}\text { One-sided } \\
\text { exposure }\end{array}$ & $\begin{array}{c}\text { Two-sided } \\
\text { exposure }\end{array}$ & \\
\hline 23.7 & 0.8 & 19.0 & 54 & 39 & 0.73 \\
\hline 23.7 & 0.6 & 14.2 & 61 & 42 & 0.69 \\
\hline 23.7 & 0.4 & 9.5 & 73 & 46 & 0.63 \\
\hline 23.7 & 0.2 & 4.7 & 88 & 53 & 0.60 \\
\hline 23.7 & 0.17 & 4.0 & 90 & 54 & 0.60 \\
\hline 23.7 & 0.08 & 2.0 & 98 & 57 & 0.58 \\
\hline
\end{tabular}

Table 7.7 - Predicted failure times of $140 \mathrm{~mm}$ x $45 \mathrm{~mm}$ stud with $13 \mathrm{~mm}$ fire-rated gypsum plasterboard

\begin{tabular}{|c|c|c|c|c|c|}
\hline $\begin{array}{c}\text { Predicted } \\
\text { ambient critical } \\
\text { load }(\mathrm{kN})\end{array}$ & \multirow{2}{*}{$\begin{array}{c}\text { Load } \\
\text { ratio }\end{array}$} & $\begin{array}{c}\text { Applied axial } \\
\text { load }(\mathrm{kN})\end{array}$ & \multicolumn{2}{|c|}{ Predicted failure time (min) } & \begin{tabular}{c} 
Retention \\
factor \\
\cline { 4 - 5 }
\end{tabular} \\
\cline { 4 - 5 } & 0.8 & 70.5 & 26 & 21 & 0.81 \\
\hline 88.2 & 0.6 & 52.9 & 30 & 24 & 0.80 \\
\hline 88.2 & 0.4 & 35.2 & 39 & 30 & 0.76 \\
\hline 88.2 & 0.2 & 17.6 & 52 & 34 & 0.66 \\
\hline 88.2 & 0.05 & 4.0 & 81 & 48 & 0.60 \\
\hline 88.2 & 0.02 & 2.0 & 86 & 50 & 0.59 \\
\hline
\end{tabular}

Table 7.8 - Predicted failure times of $140 \mathrm{~mm}$ x $45 \mathrm{~mm}$ stud with $16 \mathrm{~mm}$ fire-rated gypsum plasterboard

\begin{tabular}{|c|c|c|c|c|c|}
\hline $\begin{array}{c}\text { Predicted } \\
\text { ambient critical } \\
\text { load }(\mathrm{kN})\end{array}$ & \multirow{2}{*}{$\begin{array}{c}\text { Load } \\
\text { ratio }\end{array}$} & $\begin{array}{c}\text { Applied axial } \\
\text { load }(\mathrm{kN})\end{array}$ & \multicolumn{2}{|c|}{ Predicted failure time (min) } & \begin{tabular}{c} 
Retention \\
factor \\
\cline { 4 - 5 }
\end{tabular} \\
\cline { 4 - 5 } & 0.8 & 70.5 & 37 & 29 & 0.77 \\
\hline 88.2 & 0.6 & 52.9 & 43 & 34 & 0.80 \\
\hline 88.2 & 0.4 & 35.2 & 51 & 39 & 0.76 \\
\hline 88.2 & 0.2 & 17.6 & 69 & 45 & 0.65 \\
\hline 88.2 & 0.05 & 4.0 & 97 & 58 & 0.59 \\
\hline 88.2 & 0.02 & 2.0 & 102 & 59 & 0.58 \\
\hline
\end{tabular}


Figures 7.10 and 7.11 show the relationship between predicted structural adequacy failure times and load ratios when subjected to one and two sided fire exposures for $90 \mathrm{~mm}$ x $45 \mathrm{~mm}$ and $140 \mathrm{~mm}$ x $45 \mathrm{~mm}$ timber studs respectively. The predicted structural adequacy failure times increased exponentially when the load ratio was reduced. It is also noted that the retention factor for the predicted structural adequacy failure times increased when the load ratio was increased.

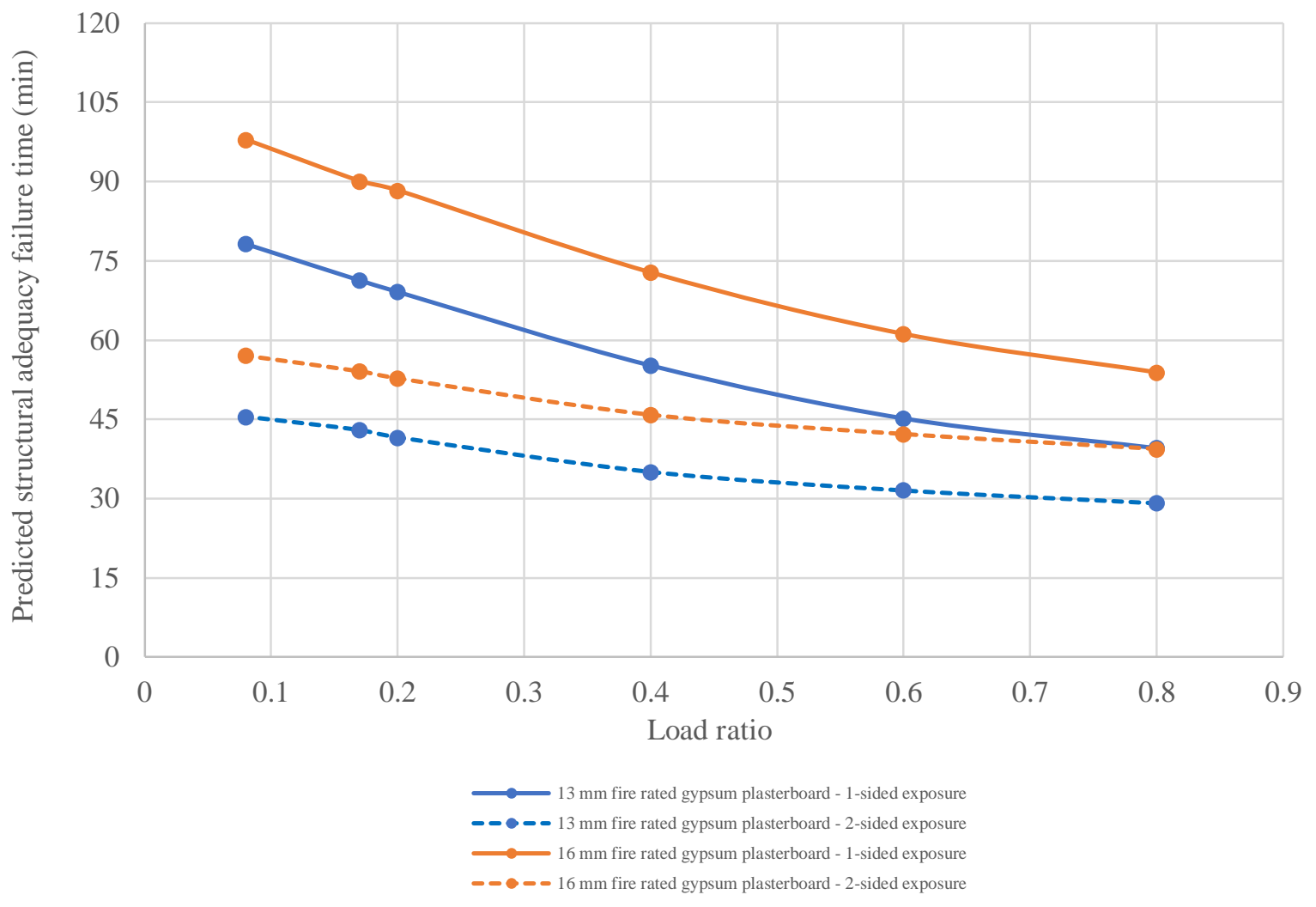

Figure 7.10 - Variation of predicted failure time with load ratio for $90 \mathrm{~mm}$ x $45 \mathrm{~mm}$ timber stud 


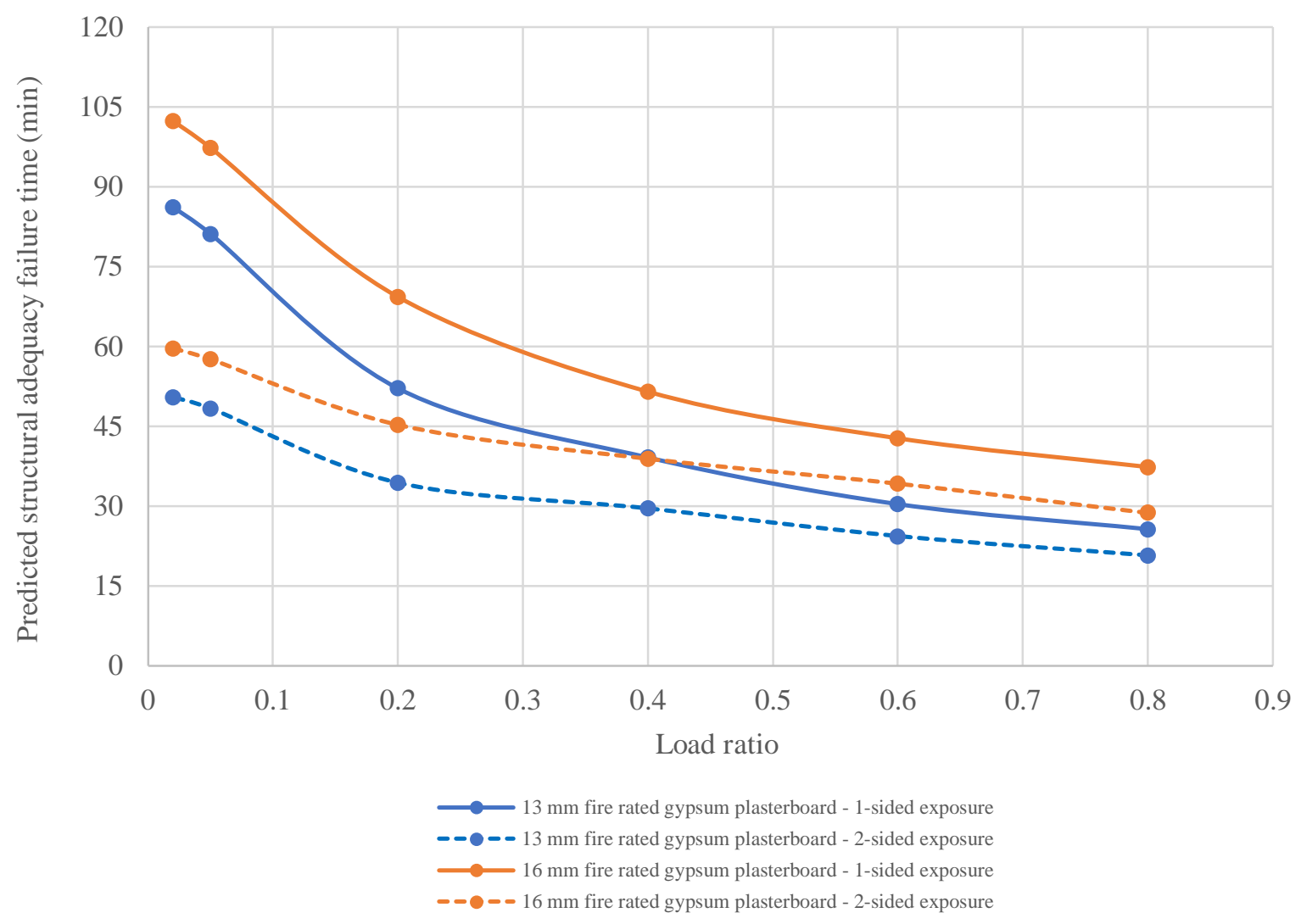

Figure 7.11 - Variation of predicted failure time with load ratio for $140 \mathrm{~mm}$ x $45 \mathrm{~mm}$ timber stud

\subsection{Proposed design methods}

Engineering design methods aim to assist with solving complex engineering issues and must be based on relevant research and data analysis. This study is based on computational finite element modelling validated against an experimental program. The results were analysed and the modelling and experimental results were compared with the aim to investigate and understand the performance of load-bearing timber-framed gypsum plasterboard lined walls subjected to one and two-sided fire exposure.

Two design methods are formulated following this research covering a broad range of wall assemblies to allow designers to predict the structural adequacy of load-bearing timber-framed gypsum plasterboard lined walls subjected to fire exposures from both sides simultaneously. It is important that the design methods are simple and efficient to implement whilst they must be detailed and thorough at the same time and fit the intended purpose.

A simplified design method is developed to conservatively predict the structural adequacy failure time for walls subjected to two-sided fire exposure based on published Fire Resistance Rating (FRR) for one-sided exposure. 
An advanced design method provides a retention factor for walls exposed to fire from two sides simultaneously, which is applied to the same wall with a known performance when tested from one side. The retention factor is determined from the structural adequacy failure time following one-sided ISO 834 standard fire exposure, and the applied axial stud load in the test. In the advanced design method, other parameters that influence structural adequacy performance, such as thickness of gypsum plasterboard and timber stud dimensions, are also considered.

\subsubsection{Simplified design method}

The simplified design method is based on 24 finite element structural modelling results consisting of two stud dimensions ( $90 \mathrm{~mm}$ x $45 \mathrm{~mm}$ and $140 \mathrm{~mm}$ x $45 \mathrm{~mm}$ ), two thicknesses of fire-rated gypsum plasterboard (13 and $16 \mathrm{~mm})$, and six load ratios for each wall assembly. Detailed modelling results are provided in Section 7.2.

Figure 7.12 shows a scatter plot of the predicted structural adequacy failure times for walls subjected to two-sided fire exposure, as a function of one-sided exposure. This scatter plot shows a strong, positive and linear correlation between the two sets of data. The linear regression line has a coefficient of determination of 0.97 .

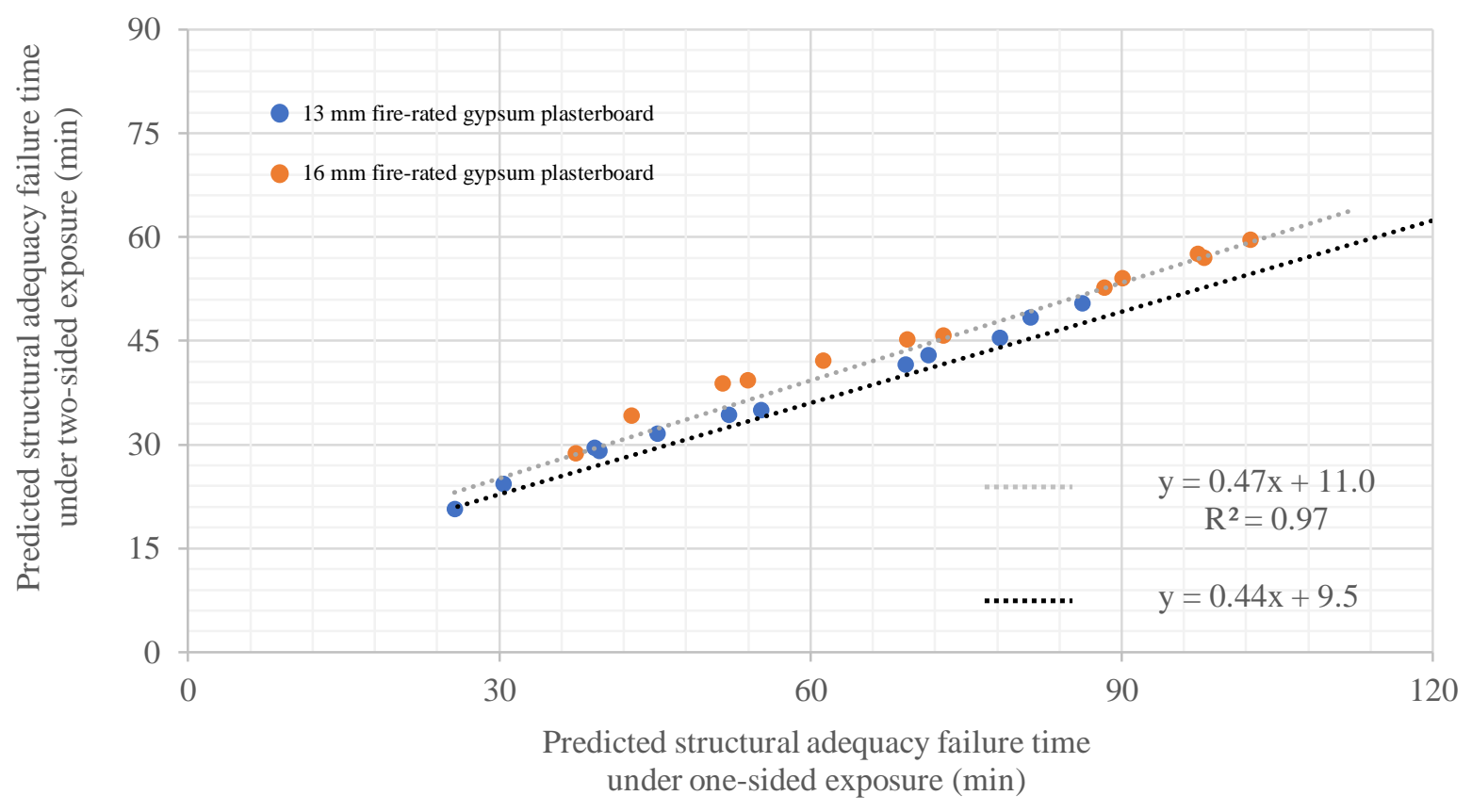

Figure 7.12 - Predicted structural adequacy when subjected to two-sided fire exposure as a function of one-sided fire exposure 
The simplified design method is developed with a conservative approach in mind in order to cover other sizes and types of the timber stud, and other thicknesses of fire-rated gypsum plasterboard available in the market which have not been studied in this research. This method is very simple and easy to follow by designers without an engineering background. In order to add conservatism, the relationship equation between the two sets of data is based on the line intersecting data points with the minimum possible gradient (black-dotted line in Figure 7.12), rather than a regression line (grey-dotted line in Figure 7.12), and a y-coordinate is reduced so all the data points sit above the relationship line.

The following proposed equation represents the predicted structural adequacy failure time of load-bearing timber-framed gypsum plasterboard lined walls subjected to two-sided fire exposure. The published FRR, by the gypsum plasterboard manufacturer, is proposed as the input FRR to give further conservatism to the simplified design method. This is because structural adequacy is generally not the governing failure mode for load-bearing timber-framed gypsum plasterboard lined walls. Commonly integrity or insulation failure occur first. Further conservatism results because published FRRs represent the last 15 or 30 minute increment exceeded in the test, and not the actual failure time.

The simplified method assumes loading equivalent to the scope of the referenced tested specification.

$$
t_{2}=0.44 \cdot t_{F R R}+9.5 \quad \text { for } 30 \leq t_{F R R} \leq 120 \quad \text { (Equation 7.1) }
$$

Where: $\quad t_{2}=$ Predicted structural adequacy under two-sided fire exposure $(\mathrm{min})$

$$
t_{F R R}=\text { Published fire resistance rating }(\mathrm{min})
$$

\subsubsection{Advanced design method}

The advanced design method is developed based on the same finite element structural modelling results as those used in the simplified design method. This design method determines a retention factor that can be directly applied to the structural adequacy failure time (either modelled or measured) of load-bearing timber-framed gypsum plasterboard lined walls subjected to one-sided ISO 834 standard fire exposure. The advanced method then predicts the structural adequacy failure time of such walls subjected to two-sided fire exposure. 
The advanced method introduces a load ratio which is determined by dividing the load applied in the reference test by the stud's critical elastic buckling load determined by modelling or calculation using Euler's critical load method.

Figure 7.13 shows the retention factor for 13 and $16 \mathrm{~mm}$ fire-rated gypsum plasterboard with $90 \mathrm{~mm}$ x $45 \mathrm{~mm}$ timber studs, versus the load ratio. The data points for each thickness of firerated gypsum plasterboard have good linear regression lines with coefficients of determination from 0.98 to 0.99 .

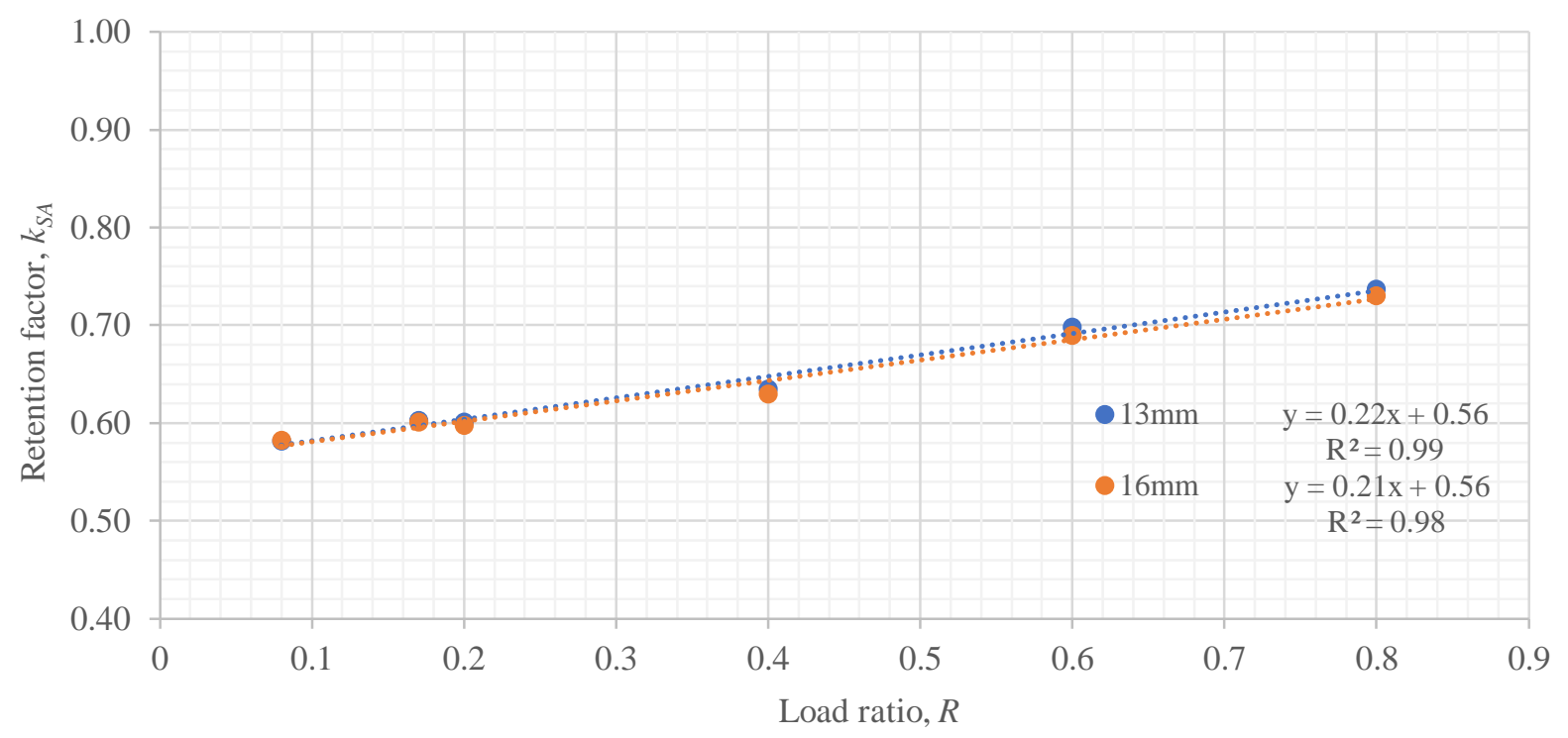

Figure 7.13 - Structural adequacy failure time retention factor for $90 \mathrm{~mm}$ x $45 \mathrm{~mm}$ stud with $13 \mathrm{~mm}$ and 16 mm fire-rated gypsum plasterboard

The following proposed equations represent the retention factors for the structural adequacy failure time of $90 \mathrm{~mm}$ x $45 \mathrm{~mm}$ timber framing when subjected to two-sided fire exposure.

For 13 mm fire-rated gypsum plasterboard,

$$
k_{S A}=0.22 \cdot R+0.56 \quad \text { for } 0<R<1
$$

For 16 mm fire-rated gypsum plasterboard,

$$
k_{S A}=0.21 \cdot R+0.56 \quad \text { for } 0<R<1
$$

Where: $k_{S A}=$ Retention factor for structural adequacy subjected to two-sided fire exposure

$$
R=\text { Load ratio }
$$


Figure 7.14 shows the retention factor for 13 and $16 \mathrm{~mm}$ fire-rated gypsum plasterboard with $140 \mathrm{~mm} \times 45 \mathrm{~mm}$ timber studs, versus the load ratio. The data points for both thicknesses of fire-rated gypsum plasterboard have good polynomial curvilinear regression lines with coefficients of determination from 0.98 to 0.99 .

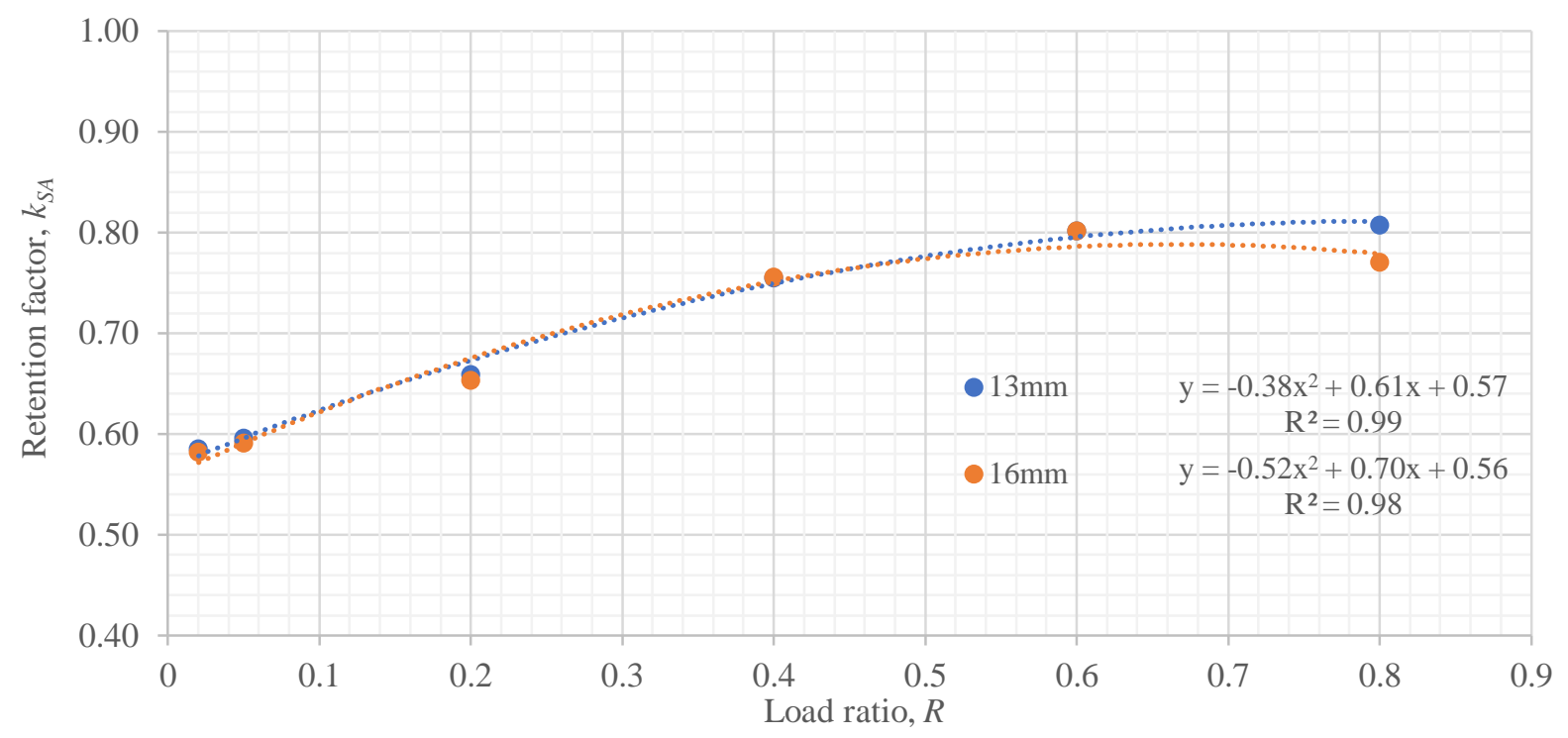

Figure 7.14 - Structural adequacy failure time retention factor for $140 \mathrm{~mm}$ x $45 \mathrm{~mm}$ stud with $13 \mathrm{~mm}$ and $16 \mathrm{~mm}$ fire-rated gypsum plasterboard

The following proposed equations represent the retention factors for the structural adequacy failure time of $140 \mathrm{~mm}$ x $45 \mathrm{~mm}$ timber framing when subjected to two-sided fire exposure.

For 13 mm fire-rated gypsum plasterboard,

$$
k_{S A}=-0.38 \cdot R^{2}+0.61 \cdot R+0.57 \quad \text { for } 0<R<1 \quad \text { (Equation 7.4) }
$$

For 16 mm fire-rated gypsum plasterboard,

$$
k_{S A}=-0.52 \cdot R^{2}+0.70 \cdot R+0.56 \quad \text { for } 0<R<1 \quad \text { (Equation } 7.5 \text { ) }
$$

\subsubsection{Worked example 1}

The first worked example is for a timber-framed multi storey apartment building which has an internal load-bearing gypsum plasterboard wall located within lower units. This wall is supporting a fire-rated floor/ceiling assembly, and is not itself a fire separation and can 
therefore be exposed to fire from both sides simultaneously. NZBC Acceptable Solution C/AS2 requires life and property ratings to be 30 minutes for such a sprinklered apartment building (risk group SM) [51].

Using the simplified design method, the minimum required published FRR is calculated as:

$$
\begin{gathered}
t_{2}=0.44 \cdot t_{F R R}+9.5 \\
30=0.44 \cdot t_{F R R}+9.5 \\
t_{F R R}=(30-9.5) \div 0.44=47 \text { minutes }
\end{gathered}
$$

According to the calculation above, a fire-rated load-bearing timber-framed wall system that has the published FRR of more than 47 minutes is suitable for withstanding a two-sided fire exposure for 30 minutes. In practice this means selecting a published FRR of 60/60/60.

In order to use the advanced design method, confirmation is required from the proprietor of the reference specimen. For example, a fire-rated timber-framed wall system consisting of $13 \mathrm{~mm}$ fire-rated gypsum plasterboard each side of 90 x 45 x 3000 mm SG8 timber framing failed structural adequacy at 65 minutes when subjected to an axial load of $6 \mathrm{kN}$ per stud.

The critical elastic buckling capacity for 90 × 45 × 3000 mm SG8 timber stud with lateral restraints at $1.0 \mathrm{~m}$ spacing is $24 \mathrm{kN}$ based on Euler's critical load method. Hence, the load ratio is calculated as:

$$
R=6 \div 24=0.25
$$

The retention factor is then calculated as:

$$
k_{S A}=0.22 \cdot R+0.56=0.22 \cdot 0.25+0.56=0.61
$$

From this, the predicted structural adequacy failure time when subjected to two-sided fire exposure is calculated. 


$$
t_{2}=0.61 \cdot 65=39 \text { minutes }
$$

The calculation indicates that the fire-rated timber-framed wall system mentioned above is suitable to withstand a two-sided fire exposure for 30 minutes.

\subsubsection{Worked example 2}

The second worked example is for internal load-bearing timber-framed walls supporting a mezzanine floor in a car storage warehouse. These walls are not acting as fire separations and can potentially be exposed to fire from both sides simultaneously. NZBC Acceptable Solution C/AS2 requires life and property ratings to be 60 minutes for unsprinklered vehicle storage and parking buildings (risk group VP) [51].

Using the simplified design method, the minimum required published FRR is calculated as:

$$
\begin{gathered}
t_{2}=0.44 \cdot t_{F R R}+9.5 \\
60=0.44 \cdot t_{F R R}+9.5 \\
t_{F R R}=(60-9.5) \div 0.44=115 \text { minutes }
\end{gathered}
$$

According to the calculation above, a fire-rated load-bearing timber-framed wall system that has a published FRR of more than 115 minutes is suitable for withstanding two-sided fire exposure for 60 minutes. This requires a published FRR of 120/120/120.

Using the advanced design method, the proprietor of the reference test information has supplied the predicted structural adequacy failure times at various load ratios for 140 x $45 \mathrm{~mm}$ SG8 timber framing lined with $16 \mathrm{~mm}$ fire-rated gypsum plasterboard when subjected to one-sided ISO 834 standard fire exposure. The information provided is similar to Figure 7.11. The axial stud load supporting the mezzanine floor in the fire design case is $3.0 \mathrm{kN}$. The critical elastic buckling capacity for $140 \times 45 \times 2400 \mathrm{~mm}$ SG8 timber stud with lateral restraints at $0.6 \mathrm{~m}$ spacing is $141 \mathrm{kN}$ based on Euler's critical load method. Hence, the load ratio is calculated as:

$$
R=3.0 \div 141=0.02
$$


The retention factor is then calculated as:

$$
k_{S A}=-0.52 \cdot R^{2}+0.70 \cdot R+0.56=-0.52 \cdot 0.02^{2}+0.7 \cdot 0.02+0.56=0.57
$$

From the test proprietor's information the predicted structural adequacy failure time for a load ratio of 0.02 is 107 minutes. From this, the predicted structural adequacy failure time when subjected to two-sided fire exposure is calculated.

$$
t_{2}=0.57 \cdot 107=61 \text { minutes }
$$

The calculation indicates that the $140 \times 45 \times 2400 \mathrm{~mm}$ SG8 timber-framed supporting walls for the mezzanine floor subjected to the axial stud load of $3.0 \mathrm{kN}$ can withstand a two-sided fire exposure for 60 minutes when lined with $16 \mathrm{~mm}$ fire-rated gypsum plasterboard each side. 


\section{Summary and Conclusions}

This research was conducted to understand the structural and fire performance of load-bearing timber-framed gypsum plasterboard lined walls subjected to two-sided fire exposure. The first key objective was to develop computational finite element thermal and structural models for predicting the performance of these walls when subjected to one and two-sided fire exposures, and to validate the models against previous experimental data and the results obtained from three full-scale fire-resistance tests conducted in this research. The modelling results were then used to conduct a comparative performance assessment of load-bearing timber-framed gypsum plasterboard lined walls subjected to two-sided and one-sided standard fire exposure with the aim to develop design methodologies that enable the prediction of structural adequacy of such walls subjected to two-sided fire exposure.

\subsection{Finite element thermal modelling}

For validation purposes, computational finite element thermal modelling was undertaken, using the Abaqus/CAE finite element software, simulating the performance of the existing timberframed gypsum plasterboard lined wall tests subjected to one-sided fire exposure. The thermal model was further developed to predict the behaviour of such walls when subjected to twosided fire exposure, and validated using the results obtained from three full-scale fire resistance experiments.

To adequately model the thermal behaviour under fire conditions, temperature-dependent thermal properties of timber and gypsum plasterboard were included in the thermal modelling. Some discrepancies were found in reported thermal properties of gypsum plasterboard due to differences in product formulations, and depending on whether the effect of ablation and cracking of gypsum plasterboard was considered. Therefore, the final thermal properties adopted for modelling purposes in this study were selected following a calibration process which reflects proprietary plasterboard formulations.

A sensitivity analysis was carried out to select an optimum mesh size by comparing model outputs with test results against measured furnace temperatures and the ISO 834 standard fire time-temperature curve. Heat transfer coefficients were also extensively investigated to obtain accurate thermal modelling results. 
Overall, the Abaqus/CAE thermal finite element model accurately predicted the thermal behaviour of timber-framed gypsum plasterboard lined walls, and good comparison was achieved between the experimental and modelled results for one-sided standard fire exposure. The thermal model developed for two-sided fire exposure was also found to be accurate and capable of predicting the behaviour of walls subjected to two-sided fire exposure, but the comparison of inner stud temperatures was not as good as the outer stud temperatures.

It was found that the length of the $100{ }^{\circ} \mathrm{C}$ dehydration temperature plateau on the back of the exposed lining subjected to one and two-sided fire exposures was very similar. However, under two-sided fire conditions, the temperature rapidly increased once the gypsum plasterboard became fully dehydrated, and then followed a logarithmic trend similar to the ISO 834 standard fire time-temperature curve, whilst the temperature increased almost linearly under one-sided fire conditions.

\subsection{Finite element structural modelling}

The Abaqus/CAE three-dimensional finite element model was used to simulate the structural behaviour of load-bearing timber-framed gypsum plasterboard lined walls under ambient and fire conditions, and to obtain the predicted structural adequacy failure time as defined in AS 1530.4:2014. An eigenvalue buckling analysis was conducted to estimate the critical buckling load of timber studs under ambient condition, and a sequentially coupled temperaturedisplacement non-linear static analysis was conducted by applying the time-temperature profiles from the thermal models.

As timber is an orthotropic material with unique and independent characteristics, the mechanical properties of SG8 Radiata pine were defined for each of the three principal axes. Temperature-dependent mechanical properties were calculated using the reduction factors obtained from Annex B of Eurocode 5: Part 1-2. The elastic and plastic properties were defined in Abaqus/CAE using engineering constants and Hill's Potential Function.

A sensitivity analysis was conducted to find an optimum mesh size and the effect of gypsum plasterboard lining and screw on the structural modelling results was investigated.

The predicted critical elastic buckling load agreed well with hand calculations based on Euler's critical load method. The difference in structural adequacy failure time between the test and model ranged from 3 to 4 minutes with an average of $5.4 \%$ for one-sided fire exposure, and 3 to 5 minutes with an average of $6.0 \%$ for two-sided fire exposure. Overall, the agreement 
between the measured and predicted structural adequacy failure times and axial displacements was good. The developed structural models were considered accurate in predicting the structural adequacy failure time of the tested timber-framed gypsum plasterboard lined wall assemblies.

\subsection{Experimental fire-resistance tests}

Three full-scale fire-resistance tests were conducted on load-bearing timber-framed gypsum plasterboard lined wall specimens at the fire testing laboratory of the Building Research Association of New Zealand (BRANZ). The tests were conducted to validate the thermal model developed for two-sided fire exposure. The test specimens consisted of two thicknesses of gypsum plasterboard, two different levels of applied axial load per stud, and two lengths of the load-bearing wall specimen.

The fire-resistance wall test method stipulated in AS 1530.4:2014 does not consider two-sided fire exposure, and hence the standard fire-resistance tests were modified in configuration and procedure to achieve simultaneous fire exposure to both sides of the wall specimen. This was achieved by extending the furnace beyond the specimen with fire-rated enclosure walls and a floor/ceiling assembly. A full height opening was incorporated at each end of the shortened load-bearing wall specimen.

However, furnace temperatures and exposure on the enclosure side were found much lower than the standard fire conditions, especially in the beginning of the experiment. Although fire exposure on each side of the test specimen were found to differ, the measured furnace temperatures were valid input for finite element modelling purposes. The recorded temperatures were used to validate the model for two-sided fire exposure, and the developed finite element model comfortably accommodated different fire exposures on opposite sides of the test specimen.

In the beginning of all three experiments, the measured load from the hydraulic jacks increased to average of $12.1 \%$ higher than the target load. It was found that the thermal expansion of the specimen was applying the pressure to the hydraulic system, hence increasing the load. The hydraulic pressure is controlled manually by a technician resulting in difficulty maintaining the target load. For future experiments it is therefore recommended that the control is automated, or pressure is monitored by a technician throughout the test. 


\subsection{Design methodologies}

In order to allow designers to predict the structural adequacy of load-bearing timber-framed gypsum plasterboard lined walls subjected to two-sided fire exposure; two design methods were formulated based on 36 finite element structural modelling results covering a broad range of timber-framed wall assemblies.

A simplified design method that is easy and efficient to implement has been developed to conservatively predict the structural adequacy failure time of walls subjected to two-sided fire exposure. This method uses the published Fire Resistance Rating (FRR) of specifications tested from one side and applies a retention factor. Sufficient conservatism is accounted for in this method as structural adequacy is generally not the governing failure mode when determining an FRR. Integrity or insulation failure commonly occurs earlier, and an FRR of a separating wall may not represent the actual failure time, rather the last 15 or 30 minute increment exceeded in the test.

An advanced design method provides a retention factor for walls exposed to fire from two sides simultaneously, which is applied to the same wall with a known performance when tested from one side. The retention factor is determined from the structural adequacy failure time following one-sided ISO 834 standard fire exposure, and the applied axial stud load in the test. However, it is unlikely that the proprietor of the reference test information has tested the identical wall assembly at various load ratios. Therefore, it is recommended for the test proprietor to perform the computational finite element analyses discussed in this research to determine the predicted structural adequacy failure times of walls subjected to one-sided fire exposure at various load ratios. This information then allows designers to predict structural adequacy performance under two-sided fire exposure at any given load ratio.

\subsection{Future research}

This research has focused on the structural and fire performance of load-bearing timber-framed gypsum plasterboard lined walls subjected to two-sided fire exposure using experimental testing and numerical modelling, and has provided a comparative performance assessment of such walls subjected to one and two-sided fire exposures. However, further research is needed in some areas, and hence the following recommendations are made based on the findings of this research. 
- The light-gauge steel-framing industry is well established and currently growing, and light-gauge steel-framed wall systems are becoming common for housing and low-rise construction. Therefore, it is recommended that the performance of load-bearing lightgauge steel-framed gypsum plasterboard lined walls subjected to two-sided fire exposure is investigated numerically and experimentally.

- There is still limited information for a recognised fire engineering design method for other panel-type construction elements subjected to two-sided fire exposure. The effect of two-sided fire exposure on load-bearing barriers such as concrete, masonry and cross laminated timber might be investigated further.

- The computational finite element modelling results can be improved by using a threedimensional analysis to consider non-uniform time-temperature profiles across the wall assembly, or a fully coupled temperature-displacement structural analysis to simultaneously simulate both thermal and structural behaviours of walls.

- Temperature-dependent thermal properties of gypsum plasterboard are not well defined due to lack of an experimental database and differences in formulation which can be further improved. The effect of ablation, cracking and integrity loss of gypsum plasterboard must be investigated and accounted for in apparent thermal property values to mimic these behaviours in finite element modelling.

- An investigation of the use of different temperature-dependent thermal conductivity values of gypsum plasterboard depending on the width of timber stud is required to account for narrower studs allowing an earlier heat transfer to the wall cavity once gypsum plasterboard sheet joints open up.

- Due to the cost and nature of fire-resistance testing, statistical variation and uncertainty of data, there is always a need for more experimental studies to enable improved accuracy of predictions, including those relating to two-sided fire exposure.

- To permit comparison with existing test data, the ISO 834 standard fire timetemperature curve was adopted in this research as the proposed two-sided fire exposure of load-bearing timber-framed gypsum plasterboard lined walls. Further investigation to understand the performance of walls subjected to fire conditions other than ISO 834 remains desirable. 


\section{References}

[1] A. H. Buchanan and A. K. Abu, Structural Design for Fire Safety. John Wiley \& Sons, 2017.

[2] N. Chu Nguong, A. H. Buchanan, and J. T. Gerlich, "Calcination of gypsum plasterboard under fire exposure," Department of Civil and Natural Resources Engineering, University of Canterbury, Christchurch, New Zealand, 2004.

[3] American Wood Council, "Calculating the fire resistance exposed wood members," American Forest \& Paper Association, American Wood Council, Washington, DC, 1999.

[4] R. M. Aseeva, B. Serkov, and A. Sivenkov, Fire behavior and fire protection in timber buildings. Springer, 2014.

[5] Methods for fire tests on building materials, components and structures - Part 4: Fireresistance test of elements of construction, AS 1530.4:2014, 2014.

[6] Eurocode 5: Design of timber structures - Part 1-2: General - Structural fire design, BS EN 1995-1-2:2004, 2004.

[7] J. T. Gerlich and A. H. Buchanan, "Design of loadbearing light steel frame walls for fire resistance," School of Engineering, University of Canterbury, Christchurch, New Zealand, 1995.

[8] F. Liu, F. Fu, Y. Wang, and Q. Liu, "Fire performance of non-load-bearing light-gauge slotted steel stud walls," JCSR Journal of Constructional Steel Research, vol. 137, pp. 228-241, 2017.

[9] Y. Dias, P. Keerthan, and M. Mahendran, "Fire performance of steel and plasterboard sheathed non-load bearing LSF walls," Fire safety journal, vol. 103, pp. 1-18, 2019.

[10] J. König, Fire resistance of timber joists and load bearing wall frames. Stockholm: Trätek, 1995.

[11] W. Chen, J. Ye, Y. Bai, and X.-L. Zhao, "Full-scale fire experiments on load-bearing cold-formed steel walls lined with different panels," JCSR Journal of Constructional Steel Research, vol. 79, pp. 242-254, 2012.

[12] V. K. R. Kodur, M. A. Sultan, and E. M. A. Denham, Temperature measurements in full-scale wood stud shear walls. Ottawa: National Research Council Canada, Institute for Research in Construction, 1996.

[13] Winstone Wallboards Limited, GIB® Fire Rated Systems - Specification and installation manual. October, 2018. 
[14] E. Ryu, H. Kim, Y. Chun, I. Yeo, and Y. Shin, "Effect of heated areas on thermal response and structural behavior of reinforced concrete walls exposed to fire," JEST Engineering Structures, vol. 207, 2020.

[15] S. Lee and C. Lee, "Fire resistance of reinforced concrete bearing walls subjected to all-sided fire exposure," MATERIALS AND STRUCTURES, vol. 46, no. 6, pp. 943-957, 2013.

[16] Eurocode 2: Design of concrete structures - Part 1-2: General rules - Structural fire design, BS EN 1992-1-2:2004, 2004.

[17] Eurocode 6: Design of masonry structures - Part 1-2: General rules - Structural fire design, BS EN 1996-1-2:2005, 2005.

[18] A. Just, J. Schmid, and J. König, Gypsum plasterboards used as fire protection Analysis of a database. Stockholm: Trätek, 2010.

[19] G. C. Thomas, "Fire resistance of light timber framed walls and floors," School of Engineering, University of Canterbury, Christchurch, New Zealand, 1997.

[20] S. Gunalan, "Structural behaviour and design of cold-formed steel wall systems under fire conditions," Doctor of philosophy, Engineering Structures Engineering Structures, Queensland University of Technology, Brisbane, Australia, 2011.

[21] C. Lee, S. Lee, and H. Kim, "Experimental observations on reinforced concrete bearing walls subjected to all-sided fire exposure," Magazine of concrete research, vol. 65, no. 1-2, pp. 82-92, 2013.

[22] N. Benichou and M. A. Sultan, Fire resistance of lightweight wood-framed assemblies : state-of-the-art report. Ottawa: National Research Council Canada, Institute for Research in Construction, 1999.

[23] J. F. Nyman, A. H. Buchanan, and J. T. Gerlich, "Equivalent fire resistance ratings of construction elements exposed to realistic fires," Department of Civil Engineering, University of Canterbury, Christchurch, New Zealand, 2002.

[24] W. Chen, J. Ye, Q. Zhao, and J. Jiang, "Full-scale experiments of gypsum-sheathed cavity-insulated cold-formed steel walls under different fire conditions," Journal of Constructional Steel Research Journal of Constructional Steel Research, vol. 164, p. $105809,2020$.

[25] B. H. Jones, A. H. Buchanan, P. J. Moss, and J. T. Gerlich, "Performance of gypsum plasterboard assemblies exposed to real building fires," School of Engineering, University of Canterbury, Christchurch, New Zealand, 2001. 
[26] I. Rahmanian, "Thermal and mechanical properties of gypsum boards and their influences on fire resistance of gypsum board based systems," School of Mechanical, Aerospace and Civil Engineering, The University of Manchester (United Kingdom), 2011.

[27] Timber-framed buildings, NZS 3604:2011, 2011.

[28] R. J. Ross, "Wood handbook: wood as an engineering material," USDA Forest Service, Forest Products Laboratory, General Technical Report FPL-GTR-190, 2010: 509 p. 1 v., vol. 190, 2010.

[29] D. Jessop, "Fire Performance of a Laterally Loaded Light Timber-framed Compartment," Department of Civil and Natural Resources Engineering, University of Canterbury, Christchurch, New Zealand, 2016.

[30] J. Fung and I. C. Page, Optimal design of timber framing in housing. Building Research Association of New Zealand, 2011.

[31] A. Frangi, V. Schleifer, M. Fontana, and E. Hugi, "Experimental and Numerical Analysis of Gypsum Plasterboards in Fire," Fire Technology, vol. 46, no. 1, pp. 149$167,2010$.

[32] J. W. O'Neill, "The Fire Performance of Timber Floors in Multi-Storey Buildings," Department of Civil and Natural Resources Engineering, University of Canterbury, Christchurch, New Zealand, 2013.

[33] M. I. Rusthi, "Experimental and Finite Element Studies of Light-gauge Steel Frame Wall Systems under Fire Conditions," School of Civil Engineering and Built Environment, Queensland University of Technology, 2017.

[34] M. A. Sultan, "A model for predicting heat transfer through noninsulated unloaded steel-stud gypsum board wall assemblies exposed to fire," Fire Technology, vol. 32, no. 3, pp. 239-259, 1996.

[35] Y. Wang, I. Burgess, F. Wald, and M. Gillie, Performance-based fire engineering of structures. CRC press, 2012.

[36] NZ Wood. "Exotic plantation species - Radiata Pine." http://www.nzwood.co.nz/forestry-2/radiata-pine/ (accessed 19th October, 2020).

[37] P. Bajpai, Biermann's handbook of pulp and paper: raw material and pulp making, Third ed. Amsterdam, Netherlands: Elsevier, 2018.

[38] H. Quiquero, J. Gales, A. Abu, and R. Al Hamd, "Finite Element Modelling of Posttensioned Timber Beams at Ambient and Fire Conditions," Fire Technology, vol. 56, no. 2, pp. 737-767, 2020. 
[39] M. Feng, Y. C. Wang, and J. M. Davies, "Thermal performance of cold-formed thinwalled steel panel systems in fire," Fire Safety Journal, vol. 38, no. 4, pp. 365-394, 2003.

[40] G. Thomas, "Modelling thermal performance of gypsum plasterboard-lined light timber frame walls using SAFIR and TASEF," Fire and Materials, vol. 34, no. 8, pp. 385-406, 2010.

[41] J. R. Mehaffey, P. Cuerrier, and G. Carisse, "A model for predicting heat transfer through gypsum-board/wood-stud walls exposed to fire," Fire and Materials, vol. 18, no. 5, pp. 297-305, 1994.

[42] P. Pichler, M. Leitner, F. Grün, and C. Guster, "Evaluation of wood material models for the numerical assessment of cutting forces in chipping processes," Wood science and technology, vol. 52, no. 1, pp. 281-294, 2018.

[43] F. Mirianon, S. Fortino, and T. Toratti, A method to model wood by using ABAQUS finite element software. Part 2. Application to dowel type connections. VTT Technical Research Centre of Finland, 2008.

[44] S. Janssens, "Numerical modelling of dowelled connections in Laminated Veneer Lumber," Department of Structural Engineering, Delft University of Technology, Delft, Netherlands, 2017.

[45] Building Research Association of New Zealand, BRANZ Appraisal No. 289 - GIB® Fire Rated Systems. BRANZ, Porirua, New Zealand, November, 2018.

[46] Winstone Wallboards Limited, GIB® Site Guide - For Residential \& Commercial Installations. 2003.

[47] D. Bastings, A. Buchanan, and P. Salt, "Fire test facilities for building research association of New Zealand," Building Services Group Proceedings, p. 669, 1979.

[48] Laminex New Zealand, Strandfloor ${ }^{\circledR}$ Technical manual (Edition 5). March, 2019.

[49] H. Ingason and U. Wickström, "Measuring incident radiant heat flux using the plate thermometer," Fire Safety Journal, vol. 42, no. 2, pp. 161-166, 2007.

[50] P. C. R. Collier, Design of Loadbearing Light Timber Framed Walls for Fire Resistance: Part 1. Building Research Association of New Zealand, 1991.

[51] MBIE, C/AS2 Acceptable Solution for Buildings other than Risk Group SH for New Zealand Building Code Clauses C1-C6 Protection from Fire. Wellington, New Zealand: Ministry of Business, Innovation and Employment, 2019. 


\section{Appendices}

Appendix A: Calibration process to determine effective temperature-dependent thermal properties of gypsum plasterboard

Appendix B: Thermal modelling results based on the ISO 834 standard fire time-temperature curve and measured furnace temperatures

Appendix C: Euler's critical buckling load method for $90 \mathrm{~mm}$ x $45 \mathrm{~mm}$ SG8 timber studs in compression

Appendix D: Euler's critical buckling load method for $140 \mathrm{~mm}$ x $45 \mathrm{~mm}$ SG8 timber studs in compression

Appendix E: General eigenvalue buckling analysis result of $140 \mathrm{~mm}$ x $45 \mathrm{~mm}$ SG8 timber stud under ambient condition

Appendix F: Detailed drawing for the two-sided fire exposure fire-resistance tests 


\section{Appendix A: Calibration process to determine effective temperature-dependent thermal properties of gypsum plasterboard}

Figures A.1 and A.2 show the time-temperature profile comparison between test FR1611 (described in Table 4.2) and the thermal model output for the wall lining and timber stud respectively. The thermal modelling results were based on the temperature-dependent thermal properties of gypsum plasterboard proposed by Wang et al. [35].

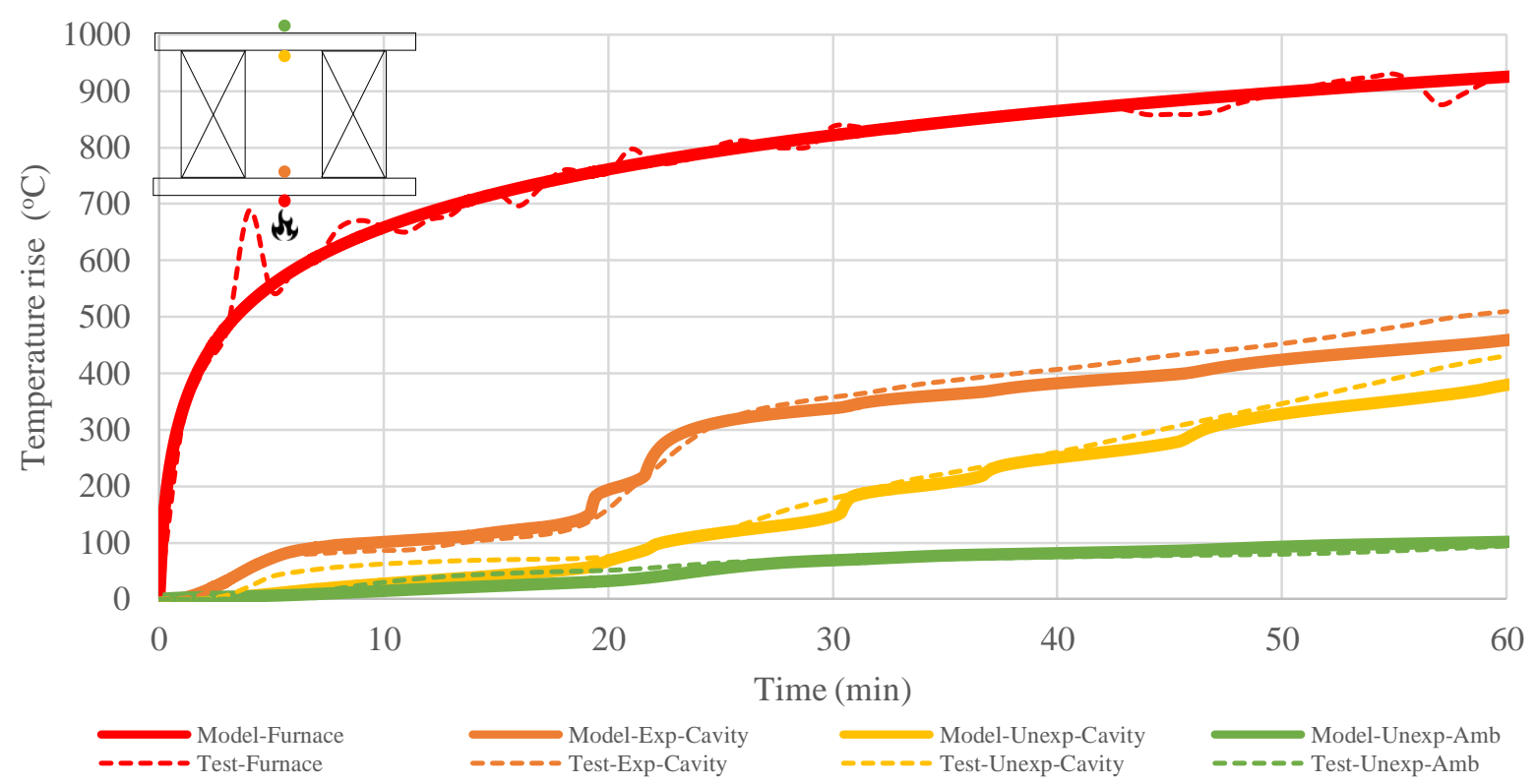

Figure A.1 - Test FR1611 time-temperature comparison with thermal model for the wall lining

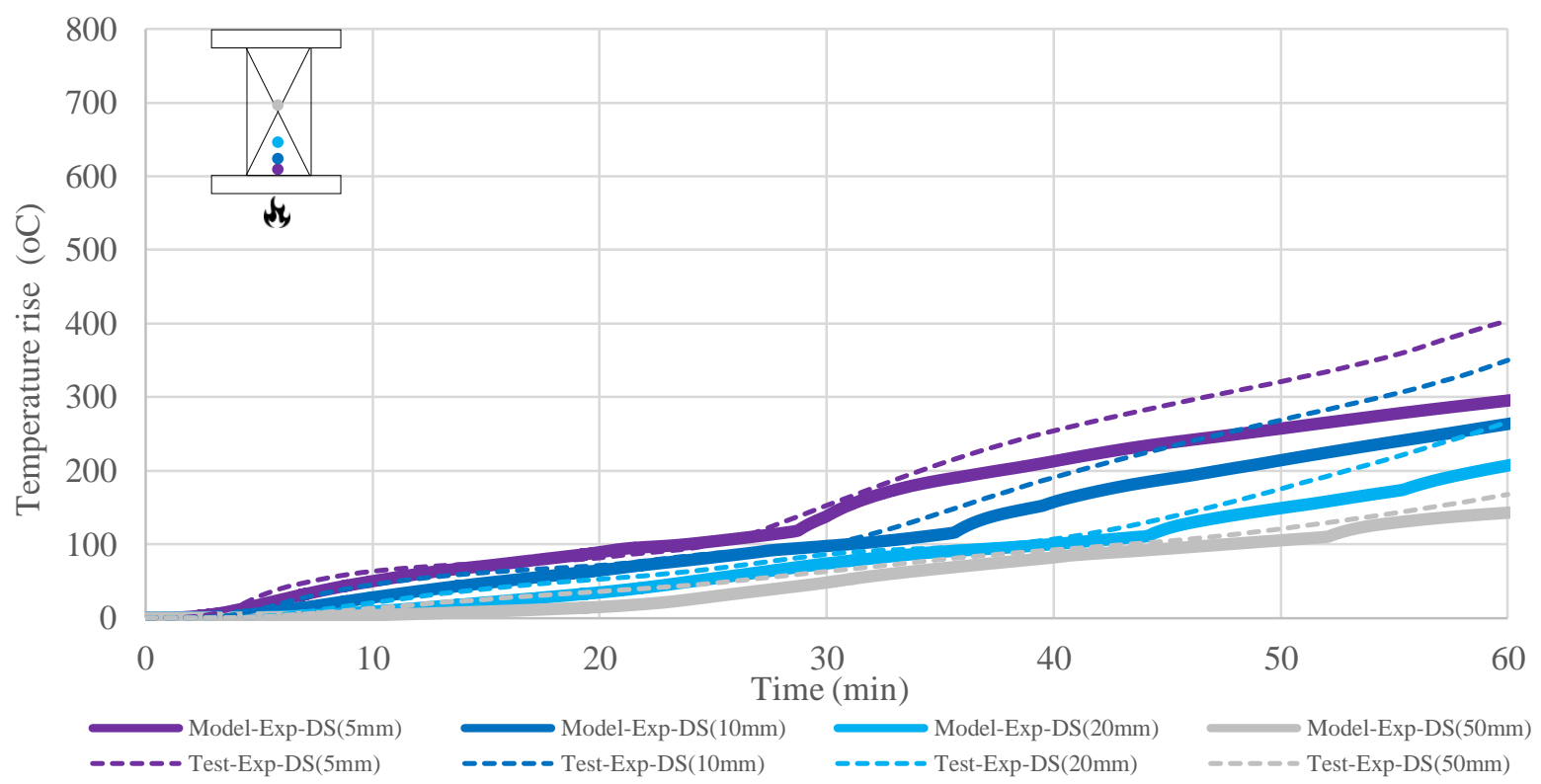

Figure A.2 - Test FR1611 time-temperature comparison with thermal model for the timber stud 
It can be seen that the comparison for the cavity was good until the temperature of gypsum plasterboard reached approximately $300{ }^{\circ} \mathrm{C}$ when the accuracy of model started to reduce predicting temperatures lower than the experimental data. Similarly, the modelled timber stud temperatures became less accurate at more elevated temperatures.

Figures A. 3 and A.4 show the time-temperature profile comparison after the calibration process by changing the heat transfer coefficients of thermal conductivity and density of gypsum plasterboard to those proposed by Thomas [19] which provided good agreement between the experimental and model results even at the elevated temperatures. Further comparisons are provided in Section 4.4.1.

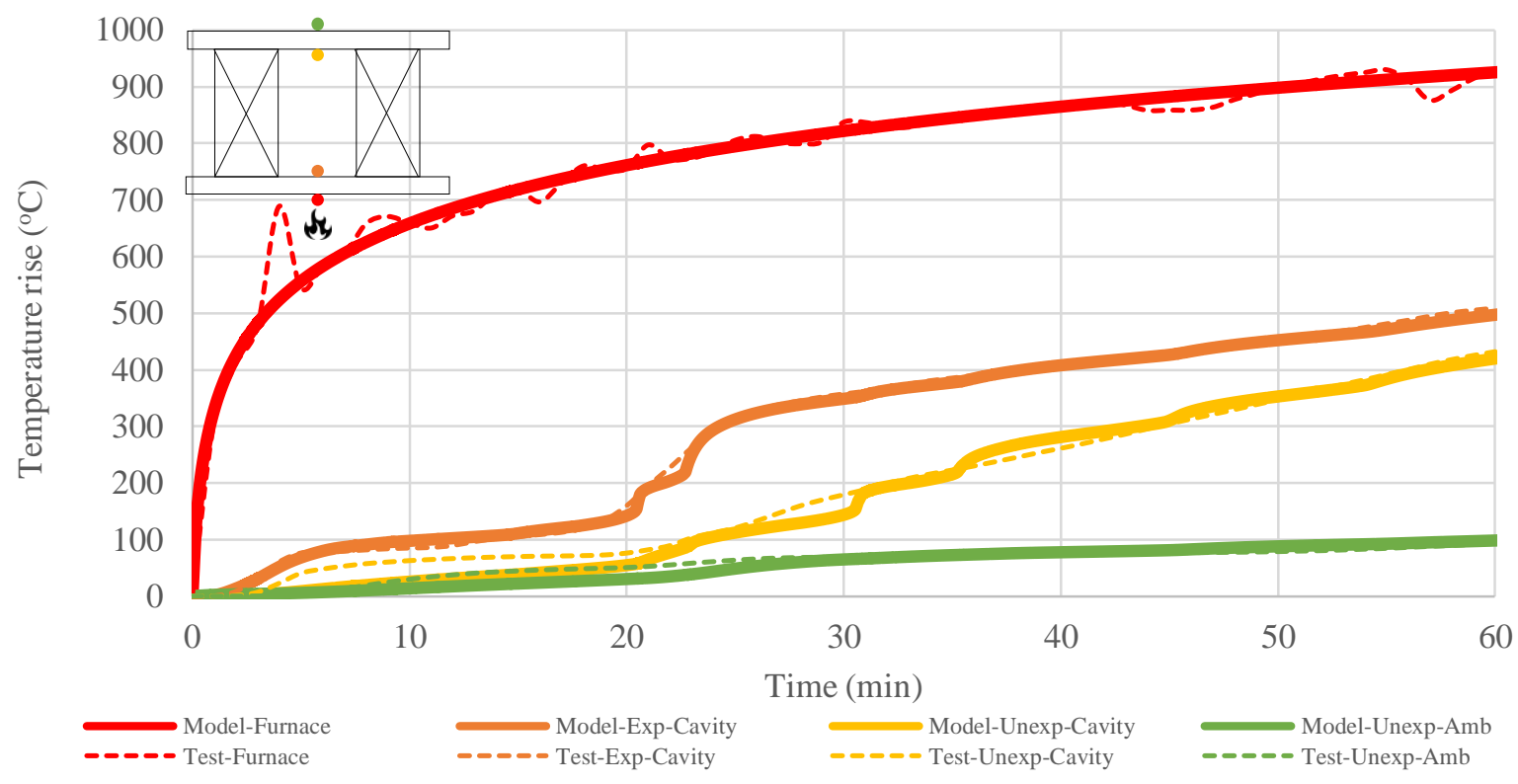

Figure A.3 - Test FR 1611 time-temperature comparison with thermal model for the wall lining after calibration 


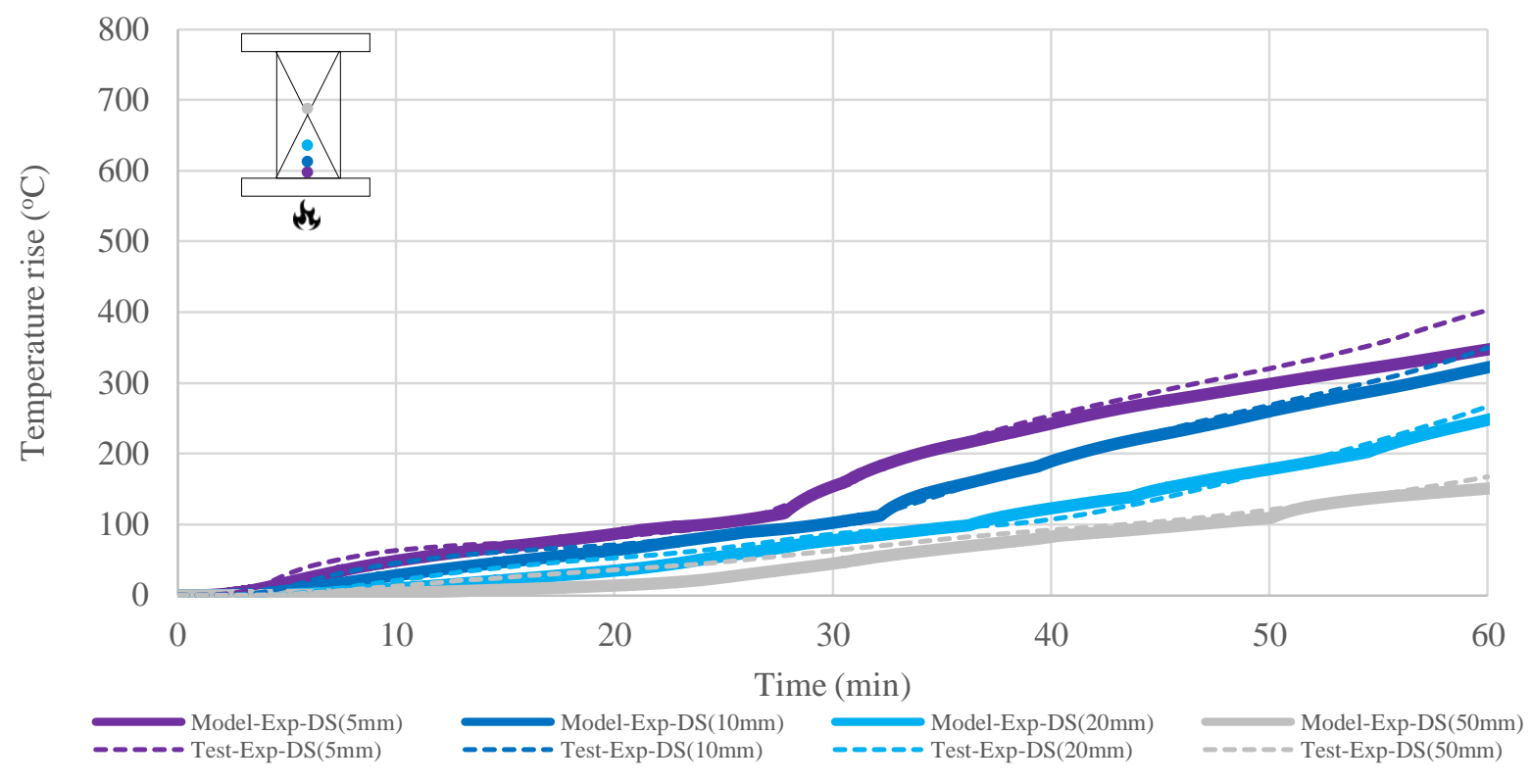

Figure A.4 - Test FR1611 time-temperature comparison with thermal model for the timber stud after calibration 


\section{Appendix B: Thermal modelling results based on the ISO 834 standard fire time-temperature curve and measured furnace temperatures}

A comparison was made for test FR1570 which has the most variation in temperatures.

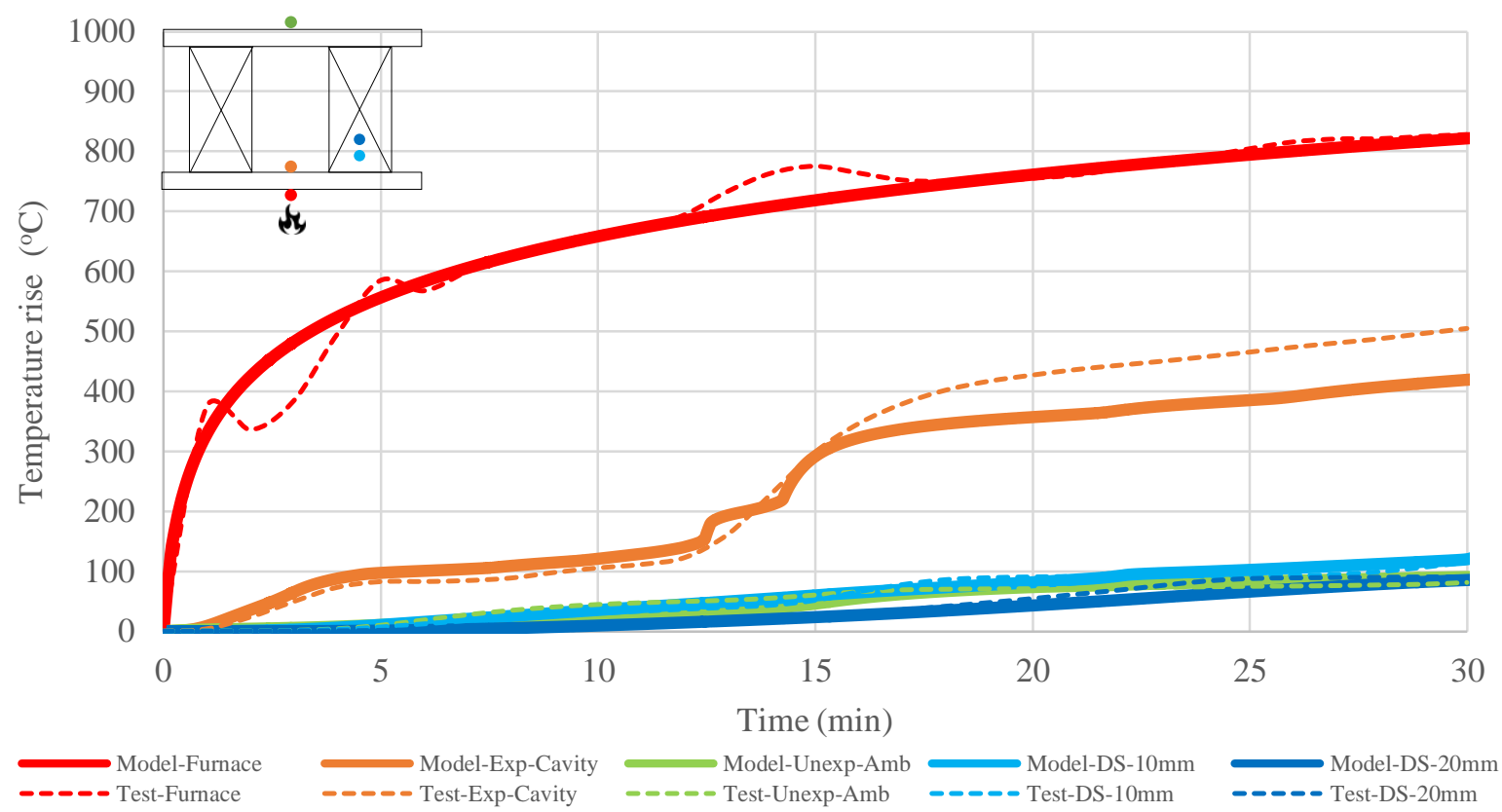

Figure B.1 - Test FR1570 time-temperature comparison with thermal model based on the ISO 834 standard fire time-temperature curve

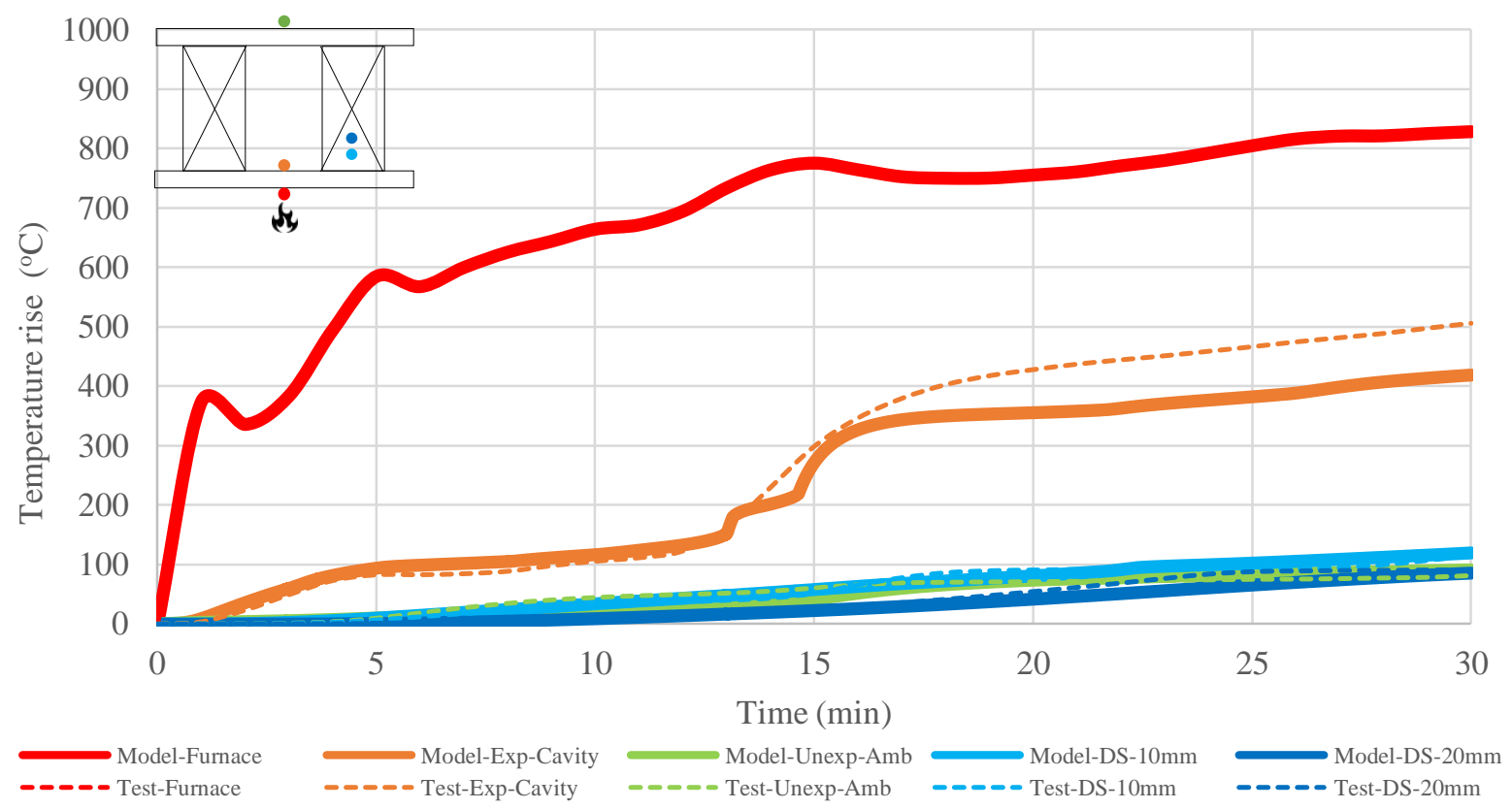

Figure B.2 - Test FR1570 time-temperature comparison with thermal model based on the measured furnace temperature 


\section{Appendix C: Euler's critical buckling load method for $90 \mathrm{~mm} \times 45 \mathrm{~mm}$ SG8 timber studs in compression}

Table C.1 - 90 mm x 45 mm SG8 timber stud nominal strength in compression for buckling based on Euler's critical load method

\begin{tabular}{|c|c|}
\hline \multicolumn{2}{|l|}{ About the major axis $x-x$} \\
\hline $\mathrm{Ix}=\mathrm{bh} 3 / 12$ & $2.7338 \mathrm{E}-06$ \\
\hline Modulus of elasticity $(\mathrm{Pa}), \mathrm{E}$ & 8.E+09 \\
\hline Column effective length factor, $\mathrm{K}$ & 1.00 \\
\hline Length of column (m), L & 3.00 \\
\hline Euler's critical load for buckling about $\mathrm{x}$ axis $(\mathrm{kN}), \mathrm{N} \mathrm{ncx}=\frac{\pi^{2} \cdot E \cdot I}{(K L)^{2}}$ & 23.98 \\
\hline \multicolumn{2}{|c|}{ About the minor axis $y-y$ (Restrained at $1.0 \mathrm{~m}$ centres using timber nogs) } \\
\hline $\mathrm{Ix}=\mathrm{bh} 3 / 12$ & $6.8344 \mathrm{E}-07$ \\
\hline Modulus of elasticity $(\mathrm{Pa}), \mathrm{E}$ & 8.E+09 \\
\hline Column effective length factor, $\mathrm{K}$ & 1.00 \\
\hline Length of column (m), L & 1.00 \\
\hline Euler's critical load for buckling about y axis $(\mathrm{kN}), \mathrm{N}$ ncy $=\frac{\pi^{2} \cdot E \cdot I}{(K L)^{2}}$ & 53.96 \\
\hline
\end{tabular}




\section{Appendix D: Euler's critical buckling load method for $140 \mathrm{~mm} \times 45 \mathrm{~mm}$ SG8 timber studs in compression}

Table D.1 - $140 \mathrm{~mm}$ x $45 \mathrm{~mm}$ SG8 timber stud nominal strength in compression for buckling based on Euler's critical load method

\begin{tabular}{|c|c|}
\hline \multicolumn{2}{|l|}{ About the major axis $x-x$} \\
\hline $\mathrm{Ix}=\mathrm{bh} 3 / 12$ & $1.0290 \mathrm{E}-05$ \\
\hline Modulus of elasticity $(\mathrm{Pa}), \mathrm{E}$ & 8.E+09 \\
\hline Column effective length factor, $\mathrm{K}$ & 1.00 \\
\hline Length of column (m), L & 3.00 \\
\hline Euler's critical load for buckling about $\mathrm{x}$ axis $(\mathrm{kN}), \mathrm{N} \mathrm{ncx}=\frac{\pi^{2} \cdot E \cdot I}{(K L)^{2}}$ & 90.27 \\
\hline \multicolumn{2}{|c|}{ About the minor axis $y-y$ (Restrained at $0.8 \mathrm{~m}$ centres using timber nogs) } \\
\hline $\mathrm{Ix}=\mathrm{bh} 3 / 12$ & $1.0631 \mathrm{E}-06$ \\
\hline Modulus of elasticity $(\mathrm{Pa}), \mathrm{E}$ & 8.E+09 \\
\hline Column effective length factor, $\mathrm{K}$ & 1.00 \\
\hline Length of column (m), L & 0.8 \\
\hline Euler's critical load for buckling about y axis $(\mathrm{kN}), \mathrm{N}$ ncy $=\frac{\pi^{2} \cdot E \cdot I}{(K L)^{2}}$ & 131.2 \\
\hline
\end{tabular}




\section{Appendix E: General eigenvalue buckling analysis result of 140 mm x 45 mm SG8 timber stud under ambient condition}

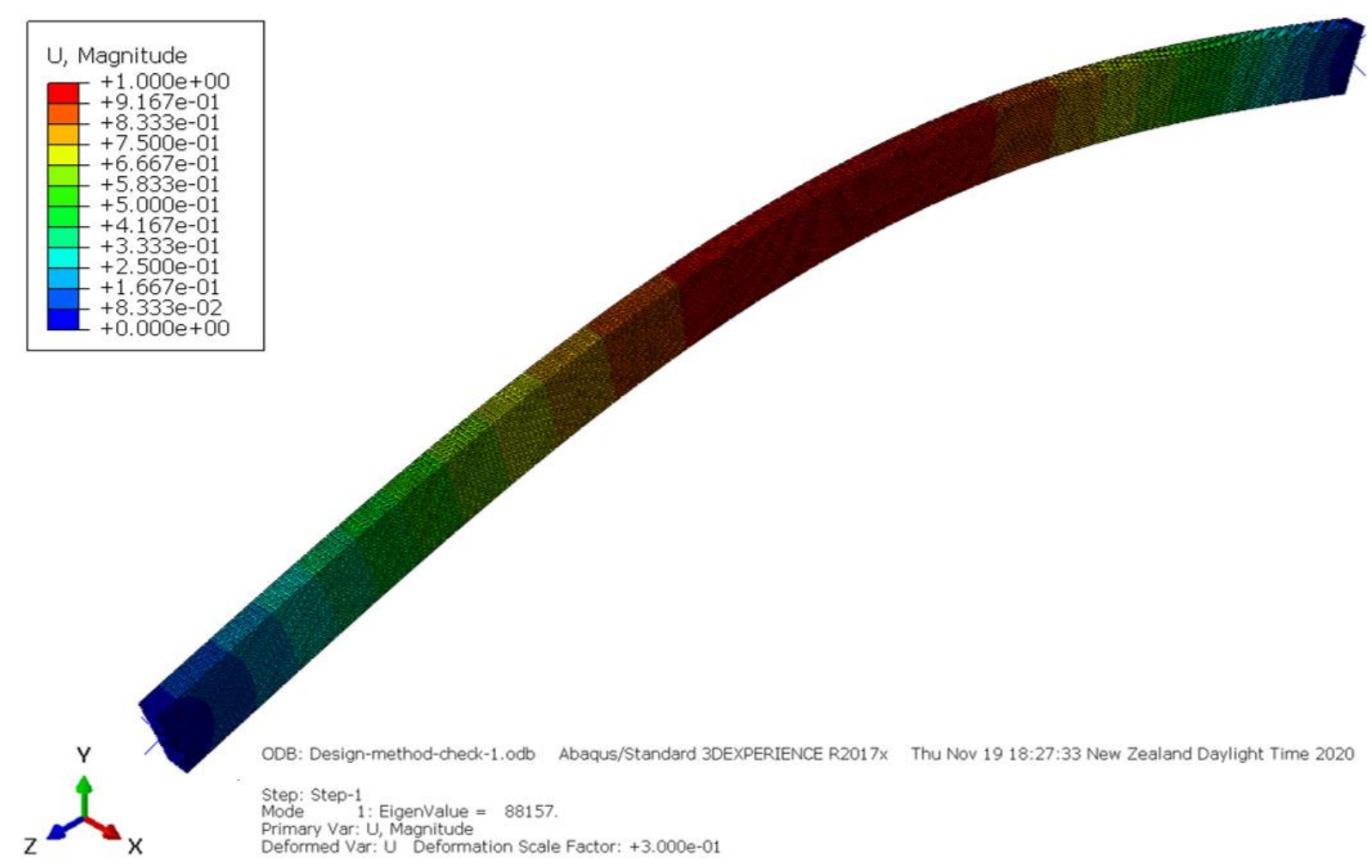

Figure E.1 - General eigenvalue buckling analysis results of 140 x 45 x 2910 timber stud

Figure above shows the general eigenvalue buckling analysis result for a $140 \mathrm{~mm}$ x $45 \mathrm{~mm}$ timber stud under ambient condition from Abaqus/CAE. The estimated critical elastic buckling load (eigenvalue) was $88.2 \mathrm{kN}$ from the first collapse mode shape which agreed well with the hand calculation result of $90.3 \mathrm{kN}$ in Appendix D which is based on Euler's critical load method. 
Appendix F: Detailed drawing for the two-sided fire exposure fire-resistance tests 


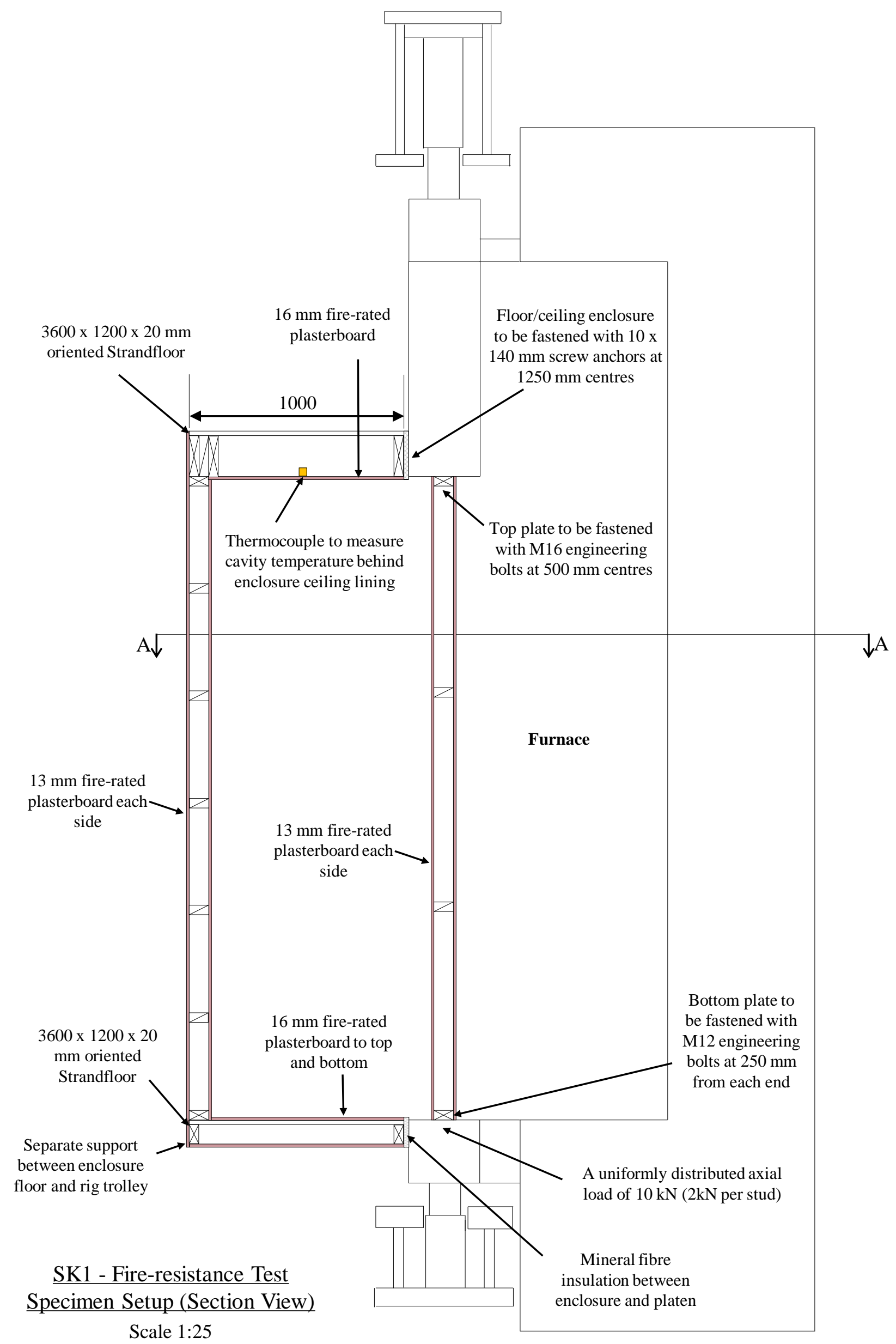

\begin{tabular}{|c|c|c|}
\hline EXPERIMENT 1 - QR1810-161 & $\begin{array}{l}\text { DRAWN BY: } \\
\text { FRANK KANG }\end{array}$ & $\begin{array}{r}\text { TESTING DATE: } \\
\text { JUL } 2020\end{array}$ \\
\hline $\begin{array}{l}\text { LOAD-BEARING TIMBER-FRAMED GYPSUM PLASTERBOARD LINED WALLS } \\
\text { SUBJECTED TO TWO-SIDED FIRE EXPOSURE }\end{array}$ & PHEET NO: & \begin{tabular}{|l} 
DWG REFERENCE: \\
SK1-SK12
\end{tabular} \\
\hline
\end{tabular}




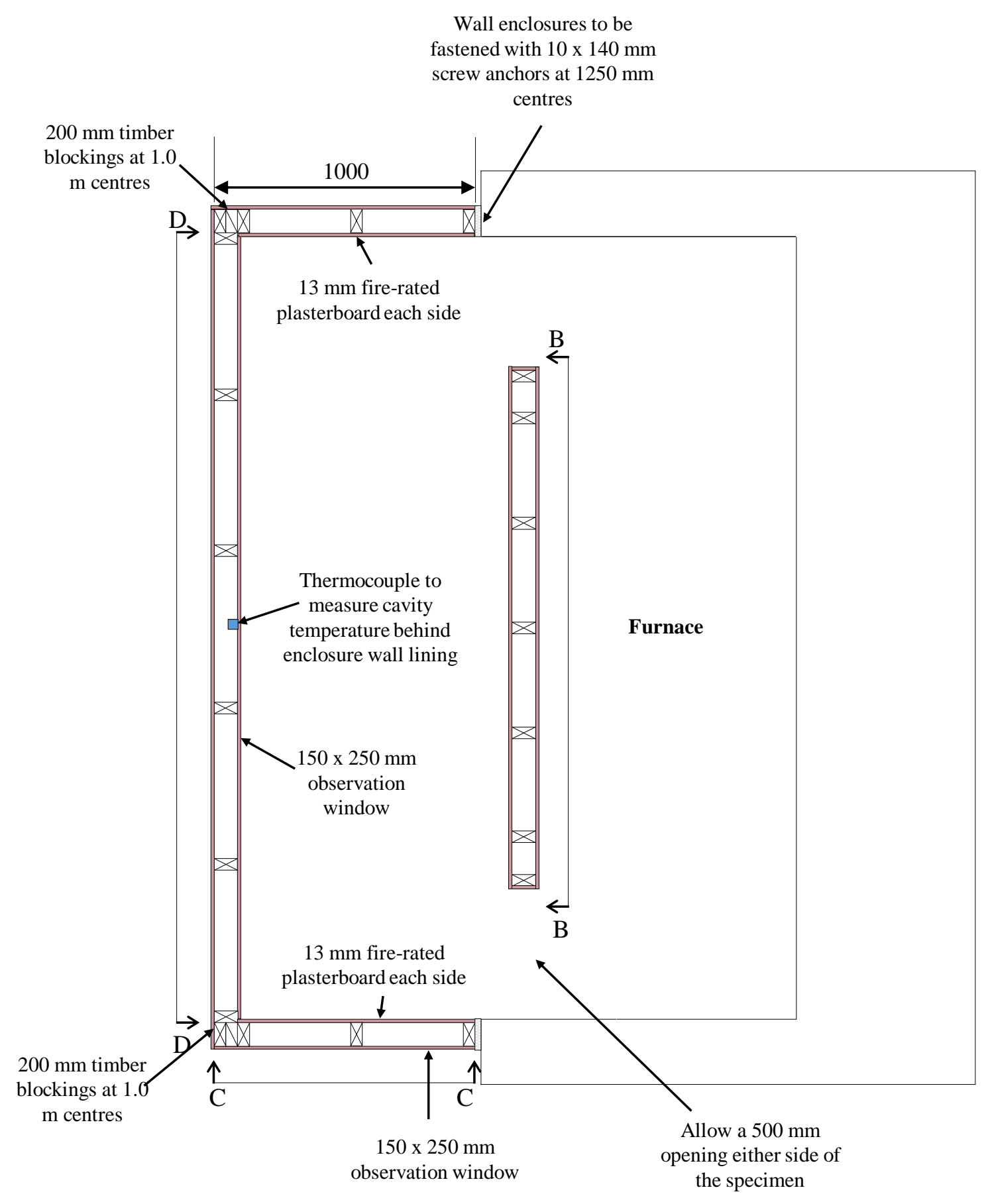

Section A-A

Scale 1:25

\begin{tabular}{|c|c|c|}
\hline EXPERIMENT 1 - QR1810-161 & $\begin{array}{l}\text { DRAWN BY: } \\
\text { FRANK KANG }\end{array}$ & $\begin{aligned} \text { TESTING DATE: } \\
\text { JUL } 2020\end{aligned}$ \\
\hline $\begin{array}{l}\text { LOAD-BEARING TIMBER-FRAMED GYPSUM PLASTERBOARD LINED WALLS } \\
\text { SUBJECTED TO TWO-SIDED FIRE EXPOSURE }\end{array}$ & PHEET NO: & $\begin{aligned} \text { DWG REFERENCE: } \\
\text { SK1-SK12 }\end{aligned}$ \\
\hline
\end{tabular}


Timber framing

Dummy studs

Sheet Joints - Furnace side 1

Sheet Joints - Furnace side 2

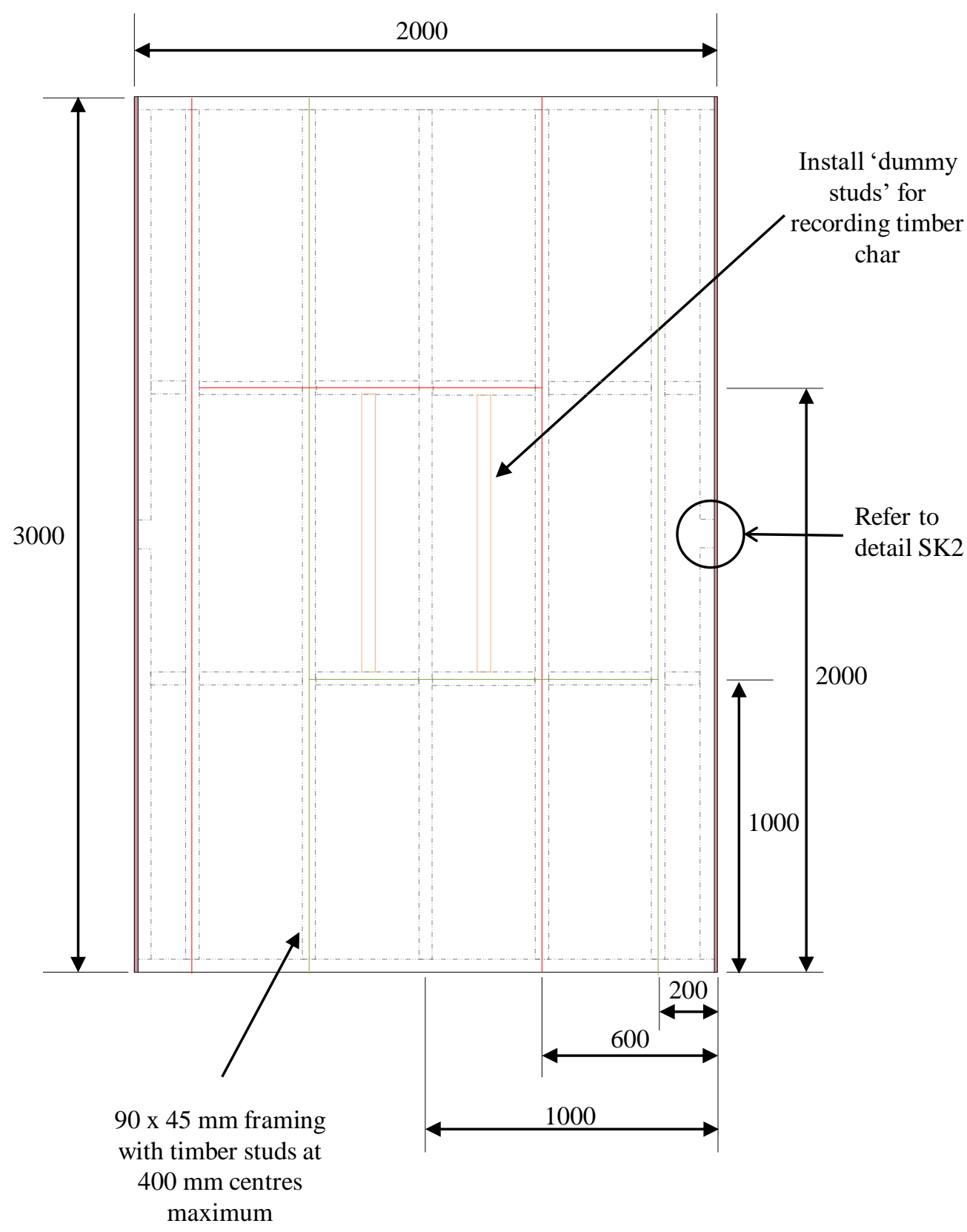

Section B-B

Scale 1:25

\begin{tabular}{|c|c|c|}
\hline \multirow{2}{*}{$\begin{array}{l}\text { PROJECT TITLE: } \quad \text { EXPERIMENT 1 - QR1810-161 } \\
\text { LOAD-BEARING TIMBER-FRAMED GYPSUM PLASTERBOARD LINED WALLS } \\
\text { SUBJECTED TO TWO-SIDED FIRE EXPOSURE }\end{array}$} & $\begin{array}{l}\text { DRAWN BY: } \\
\text { FRANK KANG }\end{array}$ & \begin{tabular}{|} 
TESTING DATE: \\
JUL 2020
\end{tabular} \\
\hline & PHEET NO: & \begin{tabular}{|c|} 
DWG REFERENCE: \\
SK1-SK12
\end{tabular} \\
\hline
\end{tabular}




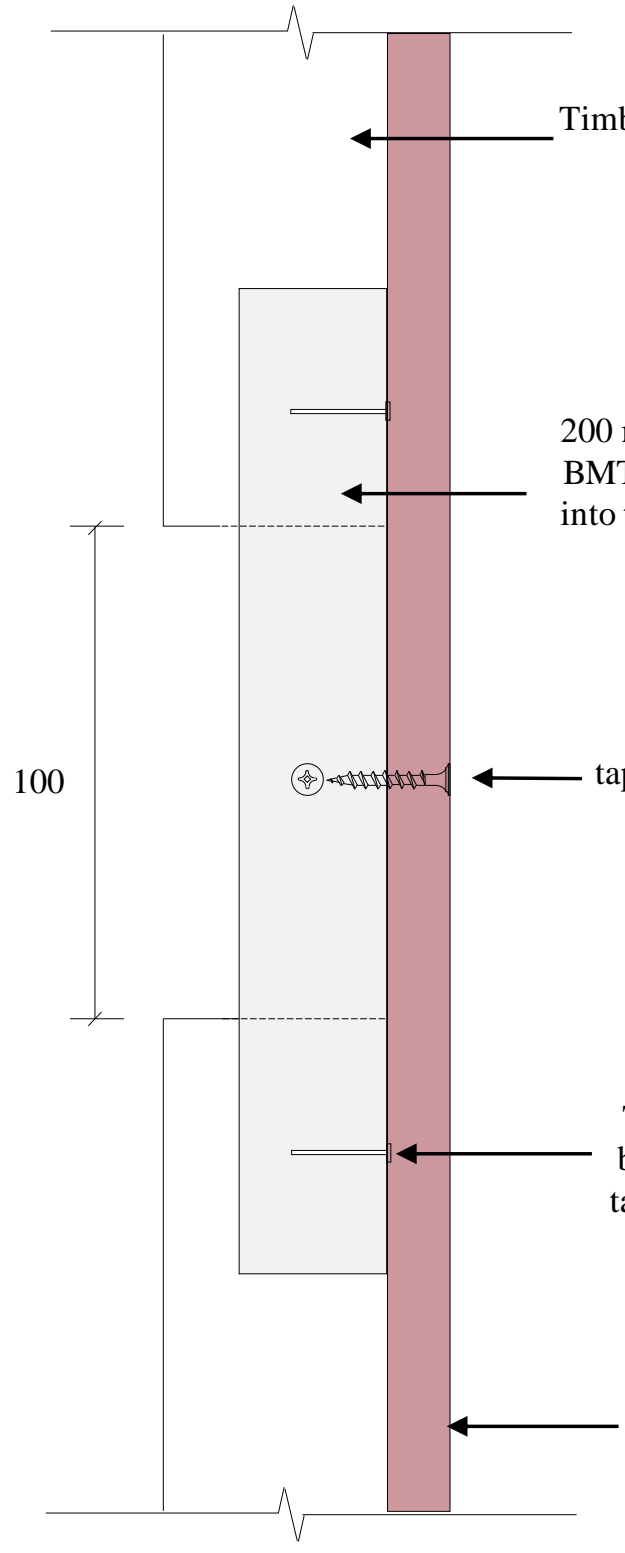

$6 \mathrm{~g} \mathrm{x} 25 \mathrm{~mm}$ self tapping drywall screws fixed into the steel channel

Temporary fixings to be removed when self tapping drywall screws are installed

$13 \mathrm{~mm}$ fire-rated gypsum plasterboard strip

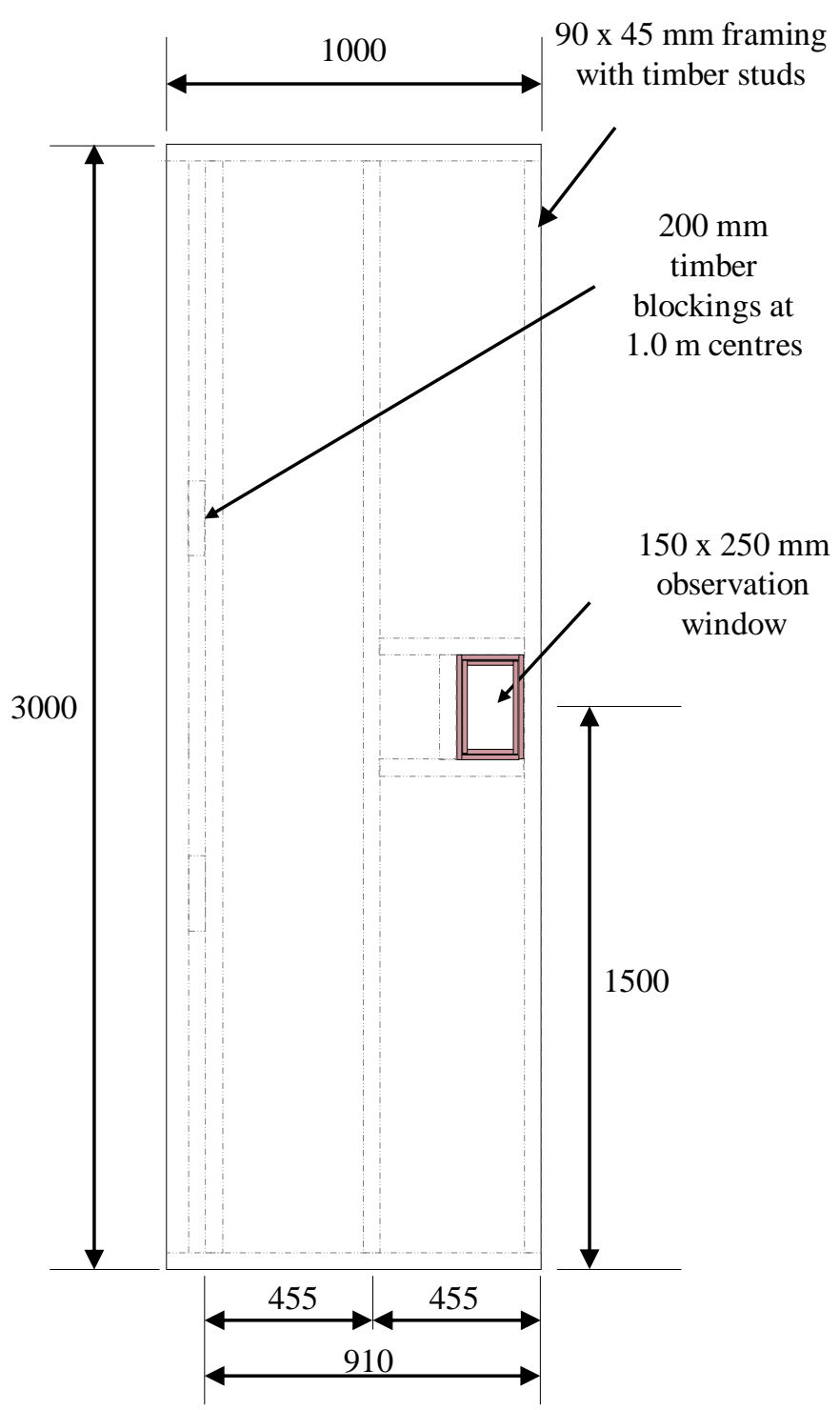

Section C-C

Scale 1:25 


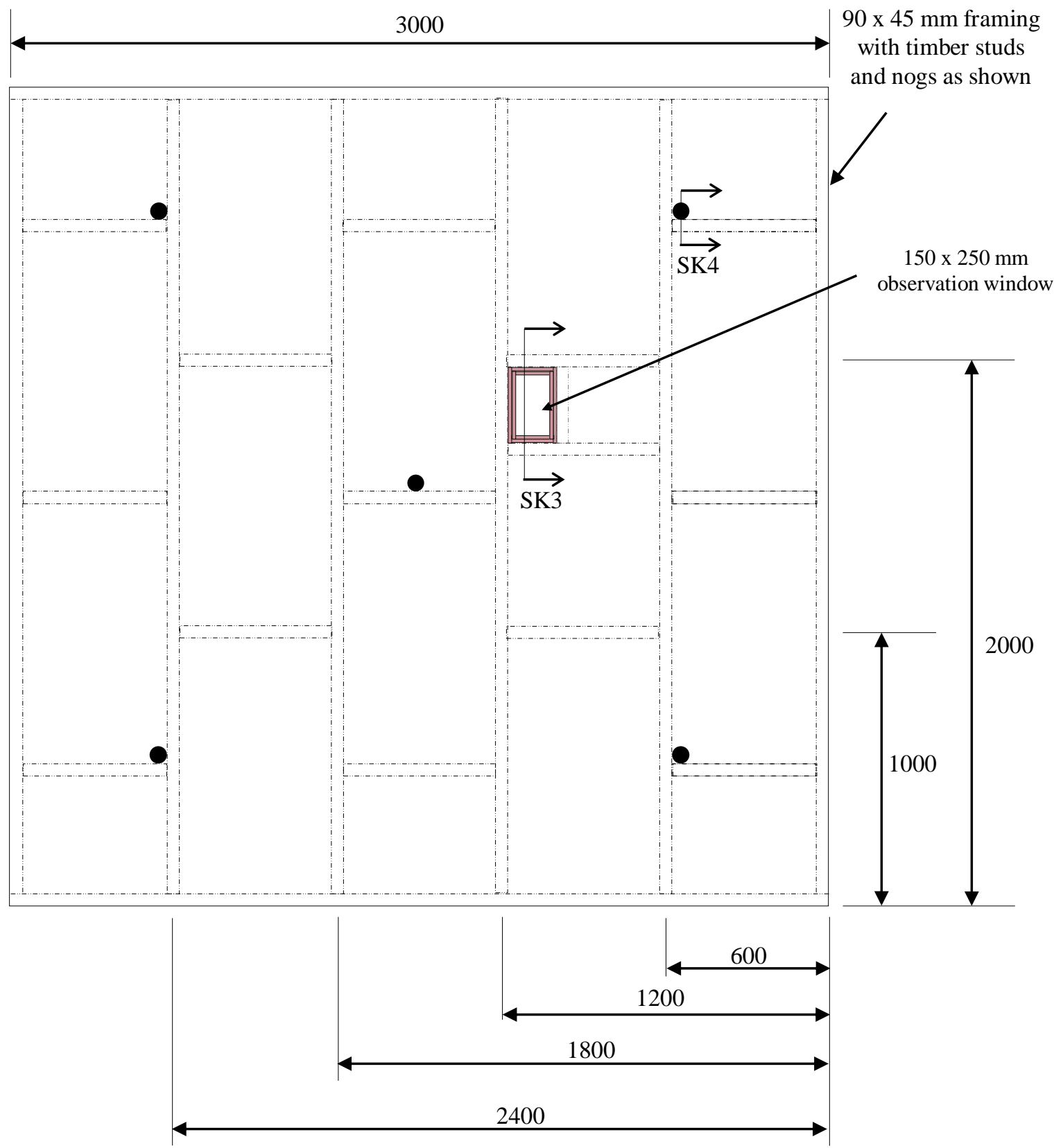

$\underline{\text { Section D-D }}$

Scale 1:25

\begin{tabular}{|c|c|c|}
\hline EXPERIMENT 1 - QR1810-161 & $\begin{array}{l}\text { DRAWN BY: } \\
\text { FRANK KANG }\end{array}$ & $\begin{array}{r}\text { TESTING DATE: } \\
\text { JUL } 2020\end{array}$ \\
\hline $\begin{array}{l}\text { LOAD-BEARING TIMBER-FRAMED GYPSUM PLASTERBOARD LINED WALLS } \\
\text { SUBJECTED TO TWO-SIDED FIRE EXPOSURE }\end{array}$ & PHEET NO: & $\begin{aligned} \text { DWG REFERENCE: } \\
\text { SK1-SK12 }\end{aligned}$ \\
\hline
\end{tabular}




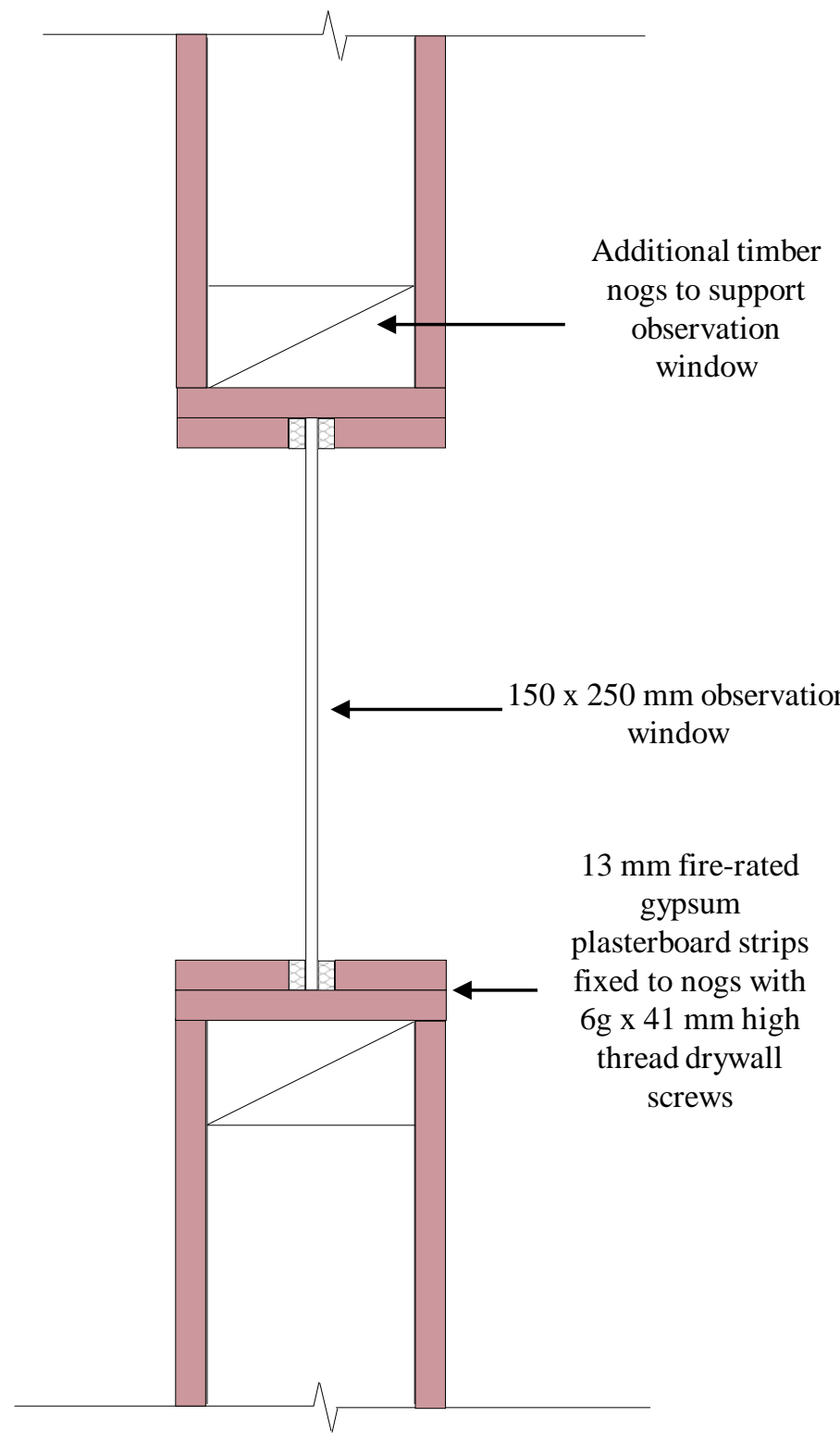

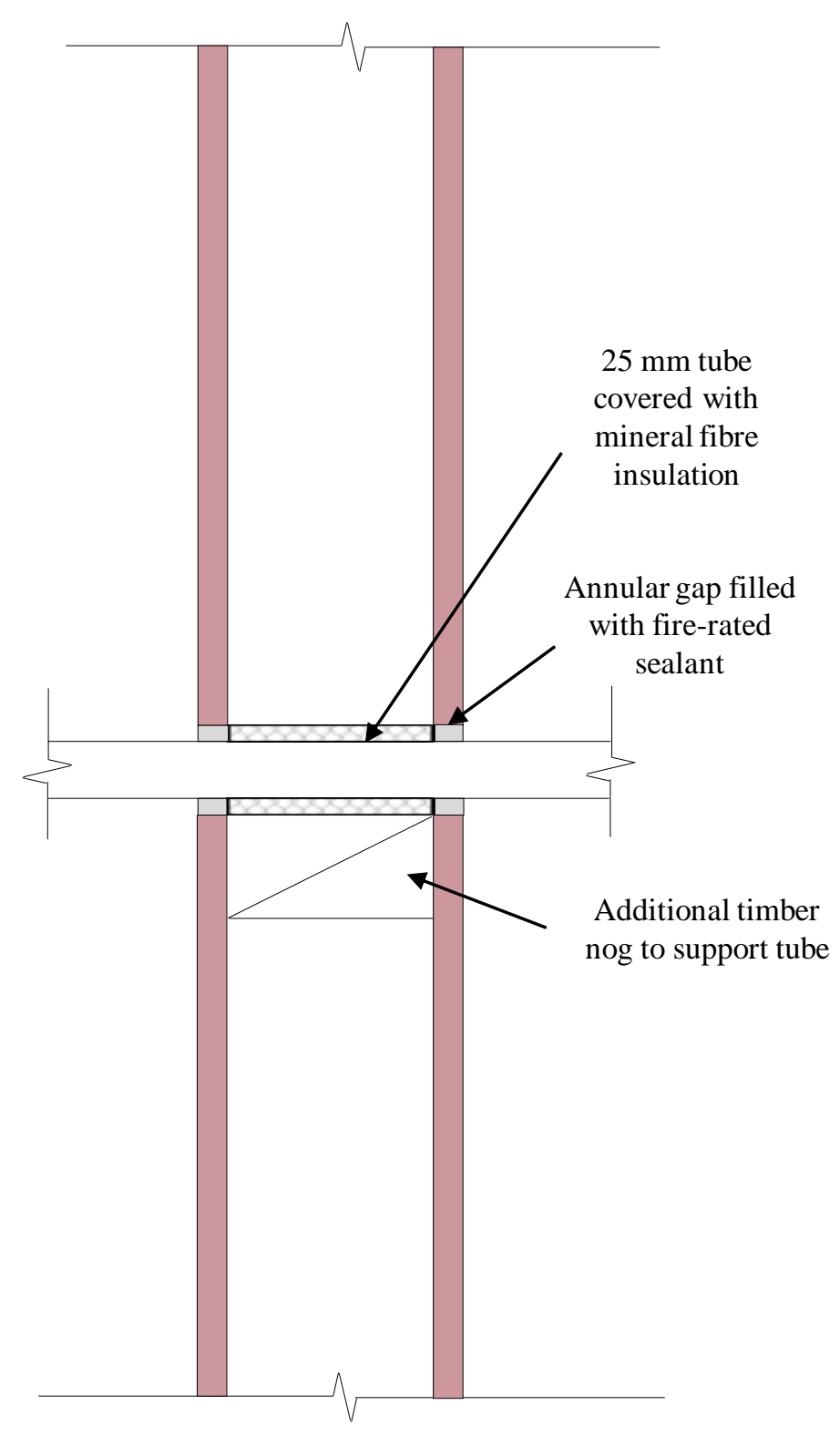

SK4 - MIMS thermocouple and plate thermometer tube detail

Scale 1:4 


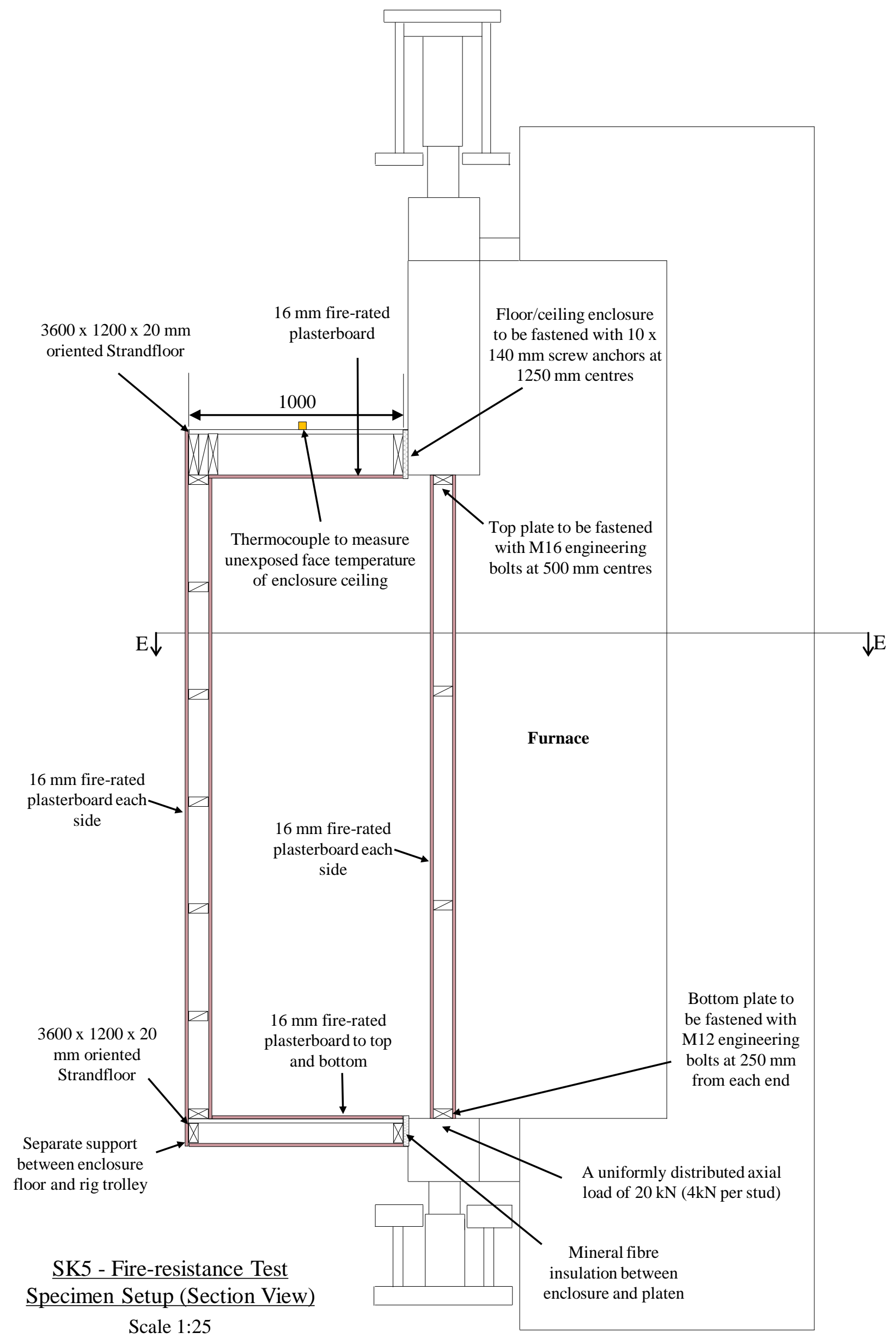

\begin{tabular}{|c|c|c|}
\hline \multirow{2}{*}{\begin{tabular}{cc|} 
PROJECT TITLE: & EXPERIMENT 2 - QR1810-162 \\
LOAD-BEARING TIMBER-FRAMED GYPSUM PLASTERBOARD LINED WALLS \\
SUBJECTED TO TWO-SIDED FIRE EXPOSURE
\end{tabular}} & $\begin{array}{l}\text { DRAWN BY: } \\
\text { FRANK KANG }\end{array}$ & $\begin{array}{l}\text { TESTING DATE: } \\
\text { AUG } 2020\end{array}$ \\
\hline & PHEET NO: & $\begin{array}{l}\text { DWG REFERENCE: } \\
\text { SK1-SK12 }\end{array}$ \\
\hline
\end{tabular}




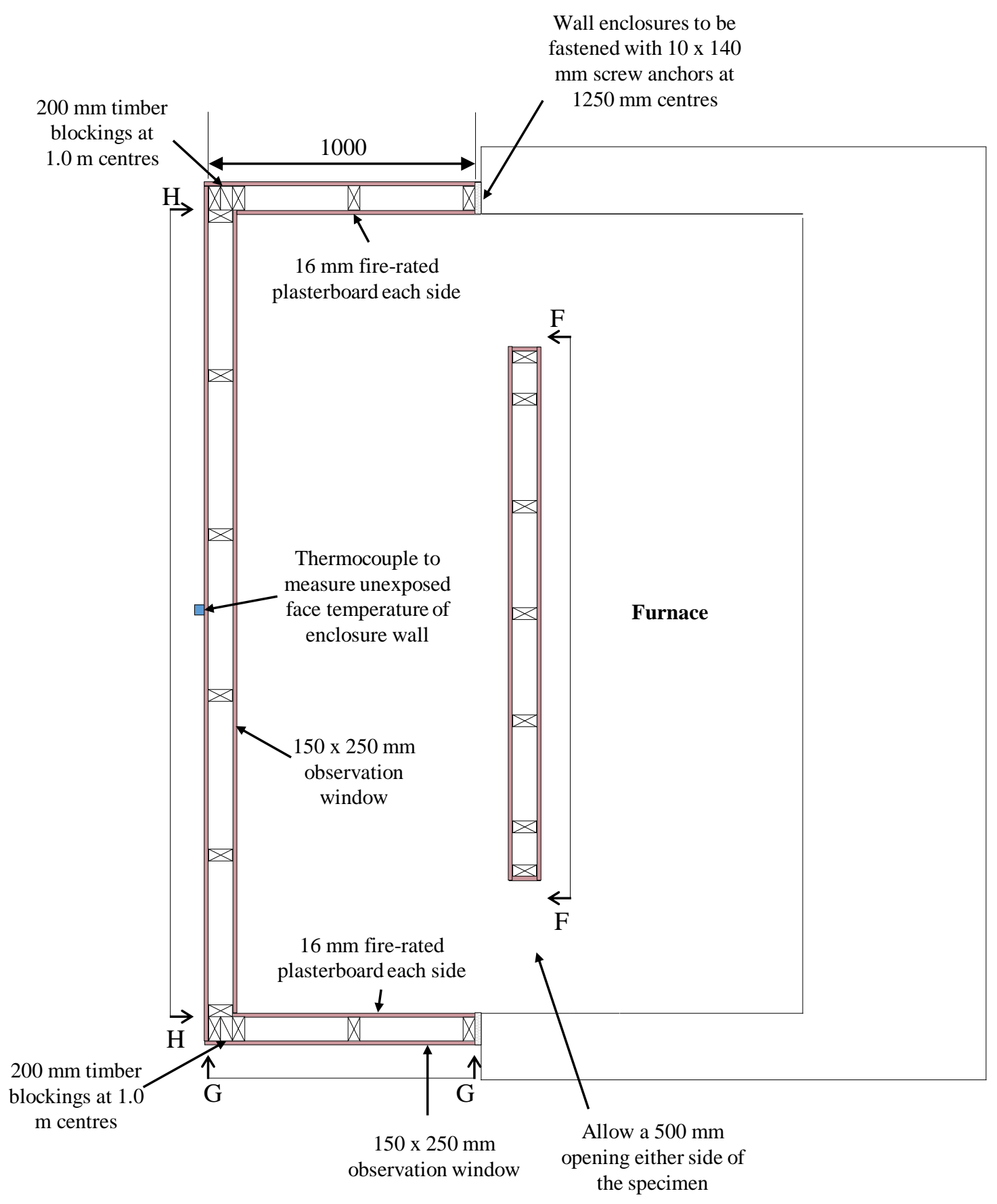

Section E-E

Scale 1:25

\begin{tabular}{|c|c|c|}
\hline \multirow{2}{*}{$\begin{array}{l}\text { PROJECT TITLE: } \quad \text { EXPERIMENT 2 - QR1810-162 } \\
\text { LOAD-BEARING TIMBER-FRAMED GYPSUM PLASTERBOARD LINED WALLS } \\
\text { SUBJECTED TO TWO-SIDED FIRE EXPOSURE }\end{array}$} & $\begin{array}{l}\text { DRAWN BY: } \\
\text { FRANK KANG }\end{array}$ & \begin{tabular}{|} 
TESTING DATE: \\
AUG 2020
\end{tabular} \\
\hline & PHEET NO: ${ }_{\text {S107 }}$ & \begin{tabular}{|c|} 
DWG REFERENCE: \\
SK1-SK12
\end{tabular} \\
\hline
\end{tabular}


Timber framing

Dummy studs

Sheet Joints - Furnace side 1

Sheet Joints - Furnace side 2

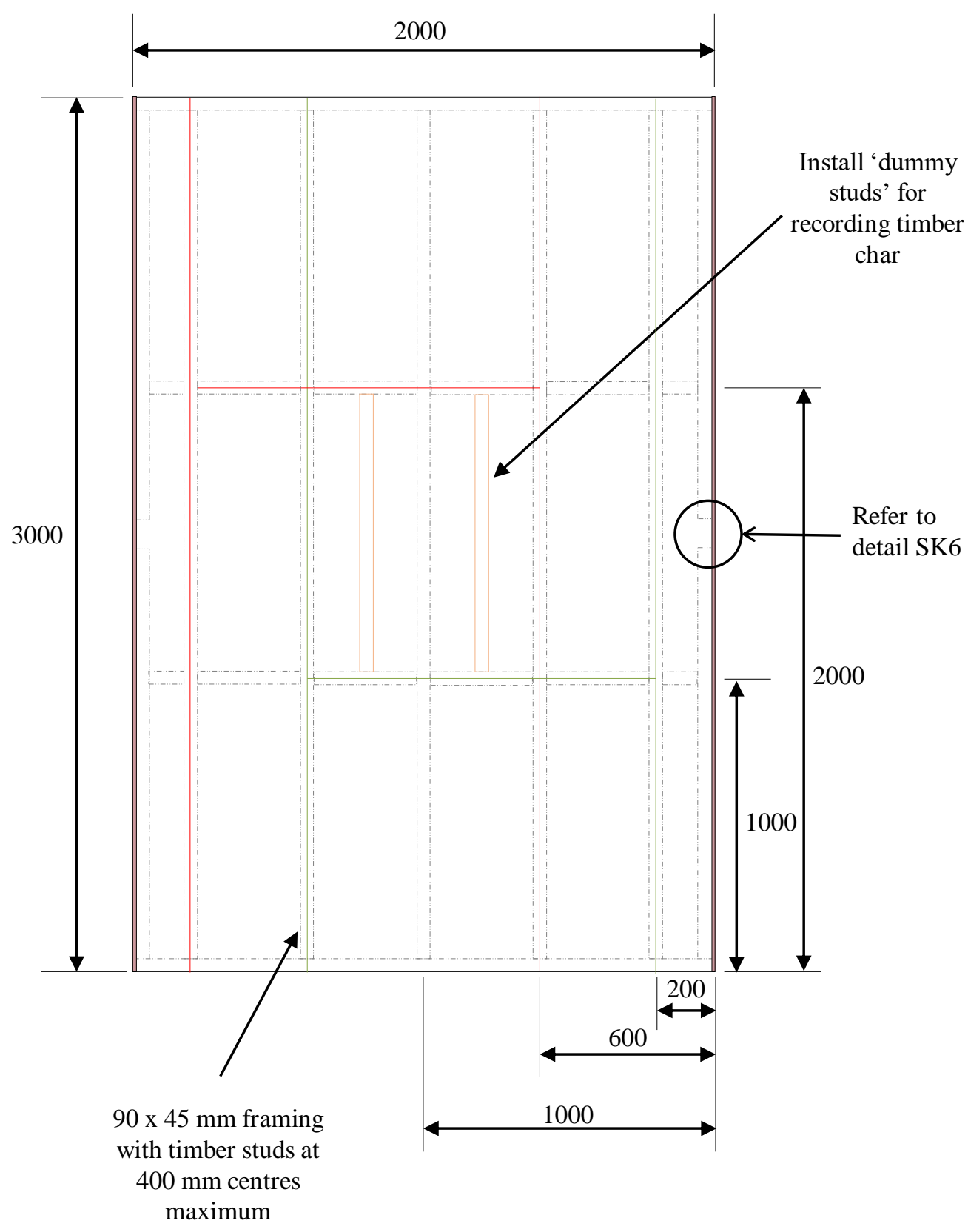

Section F-F

Scale 1:25

\begin{tabular}{|c|c|c|}
\hline \multirow{2}{*}{$\begin{array}{l}\text { PROJECT TITLE: } \quad \text { EXPERIMENT 2 - QR1810-162 } \\
\text { LOAD-BEARING TIMBER-FRAMED GYPSUM PLASTERBOARD LINED WALLS } \\
\text { SUBJECTED TO TWO-SIDED FIRE EXPOSURE }\end{array}$} & $\begin{array}{l}\text { DRAWN BY: } \\
\text { FRANK KANG }\end{array}$ & \begin{tabular}{|} 
TESTING DATE: \\
AUG 2020
\end{tabular} \\
\hline & PHEET NO: & \begin{tabular}{|c|} 
DWG REFERENCE: \\
SK1-SK12
\end{tabular} \\
\hline
\end{tabular}



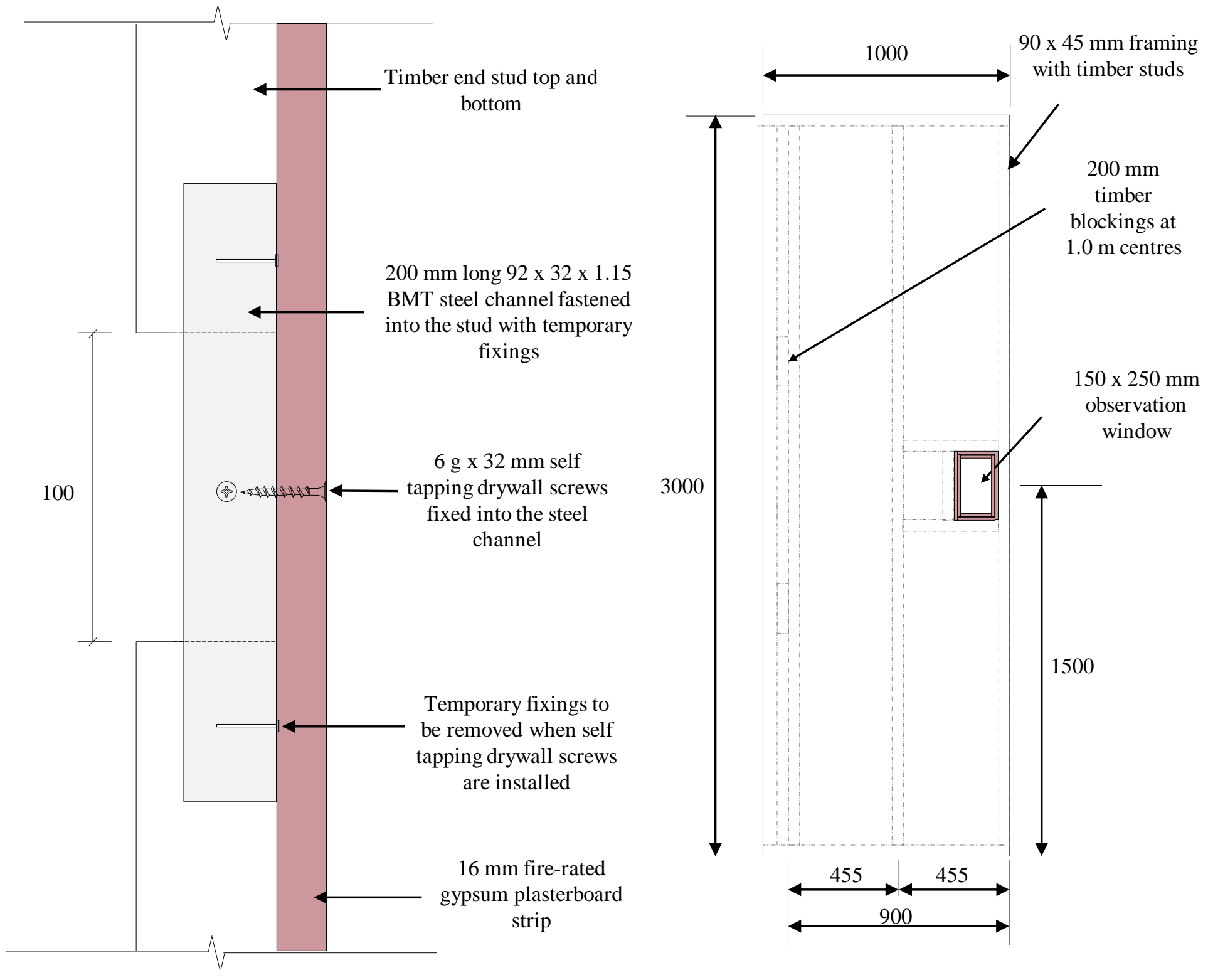

$\underline{\text { SK6 - Temporary fixing detail }}$

Scale 1:2

Section G-G

Scale 1:25

\begin{tabular}{|c|c|c|}
\hline \multirow{2}{*}{$\begin{array}{l}\text { PROJECT TITLE: } \quad \text { EXPERIMENT 2 - QR1810-162 } \\
\text { LOAD-BEARING TIMBER-FRAMED GYPSUM PLASTERBOARD LINED WALLS } \\
\text { SUBJECTED TO TWO-SIDED FIRE EXPOSURE }\end{array}$} & $\begin{array}{l}\text { DRAWN BY: } \\
\text { FRANK KANG }\end{array}$ & \begin{tabular}{|} 
TESTING DATE: \\
AUG 2020
\end{tabular} \\
\hline & PHEET NO: & \begin{tabular}{|c|} 
DWG REFERENCE: \\
SK1-SK12
\end{tabular} \\
\hline
\end{tabular}




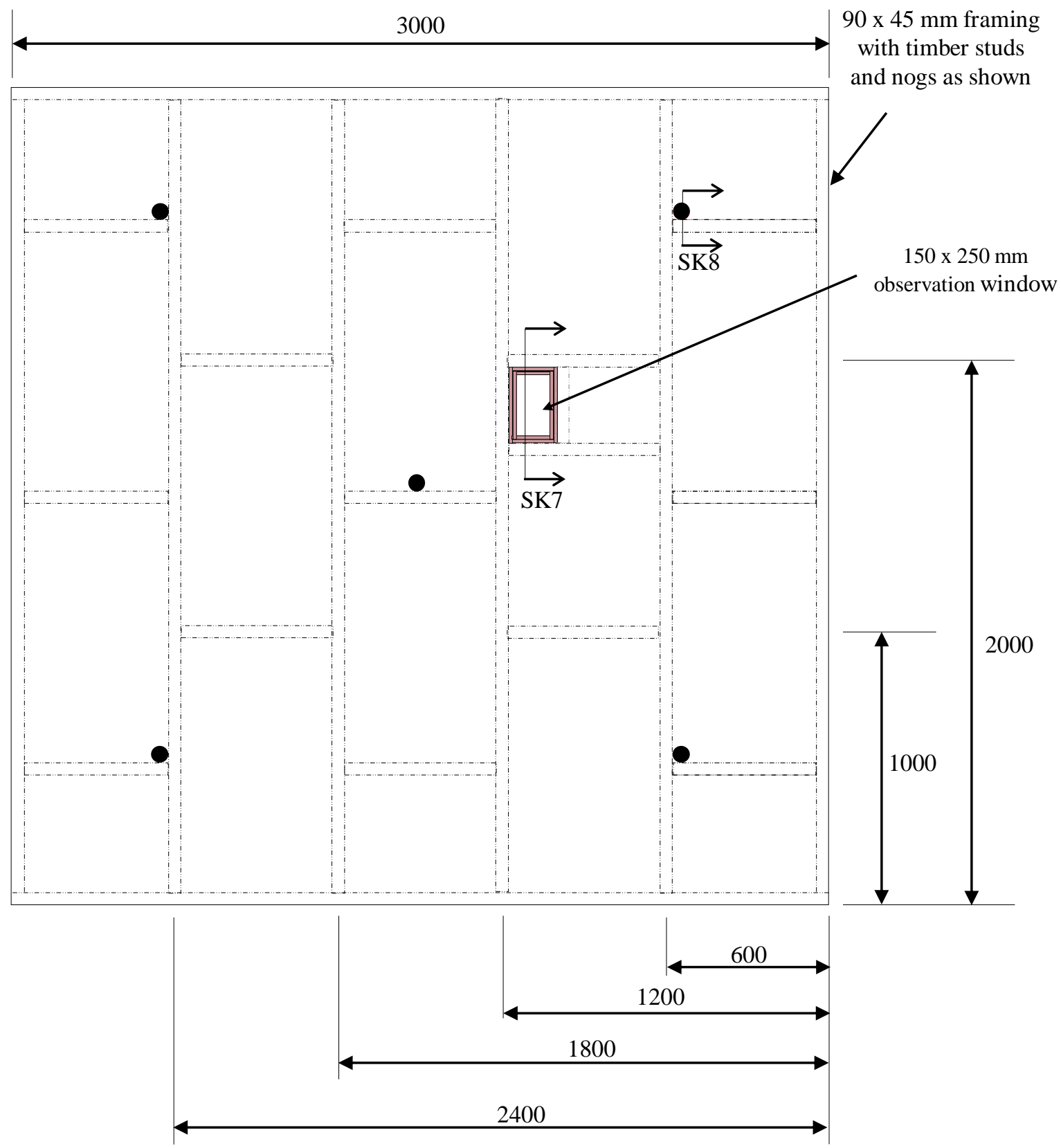

Section H-H

Scale 1:25

\begin{tabular}{|c|c|c|}
\hline \multirow{2}{*}{$\begin{array}{l}\text { PROJECT TITLE: } \quad \text { EXPERIMENT 2 - QR1810-162 } \\
\text { LOAD-BEARING TIMBER-FRAMED GYPSUM PLASTERBOARD LINED WALLS } \\
\text { SUBJECTED TO TWO-SIDED FIRE EXPOSURE }\end{array}$} & $\begin{array}{l}\text { DRAWN BY: } \\
\text { FRANK KANG }\end{array}$ & \begin{tabular}{|} 
TESTING DATE: \\
AUG 2020
\end{tabular} \\
\hline & PHEET NO: & \begin{tabular}{|c|} 
DWG REFERENCE: \\
SK1-SK12
\end{tabular} \\
\hline
\end{tabular}



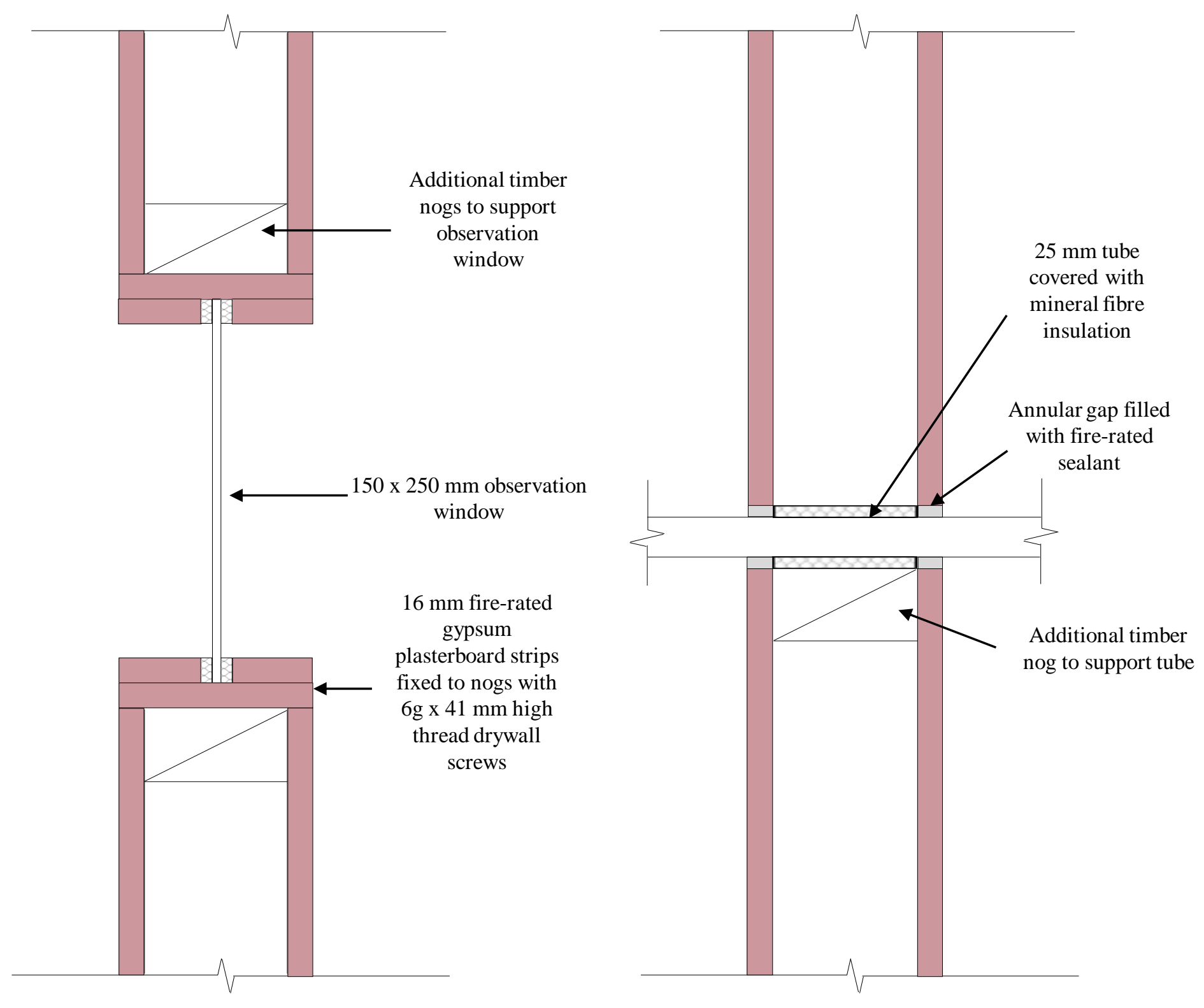

$\underline{\text { SK7 - Observation window detail }}$

Scale 1:4 $\underline{\text { SK8 - MIMS thermocouple and plate thermometer }}$ tube detail

Scale 1:4 


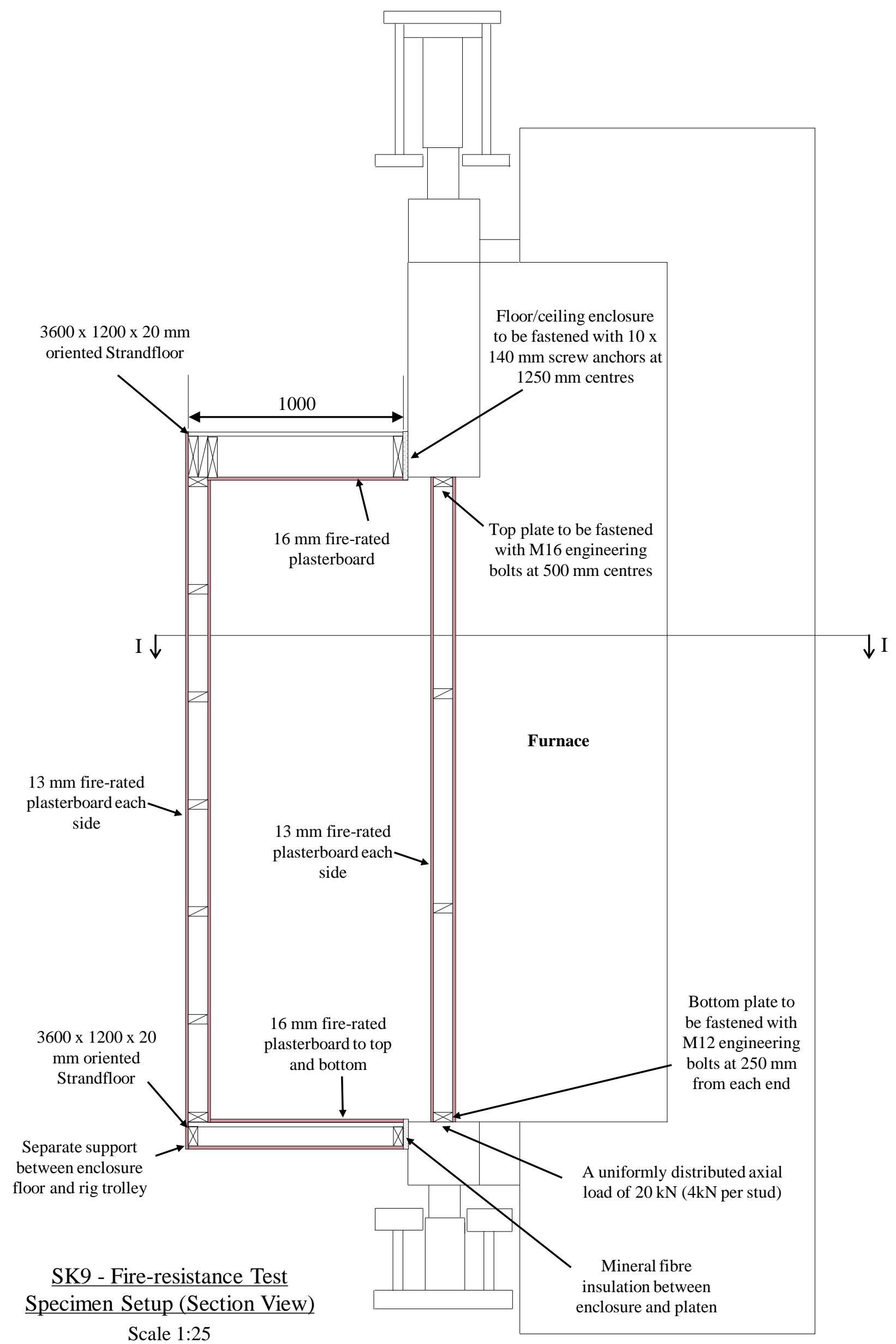

Scale 1:25

\begin{tabular}{|c|c|c|}
\hline PROJECT TITLE: $\quad$ EXPERIMENT 3 - QR1810-163 & $\begin{array}{l}\text { DRAWN BY: } \\
\text { FRANK KANG }\end{array}$ & $\begin{array}{l}\text { TESTING DATE: } \\
\text { OCT } 2020\end{array}$ \\
\hline $\begin{array}{l}\text { LOAD-BEARING TIMBER-FRAMED GYPSUM PLASTERBOARD LINED WALLS } \\
\text { SUBJECTED TO TWO-SIDED FIRE EXPOSURE }\end{array}$ & SHEET NO: & \begin{tabular}{|c|} 
DWG REFERENCE: \\
SK1-SK12
\end{tabular} \\
\hline
\end{tabular}

All measurements are in millimeters unless otherwise stated 
Wall enclosures to be fastened with $10 \times 140 \mathrm{~mm}$ screw anchors at $1250 \mathrm{~mm}$ centres

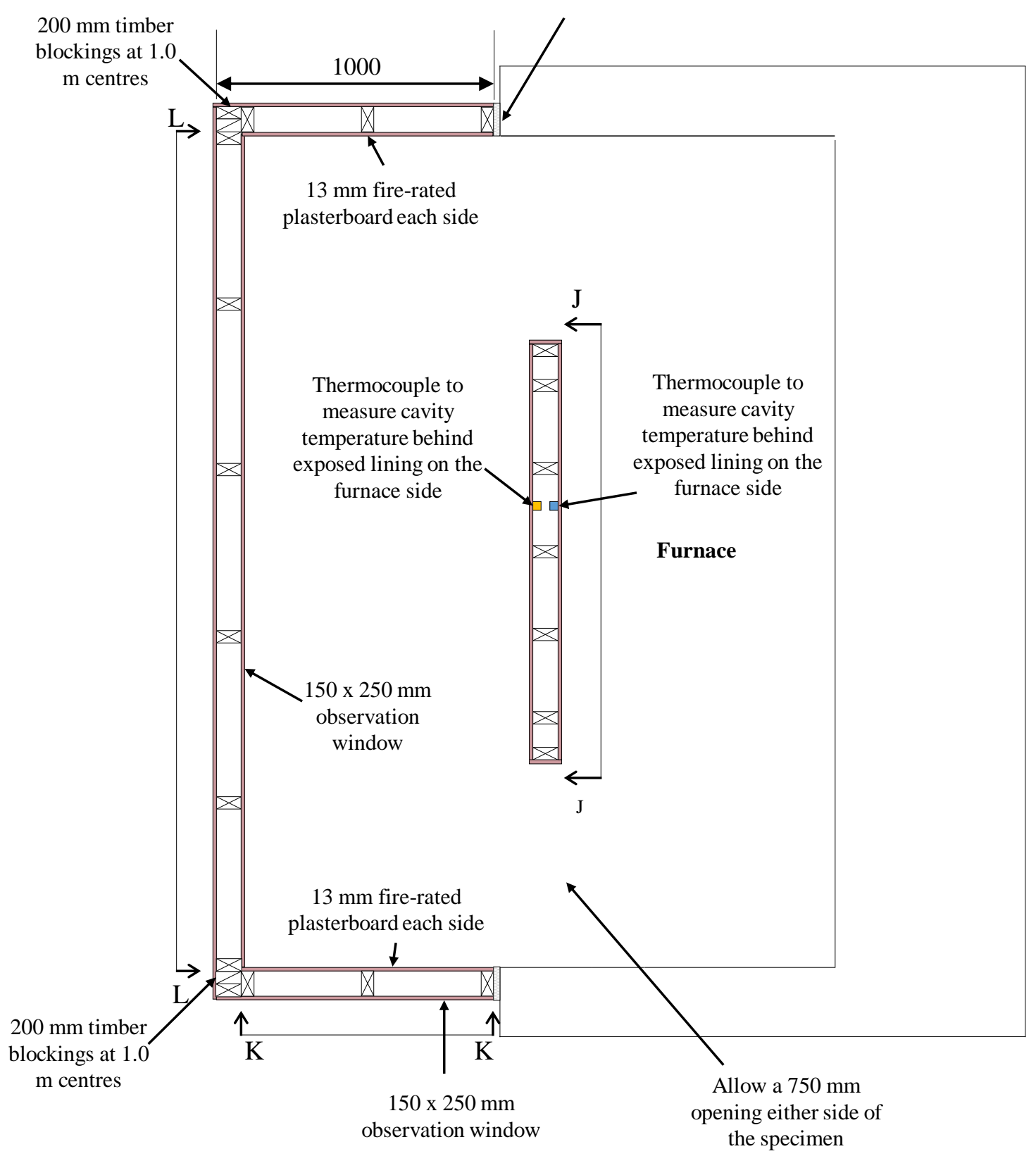

\section{Section I-I}

Scale 1:25

\begin{tabular}{|c|c|c|}
\hline \multirow{2}{*}{$\begin{array}{l}\text { PROJECT TITLE: } \quad \text { EXPERIMENT 3 - QR1810-163 } \\
\text { LOAD-BEARING TIMBER-FRAMED GYPSUM PLASTERBOARD LINED WALLS } \\
\text { SUBJECTED TO TWO-SIDED FIRE EXPOSURE }\end{array}$} & $\begin{array}{l}\text { DRAWN BY: } \\
\text { FRANK KANG }\end{array}$ & $\begin{array}{c}\text { TESTING DATE: } \\
\text { OCT 2020 }\end{array}$ \\
\hline & PHEET NO: ${ }_{\text {S113 }}$ & \begin{tabular}{|c|} 
DWG REFERENCE: \\
SK1-SK12
\end{tabular} \\
\hline
\end{tabular}


Timber framing

Dummy studs

Sheet Joints - Furnace side 1

Sheet Joints - Furnace side 2

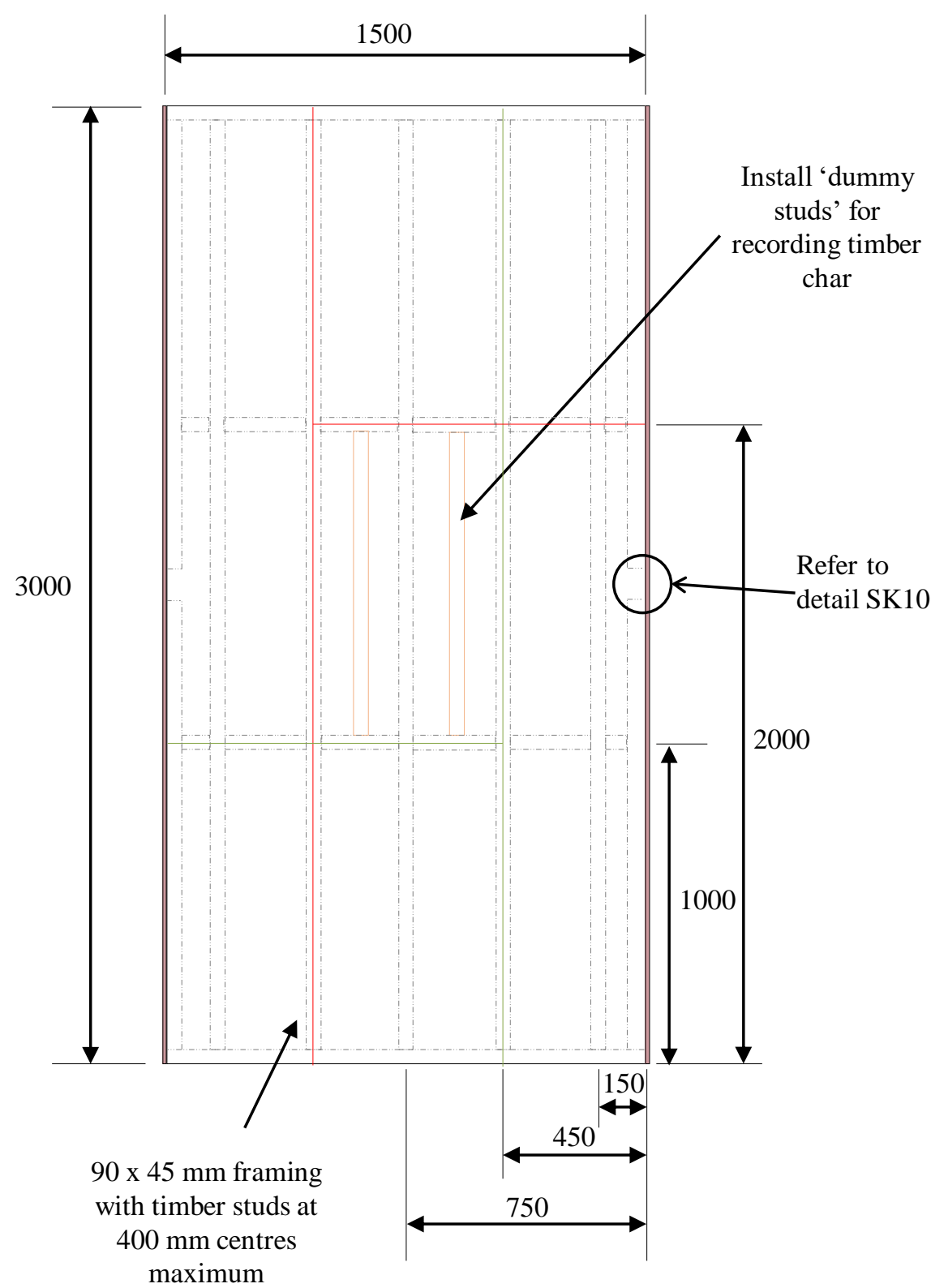

Section J-J

Scale 1:25

\begin{tabular}{|c|c|c|c|}
\hline $\begin{array}{l}\text { PROJECT TITLE: } \\
\text { LOAD-BEARING TIMBER-FRAMED GYPSUM PLASTERBOARD LINED WALLS } \\
\text { SUBJECTED TO TWO-SIDED FIRE EXPOSURE }\end{array}$ & $\begin{array}{c}\text { DRWN BY: } \\
\text { FRANK KANG }\end{array}$ & $\begin{array}{c}\text { TESTING DATE: } \\
\text { OCT 2020 }\end{array}$ \\
\cline { 2 - 4 } & SHEET NO: & S114 & $\begin{array}{r}\text { DWG REFERENCE: } \\
\text { SK1-SK12 }\end{array}$ \\
\hline
\end{tabular}




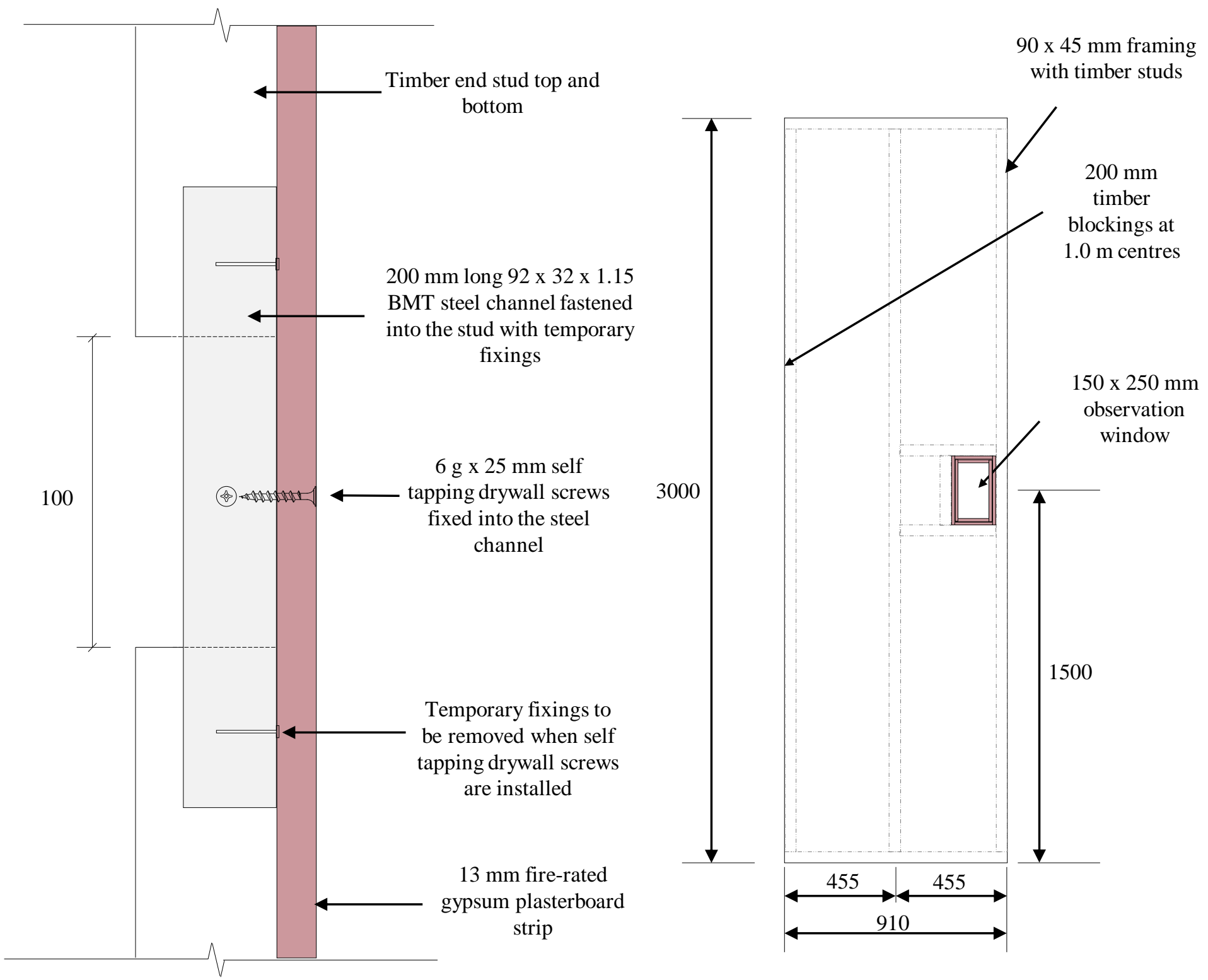

$\underline{\text { SK10 - Temporary fixing detail }}$

Scale 1:2

Section K-K

Scale 1:25

\begin{tabular}{|c|c|c|}
\hline \multirow{2}{*}{$\begin{array}{l}\text { PROJECT TITLE: } \quad \text { EXPERIMENT 3 - QR1810-163 } \\
\text { LOAD-BEARING TIMBER-FRAMED GYPSUM PLASTERBOARD LINED WALLS } \\
\text { SUBJECTED TO TWO-SIDED FIRE EXPOSURE }\end{array}$} & $\begin{array}{l}\text { DRAWN BY: } \\
\text { FRANK KANG }\end{array}$ & $\begin{array}{c}\text { TESTING DATE: } \\
\text { OCT 2020 }\end{array}$ \\
\hline & PHEET NO: ${ }^{\text {S115 }}$ & \begin{tabular}{|c|} 
DWG REFERENCE: \\
SK1-SK12
\end{tabular} \\
\hline
\end{tabular}




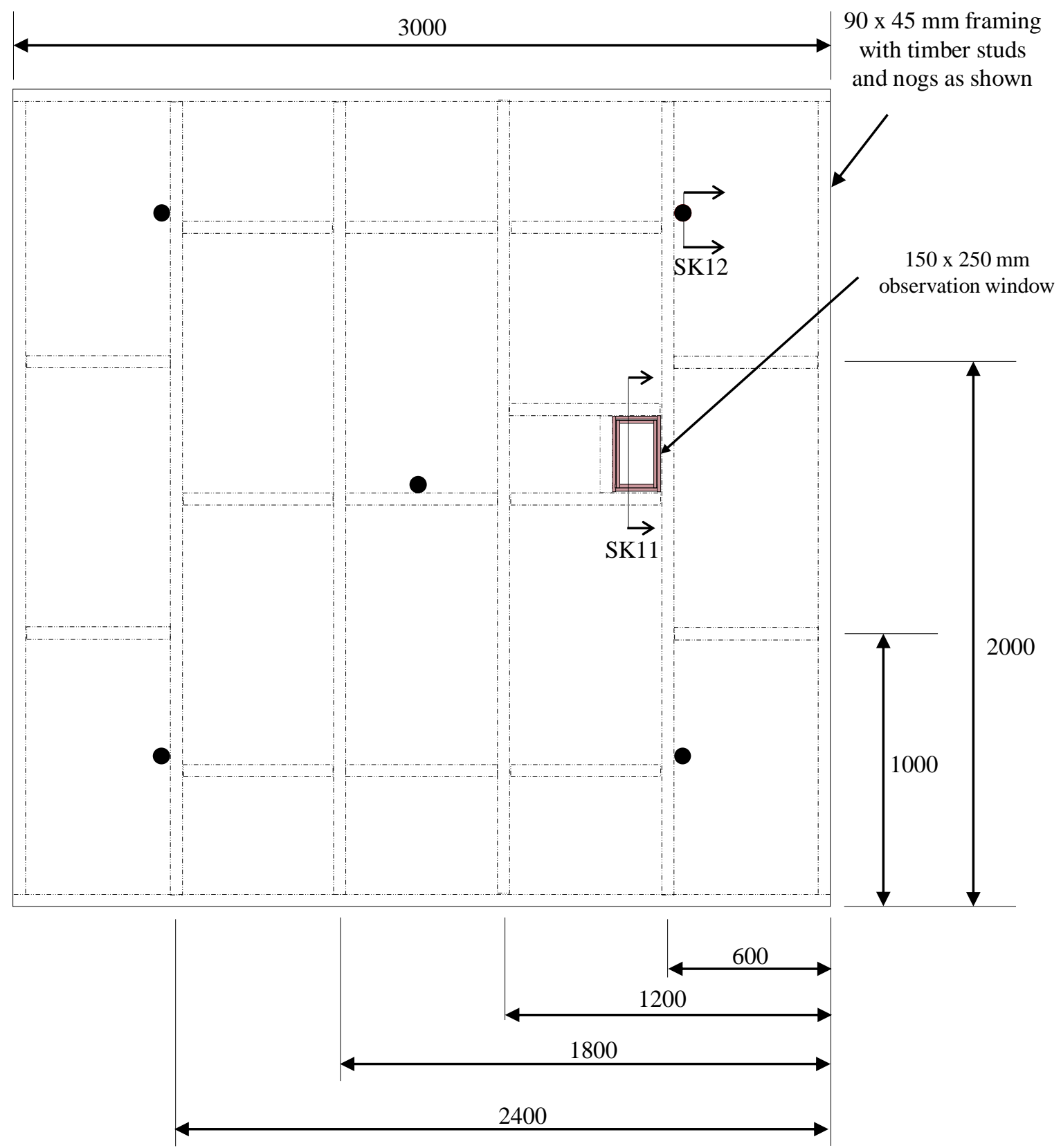

Section L-L

Scale 1:25

\begin{tabular}{|c|c|c|}
\hline EXPERIMENT 3 - QR1810-163 & \begin{tabular}{|l} 
DRAWN BY: \\
FRANK KANG
\end{tabular} & \begin{tabular}{|l} 
TESTING DATE: \\
OCT 2020
\end{tabular} \\
\hline $\begin{array}{l}\text { LOAD-BEARING TIMBER-FRAMED GYPSUM PLASTERBOARD LINED WALLS } \\
\text { SUBJECTED TO TWO-SIDED FIRE EXPOSURE }\end{array}$ & $\begin{array}{r}\text { SHEET NO: } \\
\\
\text { S116 }\end{array}$ & \begin{tabular}{|c|} 
DWG REFERENCE: \\
SK1-SK12
\end{tabular} \\
\hline
\end{tabular}



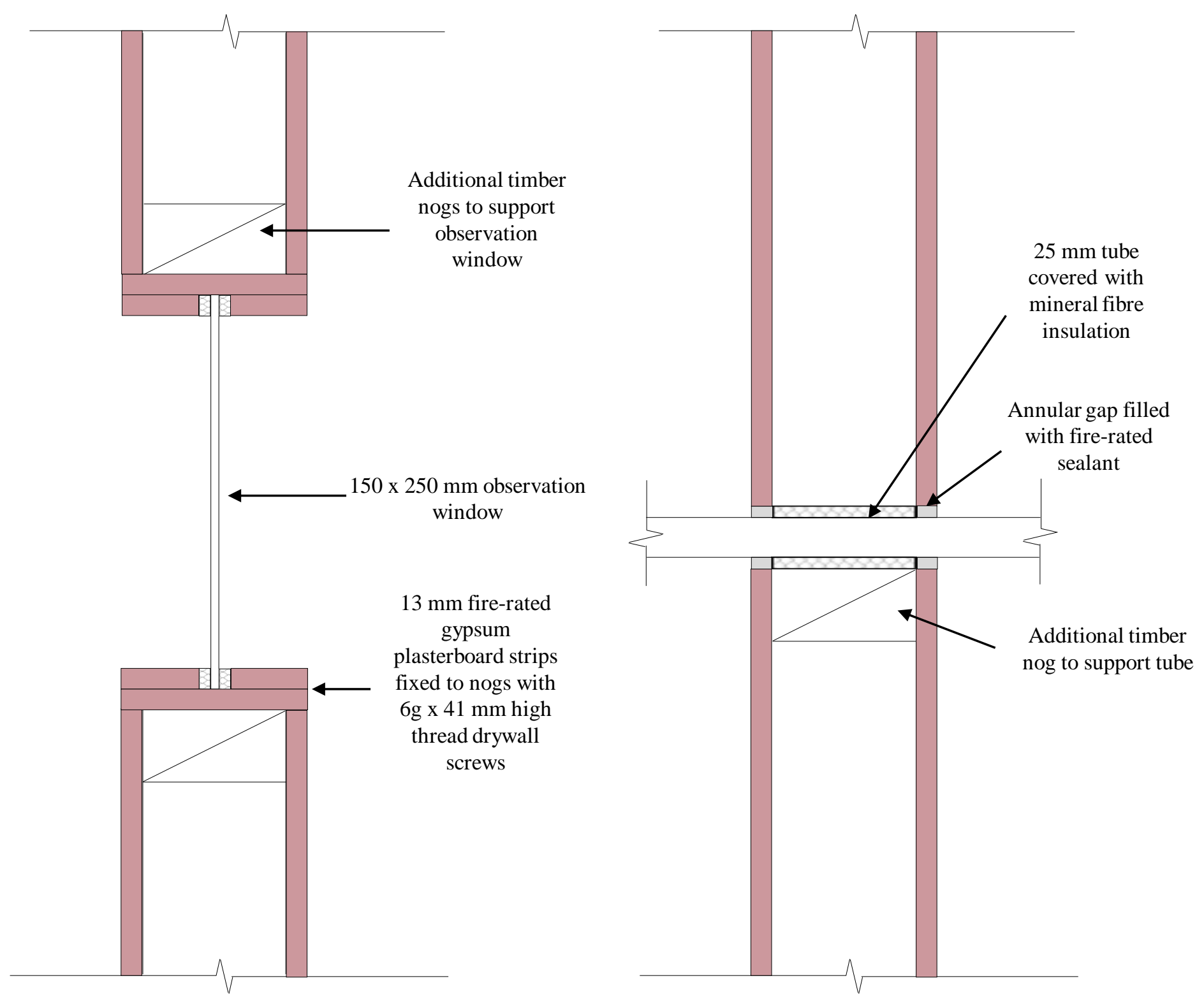

$\underline{\text { SK11 - Observation window detail }}$

Scale 1:4 $\underline{\text { SK12 - MIMS thermocouple and plate thermometer }}$ tube detail

Scale 1:4 